\title{
MODELADO CFD DE LECHOS FLUIDIZADOS BAJO DIFERENTES REGÍMENES PARA PROCESOS DE INTERÉS EN LA NORPATAGONIA ARGENTINA
}

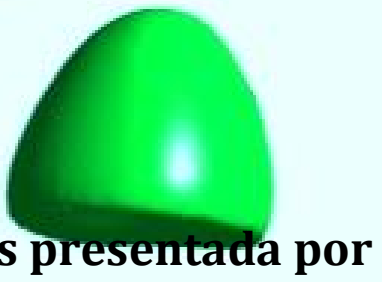 \\ FLORENCIA TOSCHI \\ Para obtener el grado de \\ DOCTORA EN INGENIERÍA
}

Director: Dr. Germán D. Mazza

Co-Directora: Dra. Mariana T. Zambon

Universidad Nacional de La Plata

Facultad de Ingeniería

Departamento de Ingeniería Química 


\section{TESIS DOCTORAL}

\section{Modelado Cfd De Lechos Fluidizados BAJo Diferentes Regímenes Para Procesos De Interés En LA Norpatagonia Argentina}

El presente trabajo de Tesis Doctoral se llevó a cabo en el Grupo de Ingeniería de Reactores y Procesos Químicos (GIRPQ) del Instituto de Investigación y Desarrollo en Ingeniería de Procesos, Biotecnología y Energías Alternativas, PROBIEN, unidad de doble dependencia del Consejo Nacional de Investigaciones Científicas y Técnicas (CONICET) y la Universidad Nacional del Comahue (UNCo), mediante una beca Doctoral del CONICET, bajo la dirección del Dr. Germán Mazza y la codirección de la Dra. Mariana Zambon. 
a mi hijo Vicente y a mis padres 


\section{AGRADECIMIENTO}

Al Dr. Germán Mazza, por la oportunidad, su dirección y enseñanzas, que permitieron concretar este trabajo.

A la Dra. Mariana Zambon, por sus enseñanzas, consejos, su guía constante y por su invaluable ayuda en cada etapa.

A mi familia, por el apoyo constante. Sin su ayuda, especialmente en tiempos de pandemia, esto no hubiera sido posible. Gracias infinitas.

A mi hijo Vicente, que sin darse cuenta fue mi mayor fuente de motivación.

A Euge Roca Jalil, por su amistad, su apoyo incondicional, por escucharme, enseñarme, contenerme. Por acompañarme en todas las etapas a lo largo de este camino, las buenas y las malas.

A los amigos que hice durante este trayecto, por el tiempo hermoso compartido, las charlas, los almuerzos, las anécdotas y enseñanzas. Porque hicieron del lugar de trabajo un gran lugar y porque su amistad trasciende el PROBIEN. Gracias Ale, Lucho, Marquitos, Beti, Pau, Santi, Cele, Horacio y Leti. Gracias Miria y Peña, por ser amigas y "madres".

A mis amigas y amigos de la vida, por su contención, por escuchar siempre los "no puedo", por contenerme en los fracasos y celebrar los avances.

Al Ing. José Luis Aprea, por su consideración, comprensión y ayuda.

A mis compañeros de grupo, Daniela, José y Andrés, por su ayuda siempre que la necesité.

A Horacio y Lucas, por su gran ayuda en la parte técnica.

Al personal administrativo del PROBIEN, por su buena predisposición siempre.

A la Facultad de Ingeniería de la Universidad Nacional del Comahue, por darme la oportunidad de seguir creciendo en el camino de la investigación y la docencia. 


\section{CAPÍTULO 1: INTRODUCCIÓN GENERAL}

1.1 - PRESENTACIÓN DEL TEMA

1.2 - OBJETIVOS

1.3 - DESCRICPICIÓN DE LOS CONTENIDOS

\section{CAPÍTULO 2: TEORÍA DE LA FLUIDIZACIÓN}

INTRODUCCIÓN

2.1 - CLASIFICACIÓN DE PARTÍCULAS

2.2 - CARACTERÍSTICAS FLUIDODINÁMICAS DE LOS LECHOS FLUIDIZADOS

2.2.1 - Velocidades lineales y superficiales de gas y sólido

2.2.2 - Diagrama de Pérdida de Carga en Función de la Velocidad Superficial del Gas

2.2.3 - Pérdida de carga para Lechos constituidos por partículas de diferentes tamaños

2.2.4 - Altura del Lecho

2.2.5 - Espacio libre entre partículas en un lecho fluidizado

2.2.6 - Velocidad de mínima Fluidización

2.2.7 - Velocidad terminal de las partículas

2.2.8 - Velocidad Terminal de las Partículas en un conjunto

\section{3 - REGÍMENES DE FLUIDIZACIÓN}

2.3.1 - Transición de lecho Fijo a fluidización Particulada y régimen Burbujeante

2.3.2 - Transición entre régimen de Burbujeo y régimen Slug

2.3.3 - Transición entre régimen Burbujeante y Turbulento

2.3.4 - Transición a fluidización rápida 


\section{CAPÍTULO 3: FLUIDIZACIÓN BAJO RÉGIMEN BURBUJEANTE}

INTRODUCCIÓN

3.1 - ASPECTOS GENERALES

3.2 - TEORÍA DE LAS DOS FASES

3.3 - LA FASE BURBUJA

3.3.1 - Características y comportamiento

3.3.2 - El modelo de burbuja de Davidson

3.3.3 - Diámetro de burbuja

3.3.3.1 - Correlación de Darton (1977)

3.3.3.2 - Correlación de Werther (1978)

3.3.3.3 - Correlación de Agarwal (1985)

3.3.3.4 - Correlación de Cai y colab. (1994)

3.3.4 - Velocidad de las burbujas

3.3.4.1 - Werther (1978)

3.3.4.2 - Hilligardt y Werther (1986)

3.3.4.3 - Kunii-Levenspiel (1991)

3.3.5 - Factor de forma de las burbujas $\omega$

3.3.6 - Frecuencia de las burbujas

3.4 - MATERIALES Y EQUIPAMIENTO

3.4.1 - Caracterización de la arena

3.4.1.1 - Diámetro de partícula

3.4.1.2 - Densidad

3.4.1.3 - Composición mineralógica

3.4.1.4 - Esfericidad y redondez 
3.4.2 - Equipamiento Experimental

3.5 - MODELADO POR CFD

3.5.1 - Generación del dominio, mallado y validación

3.5.2 - Implementación de la simulación por CFD

3.6 - CURVA DE FLUIDIZACIÓN

3.7 - ANÁLISIS Y CARACTERÍSTICAS DE LA FASE BURBUJA

3.7.1 - Post-Procesamiento de imágenes

3.7.2 - Determinación del diámetro de las burbujas

3.7.3 - Determinación de la velocidad de las burbujas

3.7.4 - Determinación de la frecuencia de burbujas

3.8 - RESULTADOS Y DISCUSIÓN DEL ESTUDIO DE LA FASE BURBUJA

3.8.1 - Diámetro $d_{s v}$

3.8.2 - Velocidad de ascenso $u_{b}$

3.8.3 - Factor de forma $\omega$

3.8.4 - Frecuencia de burbujas

3.9 - EXTRAPOLACIÓN A UN LECHO CILÍNDRICO

3.9.1 - Tratamiento de imágenes del lecho cilíndrico simulado

3.9.2 - Resultados y discusión

3.10 - ESTUDIO EXPERIMENTAL Y CFD DE UN LECHO FLUIDIZADO DE BASE CÓNICA CON PARTÍCULAS GELDART D

3.11 - CONCLUSIONES DEL CAPÍTULO 3

ANEXO 3.I: ESTUDIO DE LA FLUIDIZACIÓN DE PARTÍCULAS DE UREA

A3.I.1 - EQUIPAMIENTO EXPERIMENTAL

A3.I.2 - MODELADO POR CFD

Página IG.3 
A3.I.3 - CURVA DE FLUIDIZACIÓN

A3.I.4 - CARACTERIZACIÓN DE LA FASE BURBUJA

A3.I.4.1 - Diámetro de burbuja

A3.I.4.2 - Velocidad de ascenso de burbujas

A3.I.5 - CONCLUSIONES

ANEXO 3.II: Fluidodinámica Computacional (CFD)

A3.II.1 - ECUACIONES DE CONSERVACIÓN

A3.II.1.1 - Conservación de materia

A3.II.1.2 - Conservación de la cantidad de movimiento

A3.II.1.3 - Conservación de la energía

A3.II.2 - ECUACIONES AUXILIARES

A3.II.2.1 - Coeficiente de intercambio de cantidad de movimiento

A3.II.2.2 - Presión de sólidos

A3.II.2.3 - Función de distribución radial

A3.II.2.4 - Tensiones de corte de la fase sólida

A3.II.2.4.1 - Viscosidad bulk

A3.II.2.4.2 - Viscosidad por colisiones

A3.II.2.4.3 - Viscosidad cinética

A3.II.2.4.4 - Viscosidad friccional

A3.II.2.4.5 - Temperatura granular

A3.II.3 - MODELO DEL MEDIO POROSO

A3.II.4 - DISCRETIZACIÓN DE LAS ECUACIONES DE TRANSPORTE

A3.II.5 - PROCEDIMIENTO DE RESOLUCIÓN POR MEDIO DEL SOFTWARE

A3.II.5.1 - Pre-procesamiento

Página IG.4 
A3.II.5.2 - Resolución

A3.II.5.3 - Post-procesamiento

ANEXO 3.III: PROGRAMACIÓN AUXILIAR

A3.III.1 - ANÁLISIS DE IMÁGENES BIDIMENSIONALES

A3.III.2 - CÁLCULOS PARA IMÁGENES BIDIMENSIONALES

A3.III.2.1 - Análisis de diámetro

A3.III.2.2 - Análisis de velocidades

A3.III.3 - GENERACIÓN DE ARCHIVOS DE DATOS 3D

A3.III.4 - CÁLCULOS PARA DATOS DE ISOSUPERFICIES

A3.III.4.1 - Análisis de diámetro

A3.III.4.2 - Análisis de velocidad de burbuja

\section{CAPITULO 4: FLUIDIZACIÓN EN RÉGIMEN SLUG}

INTRODUCCIÓN

4.1 - RÉGIMEN SLUG: ASPECTOS GENERALES

4.2 - COMPORTAMIENTO FLUIDODINÁMICO DE SÓLIDOS GELDART A

4.3 - ECUACIONES Y VARIABLES FUNDAMENTALES

4.3.1 - Altura mínima requerida (umbral para el inicio de la formación de slugs axiales)

4.3.2 - Expansión del lecho

4.3.3 - Longitud y frecuencia de slugs

4.3.4 - Velocidad de ascenso de slugs

4.4 - DESCRIPCIÓN DE LAS FUENTES DE INFORMACIÓN EXPERIMENTAL

4.4.1 - Esquema experimental de Reyes Urrutia y colab. (2016)

4.4.2 - Esquema experimental de Kong y colab. (2017) 


\section{5 - MODELADO POR CFD}

4.5.1 - Simulación del sistema correspondiente a los resultados publicados por Reyes Urrutia y colab. (2016).

4.5.2 - Simulación del sistema correspondiente a los resultados publicados por Kong y colab. (2017).

4.6 - DISCUSIÓN DE RESULTADOS

4.6.1. - Resultados de la simulación y comparación con resultados experimentales de Reyes Urrutia y colab. (2016)

4.6.1.1 - Presencia de slugs en el riser

4.6.1.2 - Influencia de los slugs en la transferencia de calor paredsuspensión

4.6.1.3 - Discretización axial del dominio analizado

4.6.2 - Resultados de la simulación y comparación con resultados experimentales de Kong y colab. (2017)

4.6.2.1 - Longitud de slugs

4.6.2.2 - Frecuencia de slugs

4.6.2.3 - Velocidad de slugs

\section{7 - CONCLUSIONES}

ANEXO 4.I: MODELADO NUMÉRICO DEL FLUJO MULTIFÁSICO

ANEXO 4.II: PROGRAMACIÓN PARA ANÁLISIS DE IMÁGENES

A4.II.1 - ANÁLISIS DE IMÁGENES

A4.II. 2 - CÁLCULOS

A4.II.2.1 Análisis de longitud de slug

A4.II.2.2 Análisis de velocidad de ascenso de slug

\section{CAPÍTULO 5: FLUIDIZACIÓN DE BIOMASA}




\section{INTRODUCCIÓN}

5.1 - OBTENCIÓN DE ENERGÍA A PARTIR DE BIOMASA

5.1.1 - Gasificación y lechos fluidizados

\section{2 - MATERIALES Y EQUIPAMIENTO}

5.2.1 - Caracterización de las partículas

5.2.2 - Análisis de bioresiduos: poder calorífico superior (PCS) e inferior (PCI), contenido de lignina, celulosa y hemicelulosa

5.2.3 - Procedimiento Experimental

5.3 - MODELADO POR CFD

5.4 - RESULTADOS Y DISCUSIÓN

5.4.1 - SISTEMA 1 (aserrín- arena)

5.4.1.1 - Lecho de partículas de arena

5.4.1.2 - Lecho de partículas de aserrín

5.4.1.3 - Mezclas binarias aserrín-arena

5.4.2 - SISTEMA 2 (bagazo de manzana - esferas de vidrio)

5.4.2.1 - Lecho de esferas de vidrio

5.4.2.2 - Lecho de bagazo de manzana

5.4.2.3 - Mezclas binarias bagazo-esferas de vidrio

5.5 - CONCLUSIONES DEL CAPÍTULO 5

ANEXO 5.I: VALIDACIÓN DE LAS MALLAS DE LAS MEZCLAS BINARIAS

GENERACIÓN DEL DOMINIO, MALLADO Y VALIDACIÓN

\section{CAPÍTULO 6: CONCLUSIONES GENERALES}




\section{CAPÍTULO 1}

\section{INTRODUCCIÓN GENERAL}

1.1 - PRESENTACIÓN DEL TEMA

1.2 - OBJETIVOS

1.3 - DESCRICPICIÓN DE LOS CONTENIDOS 


\section{1 - PRESENTACIÓN DEL TEMA}

Los sistemas fluidizados gas-sólido revisten gran importancia en la industria de procesos, siendo empleados frecuentemente en instalaciones vinculadas a las industrias química, metalúrgica, biotecnológica, de alimentos, del petróleo y de producción energética. La fluidodinámica de estos sistemas, en extremo compleja, incide en gran medida en la eficiencia de contacto entre fases y, consecuentemente, en el rendimiento de los procesos que constituyen la finalidad de la operación (Kunii y Levenspiel, 1991; Alagha \& Szentannai, 2020; Shabanian \& Chaouki, 2017).

En particular, los lechos burbujeantes son de gran interés en procesos tanto químicos como físicos. El modelado y control de las propiedades de estos lechos requiere un conocimiento profundo de sus características fluidodinámicas y la mayoría de sus propiedades se encuentran fuertemente ligadas a la fase burbuja. El régimen de slug se caracteriza por la deformación de dichas burbujas, con geometría y tamaños particulares, y se produce cuando el sistema presenta características geométricas y propiedades del par gas-sólido singulares. La presencia de slugs genera un contacto ineficiente entre las fases y por lo tanto puede causar severas limitaciones en las velocidades de transferencia de calor y materia. Su análisis y caracterización resulta imprescindible a efectos de diseñar un sistema evitando perjuicios generados por este comportamiento (Baeyens y Geldart, 1974; Ramirez y colab., 2017; Singh y colab., 2020).

La aplicación de sistemas fluidizados en la valorización de residuos biomásicos (agroindustriales) y urbanos es un aspecto de gran importancia en el contexto de la sustitución de la matriz energética regional del Alto Valle de Neuquén y Río Negro y nacional en base a energías renovables (Energías renovables 2008 - Energía biomasa, Secretaría de Energía Argentina, 2008). Diferentes tratamientos térmicos, tales como pirólisis, torrefacción, gasificación y combustión pueden llevarse a cabo en lechos fluidizados burbujeantes, permitiendo la generación de químicos de alto valor y/o energía en forma eficiente y con múltiples ventajas frente a operaciones convencionales. Debe destacarse que la biomasa presenta dificultades en la fluidización 
debido a su forma, tamaño y densidad. Por este motivo, se incorpora un material inerte para mejorar el proceso, pero la fluidización de mezclas binarias aun presenta desafíos.

La provincia de Neuquén, a través de su ministerio de Producción y del Consejo de Planificación y Acción para el Desarrollo (COPADE) han formulado políticas de intensificación de la sustitución de la matriz energética, abriendo el campo de desarrollo a las energías renovables, particularmente a los recursos energéticos biomásicos (https://www.copade.gob.ar/archivos/50A-COPADE-FINAL.pdf).

El modelado de lechos fluidizados en régimen de burbujeo (en operación batch o continua) posee un potencial de optimización considerable, tanto desde el punto de vista del conocimiento de los fenómenos ocurrentes como desde los esquemas de construcción de simuladores eficientes. Las herramientas actualmente desarrolladas presentan aun campos vacantes de mejoras y su tendencia es de ineludible aplicabilidad en las diferentes industrias. En ese contexto, la elaboración de simuladores que abarquen la mayor diversidad de regímenes y aplicaciones, es un objetivo significativo para la industria de procesos.

Aplicando la técnica de fluidodinámica computacional (CFD por su sigla en inglés Computational Fluid Dynamics) se puede construir un modelo computacional que represente el sistema o equipo que se desea estudiar. En el prototipo virtual se incorporan las características físicas y químicas del flujo de fluido en estudio y el software genera como respuesta una predicción de la fluidodinámica y de los procesos físicos (y químicos) involucrados, representados por los campos de variables fundamentales en el dominio simulado. Por lo tanto, puede considerarse a la CFD como una sofisticada técnica de diseño y análisis que utiliza el equipamiento computacional para desarrollar los millones de cálculos requeridos para simular la interacción de fluidos con superficies complejas como las utilizadas en ingeniería.

\section{2 - OBJETIVOS}

Como se ha mencionado previamente, la tecnología de los sistemas fluidizados reviste un gran interés en diversas áreas particularmente relevantes para la región de 
la Norpatagonia: producción de energía y químicos de alto valor agregado por valorización de residuos forestales y agroindustriales, incineración limpia de residuos urbanos y lodos domiciliarios, secadores fluidizados en industrias jugueras, entre otros. Se propone realizar aportes relacionados con el funcionamiento de equipos fluidizados que, basados en su potencial aplicación regional, operarían bajo diferentes regímenes y utilizando diversos materiales regionales en la fluidización.

En tal contexto, el objetivo general de este trabajo de tesis doctoral consiste en estudiar y caracterizar el comportamiento de lechos fluidizados mediante modelado y simulación en plataforma CFD, validados con determinaciones experimentales específicas en laboratorio y/o escala piloto, a fin de detectar aspectos críticos desde el punto de vista fluidodinámico, que condicionen y/o limiten la performance del equipo bajo diferentes regímenes de operación y sólidos fluidizados.

Se identificarán procesos relevantes para la región del Comahue, implementables mediante tecnologías fluidizadas que permitan mejorar su rendimiento y disminuir el impacto sobre el medio, especificando el tipo de sólido particulado utilizado y el régimen de operación. Se estudiará la influencia de variables operativas y de diseño, con el fin de establecer criterios que permitan mejorar la operación. El estudio comprenderá ensayos experimentales y simulaciones rigurosas, poniendo especial atención en el análisis de la fase burbuja, responsable principal del mezclado en los contactores.

\section{3 - DESCRICPICIÓN DE LOS CONTENIDOS}

En el Capítulo 2 de esta tesis se presentan las características y conceptos teóricos fundamentales de la fluidización y la caracterización de los sólidos, ya que los diferentes regímenes de fluidización se encuentran estrechamente relacionados con el tipo de partículas. Se presentan aquí los diferentes regímenes de fluidización y las velocidades características asociadas a los mismos.

En el Capítulo 3 se presenta el estudio del régimen burbujeante en dos geometrías distintas (pseudo-2D y 3D). Se describe en forma exhaustiva la fase burbuja y se detallan los parámetros más importantes para su caracterización (diámetro, 
velocidad de ascenso, factor de forma y frecuencia). A tal fin, se proponen esquemas de análisis metodológicos para la caracterización de las burbujas de implementación accesible. Se presenta también la caracterización completa del sólido utilizado en el estudio. Se detallan los pasos a seguir para efectuar las simulaciones por CFD y los parámetros y modelos utilizados en este estudio. El Capítulo cuenta con 3 anexos en los que se presenta el estudio realizado para partículas de urea en un lecho de geometría cónica (Anexo I), la teoría asociada a la CFD (Anexo II) y los programas desarrollados en MATLAB y Autodesk 3DS Max para el estudio de la fase burbuja.

En el Capítulo 4 se estudian mediante CFD los lechos en régimen slug, tomando información experimental de dos fuentes distintas. En primera instancia, se toma como referencia el trabajo de Reyes Urrutia y colab. (2016), basado en un prototipo en escala piloto instalado en el foco de un horno solar. La segunda referencia es el trabajo de Kong y colab. (2017), en el que se presentan los resultados de experiencias de laboratorio en un lecho cilíndrico de $5 \mathrm{~cm}$ de diámetro, construido en acrílico. Se busca caracterizar los slugs y comprender el régimen, debido a que afecta significativamente la transferencia de calor.

El caso de fluidización de biomasa, de interés en procesos de valorización de residuos regionales, se aborda en el Capítulo 5. En el mismo se aplica la CFD para desarrollar una metodología eficiente para simular la fluidización de mezclas binarias biomasa-inerte, utilizando aire como agente fluidizante, como paso previo para lograr la simulación completa de un gasificador en lecho fluidizado para la valorización de residuos agro-industriales de la región del Comahue.

Por último, en el Capítulo 6, se resumen las conclusiones alcanzadas, así como las sugerencias para la realización de futuros trabajos.

Parte de los procedimientos y resultados reportados en esta tesis doctoral han sido publicados por la autora y sus directores de tesis en los siguientes artículos:

$\checkmark$ Fluidization of forest biomass-sand mixtures: experimental evaluation of minimum fluidization velocity and CFD modeling. F. Toschi, M. Zambon, J. 
Sandoval, A. Reyes Urrutia and G. D. Mazza. Particulate Science \& Technology. Published on-line (2020). https://doi.org/10.1080/02726351.2020.1786202 .

$\checkmark$ Actas del X Congreso Argentino de Ingeniería Química, Santa Fe (2019). Fluidización de mezclas binarias de bioresiduos y partículas inertes. Estudio experimental y simulación por CFD. Florencia Toschi, Rodrigo M. Rasteiro, Mariana T. Zambon, German D. Mazza.

$\checkmark$ Actas del IV Congreso Argentino de Ingeniería - X Congreso Argentino de Enseñanza de la Ingeniería, Córdoba (2018). Fluidización De Mezclas ArenaBiomasa Forestal: Predicción De La Velocidad De Mínima Fluidización. Mariana T. Zambon, Andrés Reyes, Julio Sandoval, Florencia Toschi, German D. Mazza.

$\checkmark$ Actas del IX Congreso Argentino de Ingeniería Química, Bahía Blanca (2017). Validación De Una Metodología Basada En CFD Para La Caracterización De Un Lecho Fluidizado De Partículas Geldart B En Régimen Burbujeante. Florencia Toschi, Rodrigo A. Torres Sciancalepore, Mariana T. Zambon, German D. Mazza.

$\checkmark$ Actas del VIII Congreso Argentino de Ingeniería Química, Buenos Aires (2015). Análisis De Alternativas Para La Caracterización Del Régimen Burbujeante En Sistema Fluidizado Con Partículas Geldart D De Base Cónica. Florencia Toschi, Mariana T. Zambon, German D. Mazza. 


\section{CAPÍTULO 2}

\section{TEORÍA DE LA FLUIDIZACIÓN}

\section{INTRODUCCIÓN}

\section{1 - CLASIFICACIÓN DE PARTÍCULAS}

\section{2 - CARACTERÍSTICAS FLUIDODINÁMICAS DE LOS LECHOS FLUIDIZADOS}

2.2.1 - Velocidades lineales y superficiales de gas y sólido

2.2.2 - Diagrama de Pérdida de Carga en Función de la Velocidad Superficial del Gas

2.2.3 - Pérdida de carga para Lechos constituidos por partículas de diferentes tamaños

2.2.4 - Altura del Lecho

2.2.5 - Espacio libre entre partículas en un lecho fluidizado

2.2.6 - Velocidad de mínima Fluidización

2.2.7 - Velocidad terminal de las partículas

2.2.8 - Velocidad Terminal de las Partículas en un conjunto

\section{3 - REGÍMENES DE FLUIDIZACIÓN}

2.3.1 - Transición de lecho Fijo a fluidización Particulada y régimen Burbujeante

2.3.2 - Transición entre régimen de Burbujeo y régimen Slug

2.3.3 - Transición entre régimen Burbujeante y Turbulento

2.3.4 - Transición a fluidización rápida 


\section{INTRODUCCIÓN}

La fluidización es un fenómeno que permite que un material granular en reposo pase de un estado estático (tal como el de un sólido compacto inmóvil) a un estado dinámico similar al de un fluido en movimiento. Este fenómeno tiene lugar cuando un fluido (gas, líquido o también ambos fluidos) atraviesa(n) un lecho de material granular en forma ascendente, logrando que las partículas "floten" y se muevan, suspendidas en el seno de la fase (o fases) fluida(s). El conjunto adquiere entonces, las características macroscópicas de un fluido. Si el fluido se hiciera circular con dirección descendente, no tendría lugar ningún movimiento relativo entre las partículas a menos que la orientación inicial de las mismas fuera inestable.

Cuando un lecho de partículas inicialmente en reposo (condición de lecho fijo) es atravesado de abajo hacia arriba por un fluido, el comportamiento del conjunto dependerá de la velocidad superficial del mismo. Si la velocidad a la cual circula el fluido es baja, el mismo se filtra a través de los huecos entre partículas y éstas permanecen inmóviles. Los espacios inter-particulares ofrecen una resistencia tal que provoca una caída de presión que aumentará a medida que se incremente la velocidad superficial del fluido, debido a la fricción. Si la velocidad del fluido se incrementa gradualmente, aumenta la fuerza de arrastre que actúa sobre las partículas hasta que, eventualmente, se alcanza el punto en el que la fuerza de arrastre equipara al peso aparente de las partículas. En este punto las partículas sufren un reordenamiento con el fin de ofrecer una menor resistencia al desplazamiento del fluido, la separación entre las mismas aumenta y las partículas se encontrarán flotando hidrodinámicamente. Se dice que el conjunto ha alcanzado el denominado "estado fluidizado". La velocidad superficial mínima de gas que se requiere para alcanzar la condición de fluidización, se conoce como velocidad de mínima fluidización $\left(U_{m f}\right)$. Cuando la velocidad $U$ es menor que $U_{m f}$, el lecho se comporta como un lecho fijo. Si se incrementa gradualmente la velocidad del gas, permanecerá la fuerza debida a la fricción igual al peso de las partículas, hasta que el lecho adquiera una apariencia más abierta, caracterizada por mayores distancias entre las partículas.

Los lechos fluidizados poseen características y propiedades similares a las de un líquido, como puede observarse en la Figura 2.1: 

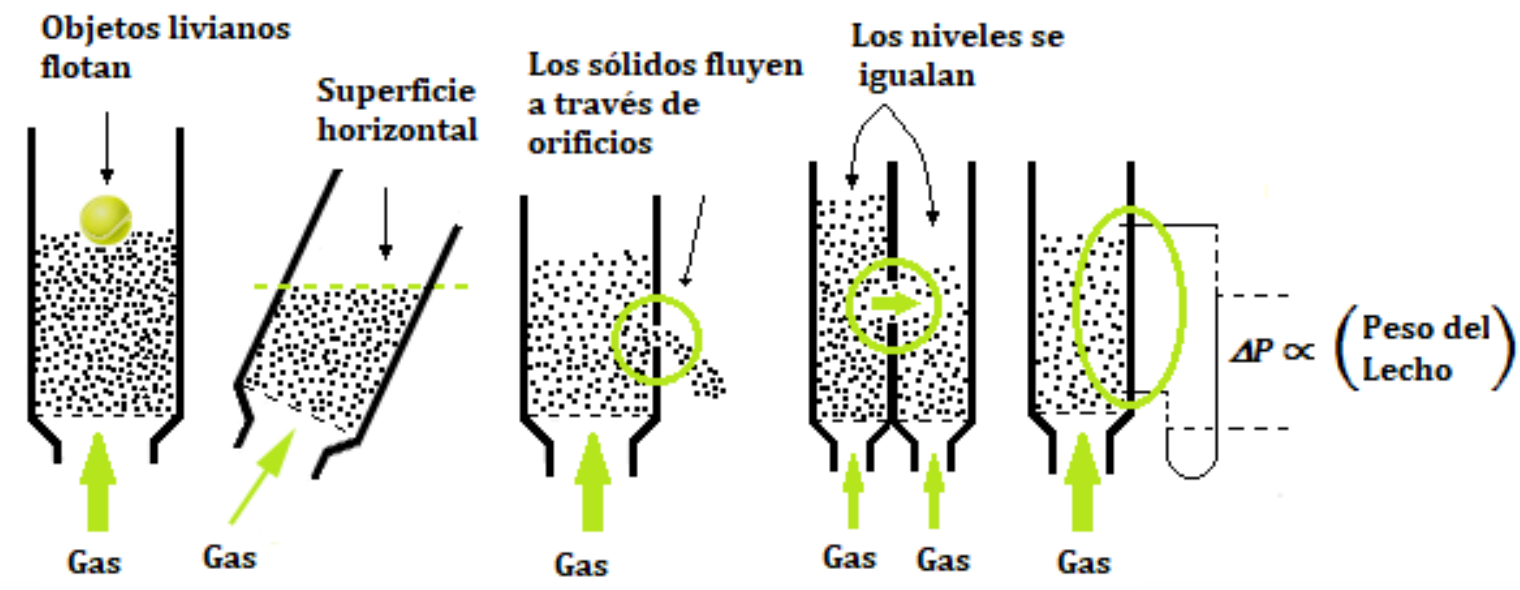

Figura 2.1 - Comportamiento de un lecho fluidizado por gas. Adaptada de Kunii y Levenspiel (1991).

$\checkmark$ Los objetos livianos flotarán sobre la superficie

$\checkmark$ El lecho mantiene la horizontalidad de la superficie aun si se inclina el recipiente

$\checkmark$ Los sólidos saldrán como un chorro que brota de perforaciones en el recipiente

$\checkmark$ Dos recipientes que contienen lechos fluidizados y se conectan, por el principio de vasos comunicantes tenderán a igualar el nivel del "fluido"

$\checkmark$ La caída de presión entre dos puntos que signifiquen dos alturas del lecho es aproximadamente igual a la presión hidrostática entre ambos puntos.

Los lechos fluidizados, particularmente los lechos fluidizados por gas, facilitan un contacto apropiado entre las fases sólida y gaseosa. Esta característica resulta de gran utilidad en aplicaciones industriales debido a los grandes volúmenes de sólidos a procesar. Si bien en los lechos fluidizados pueden llevarse a cabo reacciones altamente endotérmicas o exotérmicas, la fluidización promueve altas velocidades de transferencia de calor, generando condiciones macroscópicamente isotérmicas, con un mezclado considerable en la fase sólida; además, debido al comportamiento similar al de un líquido, los sólidos pueden circular mecánicamente de un recipiente a otro de acuerdo a las necesidades de los diferentes procesos en los que se los utilice.

El comportamiento de los lechos fluidizados, si bien es muy apropiado para el contacto entre fases fluidas y sólidas, presenta algunas particularidades que deben considerarse al evaluar estos contactores. Si bien proporcionan un excelente mezclado de partículas, el mezclado del gas no es tan bueno y la existencia de burbujas (su presencia se explica en la sección 3 del Capítulo 3) modifica el contacto entre ambas fases. También 
puede producirse el fenómeno de atrición o rotura de los sólidos debido a la agitación vigorosa y al choque con las paredes u objetos sumergidos y la erosión de paredes o tuberías por el mismo motivo. Otras situaciones potenciales, como la segregación, "bypass" y aglomeración, pueden presentarse en diferentes condiciones de operación y deben ser minuciosamente analizadas.

En la presente tesis, el estudio se centrará en sistemas fluidizados gas-sólido.

En este capítulo se presentan las características generales de la fluidización y los parámetros más importantes para su descripción. En la sección 2.1 se presenta la clasificación de las partículas según Geldart (1973), de gran importancia puesto que los diferentes regímenes de fluidización se encuentran estrechamente relacionados con el tipo de partícula. En la sección 2.2 se describen los diferentes parámetros característicos de los lechos fluidizados, como las diferencias entre velocidad lineal y superficial, el diagrama de pérdida de carga a través del lecho y su importancia, la velocidad de mínima fluidización $U_{m f}$, la altura y porosidad del lecho. Finalmente, en la sección 2.3 se describen los distintos regímenes de fluidización y las velocidades características asociadas a ellos.

\section{1 - CLASIFICACIÓN DE PARTÍCULAS}

El fenómeno de fluidización en los sistemas gas-sólido se encuentra fuertemente ligado al tipo de sólidos utilizados. A fin de sistematizar el comportamiento esperable de lechos de diferentes sólidos (y fluido que actúa como agente fluidizante), se han desarrollado diferentes clasificaciones, entre las que destaca la reportada por Geldart (1973). Este autor estudió la fluidización de una gran cantidad de sólidos de diferentes tipos y tamaños, en condiciones ambiente, y reconoció que existían cuatro clases de partículas bien definidas. La definición de clases para el análisis de partículas permite agrupar aquellas cuyo comportamiento potencial, en relación a la fluidización, será similar. De esta forma, las conclusiones en relación a las mismas son extrapolables a sólidos de propiedades semejantes. Geldart definió, de esta manera, cuatro grupos, denominados A, B, C y D, caracterizados por la diferencia de densidades entre las partículas y el gas $\left(\rho_{s}-\rho_{g}\right)$ y el tamaño medio de las partículas $\left(d_{p}\right)$. La transición de un grupo a otro no es directa sino progresiva, lo que significa que los grupos adjuntos en sus regiones de separación crean subgrupos con propiedades parciales de los grupos 
adyacentes. En la Figura 2.2, se presenta la clasificación de Geldart, con las partículas ordenadas de menor a mayor tamaño:

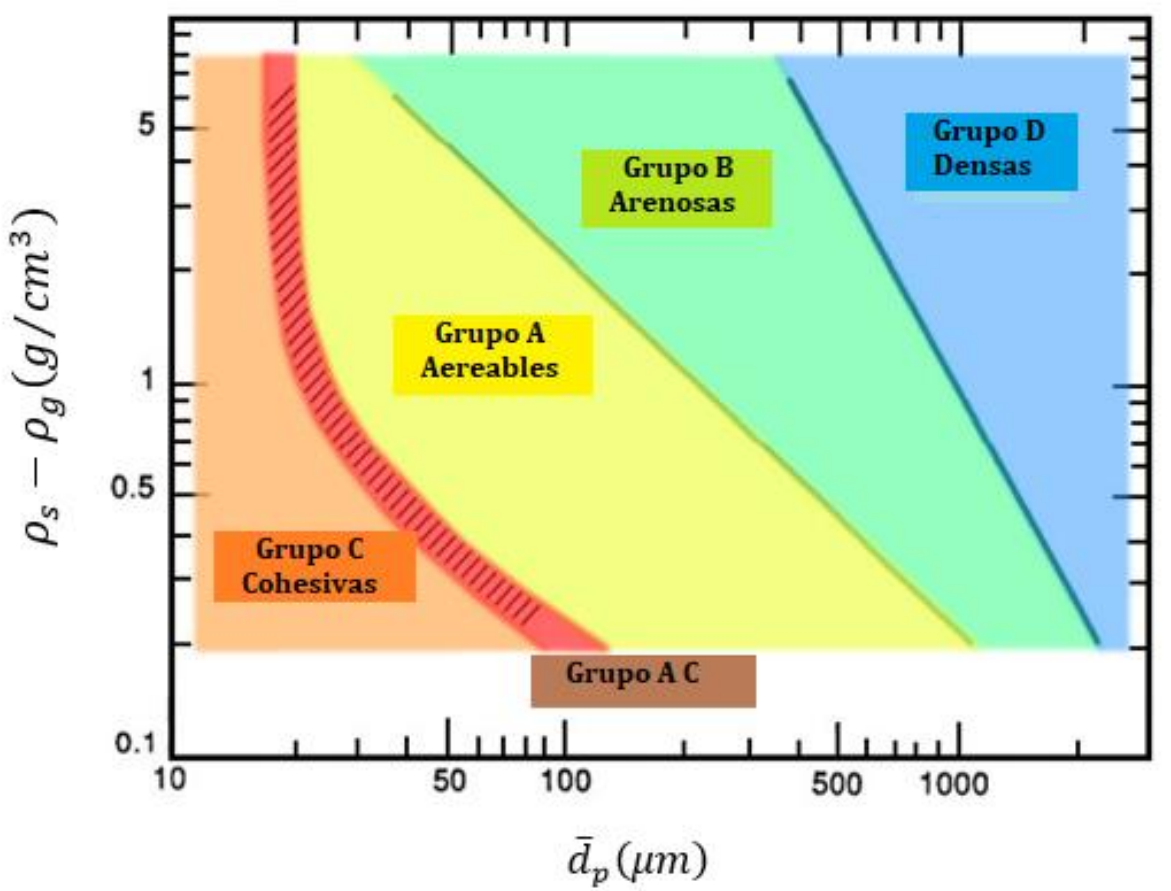

Figura 2.2 - Clasificación de partículas propuesta por Geldart (1973). Adaptada de la norma ASTM D-7743 12.

Grupo C: Son partículas que presentan severas dificultades para ser fluidizadas, debido a su pequeño diámetro, que provoca que las fuerzas cohesivas entre ellas sean importantes y tiendan a formar aglomerados. En los lechos conformados por partículas Geldart C, aparecen canales transversales, que separan las partículas y generan grietas, sin que se produzca la fluidización del mismo. Este problema puede evitarse combinando estas partículas con otras de mayor tamaño a fin de reducir estos canales y aumentar la fluidización del conjunto. Como ejemplo de partículas Geldart C, puede citarse la harina, el almidón, el talco y el azúcar impalpable.

Grupo A: Son partículas de pequeño tamaño, que permiten una fluidización fácil y controlable, cuyos diámetros quedan comprendidos entre 30 y $100 \mu \mathrm{m}$, y su densidad es relativamente baja $\left(\rho_{s}<1400 \mathrm{~kg} / \mathrm{m}^{3}\right)$. Cuando, a partir de la condición de reposo, se incrementa la velocidad superficial del gas que atraviesa un lecho de estas partículas, se produce inicialmente una expansión homogénea del mismo, sin la aparición de burbujas, hasta un valor de velocidad denominada de "mínimo burbujeo" Esta característica es exclusiva de esta clase de partículas (Barreto y colab., 1984). A partir de la existencia de 
la expansión homogénea, se observa que la velocidad de mínimo burbujeo (aparición de la burbuja detectable) es mayor que la de mínima fluidización. Los catalizadores en general, y los de craqueo catalítico en particular, constituyen un ejemplo de partículas Geldart A.

Grupo B: Son partículas de diámetro comprendido entre $40 \mu \mathrm{m}$ y $500 \mu \mathrm{m}$ y con densidades entre 1400 y $4000 \mathrm{~kg} / \mathrm{m}^{3}$. Estos sólidos fluidizan bien, formando burbujas vigorosas que crecen hasta tamaños importantes. Las burbujas aparecen tan pronto como se alcanza la velocidad mínima de fluidización. Un ejemplo típico son los granos de arena, por lo cual estas partículas también son conocidas como arenosas.

Grupo D: Son partículas de diámetro superior a las $500 \mu \mathrm{m}$ y/o densas, de las cuales existe menor cantidad de información publicada. Tienen un comportamiento errático. Con este tipo de sólidos se obtienen lechos de chorro estables (spouted beds). En general, el gas se canaliza y se requieren grandes caudales para lograr la fluidización. En estos casos los lechos burbujeantes pueden lograrse si se utilizan lechos de poca altura (esencialmente requeridos por el peso de los sólidos y los niveles usuales de velocidad superficial del gas), si la velocidad del gas no es mucho mayor que la correspondiente a la condición de mínima fluidización. Puede alcanzarse una condición de slugging (se describirá este fenómeno en el Capítulo 4 de esta tesis). A fin de evitarlo, es usual diseñar la parte superior del lecho con un área mayor. Ejemplos de partículas Geldart D son los granos de café, garbanzos, carbón para gasificación, chips de biomasa y partículas de urea granulada.

Si bien hay diversas clasificaciones disponibles, todas remiten, en cierta manera, a la base conceptual propuesta por Geldart. Cabe mencionar, por ejemplo, la interpretación de la clasificación de Geldart llevada a cabo por Molerus (1982), en la cual se tiene en cuenta la magnitud de las fuerzas de cohesión inter-particulares; la modificación propuesta por Grace (1986) que establece nuevas fronteras entre los grupos $\boldsymbol{A}$ y $\boldsymbol{B}$ y entre los grupos $\boldsymbol{B}$ y $\boldsymbol{D}$ de la clasificación original de Geldart y la clasificación de Goossen (1998) basada en rangos del número de Arquímedes, $A r=d_{p}^{3} \rho_{g}\left(\rho_{s}-\rho_{g}\right) g / \mu^{2}$.

En la Figura 2.3, se presenta un esquema visual de comparación de tamaños de los diferentes tipos de partículas, de acuerdo a la clasificación de Geldart. 


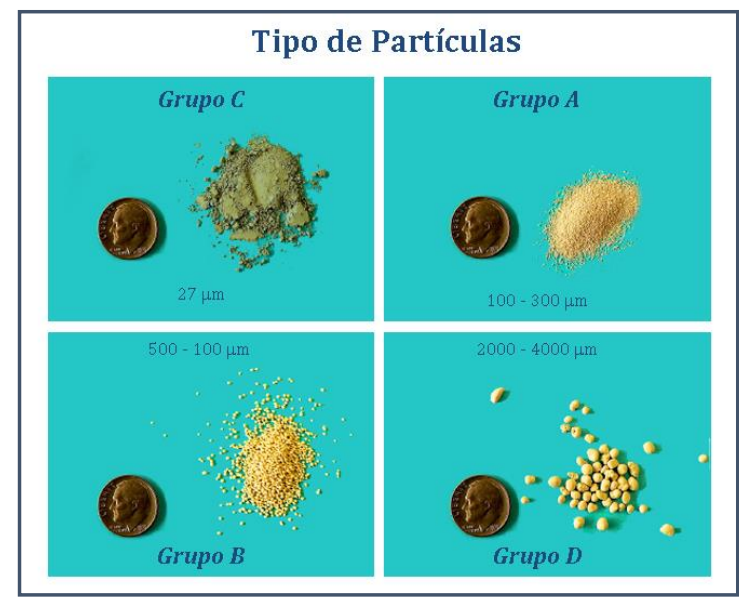

Figura 2.3 - Tipo de partículas de acuerdo a la clasificación de Geldart.

\section{2 - CARACTERÍSTICAS FLUIDODINÁMICAS DE LOS LECHOS FLUIDIZADOS}

\subsection{1 - Velocidades lineales y superficiales de gas y sólido}

Para el estudio del comportamiento de los lechos fluidizados, es necesario establecer definiciones precisas de las velocidades de gas y partículas y de la velocidad relativa entre ambos.

La velocidad superficial del gas se define como el cociente entre el flujo volumétrico de gas y la sección transversal del tubo o recipiente que contiene al medio fluidizado.

$$
U=\frac{Q}{A}
$$

Análogamente, la velocidad superficial de los sólidos se define como el cociente entre el flujo volumétrico de partículas y el área transversal del recipiente:

$$
U_{s}=\frac{Q_{s}}{A}
$$

La fracción de la superficie transversal del recipiente disponible para el flujo de gas, se supone igual a la fracción volumétrica de gas, es decir a la porosidad o fracción de huecos $(\varepsilon)$. En consecuencia, la fracción de área transversal disponible para el flujo de sólidos es $(1-\varepsilon)$. En este contexto, las velocidades reales (lineales) de la fase gaseosa y del sólido, $u$ y $u_{s}$ se expresan mediante las siguientes relaciones:

$$
u=\frac{Q}{A \varepsilon}
$$




$$
u_{s}=\frac{Q_{s}}{A(1-\varepsilon)}
$$

Las velocidades reales y superficiales se vinculan mediante las relaciones (2.3) que se indican a continuación:

$$
\begin{gathered}
u=\frac{U}{\varepsilon} \\
u_{s}=\frac{U_{s}}{(1-\varepsilon)}
\end{gathered}
$$

La velocidad relativa entre las fases $u_{r e l}$, también conocida como slip velocity $u_{\text {slip }}$, se define como la diferencia entre las velocidades reales del gas y el sólido respectivamente, como se expresa en la ecuación (2.4).

$$
u_{\text {rel }}=u_{\text {slip }}=u-u_{s}
$$

\subsection{2 - Diagrama de Pérdida de Carga en Función de la Velocidad Superficial del Gas}

El fenómeno de fluidización puede ser caracterizado mediante un gráfico de caída de presión a través del lecho en función de la velocidad superficial del gas en la entrada, normalmente conocido como curva de fluidización del sistema. Este diagrama resulta de gran utilidad, inclusive para estimar la potencial calidad de la fluidización.

En la situación en la que la velocidad $U$ excede en un alto grado el valor de mínima fluidización $U_{m f}$, puede alcanzarse un estado en el cual los sólidos son expulsados del lecho, correspondiendo esta situación a la denominada condición de trasporte neumático. La velocidad superficial mínima de gas que se requiere para alcanzar la condición de trasporte neumático, se conoce como velocidad terminal $\left(U_{t}\right)$, definida como la velocidad a la cual la fuerza de arrastre que ejerce el gas sobre las partículas, supera su peso y éstas son arrastradas con la corriente de gas.

Si se grafica la caída de presión medida a lo largo del lecho en función de la velocidad superficial del gas a través del mismo para partículas Geldart B, se tendrá la apariencia que se grafica en la Figura 2.4. Tal como puede observarse, se obtiene una variación lineal de la caída de presión si el régimen es laminar hasta el punto en que tiene lugar la expansión del lecho, las partículas se reacomodan y la porosidad del lecho aumenta, pasando de $\varepsilon$ (porosidad del lecho fijo) a $\varepsilon_{m f}$. Al aumentar la velocidad, la caída de presión pasa por un máximo, disminuyendo entonces ligeramente y adoptando un 
valor aproximadamente constante, independiente de la velocidad superficial del gas. Si se reduce gradualmente la velocidad, el lecho se contrae hasta alcanzar la condición en que las partículas se reubican superponiéndose; la porosidad tiene entonces el valor máximo estable para un lecho fijo de las partículas en cuestión. Si la velocidad disminuye aún más, el lecho permanece entonces en esa condición suponiendo que no se agite. La caída de presión en este lecho fijo reformado es menor que la obtenida originalmente a la misma velocidad, debido a que las partículas se reacomodan con una porosidad mayor a la inicial, J. Couderc (1952), citado por G. Mazza, (1993), Kunii y Levenspiel (1991). Si se aumentara ahora de nuevo la velocidad, sería de esperar que se siguiera la nueva curva y que la pendiente cambiara súbitamente en el punto de fluidización.

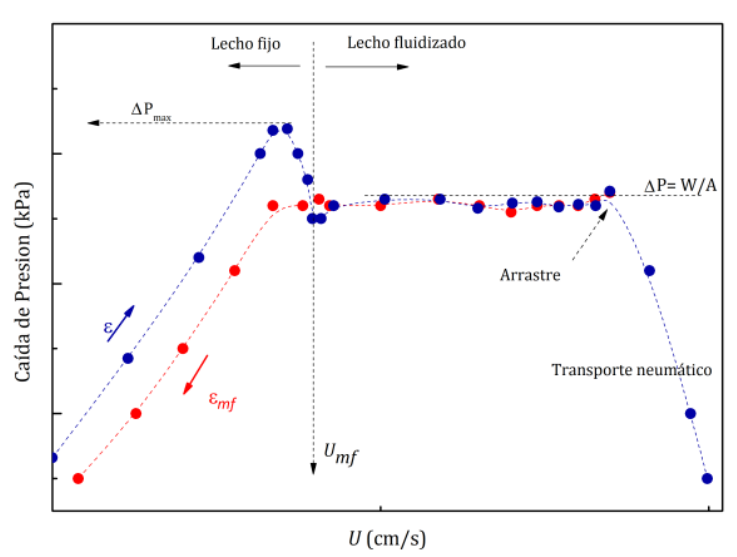

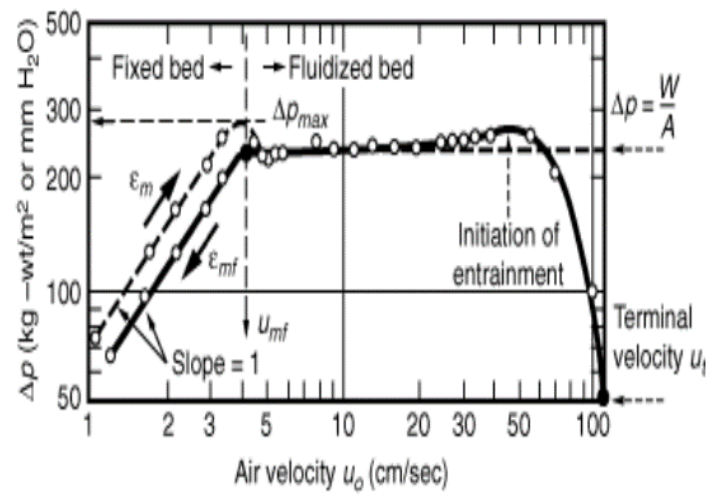

b

Figura 2.4 - Comportamiento de un lecho de partículas para distintas velocidades de gas. a - Explicación para un sólido genérico. b - arena, fuente: Kunii y Levenspiel, Fluidization Engineering (Melbourne, Fla.: Robert E. Krieger Publishing Co., 1991).

Como se mencionó anteriormente, la Figura 2.4 muestra un diagrama característico de la caída de presión a lo largo del lecho $(\Delta P)$, en función de la velocidad superficial $U$. El valor de $\Delta P$ corresponde a la diferencia de presión entre una posición en la sección superior, definida por la altura del lecho en reposo, y otra, ubicada inmediatamente sobre la placa distribuidora de gas. Por lo tanto, $\Delta P$ no incluye la pérdida de carga en el distribuidor.

La región correspondiente a velocidades $U<U_{m f}$ identifica el comportamiento de lecho fijo, en el cual $\Delta P$ aumenta con el aumento de la velocidad $U$, hasta alcanzarse la máxima caída de presión, $\Delta P_{\text {máx }}$ correspondiente a $U=U_{m f}$. Este valor máximo se 
produce porque deben vencerse las fuerzas de cohesión partícula - partícula en adición al peso de las mismas. En esta región la caída de presión se puede estimar mediante la correlación propuesta por Ergun (1952).

$$
\frac{\Delta P}{H}=\frac{1,75(1-\varepsilon) \rho_{g}}{\varepsilon^{3}\left(\psi_{s} d_{p}\right)} U^{2}+\frac{150(1-\varepsilon)^{2} \mu}{\varepsilon^{3}\left(\psi_{s} d_{p}\right)^{2}} U
$$

donde $\psi_{s}$ es la esfericidad de las partículas, y $\varepsilon$ puede ser hallada experimentalmente teniendo en cuenta el volumen de sólido cargado en el lecho:

$$
\varepsilon=\frac{\text { Volumen total de lecho }- \text { Volumen de sólidos }}{\text { Volumen total de lecho }}=\frac{A H-\rho_{S} m}{A H}
$$

Cuando la velocidad $U>U_{m f}$, la región corresponde a la condición de lecho fluidizado, en la cual el valor de $\Delta P$ se estabiliza en el valor correspondiente al peso del lecho dividido el área de la sección transversal del mismo, $(W / A)$. En la práctica, sin embargo, la caída de presión en la condición de mínima fluidización es en realidad menor que $W / A$ debido a que un pequeño porcentaje de las partículas del lecho es soportado por las paredes del mismo, a que el diseño del distribuidor no es perfecto, las dimensiones del recipiente son finitas y a que hay posibilidades de canalización.

La caída de presión en esta región se puede estimar realizando un balance de fuerzas en la condición de mínima fluidización. Ignorando las fuerzas que se ejercen sobre la pared del recipiente, se tiene que:

$$
\left(\begin{array}{c}
\text { Fuerza de arrastre } \\
\text { ejercida por el gas }
\end{array}\right)=\left(\begin{array}{c}
\text { Peso aparente de } \\
\text { las partículas }
\end{array}\right)
$$

donde el peso aparente de las partículas se define como el resultado de restar la fuerza de empuje a su peso real. En la Figura 2.5 puede observarse un esquema del balance de fuerzas que actúan sobre una partícula.

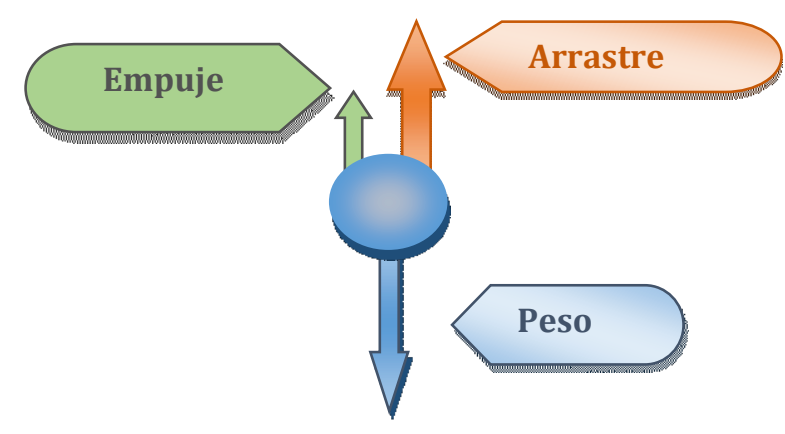

Figura 2.5 -Balance de fuerzas sobre una partícula en el estado de mínima fluidización. 
El peso de las partículas puede expresarse como

$$
\text { Peso }=\text { masa }_{\text {partículas }} g=V_{p} \rho_{p} g
$$

y el empuje puede expresarse como

$$
\text { Empuje }=\text { masa }_{\text {fluido }} g=V_{p} \rho_{f} g
$$

donde $V_{p}$ es el volumen ocupado por las partículas. Teniendo en cuenta la ecuación 2.6, el volumen $V_{p}$ puede ser expresado en función del volumen del lecho $V_{p}=(1-\varepsilon) V$. Por lo tanto, considerando las definiciones de peso y empuje, la ecuación 2.7 puede escribirse del siguiente modo:

$$
\Delta P A=W_{\text {aparente }}=A H_{m f}\left(1-\varepsilon_{m f}\right)\left(\rho_{s}-\rho_{g}\right) g
$$

que se puede reescribir como:

$$
\frac{\Delta P}{H_{m f}}=g\left(\rho_{s}-\rho_{g}\right)\left(1-\varepsilon_{m f}\right)
$$

donde $\varepsilon_{m f}$ y $H_{m f}$ son la porosidad y la altura del lecho en condiciones de mínima fluidización, $\rho_{g}$ y $\rho_{s}$ las densidades de gas y sólido, respectivamente, $A$ el área de la sección transversal del lecho y $\Delta P$ se toma positivo.

Finalmente, un incremento de la velocidad $U$ por encima de la velocidad terminal $U_{t}$, conducirá a la condición de transporte neumático con la gradual disminución de $\Delta P$ conforme aumenta $U$, debido a que la cantidad de partículas en el lecho comienza a disminuir.

Un aspecto relevante de los lechos fluidizados por gas, se presenta para valores de velocidad superficial que superan el límite de mínima fluidización, pero se mantienen menores al correspondiente a la condición de transporte neumático, $\left(U_{m f}<U<U_{t}\right)$. Debido a que la diferencia de presión entre la parte superior del lecho y la base sobre el distribuidor debe mantenerse constante para que las partículas permanezcan en el lecho, éste debe expandirse para reducir la fricción ejercida por el gas, produciéndose la formación de bolsones de gas, que prácticamente carecen de partículas en su interior, y ascienden a través del lecho con una velocidad determinada por el balance de fuerzas de inercia y de flotación ejercidas por el resto del lecho. Puede decirse entonces que el lecho se compone prácticamente de dos fases: la denominada fase densa o emulsión, que se 
encuentra en condiciones de mínima fluidización y en la cual la velocidad del gas tendrá un valor $U_{d}$ (expresada por unidad de área de fase densa); y una segunda fase, discontinua en sí, formada por los bolsones de gas, que se conoce como fase burbuja debido a su semejanza con las burbujas gaseosas formadas en una masa de líquido. Existe, pese a la similitud, una diferencia sustancial entre las "burbujas" de un lecho fluidizado y las burbujas en un líquido: la frontera entre la burbuja de un lecho fluidizado y la fase densa que la rodea es "abierta" permitiendo la permeación de gas hacia el interior de la burbuja y desde ella hacia el entorno.

\subsection{3 - Pérdida de carga para Lechos constituidos por partículas de diferentes tamaños}

Cuando se fluidiza un lecho en el que existen partículas de tamaños diferentes, a medida que se incrementa la velocidad del gas, las partículas más pequeñas pueden ubicarse en los intersticios existentes entre partículas grandes y adquirir un estado fluidizado cuando las partículas grandes aún permanecen en reposo, constituyendo pequeñas celdas locales de sólido fluidizado contenido por "paredes" montadas por las partículas de mayor tamaño. En esta situación, tiene lugar una fluidización parcial del lecho, provocando una caída de presión intermedia. Posteriores incrementos de la velocidad del gas determinarán que $\Delta P$ se aproxime al valor $W / A$, lo que indicará que todo el lecho está fluidizado. La Figura 2.6, típica de estos sistemas con amplia distribución de tamaños, permite visualizar esta fluidización progresiva del lecho. Para mezclas que contienen partículas grandes $\left(d_{p}>1 \mathrm{~mm}\right)$, puede ocurrir la segregación y el asentamiento de esas partículas grandes, dando un incremento escalonado en el $\Delta P$ y la histéresis de la curva del $\Delta P$ frente a la velocidad $U$. Sin embargo, esa histéresis desaparece cuando el lecho contiene una gran fracción de finos. En estos sistemas de partículas mixtas, la velocidad $U_{m f}$ se define por convención como la intersección de la línea de $\Delta P$ correspondiente a la región del lecho fijo con la línea horizontal que representa el valor de $W / A$ (punto B en la Figura 2.6). 


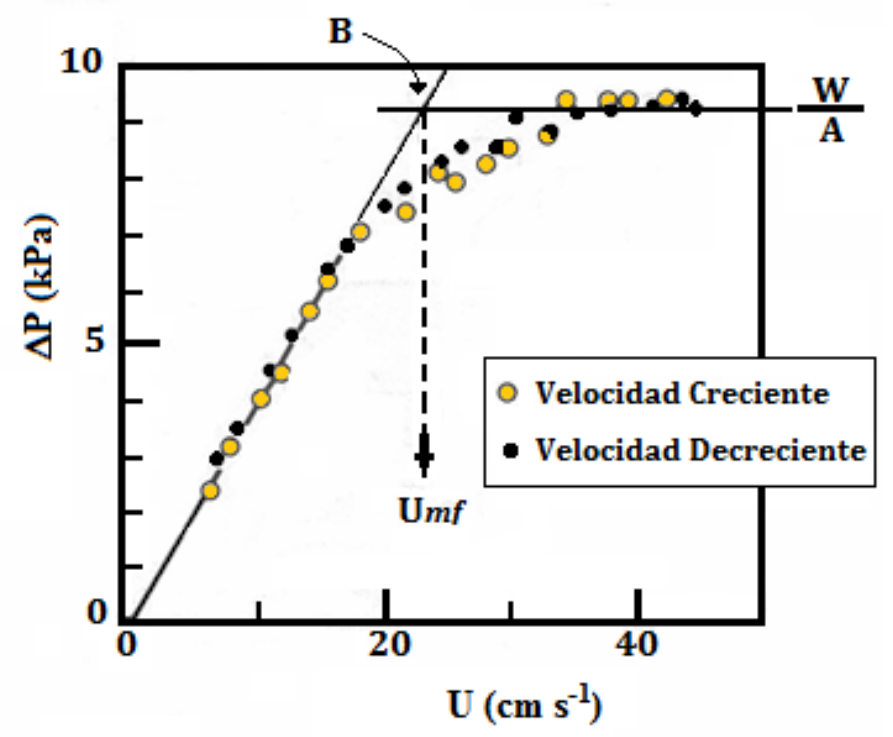

\section{Figura 2.6 - Caída de presión en función de la velocidad de fluidización, para partículas con amplia distribución de tamaños. Adaptada de Kunii y Levenspiel (1991).}

\subsection{4 - Altura del Lecho}

Diferenciando los estados de lecho fijo y fluidizado resulta relevante describir la altura del lecho como variable fundamental. En el régimen de lecho fijo, la altura del mismo permanece constante ante aumentos progresivos de la velocidad superficial del gas debido a que la distancia inter-particular permanece invariable y las partículas aun no poseen movilidad.

Cuando se alcanza la condición de mínima fluidización se produce la expansión del lecho, con el aumento de su altura que corresponderá al valor de la altura de mínima fluidización $H_{m f}$.

\subsection{5 - Espacio libre entre partículas en un lecho fluidizado}

El espacio libre entre las partículas de un lecho fluidizado define la porosidad del lecho y en condiciones de fluidización incipiente corresponde a la porosidad de mínima fluidización $\varepsilon_{m f}$. Es sumamente importante conocer el valor de la porosidad de mínima fluidización, que puede ser medida experimentalmente o estimarse. En la Tabla 2.1 se muestran valores experimentales de $\varepsilon_{m f}$ 
Tabla 2.1 Porosidad en condiciones de mínima fluidización - Fuente: Kunii y Levenspiel (1991).

\begin{tabular}{|l|c|c|c|c|c|c|}
\hline \multirow{2}{*}{ Partículas } & \multicolumn{6}{|c|}{ Tamaño, $\mathrm{d}_{\mathrm{p}}[\mathrm{mm}]$} \\
\cline { 2 - 7 } & 0,05 & 0,07 & 0,10 & 0,20 & 0,30 & 0,40 \\
\hline Arena angular, $\psi_{\mathrm{s}}=0,67$ & 0,60 & 0,59 & 0,58 & 0,54 & 0,50 & 0,49 \\
\hline Arena redondeada, $\psi_{\mathrm{s}}=0,86$ & 0,56 & 0,52 & 0,48 & 0,44 & 0,42 & -- \\
\hline
\end{tabular}

\subsection{6 - Velocidad de mínima Fluidización}

Experimentalmente, se ha comprobado que la velocidad de mínima fluidización, es dependiente del tamaño y la densidad de las partículas del lecho, de las propiedades del gas fluidizante y de las condiciones de presión y temperatura en las que se lleva a cabo el proceso.

La velocidad de mínima fluidización define el paso del estado de lecho fijo al de lecho fluidizado. De este modo, es posible obtener una expresión para su cálculo igualando la expresión de pérdida de carga en el lecho fijo (2.5), particularizada para las condiciones de mínima fluidización, con la expresión de pérdida de carga en el lecho fluidizado (2.9). Así, se obtiene:

$$
\frac{1,75\left(1-\varepsilon_{m f}\right) \rho_{g}}{\varepsilon_{m f}^{3} \psi_{s} d_{p}} U_{m f}^{2}+\frac{150\left(1-\varepsilon_{m f}\right)^{2} \mu}{\varepsilon_{m f}^{3}\left(\psi_{s} d_{p}\right)^{2}} U_{m f}=g\left(\rho_{s}-\rho_{g}\right)\left(1-\varepsilon_{m f}\right)
$$

La ecuación (2.10) permite determinar la velocidad de mínima fluidización conocidas las propiedades de las partículas y del fluido, además de la porosidad del lecho. Esta expresión se puede re-escribir en función del número adimensional de Reynolds, que evalúa el movimiento entre el fluido y la partícula en función de la velocidad de éste, y el número adimensional de Arquímedes, que cuantifica la interacción entre fluido y partícula en función de la diferencia de sus densidades.

$$
\frac{1,75}{\varepsilon_{m f}^{3} \psi_{s}}\left(\frac{d_{p} U_{m f} \rho_{g}}{\mu}\right)^{2}+\frac{150\left(1-\varepsilon_{m f}\right)}{\varepsilon_{m f}^{3} \psi_{s}^{2}}\left(\frac{d_{p} U_{m f} \rho_{g}}{\mu}\right)=\frac{d_{p}^{3} \rho_{g}\left(\rho_{s}-\rho_{g}\right) g}{\mu^{2}}
$$

que se puede escribir del siguiente modo:

$$
\frac{1,75}{\varepsilon_{m f}^{3} \psi_{s}} R e_{m f}^{2}+\frac{150\left(1-\varepsilon_{m f}\right)}{\varepsilon_{m f}^{3} \psi_{s}^{2}} R e_{m f}=A r
$$

donde $R e_{m f}$ es el número de Reynolds en condiciones de mínima fluidización y $A r$ el número de Arquímedes: 


$$
\begin{gathered}
R e_{m f}=\frac{d_{p} U_{m f} \rho_{g}}{\mu} \\
A r=\frac{d_{p}^{3} \rho_{g}\left(\rho_{s}-\rho_{g}\right) g}{\mu^{2}}
\end{gathered}
$$

Cuando se desconocen los valores de $\varepsilon_{m f}$ y $\psi_{s}$, pero se tiene un lecho de partículas de forma isotrópica, se puede estimar el valor de $U_{m f}$. Para ello se re-escribe la ecuación 2.11 del siguiente modo:

$$
K_{1} R e_{m f}^{2}+K_{2} R e_{m f}=A r
$$

Wen y Yu (1966) basados en datos experimentales, observaron que $K_{1}$ y $K_{2}$ permanecían relativamente constantes para varios tipos de partículas en un amplio rango de condiciones, dando predicciones de $U_{m f}$ con un desvío estándar de $\pm 34 \%$. Otros investigadores llevaron a cabo estudios similares para estimar los valores de $K_{1}$ y $K_{2}$, tal como se indica en la Tabla 2.2.

Tabla 2.2 Valores de $K_{1}$ y $K_{2}$ - Adaptada de: Kunii y Levenspiel (1991).

\begin{tabular}{|l|c|c|}
\hline Autores & $\mathrm{K}_{2} / 2 \mathrm{~K}_{1}$ & $1 / \mathrm{K}_{1}$ \\
\hline Wen y Yu (1966) & 33,7 & 0,0408 \\
\hline Richardson (1971) & 25,7 & 0,0365 \\
\hline Saxena y Vogel (1977) & 25,3 & 0,0571 \\
\hline Grace (1982) & 27,2 & 0,0408 \\
\hline
\end{tabular}

\subsection{7 - Velocidad terminal de las partículas}

Cuando una partícula de diámetro $d_{p}$ cae a través de un fluido, su velocidad terminal de caída libre puede estimarse a partir de consideraciones de la mecánica de los fluidos mediante la expresión:

$$
U_{t}=\left[\frac{4 d_{p}\left(\rho_{s}-\rho_{g}\right) g}{3 \rho_{g} C_{D}}\right]^{1 / 2}
$$

donde $C_{D}$ es un coeficiente de arrastre determinado experimentalmente. Haider y Levenspiel (1989) formularon la siguiente expresión predictiva para $C_{D}$ 


$$
\begin{gathered}
C_{D}=\frac{24}{R e_{s}}[1+ \\
+\frac{73,69\left(e^{-5,0748 \psi_{s}}\right) R e_{s}}{R e_{s}+5,378 e^{6,2122 \psi_{s}}}
\end{gathered}
$$

Para el caso de partículas esféricas $\left(\psi_{s}=1\right)$, la expresión (2.15) se reduce a

$$
C_{D}=\frac{24}{R e_{s}}+3,3643 R e_{s}^{0,3471}+\frac{0,4607 R e_{s}}{R e_{s}+2682,5}
$$

Debe señalarse que el cálculo de la velocidad terminal requiere un procedimiento iterativo a partir de las expresiones precedentes.

Una representación gráfica de estas ecuaciones puede hacer ágil el cálculo, visualizando las variables comprendidas en el mismo convenientemente agrupadas, permitiendo una evaluación directa de $U_{t}$. Se introducen dos variables adimensionales, que son el diámetro $d_{p}^{*}$ y la velocidad adimensional del gas $U_{t}^{*}$, definidas a partir de las siguientes relaciones:

$$
\begin{gathered}
d_{p}^{*}=d_{p}\left[\frac{\rho_{g}\left(\rho_{s}-\rho_{g}\right) g}{\mu^{2}}\right]^{1 / 3}=A r^{1 / 3}=\left(\frac{3}{4} C_{D} R e_{s}^{2}\right) \\
U_{t}^{*}=U_{t}\left[\frac{\rho_{g}^{2}}{\mu\left(\rho_{s}-\rho_{g}\right) g}\right]^{1 / 3}=\frac{R e_{s}}{A r^{1 / 3}}=\left(\frac{4 R e_{s}}{3 C_{D}}\right)
\end{gathered}
$$

La Figura 2.7 es la representación de estas ecuaciones para la evaluación directa de la velocidad terminal, dado el valor del diámetro de partículas y las propiedades físicas del sistema. 


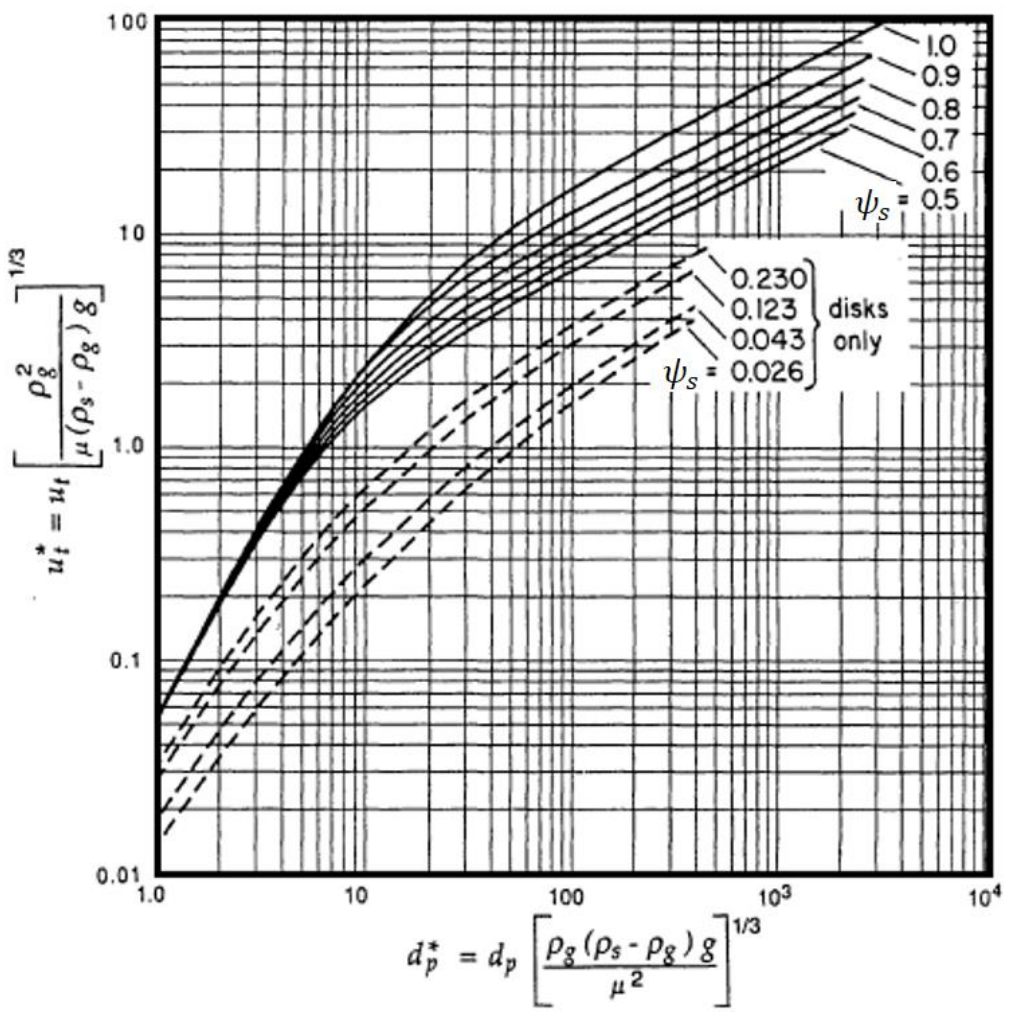

Figura 2.7 - Determinación de la velocidad terminal de partículas cayendo a través de fluidos, a partir de Haider y Levenspiel, (1989). Fuente: Kunii y Levenspiel (1991).

Haider y Levenspiel (1989) presentaron una aproximación muy útil para la evaluación directa de la velocidad terminal de partículas:

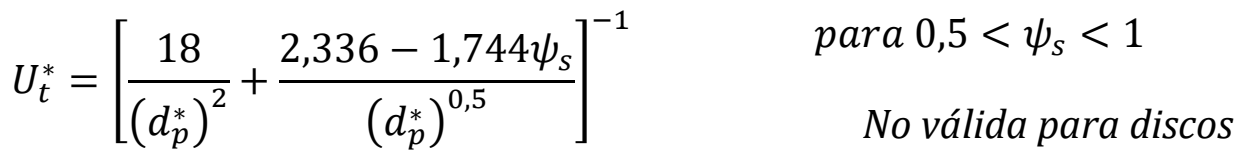

Para partículas esféricas $\left(\psi_{s}=1\right)$, esta expresión se reduce a:

$$
U_{t}^{*}=\left[\frac{18}{\left(d_{p}^{*}\right)^{2}}+\frac{0,591}{\left(d_{p}^{*}\right)^{0,5}}\right]^{-1}
$$

Para evitar el arrastre fuera del lecho de las partículas, debe mantenerse la velocidad entre el valor de mínima fluidización y la velocidad terminal calculada como se ha mostrado en esta sección. En el cálculo de $U_{m f}$ se debe usar el valor medio del diámetro para la distribución de tamaños que pueda existir en el lecho mientras que para la velocidad terminal, debe usarse el menor tamaño de sólidos que se encuentre en cantidades apreciables en el lecho. 


\subsection{8 - Velocidad Terminal de las Partículas en un conjunto}

Cuando se desea evaluar la condición de velocidad terminal de partículas integrantes de un conjunto que fluye en un fluido, el movimiento de cada partícula se ve perturbado por la acción generada por las restantes. Las expresiones derivadas para la velocidad terminal correspondiente a una partícula que cae en un fluido sin presencia de otros sólidos en forma simultánea no son válidas para estimar la caída de una partícula cuando la rodea una suspensión. Para un arreglo de sólidos la velocidad de decantación o caída es típicamente mucho menor que la velocidad terminal de una partícula única y aislada en el mismo fluido. La reducción en esta velocidad se produce por dos efectos complementarios:

$\checkmark$ El desplazamiento de fluido por las partículas que caen causa un flujo hacia arriba a través de los espacios vacíos inter-particulares.

$\checkmark$ La resistencia sobre cada partícula individual se incrementa por el efecto de las partículas vecinas en el perfil de velocidad en el fluido intersticial (deflexiones)

Considerando como determinantes a estos dos efectos y despreciando eventuales interacciones partícula-partícula, el efecto combinado puede describirse por la correlación de Richardson-Zaki:

$$
U_{t}^{\prime}=U_{t} \varepsilon^{n}
$$

donde $U_{t}^{\prime}$ y $U_{t}$ son la velocidad de sedimentación "obstaculizada" por encontrarse la partícula en una dispersión y la velocidad terminal de una partícula única aislada, respectivamente. Además, $\varepsilon$ es la porosidad del medio en el que se calcula $U_{t}^{\prime}$. El exponente $n$ depende del número de Reynolds evaluado para la partícula aislada o de $d_{p}^{*}$, pudiendo observarse algunos valores en la Tabla 2.3.

Tabla 2.3 - Valores del exponente $n$ en la ecuación de Richardson-Zaki (tomado de Seville y colab., 1997).

\begin{tabular}{|c|c|}
\hline $\begin{array}{c}\text { Res evaluado a la Velocidad } \\
\text { Terminal }\end{array}$ & Valor de $n$ \\
\hline $\operatorname{Re}_{s} \leq 0,2$ & 4,6 \\
\hline $0,2<\operatorname{Re}_{s}<1$ & $4,4 \mathrm{Re}_{\mathrm{s}}{ }^{-0,033}$ \\
\hline $1 \leq \mathrm{Re}_{\mathrm{s}}<500$ & $4,4 \mathrm{Re}_{\mathrm{s}}{ }^{-0,1}$ \\
\hline $500 \leq \mathrm{Re}_{\mathrm{s}}$ & 2,4 \\
\hline
\end{tabular}




\section{3 - REGÍMENES DE FLUIDIZACIÓN}

Partiendo de la condición de lecho fijo, el incremento progresivo de la velocidad superficial del gas, luego de alcanzar la mínima fluidización, conduce a observar diferentes regímenes, como puede apreciarse en la Figura 2.8. Puede decirse que hay dos grandes categorías en las que pueden agruparse los regímenes de fluidización, que son la fluidización particulada u homogénea y la agregativa o burbujeante (Harrison y colab., 1961).

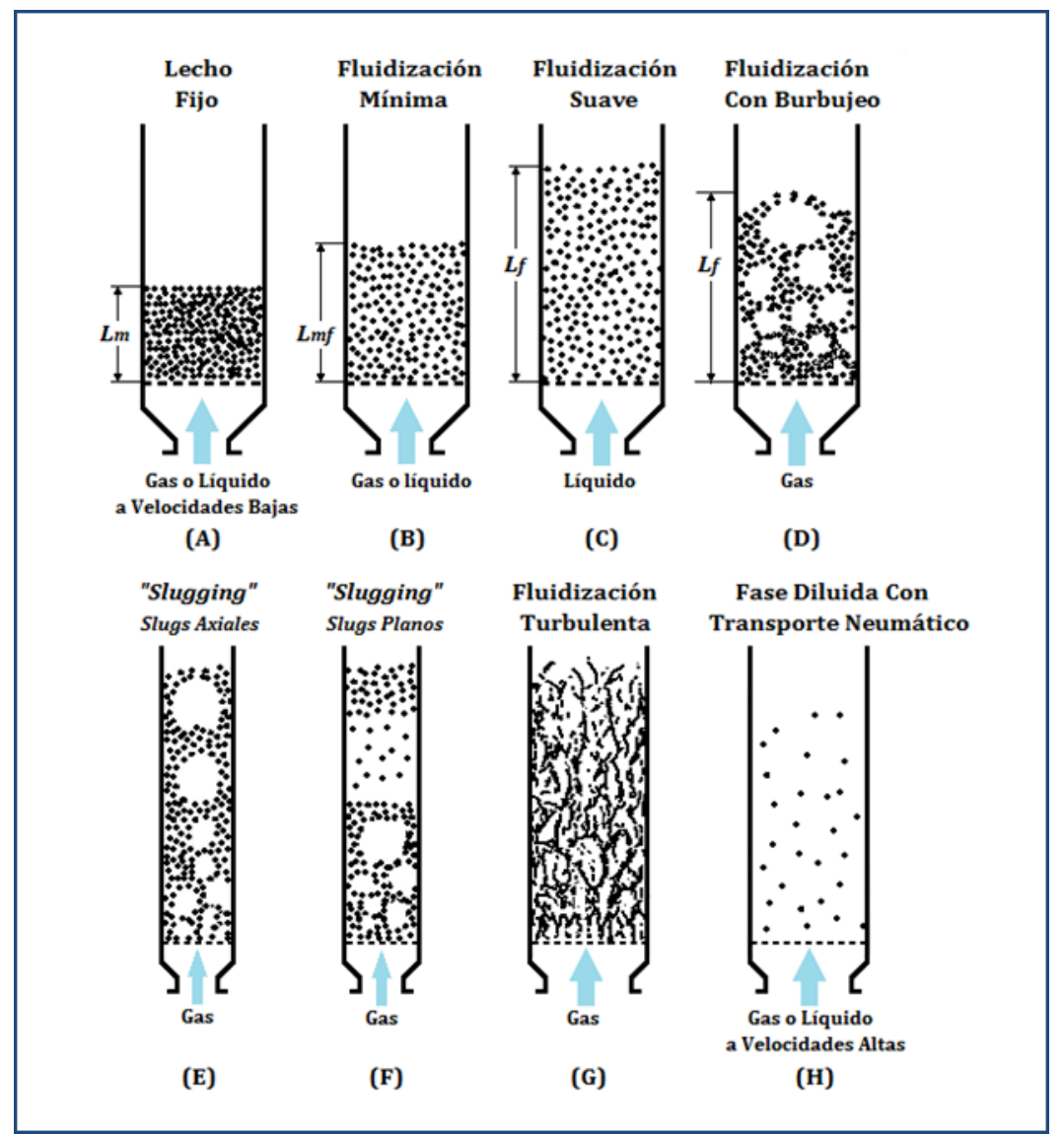

Figura 2.8 - Regímenes de fluidización en función del incremento de la velocidad superficial del fluido. Fuente: Kunii y Levenspiel (1991).

En el caso en que el fluido sea un líquido (o gas, pero en este caso con partículas Geldart A exclusivamente), un aumento en su velocidad más allá de la mínima fluidización resulta en una expansión suave y progresiva del lecho, recibiendo el nombre de fluidización homogénea. En aquéllos casos en los que el fluido es un gas, esta situación se observa únicamente cuando las partículas son pequeñas y livianas.

Por otro lado, en la fluidización agregativa pueden observarse huecos libres de sólidos, que reciben el nombre de burbujas. Dichos huecos pueden hallarse bien definidos, 
como en un lecho burbujeante o en régimen slug, o pueden ser pequeñas zonas en las que aparecen y desaparecen clusters con sólidos rápidamente, como en el régimen turbulento o en la fluidización rápida.

En el presente trabajo se analizan sistemas fluidizados gas-sólido, por lo que se procederá a realizar una descripción más profunda de los mismos. Al aumentar la velocidad superficial del gas más allá de la de mínima fluidización, comienzan a observarse inestabilidades con burbujeo y canalización del aire. Estos lechos reciben el nombre de fluidizados con burbujeo. Las burbujas de gas coalescen y crecen a medida que ascienden por el lecho, y en lechos lo suficientemente profundos y con diámetro pequeño pueden crecer hasta ocupar casi el ancho del recipiente. En el caso de partículas pequeñas, los sólidos descienden suavemente por la pared alrededor del bolsón de aire, recibiendo el nombre de slugging con slugs axiales. En cambio, en el caso de partículas más grandes, la porción del lecho sobre el slug es empujada hacia arriba como un pistón y las partículas van cayendo como una lluvia hasta que el slug finalmente se desintegra. Esto recibe el nombre de flat slug. También puede haber presentes slugs de pared, que son aquéllas burbujas que crecen solidarias a la pared del recipiente (este régimen se analizará particularmente en el Capítulo 4 de la presente tesis).

Reciben el nombre de lechos densos o cautivos aquéllos sistemas en los que no hay arrastre natural de partículas y donde la superficie límite superior (llamada freeboard) se encuentra bien definida. En cambio, cuando la velocidad superficial del gas es tal que comienza a haber arrastre de sólidos, se entra en un régimen de fase diluida con transporte neumático, que terminará por conducir a la condición de lecho "circulante" o "abierto".

Cuando los lechos son operados a velocidades superiores a la de transporte, deben colocarse sistemas de reciclaje de partículas y pueden considerarse regímenes de fluidización adicionales, como los lechos circulantes. Debe tenerse en cuenta que no todos los sistemas pueden presentar todos los regímenes, ya que muchos de ellos dependen también del tamaño del equipo utilizado

\subsection{1 - Transición de lecho Fijo a fluidización Particulada y régimen Burbujeante}

Para los lechos que contienen partículas tipo Geldart B o D, la transición se presenta de lecho fijo a burbujeante cuando la velocidad superficial del gas supera la de mínima fluidización para el sistema. Por el contrario, en los lechos de partículas tipo 
Geldart A se observa una expansión homogénea sin presencia de burbujas. En este último caso pueden observarse burbujas únicamente superando la velocidad de mínimo burbujeo.

\subsection{2 - Transición entre régimen de Burbujeo y régimen Slug}

El régimen slug ocurre sólo en aquéllos casos en los que la relación entre la altura del lecho y su diámetro (H/D) es superior a 2, debido a que proveen del suficiente tiempo a las burbujas para coalescer en burbujas más grandes. Cuando las burbujas alcanzan aproximadamente 2/3 del diámetro del lecho, éste entra en régimen slug, caracterizado por el pasaje periódico de grandes burbujas y elevada fluctuación de la caída de presión asociada a la frecuencia de las mismas. Cabe destacar que en la mayoría de los casos este es un régimen que trata de evitarse.

\subsection{3 - Transición entre régimen Burbujeante y Turbulento}

Al aumentar progresivamente la velocidad superficial del gas, las burbujas aumentan su tamaño debido a la coalescencia y el burbujeo puede derivar en slugs si las partículas son grandes y el diámetro del lecho es pequeño. Si se grafica el desvío estándar de las fluctuaciones de presión en el lecho en función de la velocidad superficial del gas, pueden identificarse dos velocidades características, $U_{c}$ y $U_{k}$, sugeridas por primera vez por Yerushalmi y Cankurt en 1979. La velocidad $U_{c}$ corresponde a un lecho operando en condiciones tales que las burbujas o slugs han alcanzado el máximo diámetro posible, generando por consiguiente el mayor desvío estándar en la fluctuación de presión. Si la velocidad superficial del gas se incrementa más allá de $U_{c}$, las burbujas grandes comienzan a romperse en burbujas más pequeñas, generando por consiguiente una disminución en las fluctuaciones de presión, hasta que finalmente el desvío estándar de las fluctuaciones de presión alcanza un estado estable. En este punto la velocidad característica recibe el nombre de $U_{k} \mathrm{y}$ marca la transición entre el régimen burbujeante y el turbulento. Sin embargo, hay autores que consideran que existe una única velocidad de transición $U_{c}$, de modo que el régimen turbulento comienza en $U_{c}$ y finaliza con $U_{t}$, velocidad capaz de transportar todas las partículas fuera del lecho. Aun hoy en día sigue existiendo controversia respecto de la transición entre el régimen burbujeante y el turbulento. 
Basándose en valores experimentales de los desvíos estándar de las fluctuaciones de presión varios autores han propuesto correlaciones, para predecir el valor de las velocidades $U_{c}$ y $U_{k}$. En 1986, Horio propuso las siguientes ecuaciones:

$$
R e_{c}=\frac{d_{p} \rho_{g} U_{c}}{\mu}=0,936 A r^{0,472}
$$

Para el cálculo de $U_{k}$, propuso dos ecuaciones diferentes para ajustar dos series diferentes de datos:

$$
\begin{gathered}
R e_{k}=\frac{d_{p} \rho_{g} U_{k}}{\mu}=1,46 A r^{0,472} \text { para los datos de Canada y colab. (1978) } \\
R e_{k}=\frac{d_{p} \rho_{g} U_{k}}{\mu}=1,41 A r^{0,56} \text { para los datos de Yerushalmi y colab. }
\end{gathered}
$$

Basándose en una extensa base de datos de fluctuaciones de presión absoluta y mediciones de expansión del lecho, Cai y colab. (1989) propusieron:

$$
R e_{c}=\frac{d_{p} \rho_{g} U_{c}}{\mu}=0,57 A r^{0,46}
$$

Perales y colab. (1990) sugieren ecuaciones para el cálculo de $U_{k}$ y $U_{t}$, pero dada la gran similitud entre ambas, propusieron también una ecuación simplificada para calcular dichas velocidades:

$$
R e_{k, t}=\frac{d_{p} \rho_{g} U_{k}}{\mu}=\frac{d_{p} \rho_{g} U_{t}}{\mu}=1,45 A r^{0,484}
$$

Bi y colab. (1995) correlacionaron los datos disponibles en literatura basados en las fluctuaciones de la presión diferencial y propusieron la siguiente ecuación para la transición:

$$
R e_{c}=\frac{d_{p} \rho_{g} U_{c}}{\mu}=1,24 A r^{0,45} \quad 2<A r<110^{8}
$$

\subsection{4 - Transición a fluidización rápida}

Si se continúa aumentando la velocidad de operación más allá de la necesaria para el régimen turbulento, se alcanza una velocidad crítica, llamada velocidad de transporte, en la que comienza a haber arrastre significativo de sólidos. Más allá de este punto no es posible operar el lecho si no se cuenta con un sistema para recuperar los 
sólidos arrastrados. Este régimen recibe el nombre de fluidización rápida y su velocidad de transición fue correlacionada por Bi y colab. (1995) del siguiente modo:

$$
U_{t}=1,53 A r^{0,5} \quad 2<A r<410^{0,5}
$$

Para las partículas tipo Geldart A y B, la velocidad de transición $U_{t}$ calculada con la ecuación anterior, es mayor que la velocidad terminal para las partículas individuales, mientras que para las partículas tipo Geldart D la velocidad de transición es esencialmente igual a la velocidad terminal de las partículas individuales. 


\section{CAPÍTULO 3}

\section{FLUIDIZACIÓN BAJO RÉGIMEN BURBUJEANTE}

INTRODUCCIÓN

3.1 - ASPECTOS GENERALES

3.2 - TEORÍA DE LAS DOS FASES

3.3 - LA FASE BURBUJA

3.3.1 - Características y comportamiento

3.3.2 - El modelo de burbuja de Davidson

3.3.3 - Diámetro de burbuja

3.3.3.1 - Correlación de Darton (1977)

3.3.3.2 - Correlación de Werther (1978)

3.3.3.3 - Correlación de Agarwal (1985)

3.3.3.4 - Correlación de Cai y colab. (1994)

3.3.4 - Velocidad de las burbujas

3.3.4.1 - Werther (1978)

3.3.4.2 - Hilligardt y Werther (1986)

3.3.4.3 - Kunii-Levenspiel (1991)

3.3.5 - Factor de forma de las burbujas $\omega$

3.3.6 - Frecuencia de las burbujas

3.4 - MATERIALES Y EQUIPAMIENTO

3.4.1 - Caracterización de la arena

3.4.1.1 - Diámetro de partícula

3.4.1.2 - Densidad 
3.4.1.3 - Composición mineralógica

3.4.1.4 - Esfericidad y redondez

3.4 .2 - Equipamiento Experimental

3.5 - MODELADO POR CFD

3.5.1 - Generación del dominio, mallado y validación

3.5.2 - Implementación de la simulación por CFD

3.6 - CURVA DE FLUIDIZACIÓN

3.7 - ANÁLISIS Y CARACTERÍSTICAS DE LA FASE BURBUJA

3.7.1 - Post-Procesamiento de imágenes

3.7.2 - Determinación del diámetro de las burbujas

3.7.3 - Determinación de la velocidad de las burbujas

3.7.4 - Determinación de la frecuencia de burbujas

3.8 - RESULTADOS Y DISCUSIÓN DEL ESTUDIO DE LA FASE BURBUJA

3.8.1 - Diámetro $d_{s v}$

3.8.2 - Velocidad de ascenso $u_{b}$

3.8.3 - Factor de forma $\omega$

3.8.4 - Frecuencia de burbujas

3.9 - EXTRAPOLACIÓN A UN LECHO CILÍNDRICO

3.9.1 - Tratamiento de imágenes del lecho cilíndrico simulado

3.9.2 - Resultados y discusión

3.10 - ESTUDIO EXPERIMENTAL Y CFD DE UN LECHO FLUIDIZADO DE BASE CÓNICA CON PARTÍCULAS GELDART D

3.11 - CONCLUSIONES DEL CAPÍTULO 3

ANEXO 3.I: ESTUDIO DE LA FLUIDIZACIÓN DE PARTÍCULAS DE UREA

A3.I.1 - EQUIPAMIENTO EXPERIMENTAL

A3.I.2 - MODELADO POR CFD 
A3.I.3 - CURVA DE FLUIDIZACIÓN

A3.I.4 - CARACTERIZACIÓN DE LA FASE BURBUJA

A3.I.4.1 - Diámetro de burbuja

A3.I.4.2 - Velocidad de ascenso de burbujas

A3.I.5 - CONCLUSIONES

ANEXO 3.II: Fluidodinámica Computacional (CFD)

A3.II.1 - ECUACIONES DE CONSERVACIÓN

A3.II.1.1 - Conservación de materia

A3.II.1.2 - Conservación de la cantidad de movimiento

A3.II.1.3 - Conservación de la energía

A3.II.2 - ECUACIONES AUXILIARES

A3.II.2.1 - Coeficiente de intercambio de cantidad de movimiento

A3.II.2.2 - Presión de sólidos

A3.II.2.3 - Función de distribución radial

A3.II.2.4 - Tensiones de corte de la fase sólida

A3.II.2.4.1 - Viscosidad bulk

A3.II.2.4.2 - Viscosidad por colisiones

A3.II.2.4.3 - Viscosidad cinética

A3.II.2.4.4 - Viscosidad friccional

A3.II.2.4.5 - Temperatura granular

A3.II.3 - MODELO DEL MEDIO POROSO

A3.II.4 - DISCRETIZACIÓN DE LAS ECUACIONES DE TRANSPORTE

A3.II.5 - PROCEDIMIENTO DE RESOLUCIÓN POR MEDIO DEL SOFTWARE

A3.II.5.1 - Pre-procesamiento

A3.II.5.2 - Resolución

A3.II.5.3 - Post-procesamiento 
ANEXO 3.III: PROGRAMACIÓN AUXILIAR

A3.III.1 - ANÁLISIS DE IMÁGENES BIDIMENSIONALES

A3.III.2 - CÁLCULOS PARA IMÁGENES BIDIMENSIONALES

A3.III.2.1 - Análisis de diámetro

A3.III.2.2 - Análisis de velocidades

A3.III.3 - GENERACIÓN DE ARCHIVOS DE DATOS 3D

A3.III.4 - CÁLCULOS PARA DATOS DE ISOSUPERFICIES

A3.III.4.1 - Análisis de diámetro

A3.III.4.2 - Análisis de velocidad de burbuja 


\section{INTRODUCCIÓN}

Los lechos fluidizados burbujeantes son ampliamente utilizados en procesos y operaciones industriales, tales como reactores químicos, dispositivos de mezclado, secado e intercambio de calor, debido a que los mismos promueven elevadas velocidades de transferencia de calor y masa y buen manejo del ingreso y extracción de sólidos. La conversión en reactores burbujeantes puede variar desde valores similares a los de flujo pistón hasta muy por debajo de los obtenidos en reactores de tanque agitado, y por muchos años el aspecto más desconcertante de este comportamiento consistía en que a menudo no se podía estimar o conjeturar de forma confiable qué ocurriría en una situación no conocida. Debido a ello, el escalado a mayores tamaños era muy arriesgado e incierto (Levenspiel, 1998).

Estos lechos presentan dos componentes bien diferenciadas, que se conocen como fase burbuja y fase densa o emulsión. La fase burbuja consiste en bolsones de baja fracción de sólidos, mientras que, en la emulsión se visualiza una elevada fracción de partículas sólidas. La fase densa está compuesta por el sólido particulado y el gas intersticial (Kunii y Levenspiel, 1991). La comprensión de las características hidrodinámicas de los lechos fluidizados es fundamental para poder llevar a cabo su operación de manera apropiada. En este sentido, la caracterización de la fase burbuja es un aspecto crucial para analizar, debido a que la fluidodinámica del lecho se encuentra directamente relacionada con el comportamiento de las entidades identificadas como burbujas. El diámetro de burbuja es la variable principal que definirá el comportamiento de la misma y se encuentra directamente relacionado con la geometría del lecho, su altura, características del distribuidor y velocidad superficial del gas en exceso (por sobre el valor de mínima fluidización). Por otro lado, propiedades secundarias de la burbuja, tales como su velocidad lineal, frecuencia y factor de forma dependen del valor de su diámetro. De la misma forma, parámetros vinculados a los procesos de transferencia de masa y calor entre la fase burbuja y la emulsión se vinculan al valor del diámetro promedio de burbujas. Por este motivo, se ha dedicado un gran esfuerzo en la bibliografía para llevar a cabo la evaluación experimental (Rowe y Partridge, 1965; Baeyens y Wu, 1992; Hulme y Kantzas, 2004; Busciglio y colab., 2010; Cano-Pleite y colab., 2014) y para la predicción empírica y por modelado de esta propiedad (Davidson y Harrison, 1966; Ding y Gidaspow, 
1990; van Wachem y colab., 1998; Cammarata y colab., 2003; Cornelissen y colab., 2007; Hosseini y colab., 2010; Reuge y colab., 2008; Asegehegn y colab., 2011).

Cuando se intenta modelar la fluidodinámica de los lechos fluidizados gas-sólido, se presenta el problema del movimiento de dos fases, cuya interfase es desconocida y transiente (Gilbertson y Yates, 1996; citado Taghipour y colab., 2005). El modelado riguroso de estos sistemas contribuye a comprender el comportamiento de las burbujas. En este aspecto, la fluidodinámica computacional (CFD) está llamada a desempeñar un rol fundamental. El modelado debe contar con enfoques detallados que consideren los fenómenos locales y puedan conectarlos con la fluidodinámica global del lecho fluidizado. Teniendo en cuenta que las burbujas no pueden cuantificarse de manera directa, el modelado debe incorporar, potencialmente, un método asociado que permita la evaluación del tamaño de burbuja y sus propiedades secundarias.

Si bien las herramientas de CFD han sido frecuentemente utilizadas para el estudio de la fase burbuja, es esencial poder validar el modelado contrastando los resultados obtenidos con información experimental y con correlaciones existentes en la bibliografía. La mayor parte de los enfoques para correlaciones encontrados en la literatura son empíricos o semi-empíricos, y gran parte de los datos experimentales disponibles están basados en lechos de partículas Geldart B. En estos casos, no es posible realizar una extrapolación confiable de los resultados a sistemas/condiciones diferentes de los utilizados en las determinaciones. Las correlaciones son, con frecuencia, utilizadas para diversos objetivos, entre los que se encuentra la validación potencial de esquemas de modelado, particularmente de modelado por CFD. En tal contexto, el aporte realizado por Karimipour y Pugsley (Karimipour y Pugsley, 2011) en su trabajo de revisión de un número significativo de correlaciones existentes para la predicción de propiedades de burbujas en lechos fluidizados, reviste un considerable valor.

A lo largo de los años, se han llevado a cabo avances en relación a técnicas y métodos utilizados para estudiar las características de la fase burbuja. Los primeros estudios experimentales consistieron en fotografías de la superficie del lecho, donde las burbujas producen perturbaciones al romperse (Davidson y Harrison, 1963). La fotografía de burbujas en lechos 2D con paredes transparentes permitió obtener información del tamaño, forma, cantidad de burbujas y su velocidad (Rowe, 1962, citado por Rowe y Partridge (1965)). Posteriormente Rowe y Partridge (1965) estudiaron las 
características de la fase burbuja, como forma, tamaño y velocidad para distintos sólidos en un lecho cilíndrico, utilizando la técnica de fotografía mediante rayos X. Baeyens y Wu (1992) describieron las investigaciones teóricas y experimentales en las que se estudió la expansión del lecho y el flujo visible de burbujas, entre otros, variando distintos parámetros. Los autores describieron los estudios experimentales previos que realizaron bajos diferentes proyectos, y compararon los resultados con datos disponibles en bibliografía. Entre los estudios se encuentran los experimentos realizados en una columna de acrílico a temperatura amiente, donde se midió de forma indirecta el número y diámetro de erupción de las burbujas filmando la parte superior del lecho. Más recientemente se han implementado técnicas intrusivas, tales como sensores de fibra óptica y de presión, y no intrusivas, como rayos X, tomografía de capacitancia (Wu y colab., 2007), o aquéllas basadas en mediciones de la fluctuación de presión (Bi, 2007). AcostaIborra y colab. (2011) llevaron a cabo el estudio experimental y mediante CFD del comportamiento de un lecho cilíndrico cargado con partículas Geldart B. Los datos experimentales fueron obtenidos con técnicas intrusivas, mediante el uso de sensores de fibra óptica y de presión instalados en el lecho, mientras que en la simulación por CFD se consideraron monitores de presión y fracción de sólidos. El análisis de resultados muestra muy buena concordancia entre los valores experimentales y los obtenidos mediante CFD. De modo similar, Rüdisüli y colab. (2012) desarrollaron un algoritmo, basado en técnicas de regresión, para evaluar los datos arrojados por los sensores de fibra óptica y medir las características principales de la fase burbuja, tales como tamaño, velocidad de ascenso y distribución en el lecho. Otro estudio, desarrollado por Busciglio y colab. (2008) se enfoca en el desarrollo de una técnica de análisis de imágenes digitales (DIAT), basado en el uso de una cámara de alta velocidad acoplada con el análisis de imágenes, a fin de estudiar las características fluidodinámicas de un lecho fluidizado burbujeante bidimensional. Además de ser una técnica no intrusiva, el análisis de imágenes provee abundante información. La técnica desarrollada permite la medición simultánea de numerosas propiedades de la fase burbuja (tamaño, velocidad, hold-up, altura de lecho, entre otras). Los resultados obtenidos fueron comparados con correlaciones, mostrando muy buena concordancia. Posteriormente, los autores utilizaron la técnica desarrollada para combinar estudios experimentales y mediante CFD (Busciglio y colab., 2009). Las simulaciones se llevaron a cabo utilizando el software comercial ANSYS-CFX. Un estudio similar fue reportado por Lu y colab. (2015), quienes realizaron la simulación de un lecho 
pseudo-2D (lecho cuyo espesor es despreciable frente a las dimensiones restantes, en este caso coincidente con el diámetro de las partículas que es de 0,5 $\mathrm{mm}$ ) utilizando el método de elementos discretos (DEM). Los autores desarrollaron un programa basado en el algoritmo de flood fill para analizar los datos ("relleno por difusión") y hallaron valores de diámetro, relación de aspecto y velocidad con muy buena concordancia con correlaciones empíricas.

Recientemente, se han realizado grandes avances en el estudio experimental de la dinámica de la fase burbuja, como lo evidencia el estudio llevado a cabo por Li y colab. (2018) que consistió en el uso de tomografía de capacitancia eléctrica (ECT), el de Maurer y colab. (2016) que basaron su método en la tomografía de rayos X, o el de Fabich y colab. (2017), que obtuvieron sus datos utilizando imágenes por resonancia magnética (MRI) combinado con ultrashort echo time (UTE) para obtener mejor resolución. Kong y colab. (2019) investigaron técnicas no intrusivas mediante el uso de probetas de ultrasonido en lechos opacos, que permiten obtener propiedades esenciales de las burbujas midiendo su frecuencia. El estudio se llevó a cabo en un lecho rectangular cargado con partículas de cristobalita, y los resultados obtenidos mediante esta novedosa técnica se compararon con datos obtenidos mediante fotografías tomadas con una cámara de alta velocidad colocada en la zona superior del lecho y con predicciones basadas en la teoría de las dos fases, mostrando muy buena concordancia. Sobrino y colab. (2015) presentaron un método novedoso para el análisis de imágenes obtenidas en una simulación en entorno 3D. Las burbujas se caracterizaron utilizando la metodología de pierced bubble y tomografías. En el primer caso, las funciones de densidad de probabilidad de los anchos de onda obtenidos con monitores ópticos virtuales, fueron transformados a distribución de diámetros utilizando la metodología MEM (Sobrino y colab., 2009). El segundo método permite la obtención directa del volumen de burbuja basado en la reconstrucción tomográfica de una imagen tridimensional obtenida por CFD. Los resultados obtenidos permitieron confirmar la robustez de la metodología MEM para estudiar las propiedades de la fase burbuja.

En este capítulo se presenta un estudio exhaustivo del régimen burbujeante en dos geometrías distintas (pseudo-2D y 3D). En la sección 3.1 se describen los aspectos generales de la fase burbuja, mientras que en la sección 3.2 se presenta la Teoría de las dos fases que permite diferenciar de forma sencilla el gas que atraviesa el lecho en forma 
de burbuja del gas emulsionado con los sólidos. Luego, en la sección 3.3 se describe en forma detallada la fase burbuja y sus características. Se incluyen en esta sección una serie de subsecciones en las que se describen los parámetros más importantes, como el diámetro, la velocidad de ascenso, factor de forma y frecuencia. También se presentan en esta sección correlaciones para el cálculo de diámetros y velocidades de burbuja. En la sección 3.4 se caracteriza la arena, que es el sólido utilizado para este estudio, y se describen los equipos experimentales con los que se llevan a cabo las mediciones de pérdida de carga (lecho cilíndrico) y el estudio de la fase burbuja (lecho pseudo-2D). Luego, en la sección 3.5 se presentan los pasos a seguir para efectuar una simulación por CFD, incluyendo la validación de la malla que se utilizará. En la sección 3.6 se presenta la curva de fluidización obtenida tanto experimentalmente como mediante CFD. Posteriormente, en la sección 3.7 se describe el análisis llevado a cabo para el estudio de la fase burbuja y la validación de los parámetros y modelos utilizados en el estudio mediante CFD. Se incluye aquí una descripción de la metodología de análisis de imágenes (experimentales y obtenidas mediante CFD) aplicada para obtener los valores de diámetro, velocidad de ascenso, factor de forma y frecuencia de las burbujas. En la sección 3.8 se presentan los resultados del análisis de la fase burbuja en el lecho pesudo-2D. La extrapolación a un lecho de geometría cilíndrica, de la metodología CFD descripta es presentada en la sección 3.9. Finalmente, en la sección 3.10 se vuelcan las conclusiones alcanzadas. Este capítulo cuenta, además, con tres anexos en los que se presenta el estudio realizado para partículas de urea en un lecho de geometría cónica (Anexo 3.I), la teoría asociada a la CFD (Anexo 3.II) y los programas desarrollados en MATLAB y Autodesk 3DS Max para poder llevar a cabo el análisis de imágenes y los cálculos asociados a la fase burbuja.

\section{1 - ASPECTOS GENERALES}

Las burbujas pueden ser observadas fácilmente en un lecho "bidimensional" formado por dos paredes transparentes separadas por una distancia de aproximadamente $1-3 \mathrm{~cm}$ y sección rectangular, como puede observarse en la Figura 3.1. 


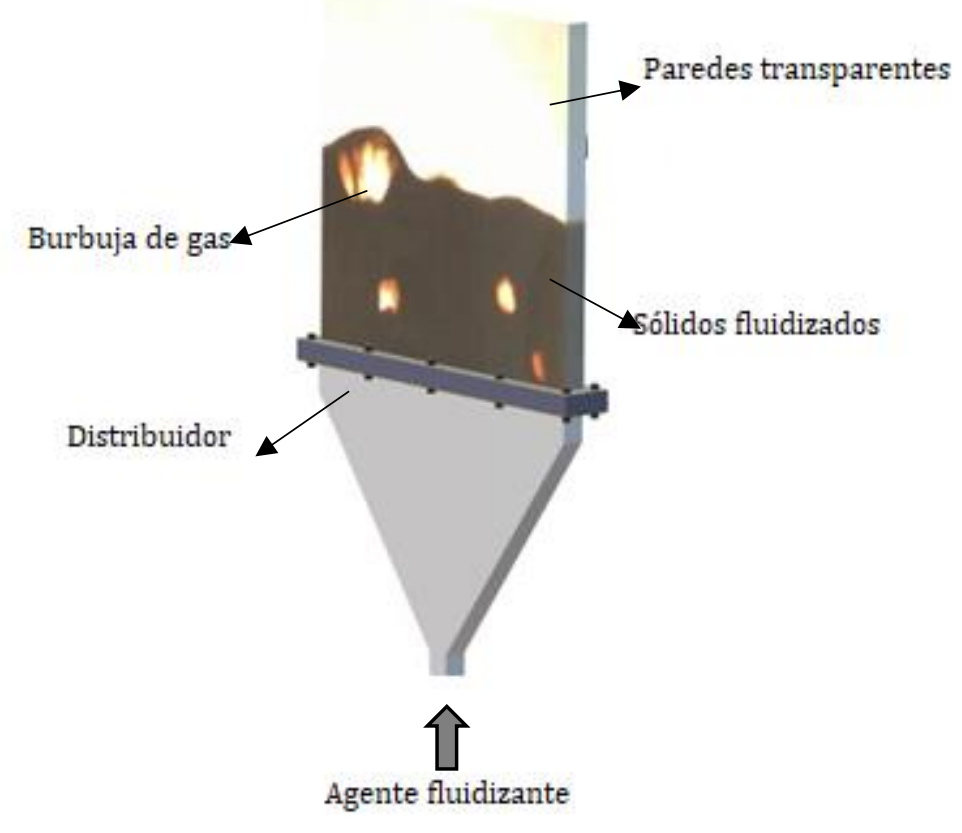

Figura 3.1- Burbuja de gas ascendiendo en un lecho fluidizado bidimensional.

En muchos aspectos, un lecho de burbujas se comporta como un líquido burbujeante de baja viscosidad:

$\checkmark$ Las burbujas son casi esféricas cuando son pequeñas, aplanadas y distorsionadas cuando tienen un tamaño intermedio y esféricas con forma de capuchón cuando son grandes.

$\checkmark$ Las burbujas pequeñas ascienden lentamente y las burbujas grandes lo hacen a mayor velocidad.

$\checkmark$ Un conjunto de burbujas puede unirse para dar burbujas más grandes (coalescencia). La interacción de un conjunto da una velocidad de ascenso de burbuja diferente.

$\checkmark$ Los efectos de pared afectan la velocidad de ascenso de las burbujas.

$\checkmark$ La velocidad de ascenso de las burbujas depende de los mismos factores y se describe mediante expresiones similares en ambos sistemas.

A diferencia de los sistemas de gas-líquido, hay un intercambio de gas entre la burbuja y la fase densa, ya que la frontera entre burbuja y emulsión es permeable al paso de gas. Experimentos adicionales en lechos burbujeantes indican que el gas en exceso del necesario para la fluidización atraviesa el mismo en forma de burbujas, mientras que la fase emulsión permanece aproximadamente en las condiciones de mínima fluidización. 


\section{2 - TEORÍA DE LAS DOS FASES}

La Teoría de las dos fases (TDF) es una teoría simple, que fue propuesta originalmente por Toomey y Johnstone (1952) y establece que todo el gas en exceso de la cantidad necesaria para la fluidización mínima, atraviesa el lecho en forma de burbujas. De esta forma, si $Q$ es el caudal volumétrico total de gas en el lecho, $Q_{m f}$ el caudal volumétrico necesario para la fluidización mínima y $Q_{b}$ el caudal volumétrico de burbujas que atraviesa la sección del lecho (Figura 3.2), se puede escribir:

$$
Q=Q_{b}+Q_{m f}
$$

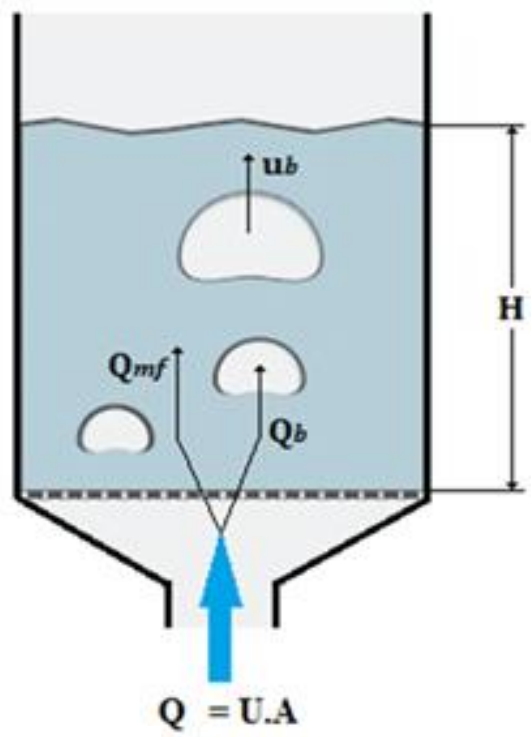

Figura 3.2 - Descripción de un lecho fluidizado según la TDF.

Si se divide la ecuación (3.1) por el área transversal del lecho vacío $(A)$, se puede obtener y despejar la velocidad superficial de burbujas:

$$
U_{b}=\frac{Q_{b}}{A}
$$

Por extensión,

$$
\frac{Q_{b}}{A}=U_{b}=U-U_{m f}
$$

La ecuación (3.3) se obtiene sobre la base de suponer que el estado fluidodinámico y las propiedades de la emulsión son exactamente aquellas correspondientes a la condición de mínima fluidización. Consecuentemente, la 
porosidad de la fase densa o emulsión $\left(\varepsilon_{e}\right)$, de acuerdo a la TDF, coincidirá con la porosidad de mínima fluidización $(\varepsilon m f)$. La información determinada por la aproximación (3.3) puede resultar muy útil en la práctica si no se cuenta con conocimiento adicional del sistema. No obstante, en las décadas de los años 70-80 se reportaron numerosos estudios experimentales en los que se había medido el caudal volumétrico de burbujas de gas en lechos de burbujeo libre y la conclusión general que se obtuvo entonces fue que, en la mayoría de los sistemas estudiados, la TDF sobreestimaba el flujo visible de burbujas en el lecho, inclusive, en ciertos casos, en valores considerables (Grace y Clift (1974), Barreto (1984)). Se propuso entonces modificar esta teoría para intentar aproximar sus predicciones a las observaciones experimentales mencionadas. Diferentes alternativas han sido reportadas para introducir una corrección a la expresión (3.3). Por ejemplo, la ecuación (3.4) muestra una de ellas:

$$
U_{b}=U-U_{m f}\left(1+n \overline{f_{b}}\right)
$$

donde $n$ es un número positivo y $\bar{f}_{b}$ es la fracción volumétrica promedio ocupada por burbujas en el lecho fluidizado. En el caso ideal de la TDF, $n=0$ y su valor va aumentando conforme aumenta el flujo de gas a través de la emulsión (gas intersticial), observándose también una desviación más ostensible de la idealidad. Locket y colab. (1967) llevaron a cabo un desarrollo teórico que permite predecir numéricamente el coeficiente de no idealidad. Los autores encontraron diferencias respecto de la TDF, proponiendo que $n=1$ en un sistema de dos dimensiones cuando el flujo de burbujas es bajo, y $n=2$ para un sistema tridimensional. La determinación del coeficiente de no idealidad $n$ ha sido reportada por diferentes autores sobre bases tanto teóricas como experimentales (Yates, 1983), considerando, en general, que las burbujas actúan como un camino de menor resistencia para el gas intersticial. Si se reescribe la ecuación (3.3) como:

$$
\frac{Q_{b}}{A}=U-U_{m f}\left(1+n \bar{f}_{b}\right)=U-U_{m f} n \bar{f}_{b}
$$

y trabajando sobre esta ecuación, teniendo en cuenta que el flujo a través de las burbujas puede ser evaluado mediante $U_{m f}(1+n)$, puede reescribirse la TDF del siguiente modo: 


$$
\frac{Q_{b}}{A}=U-\left[U_{m f}\left(1-\overline{f_{b}}\right)+U_{m f}(1+n) \overline{f_{b}}\right]
$$

En función de la ecuación (3.6), es posible definir los siguientes caudales volumétricos de gas:

$\checkmark\left[U_{m f}\left(1-\bar{f}_{b}\right)\right] / A$ : caudal volumétrico de gas que atraviesa la emulsión

$\checkmark\left[U_{m f}\left(1+\bar{f}_{b}\right)\right] / A$ : caudal volumétrico de gas que atraviesa las burbujas

Por lo tanto, la teoría supone que la velocidad superficial del gas en la emulsión permanece igual a la de mínima fluidización $U_{m f}$, mientras que en las burbujas dicha velocidad es $U_{m f}(1+n)$. Las investigaciones teóricas antes mencionadas, fueron planteadas sobre la expectativa de que el coeficiente $n$ resultara universal y, por lo tanto, representativo del flujo de gas a través de las burbujas. Lamentablemente los estudios experimentales mostraron que no lo es, y que además de variar para diversos pares gas-sólido puede variar con la altura del lecho y velocidad del gas en un mismo sistema.

En la práctica, puede evaluarse la relación $Q_{b} / A$ escribiéndola del siguiente modo:

$$
\frac{Q_{b}}{A}=\gamma\left(U-U_{m f}\right)
$$

siendo

$$
\begin{aligned}
& 0,8<\gamma<1,0 \text { para partículas tipo Geldart A } \\
& 0,6<\gamma<0,8 \text { para partículas tipo Geldart B } \\
& 0,25<\gamma<0,6 \text { para partículas tipo Geldart D }
\end{aligned}
$$

Para evaluar el coeficiente $\gamma$, puede utilizarse la expresión propuesta por Baeyens y Geldart (1985), que determina el valor de dicho coeficiente respetando los límites dados para la ecuación (3.7):

$$
\gamma=2,27 A r^{-0,21}
$$




\section{3 - LA FASE BURBUJA}

\subsection{1 - Características y comportamiento}

Las burbujas se caracterizan por contener una muy pequeña cantidad de sólido, siendo por eso una fase diluida, y por ser atravesadas por el flujo ascendente de gas en su movimiento. Los sólidos se ven obligados a desviar su trayectoria debido al flujo emergente de gas desde la interfase de la burbuja, como puede observarse en la línea discontinua de la Figura 3.3.

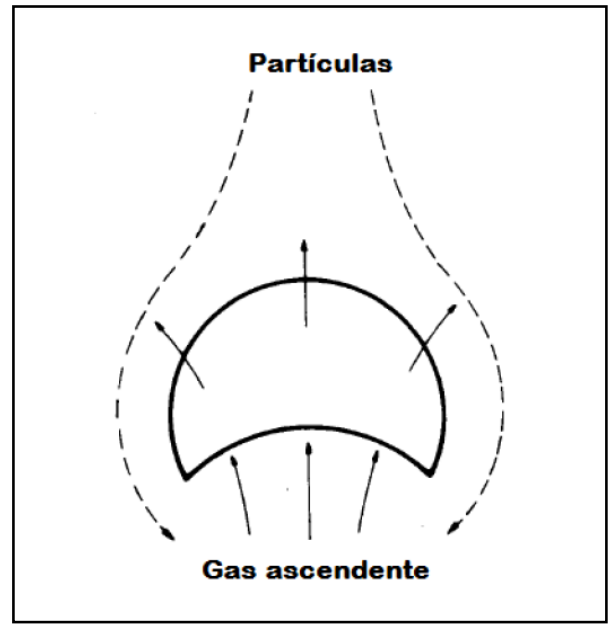

Figura 3.3 - Flujo ascendente de gas y descendente de sólidos sobre una burbuja inmóvil (Mazza, 1993).

Las burbujas no son esféricas, sino que tienen una forma semiesférica en la parte superior y son generalmente indentadas en la base. Al ascender arrastran una estela que contiene una considerable cantidad de sólidos en forma solidaria a su base. En consecuencia, el flujo neto de sólidos en la fase densa deberá ser descendente para mantener el balance de sólidos en el recipiente (Mazza, 1993). El gas en el interior de una burbuja particular permanece en forma prolongada dentro de la misma, penetrando una distancia relativamente pequeña en la fase densa. Esa región donde cantidades determinadas de gas provenientes de una burbuja que asciende penetran en la fase densa, se denomina nube. Las burbujas, en su paso, arrastran una cierta cantidad de partículas tras ellas en una zona denominada estela de la burbuja. Este mecanismo de transporte de sólidos en las estelas de las burbujas es el responsable principal del mezclado en el lecho (Yates, 1983). La formación o no de la nube depende fuertemente del tipo de partículas 
fluidizadas. El pasaje de burbujas tiene un segundo efecto sobre los sólidos, que consiste en generar un movimiento ascendente en las partículas que se encuentran sobre su línea de paso, conocido como huella de la burbuja, mientras que una corriente ascendente de sólidos alejada vuelve a compensar este cambio (Mazza, 1993). Las zonas mencionadas pueden observarse en la Figura 3.4.

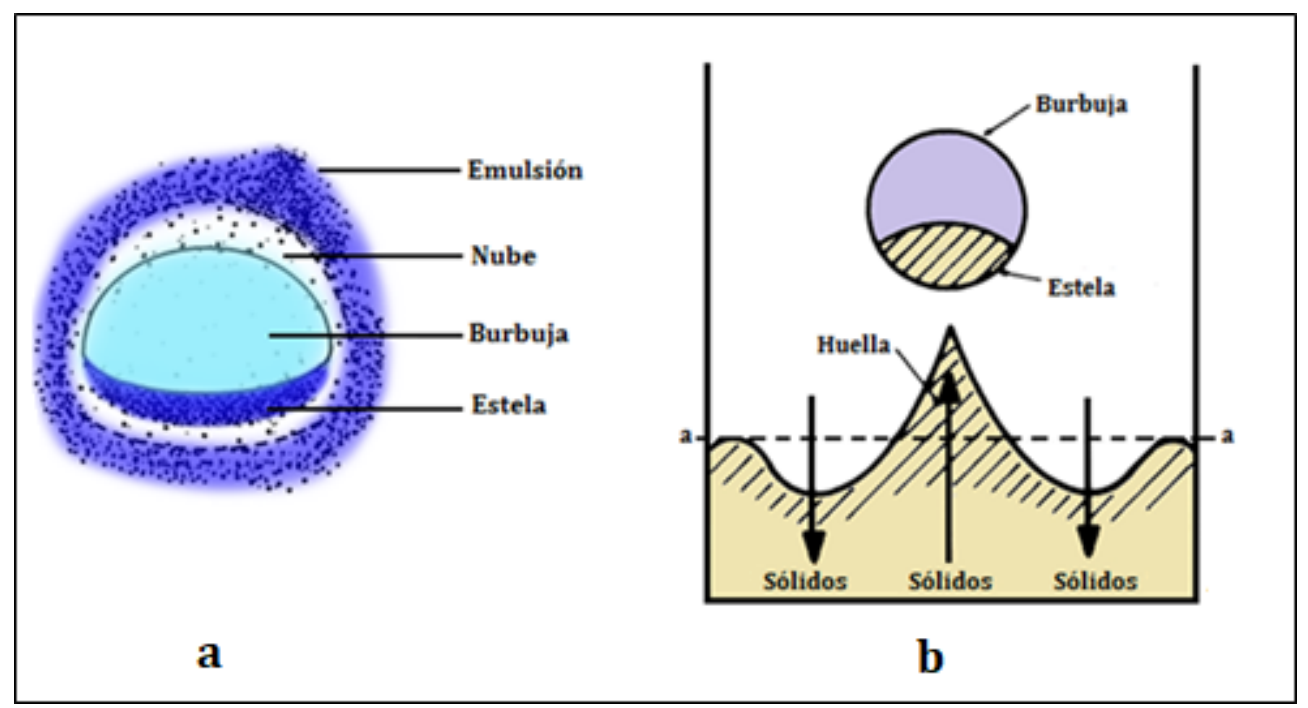

Figura 3.4 - (a) Esquema de nube, burbuja y estela. (b) Esquema de estela y huella generadas al pasar una burbuja por una determinada posición horizontal. Adaptada de Mazza (1993).

Las burbujas sufren un aumento de tamaño por un proceso de coalescencia conforme ascienden hacia la superficie libre del lecho y chocan con sus vecinas. Existe un fenómeno inverso por el que las burbujas pueden dividirse, esencialmente provocado por el choque con frentes de partículas descendentes, conocido como splitting (partición)

En los lechos reales, las burbujas interactúan notablemente entre sí, con las paredes del recipiente y con los elementos sumergidos, lo cual dificulta analizar y correlacionar datos experimentales de sus propiedades medias. Existe, en consecuencia, mucho menor grado de conocimiento que en el caso de la burbuja aislada (Rowe y Matsuno, 1971, citado por Mazza, 1993). Evidentemente, el diámetro resultante de las burbujas será consecuencia de la competencia de varios factores, incluyendo los fenómenos de coalescencia y splitting.

Debido a la presencia de las burbujas y su incidencia en la performance del lecho fluidizado, el conocimiento de sus propiedades, tales como diámetro medio 
$\mathrm{d}_{\mathrm{B}}$, caudal volumétrico total de burbujas $Q_{b}$, velocidad lineal de ascenso $u_{b}$, fracción volumétrica de burbujas $f_{B}$, y frecuencia de pulsación de burbujas, $v_{\mathrm{b}}$, resulta un aspecto crítico en la modelización del lecho fluidizado y en la cuantificación particular de los procesos de transferencia de calor y materia ocurrentes en el mismo.

\subsection{2 - El modelo de burbuja de Davidson}

El primer avance significativo para el flujo de gas en la burbuja fue realizado por Davidson, cuyo modelo sencillo explica con éxito el movimiento de gases y sólidos y la distribución de presiones en el ascenso de las burbujas (Kunii y Levenspiel, 1991). Este modelo fue desarrollado para lechos de dos y tres dimensiones y se basa en los siguientes postulados:

$1^{\circ}$ Postulado: Una burbuja de gas no tiene sólidos y tiene forma circular, por lo que es esférica en el caso tridimensional, y cilíndrica en el caso bidimensional.

2० Postulado: A medida que una burbuja se eleva, las partículas se apartan de su trayectoria, como lo haría un fluido incompresible de densidad aparente $\rho_{s}\left(1-\varepsilon_{m f}\right)$

$3^{\circ}$ Postulado: El gas fluye en la fase emulsión como un fluido viscoso incompresible; por lo tanto, la velocidad relativa entre el gas y el sólido debe satisfacer la ley de Darcy. Así, para cualquier dirección x:

$$
\left(u-u_{s}\right)_{x}=-K \frac{\partial p}{\partial x}
$$

Condiciones de contorno:

$\checkmark$ Lejos de la burbuja, existe un gradiente de presión no perturbado, dado por $-\frac{\Delta P}{H_{m f}}=g\left(\rho_{s}-\rho_{g}\right)\left(1-\varepsilon_{m f}\right)$

$\checkmark$ La presión en el interior de la burbuja es constante.

Estos postulados y condiciones de contorno son suficientes para dar tanto el patrón de flujo para sólidos y para el gas, como también la distribución de la presión, en los alrededores de la burbuja ascendente. 
Sobre la base de la TDF, Davidson y Harrison (1963) propusieron las siguientes velocidades de ascenso:

Para burbujas individuales:

$$
u_{b r}=0,711\left(g d_{b}\right)^{0,5}
$$

Para el conjunto de burbujas en un lecho de burbujeo

$$
u_{b}=U-U_{m f}+u_{b r}
$$

De acuerdo al modelo de Davidson, el patrón de flujo resultante depende solamente de la velocidad relativa de la burbuja aislada $u_{b r}$ con la del gas intersticial de la emulsión, $u_{f}=U_{m f} / \varepsilon_{m f}$. (Kunii y Levenspiel, 1991). La Figura 3.5 muestra una clara diferencia en el patrón de flujo de gas, dependiendo de si la burbuja se eleva más rápida o más lentamente que el gas en la emulsión. Pueden observarse los siguientes patrones de flujo:

$\checkmark$ Burbuja sin nube o lenta: $\boldsymbol{u}_{\boldsymbol{b}}<\boldsymbol{u}_{\boldsymbol{f}}$. En este caso, el gas intersticial se eleva más rápidamente que la burbuja; por lo tanto, utiliza a la burbuja como un atajo conveniente en su camino a través del lecho. El gas ingresa por la parte inferior de la burbuja y sale por la parte superior de la misma. Sin embargo, un anillo anular de gas circula dentro de la burbuja, moviéndose hacia arriba con ella.

$\checkmark$ Burbuja con nube o rápida: $\boldsymbol{u}_{\boldsymbol{b}}>\boldsymbol{u}_{\boldsymbol{f}}$. Al igual que con la burbuja lenta, el gas emulsionado ingresa por la parte inferior de la burbuja y sale por la parte superior. Sin embargo, como la burbuja asciende más rápidamente que el gas de la emulsión, el gas abandona la burbuja por el tope es arrastrado alrededor de la misma y retorna a la base de la burbuja. La región alrededor de la burbuja penetrada por este gas circulante se llama nube. El resto del gas en el lecho no se mezcla con el gas de recirculación, sino que se aparta a medida que pasa la burbuja rápida con su nube.

La Figura 3.5 muestra que la transición de burbuja lenta a rápida es suave. La nube tiene un espesor infinito cuando $u_{b r}=u_{f}$, pero el mismo se hace más fino al aumentar la velocidad de la burbuja. Su tamaño viene dado por:

$$
\frac{R_{C}^{2}}{R_{b}^{2}}=\frac{u_{b r}+u_{f}}{u_{b r}-u_{f}} \text { para un lecho 2D }
$$




$$
\frac{R_{C}^{3}}{R_{b}^{3}}=\frac{u_{b r}+2 u_{f}}{u_{b r}-u_{f}} \text { para un lecho 3D }
$$

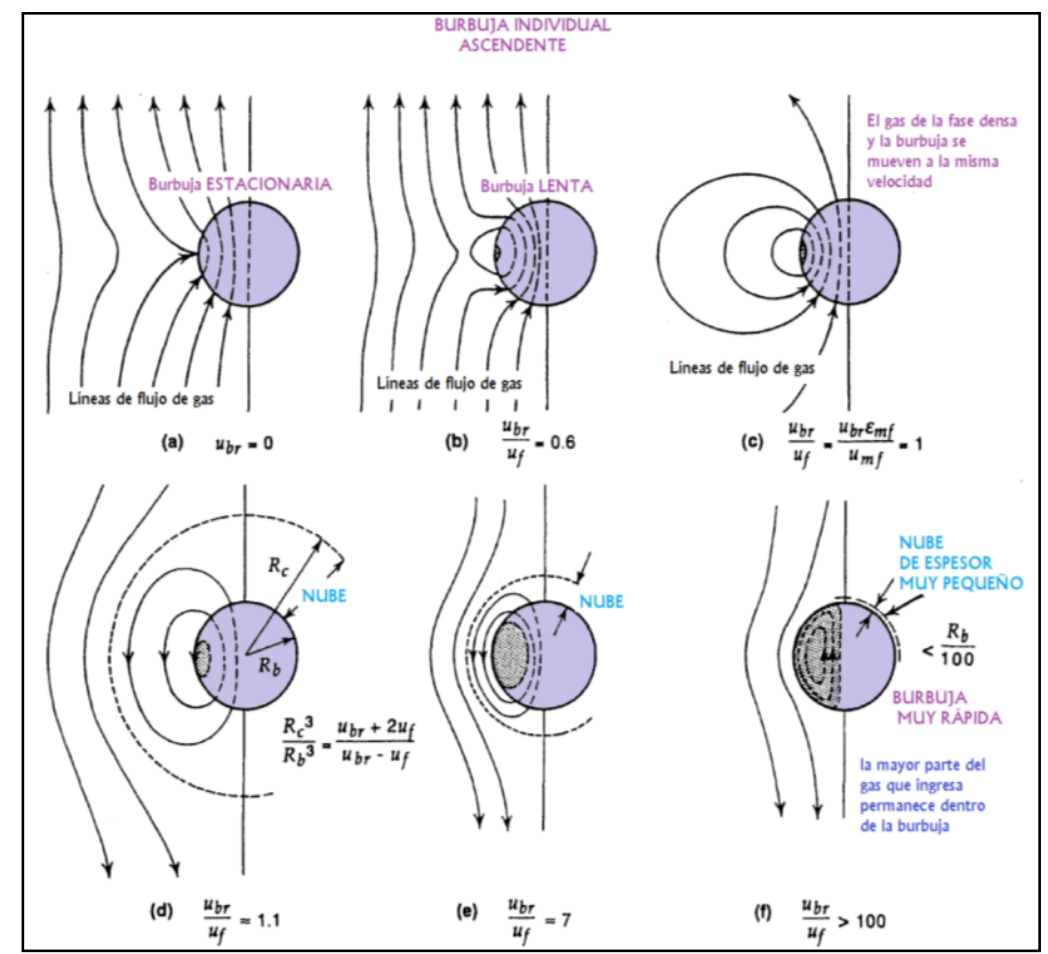

Figura 3.5 - Modelo de Davidson. Líneas de flujo cerca de una burbuja individual ascendente. Los tres esquemas superiores muestran el comportamiento en burbujas lentas, sin nube. En (c) el radio de la nube $R_{C} \rightarrow \infty$. Los tres esquemas inferiores corresponden a burbujas rápidas, con su correspondiente nube. Se muestra solamente el lado izquierdo del perfil, siendo el derecho, completamente simétrico. (f) corresponde a partículas Geldart A y (d) a Geldart B. Adaptada de Kunii-Levenspiel, 1991.

De las expresiones (3.12a) y (3.12b), la relación del volumen de nube a burbuja es:

$$
\begin{aligned}
& f_{\text {nube }}=\frac{2 u_{f}}{u_{b r}-u_{f}}=\frac{2 u_{m f} / \varepsilon_{m f}}{u_{b r}-u_{m f} / \varepsilon_{m f}} \text { para un lecho 2D } \\
& f_{\text {nube }}=\frac{3 u_{f}}{u_{b r}-u_{f}}=\frac{3 u_{m f} / \varepsilon_{m f}}{u_{b r}-u_{m f} / \varepsilon_{m f}} \text { para un lecho 3D }
\end{aligned}
$$

La teoría de Davidson también permite evaluar el caudal volumétrico de gas ascendente que ingresa y egresa de la burbuja, dado por:

$$
\begin{aligned}
& q=4 u_{m f} R_{b} L=4 u_{f} \varepsilon_{m f} R_{b} L \text { para un lecho } 2 \mathrm{D}(\text { espesor } \mathrm{L}) \\
& q=3 u_{m f} \pi R_{b}^{2}=3 u_{f} \varepsilon_{m f} \pi R_{b}^{2} \text { para un lecho } 3 \mathrm{D}
\end{aligned}
$$




\subsection{3 - Diámetro de burbuja}

En diferentes estudios, se ha encontrado que el diámetro de burbujas depende de factores tales como el diámetro del recipiente (lecho), altura sobre la placa distribuidora, velocidad superficial del gas y de elementos que afecten el régimen de fluidización de las partículas. También depende considerablemente del tipo y número de bafles existentes en el lecho, dispositivos de intercambio y todo elemento sumergido. El diseño del distribuidor de gas es un punto crítico en la calidad del burbujeo obtenido.

El tamaño de burbujas, representado por el diámetro $d_{b}$ debe evaluarse teniendo en cuenta que la mayor parte de las correlaciones se desarrolló sin objetos sumergidos, lo cual permite el crecimiento de las burbujas con mayor facilidad que cuando existen elementos internos sumergidos en el lecho.

La fluidización de los diferentes tipos de partículas según la clasificación de Geldart presenta burbujeo característico. Los sistemas de partículas Geldart A burbujean con burbujas relativamente pequeñas, usualmente no mayores de 10 $\mathrm{cm}$, mientras que mientras que las partículas Geldart B y D provocan la generación de burbujas que crecen constantemente y que pueden, incluso alcanzar el diámetro de recipientes de tamaño considerable.

Se han desarrollado varias correlaciones para estimar el crecimiento de burbujas en lechos fluidizados a partir de experimentos, principalmente en lechos de diámetro pequeño de sólidos Geldart B.

Karimipour y Pugsley (2011) han presentado una extensa recopilación de correlaciones para la estimación del diámetro de burbuja en lechos fluidizados. En las sub-secciones siguientes, se incluyen, a modo de ejemplo, algunas de las más utilizadas, conforme a su mención en la literatura específica.

En las correlaciones que se presentan a continuación deben respetarse las unidades en $\mathrm{cm}$ para $d_{b}$, la altura $h$ y diámetro del lecho $D, \mathrm{~cm} / \mathrm{s}$ para las velocidades $U, U_{m f}, u_{b r} y u_{b}, \mathrm{y} \mathrm{cm} / \mathrm{s}^{2}$ para la aceleración de la gravedad. 


\subsubsection{1 - Correlación de Darton (1977)}

Darton y colab. (1977) reportaron una correlación para la estimación del tamaño (diámetro) de burbujas basada en un patrón de crecimiento de las mismas debido a su coalescencia. Los autores asumieron que las burbujas ascienden siguiendo caminos preferenciales y que la distancia recorrida por dos burbujas vecinas es proporcional a su separación. La coalescencia ocurre en etapas sucesivas a lo largo del lecho hasta alcanzar la superficie, y de esta manera las burbujas se tornan cada vez más grandes. Dado que no consideraron ningún mecanismo de splitting, este modelo predice un crecimiento constante de las burbujas sin un tamaño límite. Por lo tanto, este modelo es inapropiado para lechos fluidizados de partículas Geldart A donde el fenómeno de splitting está fuertemente presente y se alcanza, como se ha mencionado, un tamaño máximo de burbujas.

La correlación propuesta para predecir el diámetro de las burbujas en función de la altura $h$ sobre el distribuidor es la siguiente:

$$
d_{b}=0,54 g^{-0,2}\left(U-U_{m f}\right)^{0,4}\left[h+4 \sqrt{A_{0}}\right]^{0,8}
$$

donde $A_{0}$ es el área del distribuidor por orificio, en $\mathrm{cm}^{2}$, y vale cero para placas porosas.

\subsubsection{2 - Correlación de Werther (1978)}

Werther (1978) propuso la siguiente expresión para el diámetro de burbuja a cualquier altura h en un lecho de sólidos Geldart B soportado por un distribuidor de placa porosa.

$$
d_{b}=0,853\left[1+0,272\left(U-U_{m f}\right)\right]^{1 / 3}(1+0,0684 h)^{1,21}
$$

con el siguiente rango de condiciones de operación que enmarca su aplicabilidad:

$$
\left\{\begin{array}{l}
D>20 \mathrm{~cm} \\
0,1 \leq d_{p} \leq 0,35 \mathrm{~mm} \\
1 \leq U_{m f} \leq 8 \mathrm{~cm} / \mathrm{s} \\
5 \leq U-U_{m f} \leq 30 \mathrm{~cm} / \mathrm{s}
\end{array}\right.
$$

donde $D$ corresponde al diámetro de lecho. 


\subsubsection{3 - Correlación de Agarwal (1985)}

Agarwal (1985) propuso la siguiente correlación para el diámetro de burbuja en función de la altura $h$ para partículas de vidrio y distribuidor de placa porosa:

$$
d_{b}=d_{0}+\frac{k}{11,13 m} h^{5} d_{0}^{0,5}+\left(\frac{k}{22,26}\right)^{2} \frac{h^{2 s}}{m(m-1)}
$$

donde $k=82, m=10$ y $s=0,4 ; d_{0}$ es el tamaño inicial de burbuja formado por encima del distribuidor y $h$ es la distancia por encima del distribuidor. La ecuación anterior es válida si $a=\frac{3,51\left(h+h_{0}\right)^{0,4}}{D^{0,5}-d_{0}^{0,5}} \leq 3\left(h_{0}\right.$ es la distancia vertical del distribuidor a la que se forma la burbuja). Si $a>3$ :

$$
\begin{aligned}
d_{b}=\left[d_{0}^{0,5}+\right. & 0,37\left(h+h_{0}\right)^{0,4} \\
& \left.\quad-0,036\left(h+h_{0}\right)^{0,4}\left(\frac{1,17\left(h+h_{0}\right)^{0,4}}{D^{0,5}-d_{0}^{0,5}}-1\right)\right]^{2}
\end{aligned}
$$

Ambas válidas para $4,1 \mathrm{~cm} / \mathrm{s}<U-U_{m f}<9,6 \mathrm{~cm} / \mathrm{s}$. Para estimar $d_{0}$ en el caso de distribuidores de placa porosa, se utiliza la correlación de Miwa y colab (1972):

$$
d_{0}=0,00376\left(U-U_{m f}\right)^{2}
$$

\subsubsection{4 - Correlación de Cai y colab. (1994)}

Cai y colab. (1994) presentaron su correlación para el diámetro de burbujas en lechos con diferentes tipos de partículas y distribuidor de placa porosa o perforada:

$$
d_{b}=0,138 h^{0,8}\left(U-U_{m f}\right)^{0,42} e^{\left[-2,5 \times 10^{-5}\left(U-U_{m f}\right)^{2}-10^{-3}\left(U-U_{m f}\right)\right]}
$$

válida para $0,066 \mathrm{~mm}<d_{p}<0,7 \mathrm{~mm}$ y $0<U-U_{m f}<0,6 \mathrm{~cm} / \mathrm{s}$. 


\subsection{4 - Velocidad de las burbujas}

Existen numerosas correlaciones en la bibliografía para determinar la velocidad de las burbujas. En el presente trabajo, además de la correlación de Davidson y Harrison (ecuaciones 3.10 y 3.11), se utilizan las correlaciones que se presentan a continuación.

\subsubsection{1 - Werther (1978)}

Werther (1978) propuso la siguiente correlación para la determinación de la velocidad de las burbujas, en función de su diámetro y del diámetro del lecho.

$$
u_{b}=\delta \sqrt{g d_{b}}
$$

donde, para partículas Geldart B,

$$
\delta=\left\{\begin{array}{lc}
0,64 & D \leq 10 \mathrm{~cm} \\
0,254 D^{0,4} & 10 \mathrm{~cm}<D<100 \mathrm{~cm} \\
1,6 & D \geq 100 \mathrm{~cm}
\end{array}\right.
$$

\subsubsection{2 - Hilligardt y Werther (1986)}

Hilligardt y Werther (1986), propusieron la siguiente correlación para la determinación de la velocidad de las burbujas.

$$
u_{b}=\delta\left(U-U_{m f}\right)+\vartheta u_{b r}
$$

donde, para partículas Geldart B,

$$
\begin{gathered}
\delta=\left\{\begin{array}{lc}
0,67 & h / D<1,7 \\
0,51(h / D)^{0,5} & 1,7 \leq h / D \leq 4 \\
1 & h / D>100
\end{array}\right. \\
\vartheta=0,2 D^{0,5}
\end{gathered}
$$

\subsubsection{3 - Kunii-Levenspiel (1991)}

Kunii y Levenspiel (1991), propusieron la siguiente correlación para determinar de la velocidad de las burbujas, para partículas Geldart B y diámetro de lecho $(D)$ menor que $100 \mathrm{~m}$.

$$
u_{b}=0,0032\left(\left(U-U_{m f}\right)+11,3 d_{b}^{0,5}\right) D^{1,35}+u_{b r}
$$




\subsection{5 - Factor de forma de las burbujas $\omega$}

Otro aspecto característico de las burbujas es la variación de su forma, representada por el factor de forma $\omega$. Esta propiedad es de importancia por tener una fuerte influencia en las características fluidodinámica de las burbujas y puede estimarse mediante la siguiente expresión:

$$
\omega=\frac{4 \pi(\text { Area burbuja })}{(\text { Perímetro burbuja })^{2}}
$$

\subsection{6 - Frecuencia de las burbujas}

La frecuencia de pulsación, $v_{b}$, definida como el número de burbujas que pasan por un punto determinado por unidad de tiempo, puede expresarse de la siguiente forma (Mazza, 1993):

$$
v_{b}=\frac{U_{b}}{V_{b}} S_{b h}
$$

siendo $V_{b}=4 \pi\left(d_{b} / 2\right)^{3} / 3$ el volumen ocupado por una burbuja y $S_{b h}=\pi d_{b}^{2} / 4 \mathrm{su}$ superficie proyectada sobre el plano horizontal. Teniendo en cuenta que la TDF establece que $U_{b}=U-U_{m f}$ (ecuación 3.3), la frecuencia de burbujas puede ser calculada en función de su diámetro:

$$
v_{b}=\frac{3}{2} \frac{\left(U-U_{m f}\right)}{d_{b}}
$$

También se han reportado diferentes valores de la constante existente en la ecuación precedente. Por ejemplo, dicho valor puede considerarse igual a 1,817 si se considera que la burbuja posee una configuración de un sector esférico que ocupa $3 / 4$ partes de su envolvente (Mazza, 1993)

Por otra parte, la frecuencia de pulsación puede ser estimada como (Hulme y Kantzas, 2004):

$$
v_{b}=\frac{\text { cantidad burbujas que atraviesan la sección }}{\text { período analizado }}
$$




\section{4 - MATERIALES Y EQUIPAMIENTO}

Debido a que tanto el tipo de fluidización presente en un lecho a velocidades superiores a la de mínima fluidización como las características de la burbuja dependen de las propiedades físicas de las partículas, estas deben ser caracterizadas de modo apropiado previo al desarrollo de las experiencias. En este capítulo, se estudiará el comportamiento agregativo (con burbujeo) de lechos fluidizados de partículas de arena (Geldart B) fluidizados mediante la utilización de aire (agente fluidizante). El estudio apuntará a la comprensión exhaustiva del comportamiento fluidodinámico del conjunto.

\subsection{1 - Caracterización de la arena}

En la primera etapa de la caracterización de la arena, se determinó la distribución de tamaños de la muestra del material a fluidizar y se midió su densidad. En base a los resultados obtenidos se seleccionó el rango de tamaños de partícula de modo que cumplieran con los valores de diámetro medio y densidad correspondientes a sólidos Geldart B. Se realizaron, además, determinaciones experimentales de esfericidad, redondez y se llevó a cabo un análisis mineralógico. Las sub-secciones siguientes especifican las técnicas y métodos empleados en los estudios de caracterización del material sólido.

\subsubsection{1 - Diámetro de partícula}

Para realizar el análisis granulométrico, se tomaron $200 \mathrm{~g}$ de la muestra de arena y se tamizaron, en una serie de tamices ASTM, como se muestra en la Tabla 3.1.

Tabla 3.1 - Diámetro de tamiz según norma ASTM E-11.

\begin{tabular}{|c|c|}
\hline Número de malla & Diámetro de tamiz $[\mu \mathrm{m}]$ \\
\hline 7 & 2800 \\
\hline 18 & 1000 \\
\hline 30 & 600 \\
\hline 40 & 425 \\
\hline 70 & 212 \\
\hline 120 & 125 \\
\hline
\end{tabular}

El retenido en cada tamiz fue trasvasado a vasos de precipitado (previamente pesados) utilizando agua para evitar la pérdida de muestra. Los mismos se llevaron a estufa para secado a peso constante a $105^{\circ} \mathrm{C}$ durante 24 horas. Posteriormente, se pesó 
cada uno de los retenidos en seco y se registró su masa. Luego se calcularon los porcentajes de masa retenidos en cada fracción, expresados en porcentaje respecto del total de masa de la muestra analizada, como se muestra en la Tabla 3.2.

Tabla 3.2 - Análisis granulométrico de la muestra.

\begin{tabular}{|c|c|c|c|c|c|c|c|}
\hline $\begin{array}{c}\mathrm{N}^{\circ} \\
\text { Tamiz }\end{array}$ & $\begin{array}{c}\text { Tamaño } \\
\text { abertura } \\
{[\mathrm{mm}]}\end{array}$ & $\begin{array}{c}\text { Tamaño } \\
\text { medio de } \\
\text { sólido } \\
{[\mathrm{mm}]}\end{array}$ & $\begin{array}{c}\text { Retención } \\
\text { por tamiz } \\
{[\mathrm{g}]}\end{array}$ & $\begin{array}{c}\text { Retención } \\
\text { acumulada } \\
{[\mathrm{g}]}\end{array}$ & $\begin{array}{c}\text { Pasante } \\
{[\mathrm{g}]}\end{array}$ & $\begin{array}{c}\text { Retención } \\
\text { por tamiz } \\
\%\end{array}$ & $\begin{array}{c}\text { Retención } \\
\text { acumulada } \\
\%\end{array}$ \\
\hline 18 & 1 & --- & 1,488 & 1,488 & 198,512 & 0,744 & 0,744 \\
\hline 30 & 0,6 & 0,8 & 68,988 & 70,476 & 129,524 & 34,494 & 35,238 \\
\hline 40 & 0,425 & 0,5125 & 45,974 & 116,45 & 83,55 & 22,987 & 58,225 \\
\hline 70 & 0,21 & 0,3175 & 64,765 & 181,215 & 18,785 & 32,3825 & 90,6075 \\
\hline 120 & 0,125 & 0,1675 & 6,372 & 187,587 & 12,413 & 3,186 & 93,7935 \\
\hline Fondo & $<0,125$ & --- & 12,413 & 200 & 0 & 6,2065 & 100 \\
\hline
\end{tabular}

Con el fin de trabajar con partículas Geldart B, se seleccionó la muestra que pasó la malla 30 y quedó retenida en la malla $40\left(0,425 \mathrm{~mm}<d_{p}<0,600 \mathrm{~mm}\right)$ y se adoptó $\overline{\boldsymbol{d}}_{\boldsymbol{p}}=\mathbf{0 , 5 1 2 5} \mathbf{\mathrm { mm }}$ como valor medio de diámetro de partícula.

\subsubsection{2 - Densidad}

Una de las propiedades más relevantes que emplean las ecuaciones de fluidización es la densidad de partícula (específicamente la llamada densidad aparente), definida como el valor de la masa de la partícula dividido por su volumen hidrodinámico (volumen que el fluido ve en su interacción fluidodinámica con la partícula y que incluye el volumen de todos los poros abiertos y cerrados). Esta propiedad difiere de la densidad absoluta que se define como la masa de la partícula dividida por el volumen de material sólido constituyente de la partícula (Rhodes, 1998).

En los sólidos no porosos, como es el caso de la arena, el volumen hidrodinámico se puede medir fácilmente con un picnómetro de agua y el valor de la densidad aparente coincide con el de la densidad absoluta. De este modo, se determinó la densidad de una muestra de arena correspondiente a lo retenido entre las mallas 30 y 40 . Luego de realizar el procedimiento por triplicado, se obtuvo un valor promedio de $\rho_{\text {arena }}=2650 \mathrm{~kg} / \mathrm{m}^{3}$. 
Finalmente, en función del valor del diámetro promedio de las partículas, su densidad y la densidad del aire, teniendo en cuenta la Figura 2.2 (Capítulo 2), se puede clasificar a las partículas como Geldart B.

\subsubsection{3 - Composición mineralógica}

Para determinar la composición mineralógica de la arena, se tomó una muestra de 2 g y se realizó la molienda con mortero de ágata hasta obtener un tamaño de partícula inferior a $75 \mu \mathrm{m}$. Se montó el polvo de muestra total sobre un portamuestras de carga vertical y se obtuvo un difractograma de RX en un barrido desde los $3^{\circ}$ a los $60^{\circ} 2 \theta$ a una velocidad de $3^{\circ} / \mathrm{min}$ con un ánodo de $\mathrm{Cu} \lambda=1,544 \AA$, filtro de $\mathrm{Ni}$, en un equipo DII Max-C, Rigaku, procesado por el software Jade 7.0.

El análisis del DRX mostró como principal mineral el cuarzo $\left(\mathrm{SiO}_{2}\right)$ y como escaso, feldespatos, por lo cual se puede afirmar que la muestra contiene más del 99\% de sílice.

\subsubsection{4 - Esfericidad y redondez}

La esfericidad de las partículas se refiere a la forma de los clastos comparable a una esfera en estado ideal, mientras que la redondez se relaciona con la agudeza de las aristas y de los vértices de un fragmento clástico, independientemente de la forma.

Se trabajó sobre una fracción de la muestra retenida entre las mallas 30 y 40, utilizando la metodología indicada en la norma API RP 56: Recommended practices for Testing Sand Used in Hydraulic Fracturing Operation 56 - Sec Ed., 1995.

Mediante el uso de una lupa binocular con cámara fotográfica incorporada, se tomaron imágenes de la muestra. Sobre cada imagen se realizaron observaciones de esfericidad y redondez con la carta comparativa visual sobre 300 granos de arena, superando los 30 granos solicitados por la norma API RP 56 (Figura 3.6). Posteriormente se realizó el cálculo de la media aritmética de cada uno de los parámetros analizados.

En base al análisis realizado, puede concluirse que la arena seleccionada tiene una esfericidad $\psi=0,8$, que corresponde a esfericidad moderada y redondez $R=0,6$, que la clasifica como arena subredondeada a redondeada. 


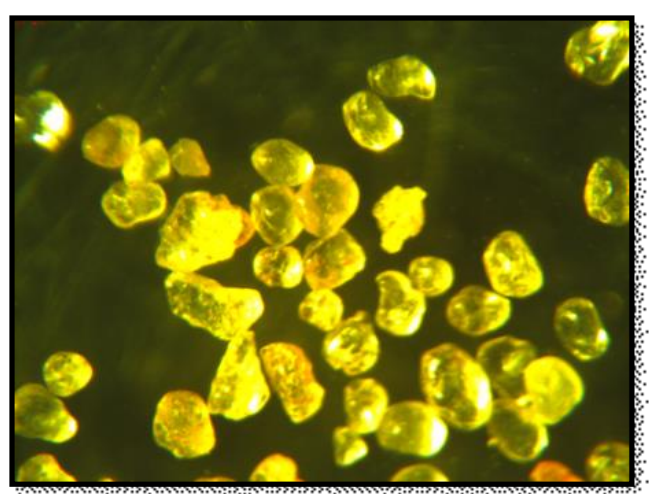

a

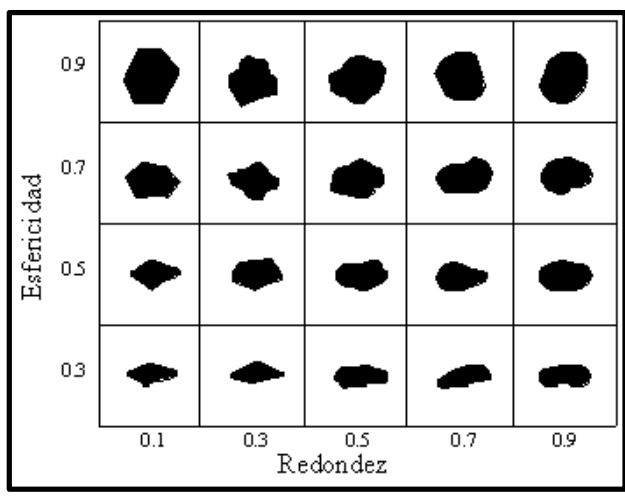

b

Figura 3.6 - Arena vista con lupa binocular (a), y carta comparativa de esfericidad y redondez, API RP 56 (b).

\subsection{2 - Equipamiento Experimental}

En el presente estudio, se utilizaron dos lechos fluidizados construidos en acrílico. Uno de ellos es un un lecho cilíndrico de 0,85 m de alto y 0,1093 m de diámetro interno (Figura 3.7a), con un distribuidor de placa perforada con orificios de $1 \mathrm{~mm}$ de diámetro en arreglo alineado y que cuenta con sensores de presión diferencial y temperatura conectados a un sistema de adquisición de datos. El otro equipo es un lecho pseudo-2D, de 0,59 $\mathrm{m}$ de ancho, 0,7 $\mathrm{m}$ de alto y 0,025 $\mathrm{m}$ de profundidad, con un distribuidor de placa perforada de las mismas características que el correspondiente al lecho cilíndrico (Figura 3.7b). Ambos equipos pueden conectarse a un compresor de $3 \mathrm{~kW}$ y 2860 rpm para impulsar el aire hacia el interior del lecho. La línea de descarga del compresor está dividida en 2 ramas, una que conduce el aire al lecho y posee una válvula que permite la regulación del caudal durante las experiencias, y otra secundaria, que constituye la línea de venteo que se dirige al ambiente exterior. En la rama que impulsa el aire al equipo, se encuentra instalado un anemómetro de hilo caliente, conectado al sistema de adquisición de datos, que permite registrar valores de caudal y temperatura. 


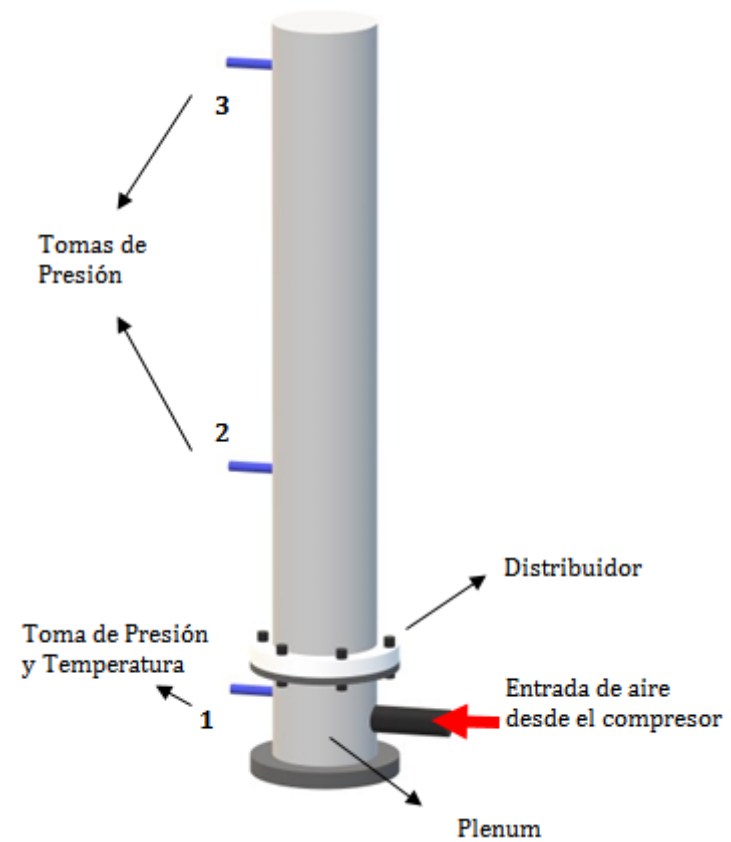

a

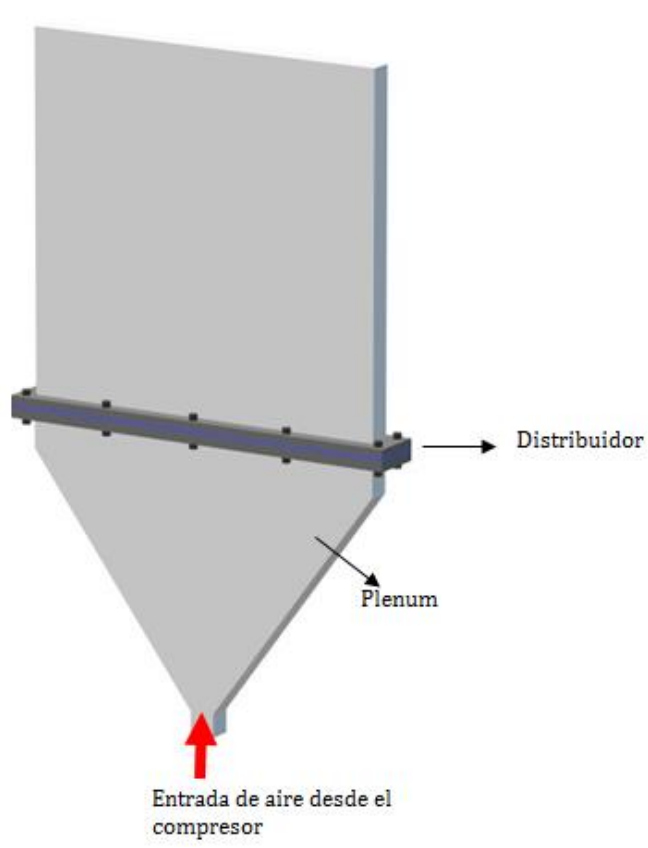

$\mathrm{b}$

Figura 3.7 - Equipos experimentales: lecho cilíndrico (a) y lecho pseudo-2D(b).

\section{5 - MODELADO POR CFD}

Las simulaciones fueron realizadas con el software de fluidodinámica computacional ANSYS-Fluent 18.1. El programa cuenta con la plataforma Workbench, desde la que se crean los proyectos de análisis y que incluye las etapas de modelado, mallado, simulación y post-procesamiento de resultados. La Figura 3.8 muestra un diagrama lógico que permite la visualización de las etapas necesarias para llevar a cabo la simulación por CFD. En la sección 5 del Anexo 3.II, se presenta una descripción detallada de dichas etapas. 


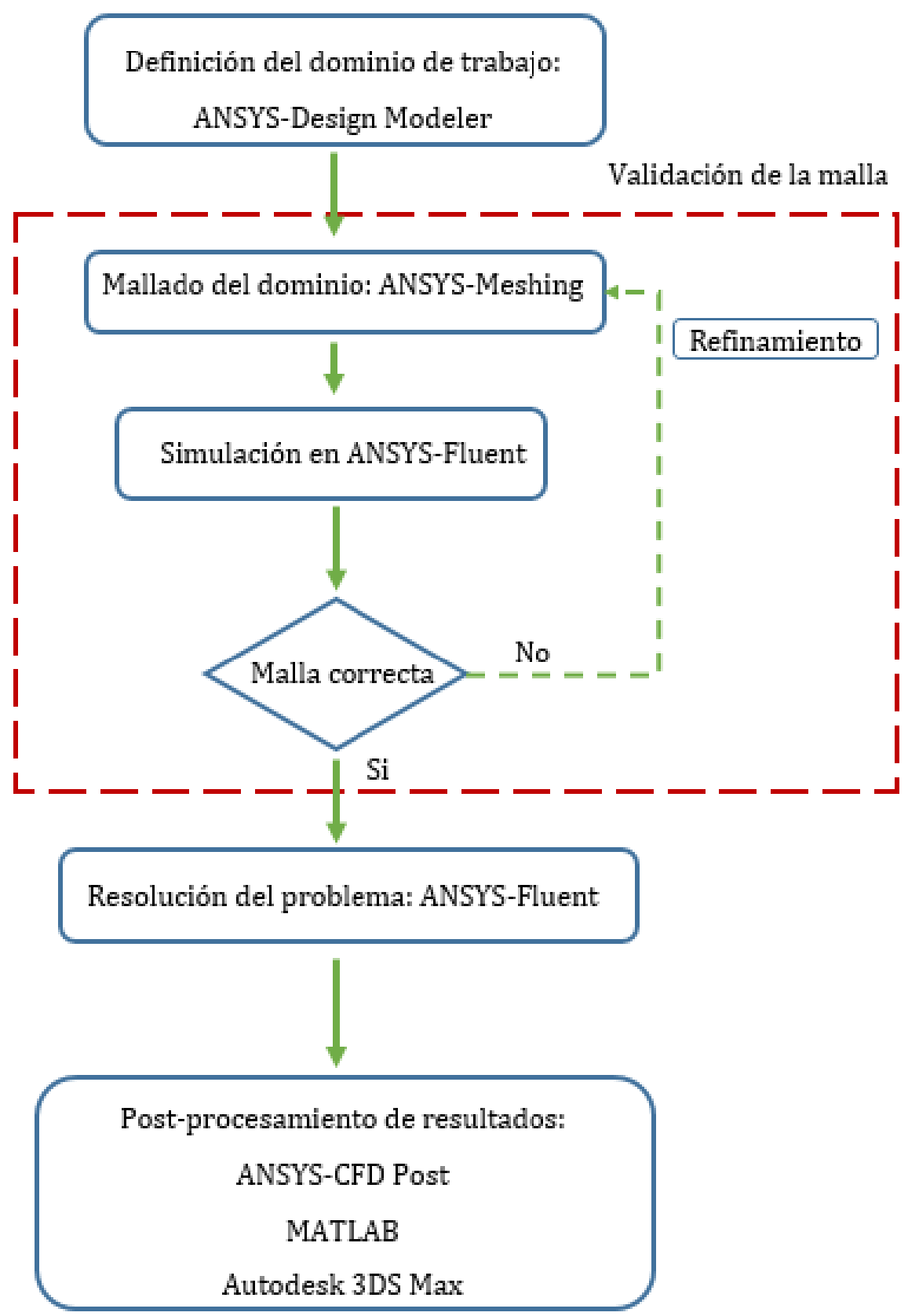

Figura 3.8 - Pasos llevados a cabo en el proceso de simulación del sistema.

\subsection{1 - Generación del dominio, mallado y validación}

Mediante el programa ANSYS-Design Modeler se dibujó el lecho cilíndrico a estudiar, creando así el dominio para la resolución numérica. Para discretizar el dominio se utilizó una malla de tipo estructurada con elementos hexaédricos. Se evaluaron tres tamaños de elementos diferentes, como puede observarse en la Figura 3.9. 


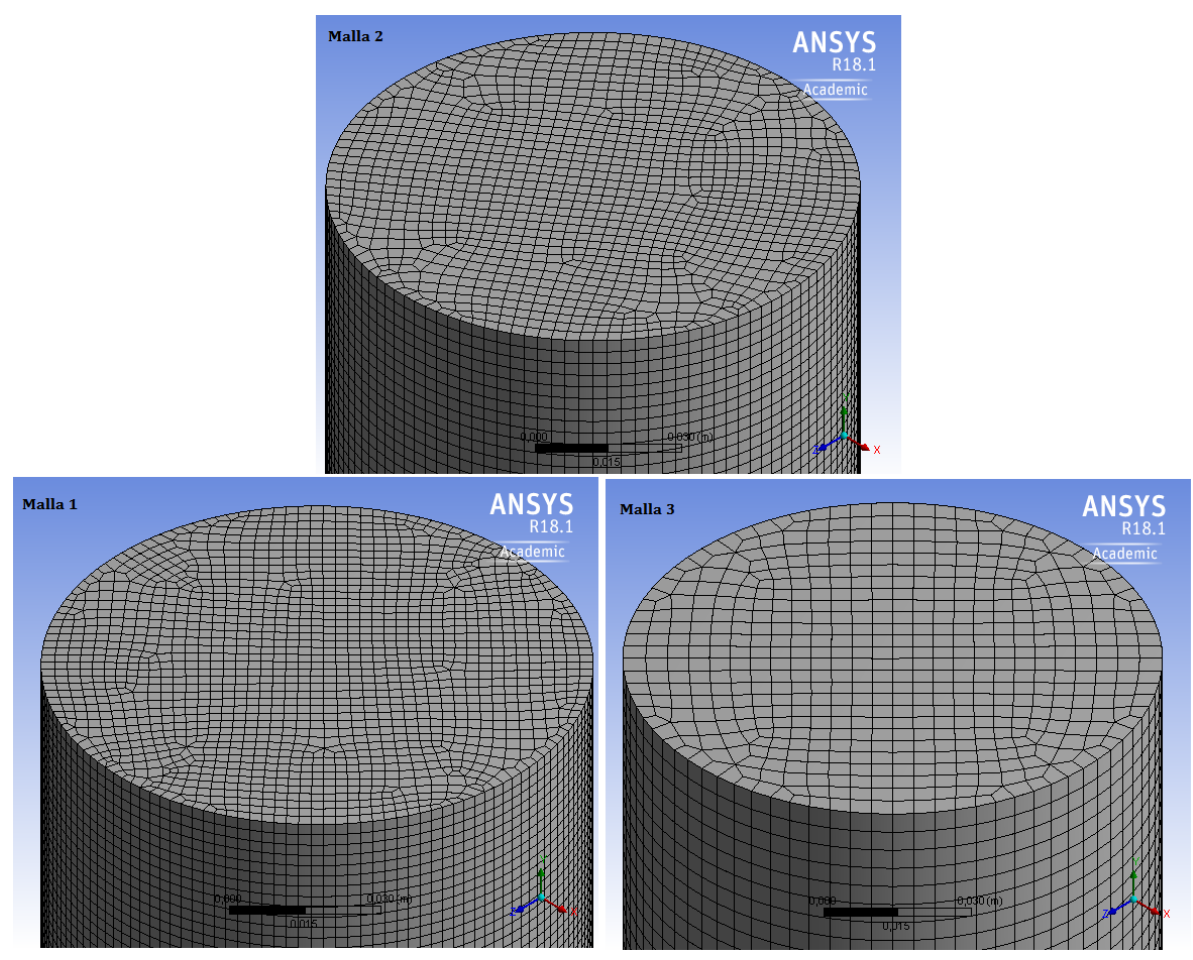

Figura 3.9 - Esquema de las mallas con distinto tamaño de elemento.

Para efectuar la validación se adoptó la pérdida de carga a través del lecho como parámetro de referencia. Se realizó la simulación, para una velocidad superficial del aire de $0,35 \mathrm{~m} / \mathrm{s}$. Se registró la pérdida de carga durante un intervalo de 12 segundos y se obtuvo un valor promedio para cada malla. El error relativo fue calculado respecto de la Malla 1, debido a que es la que cuenta con mayor densidad de elementos. El análisis se realizó simulando el lecho en régimen fluidizado, aplicando un modelado de estado transitorio. En la Tabla 3.3 se muestran los resultados de la validación.

Tabla 3.3 - Validación de mallas para desarrollo de experiencias en CFD.

\begin{tabular}{|l|c|c|c|c|c|}
\cline { 2 - 6 } \multicolumn{1}{c|}{} & $\begin{array}{c}\text { Tamaño } \\
\text { celda }[\mathrm{m}]\end{array}$ & $\Delta \mathrm{P}[\mathrm{Pa}]$ & $\begin{array}{c}\text { Cantidad } \\
\text { de celdas }\end{array}$ & $\begin{array}{c}\text { Error } \\
\text { relativo \% }\end{array}$ & $\begin{array}{c}\text { Tiempo de } \\
\text { cómputo [días] }\end{array}$ \\
\hline Malla 1 & 0,0025 & 1830,14 & 245600 & --- & 10 \\
\hline Malla 2 & 0,0029 & 1843,04 & 162564 & 0,70 & 6 \\
\hline Malla 3 & 0,0045 & 1808,37 & 48772 & 1,19 & 2 \\
\hline
\end{tabular}

Dado que el error relativo de la Malla 2 fue inferior al 1\% y el tiempo de cómputo se redujo en un $40 \%$ respecto de la Malla 1, se decidió utilizar dicha malla para las simulaciones. Cabe destacar que, si bien el error relativo de la Malla 3 no es significativamente superior al de la Malla 2, las imágenes de burbujas obtenidas con esta malla no tienen una definición adecuada para el análisis de las mismas. 


\subsection{2 - Implementación de la simulación por CFD}

El estudio realizado mediante CFD implicó la obtención de la curva de fluidización del lecho y el análisis exhaustivo de la fase burbuja. Para construir la curva de fluidización del lecho, se realizaron simulaciones en condición de lecho fijo y de lecho fluidizado. La principal diferencia entre estas dos simulaciones reside en que el lecho fijo se simula en estado estacionario, mientras que el lecho fluidizado se simula en estado transitorio. Sumado a esto, en el caso de lecho fijo, la geometría, y por lo tanto la malla, se reduce a la sección del lecho ocupada por el sólido (medio poroso).

El modelo del medio poroso (PMM) incorpora y determina empíricamente una resistencia al flujo en la región definida como porosa. Para aplicar este modelo, deben definirse dos parámetros fundamentales: la permeabilidad del medio poroso ( $\alpha$ ) y el factor de resistencia inercial $\left(C_{2}\right)$. Si bien existen diferentes alternativas para determinar dichos parámetros, en este trabajo los mismos fueron ajustados a partir de datos experimentales de pérdida de carga en función de la velocidad superficial del aire. Se utilizó para ello la curva experimental de desfluidización, correspondiente a la zona de lecho fijo, como puede observarse en la Figura 3.10, dando como resultado valores de $C_{2}=$ $5,4592 \mathrm{~m}^{-1}$ y $1 / \alpha=4,163810^{9} \mathrm{~m}^{-2}$.

La zona de lecho fluidizado se simuló considerando flujo multifásico, aplicando el enfoque Euleriano-Euleriano, cuya principal característica es considerar a las fases involucradas como continuas e interpenetrantes. ANSYS-Fluent cuenta, en su menú directo, con tres modelos basados en dicho enfoque, y en el presente trabajo se decidió trabajar con el modelo Euleriano, que es el modelo multifásico más complejo disponible en el software utilizado. Sus aplicaciones principales, incluyen: columnas de burbujeo, risers, suspensiones de partículas y lechos fluidizados. 


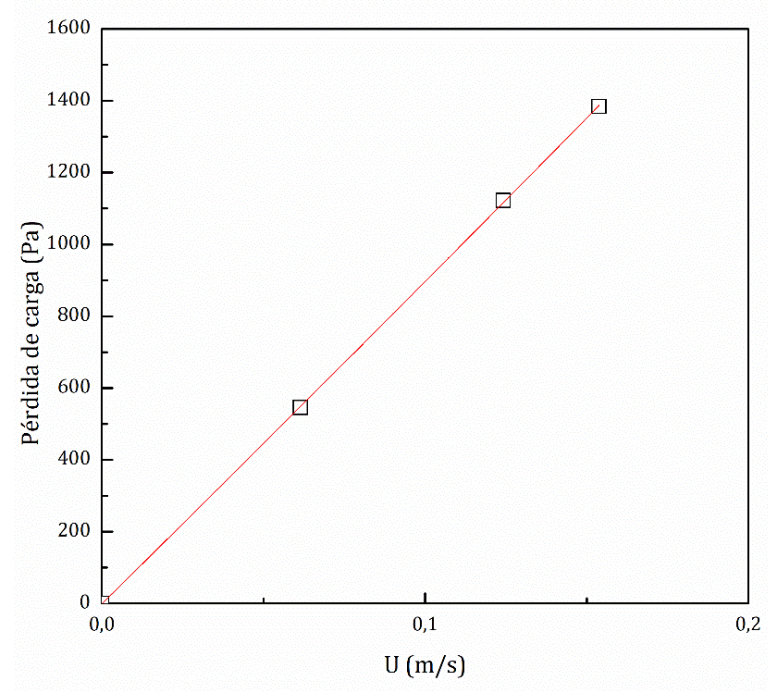

Figura 3.10 - Curva de desfluidización en la zona de lecho fijo, cuya regresión fue utilizada para el cálculo de los coeficientes $\alpha$ y $C_{2}$.

El modelo Euleriano resuelve un conjunto de ecuaciones de continuidad y momento para cada una de las $n$ especies en las fases consideradas. El acoplamiento de estas ecuaciones se logra a través de la presión (que es la misma para todas las fases) y los coeficientes de intercambio entre fases. El modo en el cual se maneja dicho acople depende del tipo de flujos involucrados, ya sean éstos granulares (sólido-fluido) o no granulares (fluido-fluido). Para flujos granulares, las propiedades se obtienen de la aplicación de la teoría cinética.

El modelo utiliza el coeficiente de intercambio entre fases para poder resolver la ecuación de conservación de cantidad de movimiento. En la literatura se han reportado numerosas correlaciones empíricas para el cálculo de dicho coeficiente. ANSYS-Fluent presenta diversos modelos disponibles para su cálculo, entre los cuales se encuentran Gidaspow (Gidaspow y colab., 1992), Syamlal O’Brien (Syamlal y colab., 1993), Wen y Yu (Wen y Yu 1966), y Gibilaro (Gibilaro, 1985), cuya principal diferencia radica en el modelo de arrastre utilizado. Otro parámetro necesario en la resolución de la ecuación de cantidad de movimiento es el esfuerzo cortante de los sólidos, que tiene un término debido a colisiones, otro debido a traslación (cinético) y un término friccional. Este último es opcional y considera la fricción entre partículas mediante la ecuación de Schaeffer (Schaeffer, 1987). En el Anexo 3.II del presente capítulo se incluye una descripción detallada de las ecuaciones que integran la formulación de cada modelo mencionado. 
Las simulaciones se llevaron a cabo utilizando esquemas de discretización espacial de segundo orden (Second Order Upwind) para las ecuaciones de momento y de primer orden para la fracción volumétrica (First Order Upwind), mientras que el tiempo se discretizó usando un esquema de segundo orden (Second Order Implicit). Se empleó el esquema de resolución Phase Coupled SIMPLE para resolver la ecuación de presión y velocidad. Para inicializar la solución se debe indicar la altura del lecho $\left(H_{o}\right)$ y la fracción volumétrica del sólido $\left(\alpha_{s}\right)$, que fue calculada a partir de los datos de masa, densidad y volumen de lecho de arena. En la Tabla 3.4 se resumen los parámetros principales de la simulación.

Tabla 3.4 - Principales parámetros asignados en la simulación.

\begin{tabular}{|l|c|}
\hline Parámetro & Valor \\
\hline$\rho_{g}\left[\mathrm{~kg} / \mathrm{m}^{3}\right]$ & 1,225 \\
\hline$\mu[\mathrm{Pa} \cdot \mathrm{s}]$ & $1,789.10^{-5}$ \\
\hline$\rho_{s}\left[\mathrm{~kg} / \mathrm{m}^{3}\right]$ & 2650 \\
\hline$d_{p}[\mathrm{~mm}]$ & 0,5125 \\
\hline Paso de tiempo $[\mathrm{s}]$ & 0,001 \\
\hline$H_{o}[\mathrm{~m}]$ & 0,12 \\
\hline$\alpha_{s}$ & 0,6 \\
\hline $\begin{array}{l}\text { Máx. Iteraciones/paso } \\
\text { de tiempo }\end{array}$ & 40 \\
\hline Criterio de convergencia & 0,001 \\
\hline Condiciones de borde & Valor \\
\hline Wall (aire) & No slip \\
\hline Wall (sólido) & $\varphi: 0,5$ \\
\hline Velocity inlet (aire) $[\mathrm{m} / \mathrm{s}]$ & $0,2-0,86$ \\
\hline
\end{tabular}

\begin{tabular}{|l|c|}
\hline Parámetro & Modelo/ Valor \\
\hline Viscosidad granular $\left(\mu_{s, k i n}-\mu_{s, \text { col }}\right)$ & GD \\
\hline Viscosidad granular granel $\left(\lambda_{s}\right)$ & Cte: 0 \\
\hline Viscosidad friccional $\left(\mu_{s, f r}\right)$ & None \\
\hline Temperatura granular & Algebraic \\
\hline Presión de sólidos $\left(\nabla P_{S}\right)$ & LUN \\
\hline Distribución radial & OGA \\
\hline Módulo de elasticidad $(G)$ & Derived \\
\hline $\begin{array}{l}\text { Límite de empaquetamiento } \\
\left(\alpha_{s, m a x}\right)\end{array}$ & Cte: 0,63 \\
\hline Fuerza de masa virtual & None \\
\hline Modelo de arrastre & GD \\
\hline Fuerza de sustentación & None \\
\hline Coeficiente de restitución $\left(e_{s s}\right)$ & Cte: 0,9 \\
\hline
\end{tabular}

Referencias: GD: Gidaspow y colab. (1992), LUN: Lun y colab. (1984), OGA: Ogawa y colab. (1980).

Como se mencionó anteriormente, cuando se llevó a cabo el proceso de mallado del lecho, se definieron las zonas para aplicar las condiciones de borde necesarias. Se puede observar que la condición de borde de la pared toma distintos valores según la fase. Para el aire se consideró la condición de no deslizamiento (No Slip), de modo que la velocidad del aire en la misma es nula. Sin embargo, para los sólidos es común que se cumpla con una condición de deslizamiento parcial en la pared. Existen diferentes modelos para el deslizamiento de sólidos en la pared, pero debido a su simplicidad y fundamentación física, el modelo propuesto por Johnson y Jackson (1987) es el más utilizado (Askaripour y colab., 2015; Altantzis y colab., 2015; Bakshi y colab., 2014; Loha 
y colab., 2013). Este modelo, en función de definir la velocidad de deslizamiento de los sólidos en las paredes, considera la transferencia de cantidad de movimiento a la pared en la dirección tangencial a través de las colisiones de las partículas, caracterizada por el coeficiente de especularidad, $\varphi$. Este coeficiente se utiliza específicamente en modelos multifásicos con presencia de flujo de sólidos granulares. Constituye una medida de la fracción de colisiones que transfieren cantidad de movimiento a la pared, toma valores entre 0 y 1 , y se relaciona, además, con la rugosidad de las paredes. Cuando el coeficiente $\varphi$ es cero, ello implica que no se transfiere cantidad de movimiento a la pared y la colisión es perfectamente especular (suave), mientras que un valor igual a la unidad para el coeficiente $\varphi$ implica la máxima transferencia de cantidad de movimiento hacia la pared y la colisión es, en tal caso, perfectamente difusa (dura) (Loha y colab., 2013; ANSYSFluent User's Guide). Altantiz y colab. (2014) realizaron distintas pruebas variando el coeficiente $\varphi$ entre 0,0005 y 0,5. Los autores concluyeron que este coeficiente es función de la velocidad superficial del gas y que los parámetros representativos de las burbujas se encuentran estrechamente relacionados con su valor, al menos en la geometría pseudo2D estudiada. Al aumentar el valor de $\varphi$, el lecho fluidizado tiende al régimen de burbujeo y sumado a ello, el diámetro y velocidad de las burbujas disminuyen. En este trabajo se evaluará la influencia de este parámetro sobre las propiedades de la fase burbuja.

\section{6 - CURVA DE FLUIDIZACIÓN}

Para trazar la curva experimental de fluidización de arena, se utilizó el lecho cilíndrico. En primera instancia se midió la pérdida de carga provocada por el distribuidor con el lecho vacío, conectando un manómetro digital en las tomas 1 y 2 (Figura 3.7a). Durante la experiencia fue variándose gradualmente el caudal del aire y registrándose la pérdida de carga en cada condición. Con los datos obtenidos se trazó la curva y se obtuvo, mediante un ajuste por mínimos cuadrados, una función polinómica de segundo grado de la pérdida de carga del distribuidor en función de la velocidad superficial del aire.

Una vez obtenida la información de la pérdida de carga en el distribuidor, se cargó el recipiente cilíndrico con la arena caracterizada en la Sección 3.4.1, hasta alcanzar una altura de $0,12 \mathrm{~m}$. El esquema del equipamiento experimental para la toma de mediciones y operación del lecho se muestra en la Figura 3.11. Durante el ensayo se registraron los valores de velocidad superficial del aire, temperatura y pérdida de carga a través del 
lecho, en cada condición de operación. La velocidad del aire fue incrementada hasta alcanzar el estado de fluidización del lecho. A partir de dicho estado, con incrementos aún mayores de la velocidad superficial del aire, se observó que el lecho permanecía en estado fluidizado y que la pérdida de carga oscilaba siempre alrededor de un valor constante. Finalmente se procedió a disminuir gradualmente el caudal de aire, registrando los datos para obtener la correspondiente curva de desfluidización del lecho.

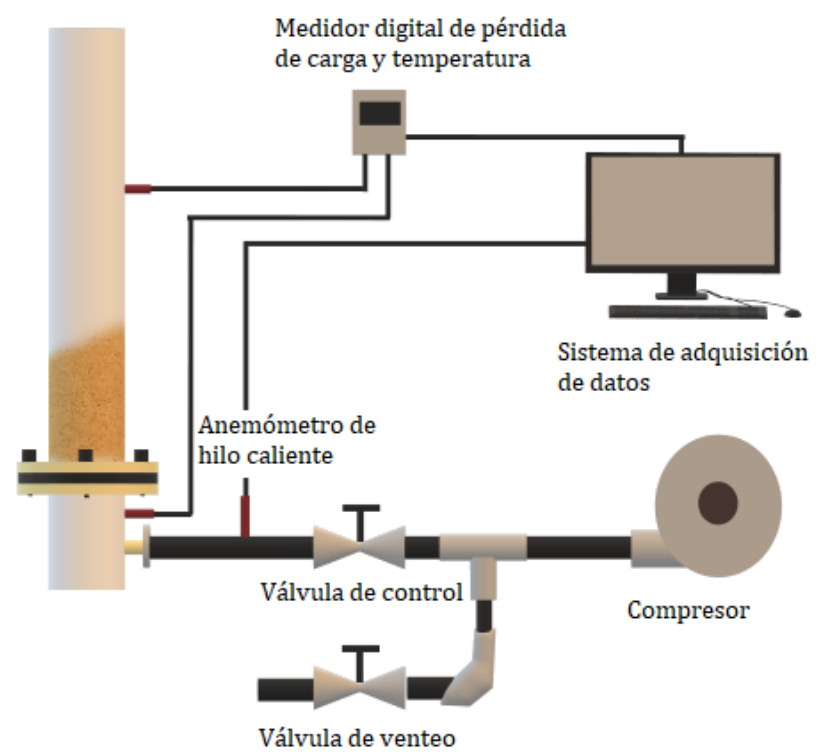

Figura 3.11 - Esquema de equipamiento experimental. Lecho experimental conectado para la obtención de datos.

Con el conjunto de datos obtenidos de pérdida de carga y velocidad superficial del aire, se construyeron las curvas de fluidización y desfluidización del lecho experimental (descriptas en el Capítulo 2, Sección 2.2.2). En la Figura 3.12 se muestran las dos curvas obtenidas. La determinación de la velocidad $U_{m f}$ se realizó siguiendo las recomendaciones de la norma ASTM D7743-12, que propone utilizar los valores de caída de presión obtenidos para velocidades de gas decrecientes, y determinar la velocidad $U_{m f}$ como la intersección entre las curvas correspondientes a lecho fluidizado y fijo. Dichas recomendaciones son coincidentes con lo recomendado por Yates (1983) y Kunii y Levenspiel (2013). En el caso del lecho experimental, el valor de dicha velocidad fue $U_{m f}=0,19 \mathrm{~m} / \mathrm{s}$.

En la Figura 3.12 también se observa que la pérdida de carga aumenta linealmente con el aumento de la velocidad superficial del gas en la zona de lecho fijo, y que permanece prácticamente constante una vez superado el valor de la velocidad $U_{m f}$. 
También se observa que la pendiente de la curva de fluidización en la zona de lecho fijo es superior que la correspondiente a la de desfluidización, debido a que la porosidad inicial del lecho es menor por encontrarse en un mayor grado de compactación, lo cual demuestra la presencia del fenómeno de histéresis. Finalmente, puede verse un punto máximo de pérdida de carga, correspondiente al valor en el cual los sólidos incrementan su movilidad y el lecho alcanza el estado de fluidización, produciéndose la modificación de la porosidad del mismo hasta alcanzar el valor correspondiente a la mínima fluidización.

Por último, cabe destacar que la velocidad $U_{m f}$ es una característica del sistema aire-sólido, por lo que es independiente de la altura inicial del lecho y de cualquier característica geométrica del mismo.

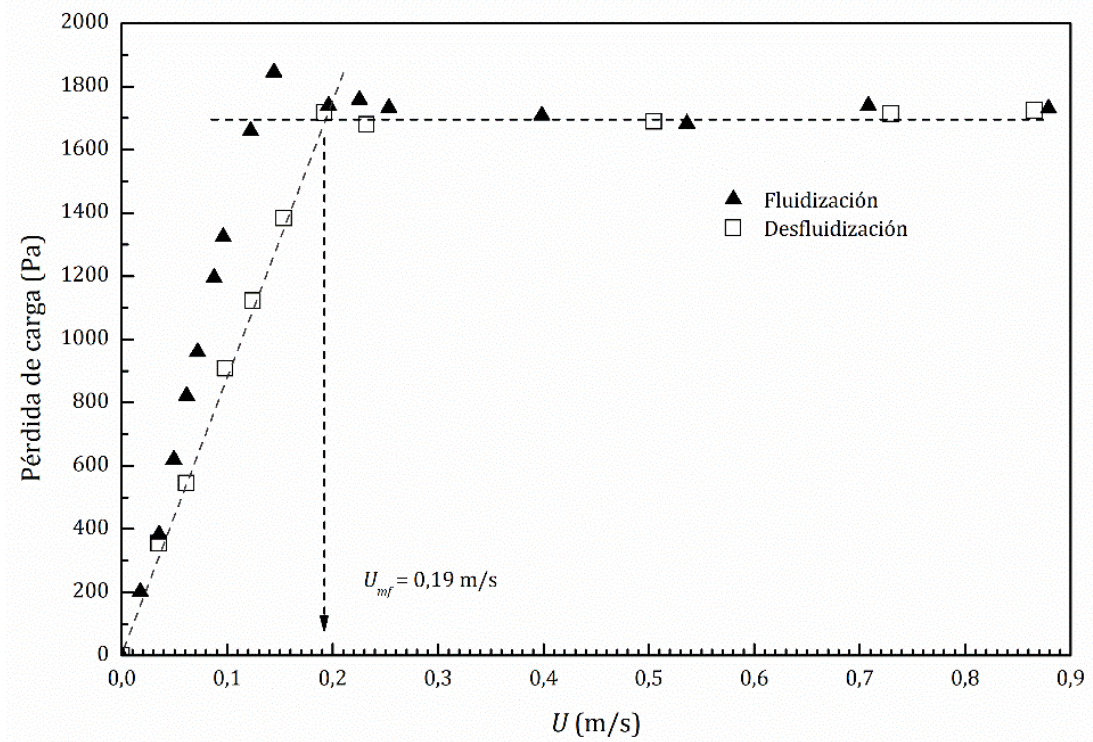

Figura 3.12 - Curva de fluidización experimental. Obtención de la velocidad $U_{m f}$.

Para obtener la curva de fluidización mediante CFD, se llevaron a cabo las simulaciones en estado estacionario para velocidades superficiales de gas entre 0,035 y $0,19 \mathrm{~m} / \mathrm{s}$ y simulaciones en estado transitorio para velocidades entre 0,2 y 0,86 m/s. En todos los casos, se asignó un monitor de presión en la zona denominada como Velocityinlet, para registrar la presión manométrica de la mezcla aire-arena en la misma. Se utilizó el modelo de arrastre de Gidaspow, de acuerdo a lo propuesto en los trabajos de Busciglio y colab. (2009), Acosta-Iborra y colab. (2011), Loha y colab. (2013), Altantzis y colab. (2015) y Bakshi y colab. (2015), Lu y colab. (2015). Sumado a ello, Zambón y colab. (2011) 
demostraron que es el más adecuado para el estudio de la pérdida de carga del sistema arena-aire. Se trabajó sin modelo friccional para viscosidad y con la condición de borde de No Slip para el coeficiente $\varphi$ tanto del sólido como del gas, por tratarse de valores definidos por defecto en el programa. Las simulaciones en estado estacionario se realizaron hasta alcanzar la convergencia de los resultados, obteniendo un único valor de presión estática. Por otro lado, las simulaciones en estado transitorio se condujeron durante un período de 14 s y, de acuerdo a lo reportado por Asegehegn y colab. (2011), se descartaron los registros de los primeros $3 \mathrm{~s}$, con el fin de evitar los efectos iniciales de la simulación. En este caso, se calculó un valor de presión promedio a lo largo del tiempo simulado.

Al igual que en el caso experimental, la curva de fluidización se construyó graficando los valores de pérdida de carga en función de la velocidad superficial del gas (Figura 3.13). En este caso se obtiene una única curva, ya que la CFD no permite la diferenciación entre fluidización y desfluidización.

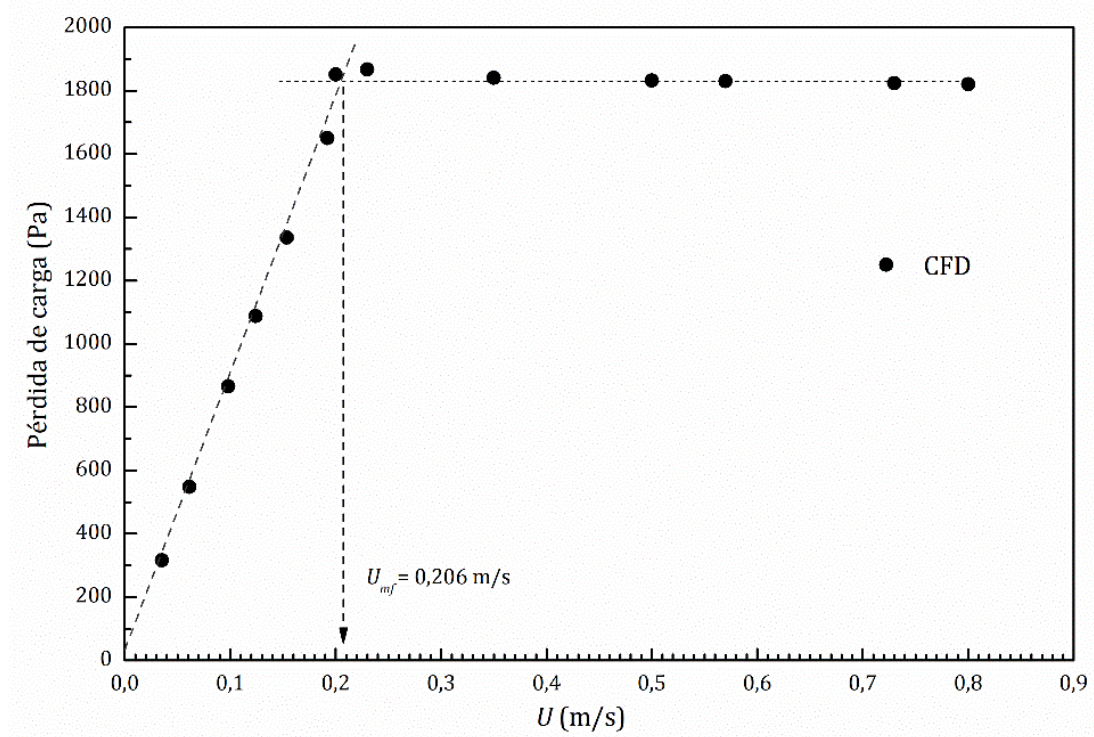

Figura 3.13 - Curva de fluidización obtenida mediante CFD.

Siguiendo el mismo procedimiento que en el caso experimental, se obtuvo un valor de velocidad $U_{m f}=0,206 \mathrm{~m} / \mathrm{s}$.

Por otro lado, se analizaron los valores de pérdida de carga obtenidos en la condición de fluidización en el estudio experimental y en las simulaciones CFD, 
comparándolos, además, con el valor teórico (W/A). Los valores medios se muestran en la Tabla 3.5 así como el correspondiente valor de W/A.

Tabla 3.5 - Pérdida de carga media en fluidización.

\begin{tabular}{|c|c|c|}
\hline Experimental & CFD & W/A \\
\hline $1719,6 \mathrm{~Pa}$ & $1837,7 \mathrm{~Pa}$ & $1881 \mathrm{~Pa}$ \\
\hline
\end{tabular}

El error relativo porcentual de la pérdida de carga obtenida por CFD en la región fluidizada respecto del resultado experimental es de 6,9\%. Por otro lado, lo errores relativos porcentuales del lecho experimental y el lecho simulado respecto de W/A son de $8,6 \%$ y $2,3 \%$ respectivamente.

La Figura 3.14 muestra las curvas conjuntas de pérdida de carga experimentales, CFD y valor teórico

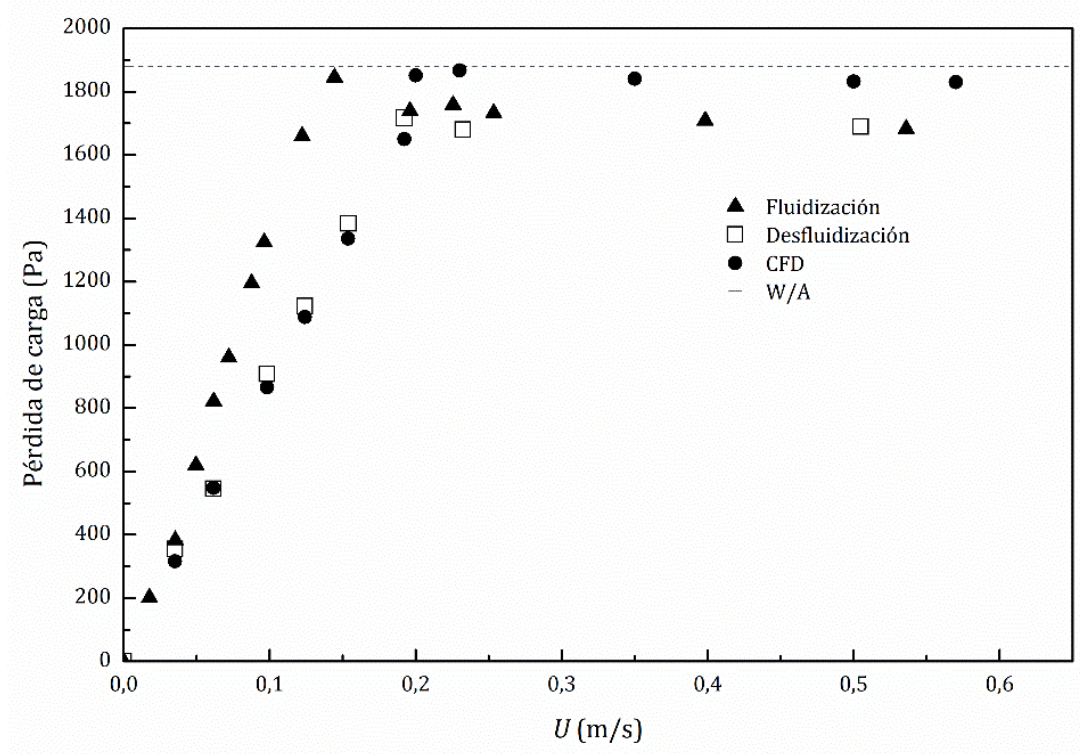

Figura 3.14 - Curvas de pérdida de carga experimental, CFD y W/A.

\section{7 - ANÁLISIS Y CARACTERÍSTICAS DE LA FASE BURBUJA}

Para estudiar el comportamiento de la fase burbuja del par aire-arena de modo experimental, se utilizó el lecho pseudo-2D descripto en la Sección 3.4.2. Se cargó el lecho con arena hasta una altura inicial de $0,33 \mathrm{~m}$ y se operó a distintas velocidades $U(0,35$, $0,40,0,53$ y $0,62 \mathrm{~m} / \mathrm{s}$ ). En la parte posterior del lecho se colocaron reflectores de alta potencia para mejorar la definición de las burbujas observadas. Mediante una cámara de alta velocidad (60 cuadros por segundo) se tomaron fotografías del lecho operando en 
régimen de burbujeo, como puede observarse en la Figura 3.15. Se tomaron 500 fotografías en un intervalo de tiempo de $25 \mathrm{~s}$.
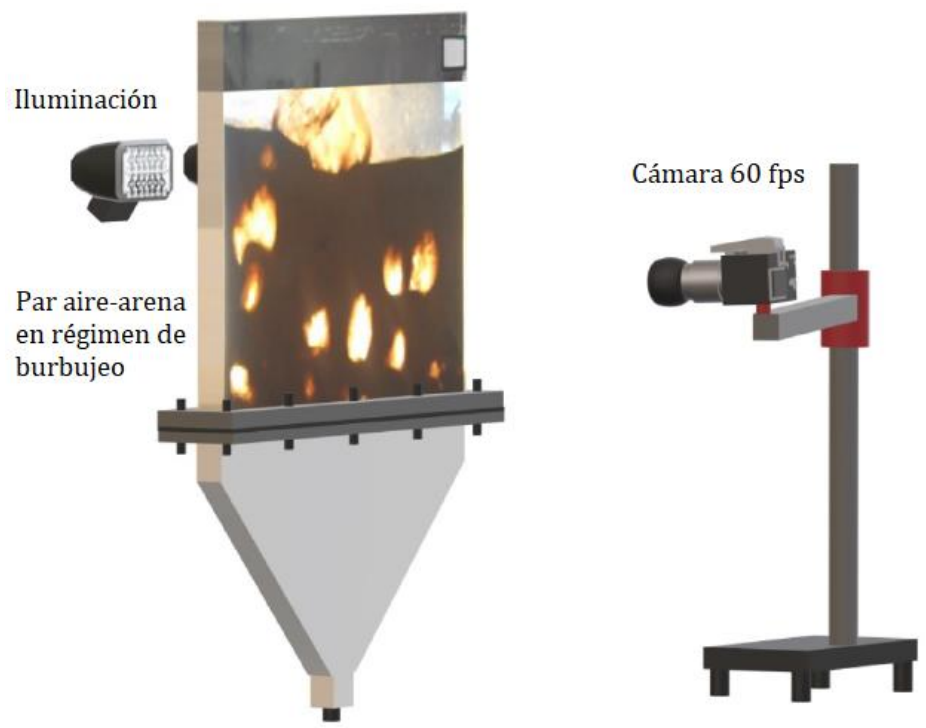

Figura 3.15 Sistema para el análisis de la fase burbuja.

Para llevar a cabo el post-procesamiento de las imágenes obtenidas, fue necesario colocar una referencia gráfica en el lecho, por lo que se incorporó una figura de geometría cuadrada y área conocida (Figura 3.16). Las imágenes se analizaron mediante un software desarrollado con la herramienta $M A T L A B$, con el objetivo de determinar diámetro, velocidad y frecuencia de las burbujas.

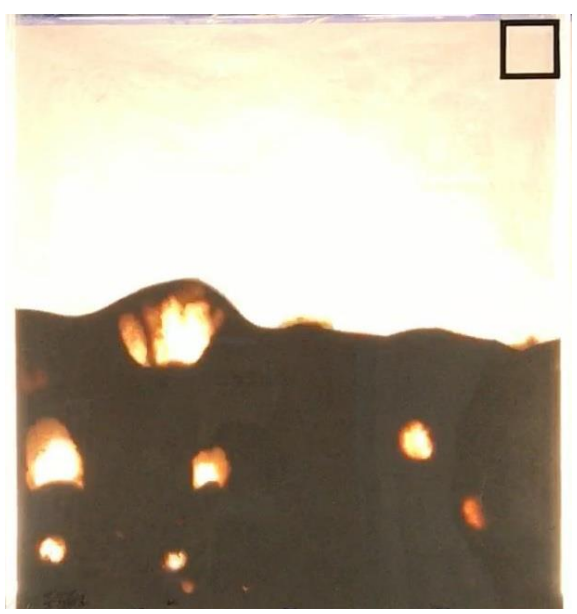

Figura 3.16 - Imagen del lecho pseudo-2D con la referencia utilizada.

El análisis del comportamiento de las burbujas en el lecho pseudo-2D también se llevó a cabo mediante CFD, utilizando una malla estructurada con el mismo tamaño de elemento que el considerado en el lecho cilíndrico. No obstante, en el caso del lecho 
pseudo-2D, por tener mayores dimensiones, la malla posee mayor cantidad de elementos (570996) y por lo tanto requirió mayor tiempo de cómputo (aproximadamente 25 días por experiencia). Los parámetros de la simulación son coincidentes con los mencionados en la Tabla 3.4. Las diferencias radican en la configuración geométrica del lecho y en el valor de altura inicial de arena (0,33 m en este caso, con el fin de contar con una mayor altura para el estudio de las burbujas. Se obtuvieron imágenes del lecho cada 17 pasos de tiempo, lo que significó un número de 60 imágenes por segundo (igual cantidad de imágenes y espaciado de tiempo que en el caso experimental).

En este caso, la referencia utilizada para el post-procesamiento de las imágenes consistió en la imagen obtenida cuando se inicializó el problema en ANSYS-Fluent (Figura 3.17), ya que se conocen las dimensiones exactas de las zonas.

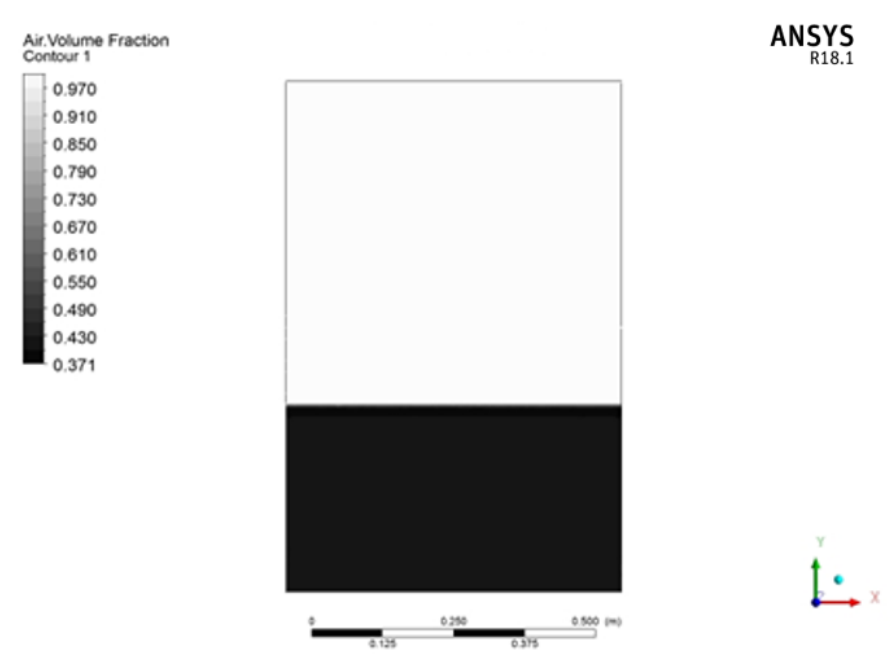

Figura 3.17 - Inicialización del caso en CFD: la zona superior del lecho (color blanco) se usa como referencia para el post-procesamiento.

Para visualizar y analizar la fase burbuja se obtuvieron imágenes de contorno de la fracción volumétrica de aire $\left(\alpha_{g}\right)$ en un plano colocado sobre la pared del lecho. No existe una definición exacta respecto del límite de la fase burbuja, por lo que diversos investigadores plantean umbrales para la fracción de aire tales como 0,7, o 0,8 (Hulme y colab. 2005, Patil y colab. 2005, Acosta-Iborra y colab. 2011, Altantzis y colab. 2015, Bakshi y colab. 2015). En este trabajo se adoptó un valor de $\alpha_{g}$ mayor o igual a 0,7 para la fase burbuja.

Las imágenes se generaron en escala de grises para favorecer el postprocesamiento, como se muestra en la Figura 3.18. En el margen izquierdo de la imagen 
se observa una escala colorimétrica que permite visualizar, en base al umbral adoptado, el límite entre emulsión y burbuja.

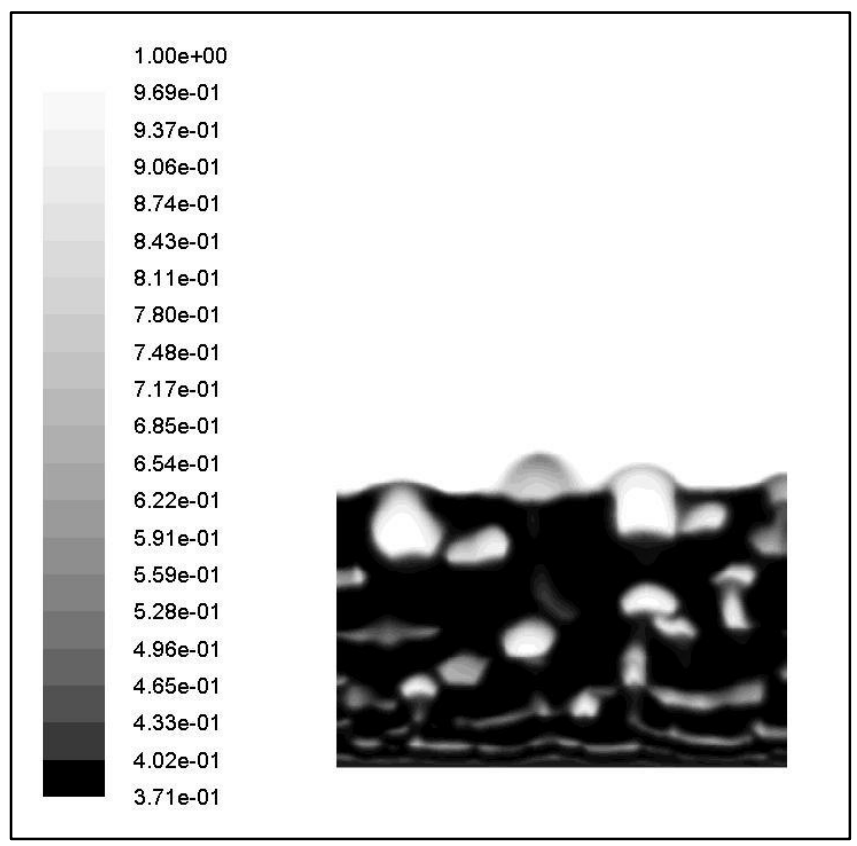

Figura 3.18 - Curvas de contorno de la fracción volumétrica de aire sobre la pared del lecho.

\subsection{1 - Post-Procesamiento de imágenes}

El estudio de la fase burbuja se basó en la interpretación de las imágenes obtenidas experimentalmente y de las generadas mediante las simulaciones CFD. Ambos tipos de imágenes debieron ser tratadas previamente con un software especialmente desarrollado para este fin en la plataforma $M A T L A B$, utilizando el paquete IMAGE Processing Toolbox. El diagrama presentado en la Figura 3.19 permite la visualización de los pasos llevados a cabo para el tratamiento de las imágenes. El desarrollo del programa completo se presenta en la sección 1 del Anexo 3.III.

En el caso de las imágenes obtenidas experimentalmente, al ser fotografías en color (RGB), el primer paso consistió en transformarlas en escala de grises. El tratamiento posterior fue equivalente para los dos casos en estudio, teniendo en cuenta únicamente que las referencias utilizadas fueron distintas. 


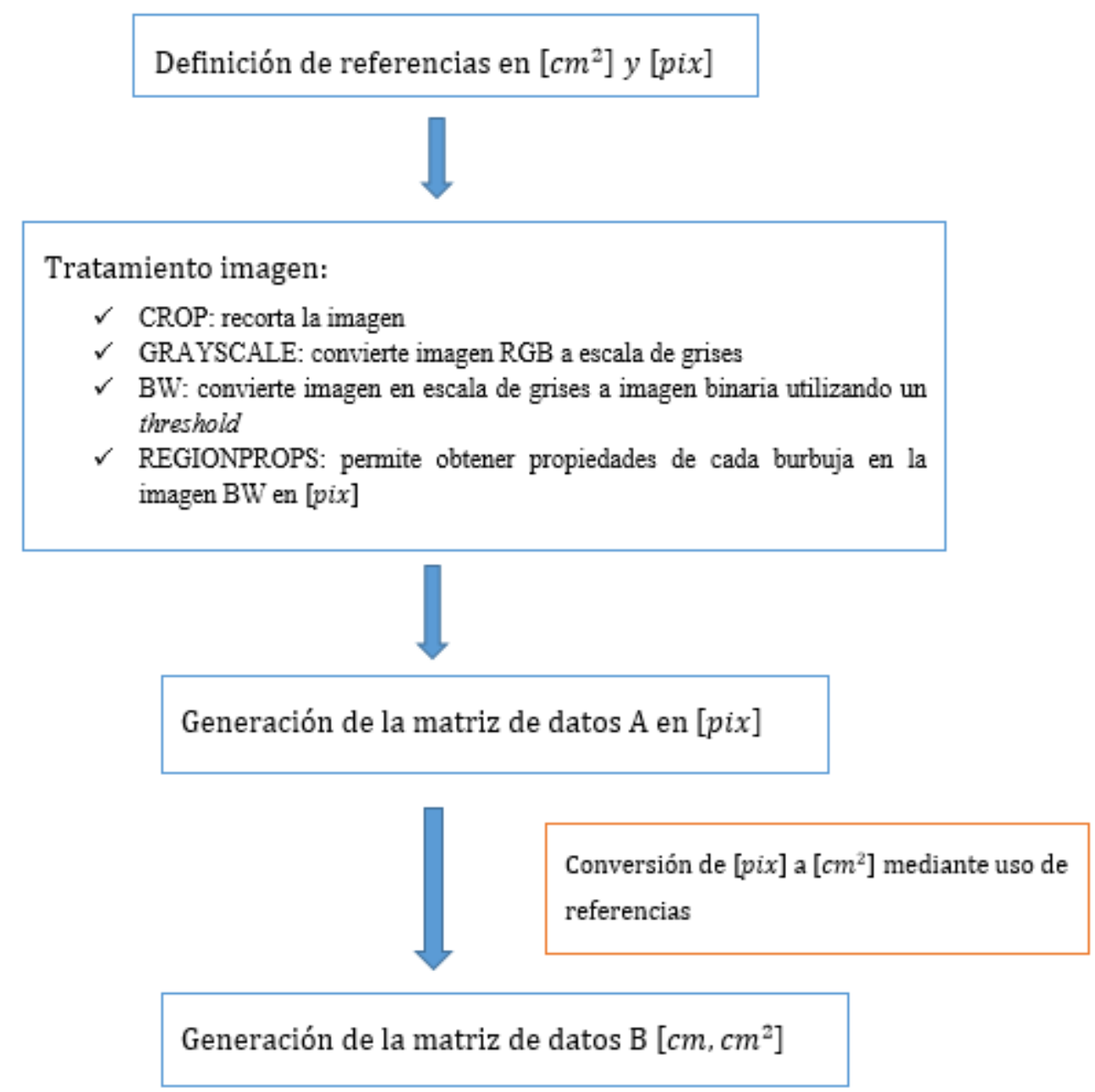

Figura 3.19 - Diagrama lógico del tratamiento de imágenes.

El programa recorta las imágenes originales, dejando sólo el lecho fluidizado y luego las transforma en imágenes binarias (blanco y negro). A partir de los datos binarios, el programa calcula el centro de masa, área y perímetro de cada burbuja expresados en píxeles. Se entiende como pixel a la superficie homogénea más pequeña que forma parte de una imagen, que a simple vista se presenta como pequeños cuadrados o rectángulos.

Para generar la imagen binaria, debe seleccionarse un umbral de luminosidad (threshold), que separa aquello que se convertirá en blanco o negro en la imagen binaria. El programa les adjudica a todos los pixeles de la imagen de entrada que tienen un valor de luminosidad mayor que el threshold, el valor 1 (blanco) y al resto el valor 0 (negro). El valor de este umbral está directamente relacionado con la determinación de la región que se considera como fase burbuja. La selección de su valor se realizó por comparación visual entre la imagen original y la imagen binaria obtenida para distintos valores de threshold. 
Luego de varias pruebas se determinaron los valores que mejor se ajustaron al tamaño y forma de las burbujas:

$\checkmark$ Experimental: 0,25

$\checkmark$ Simulación: 0,65

A partir de la imagen binaria, el programa genera una nueva figura, en la que se señala el contorno de las dos fases y se numera a las burbujas consideradas (Figura 3.20). A partir de esta imagen se obtienen los datos antes mencionados de cada burbuja.

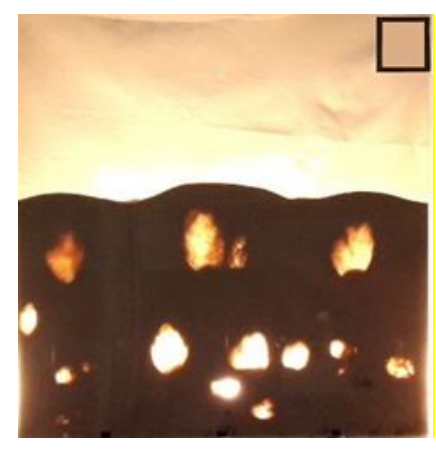

a. Original

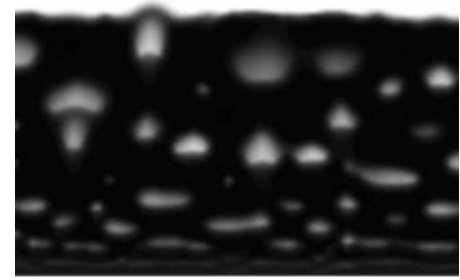

b. Original

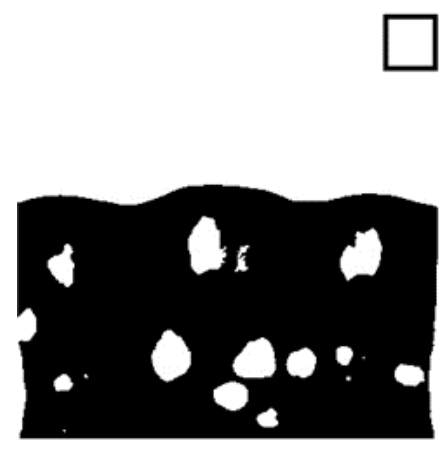

Binaria

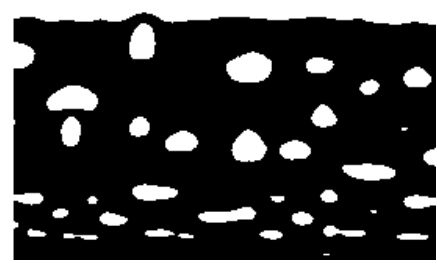

Binaria

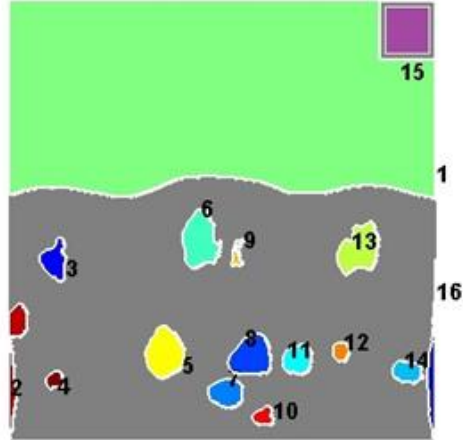

Contorno de fases

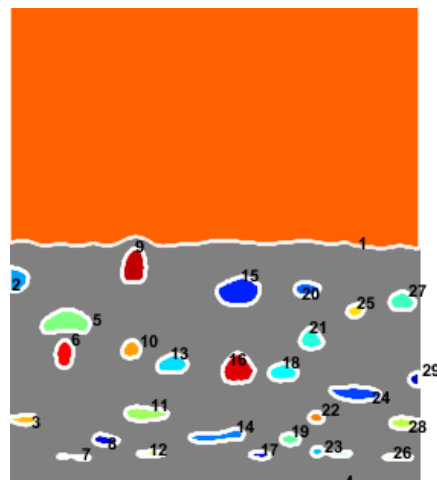

Contorno de fases

Figura 3.20- Secuencia de conversión para obtener los valores de las propiedades de la fase burbuja para imágenes experimentales (a) y obtenidas mediante simulación por CFD (b).

No existe una relación directa entre pixeles y sistema métrico. En consecuencia, se debe realizar la conversión utilizando la referencia seleccionada en cada caso. Para calcular el área de un pixel $\left(A_{p i x}\right)$ se utilizó la siguiente relación:

$$
A_{\text {real }}=n_{\text {pix }} \cdot A_{\text {pix }}
$$


donde el área real, $A_{\text {real }}$, es el área de la referencia medida en $\mathrm{cm}^{2}$, mientras que el número de pixeles, $n_{\text {pix }}$, es el valor arrojado como "área" por el programa. El valor obtenido se empleó para convertir los datos de área de las burbujas, en $\mathrm{cm}^{2}$.

Para evaluar las dimensiones lineales de un pixel $\left(L_{p i x, X}\right.$ y $\left.L_{p i x, Y}\right)$, se tomó el número de pixeles del ancho y alto de la referencia calculado por el programa $\left(n_{p i x, X} \mathrm{y}\right.$ $n_{\text {pix,Y }}$ ), y se lo comparó con las dimensiones reales:

$$
\begin{aligned}
& L_{\text {real }, X}=n_{\text {pix }, X} \cdot L_{p i x, X} \\
& L_{\text {real }, Y}=n_{\text {pix }, Y} \cdot L_{p i x, Y}
\end{aligned}
$$

En la Figura 3.21 se muestra un ejemplo a modo ilustrativo. De esta forma, utilizando las dimensiones reales de la referencia, se puede obtener el valor de alto y ancho de un pixel para convertir en $\mathrm{cm}$ lineales las coordenadas del centroide de las burbujas y su perímetro. En todos los casos se obtuvieron valores iguales de alto y ancho $\left(L_{p i x, X}=L_{p i x, Y}\right)$, por lo que los pixeles resultaron ser cuadrados. Además, se verificó que $A_{\text {pix }}=L_{p i x, X} * L_{p i x, Y}$.

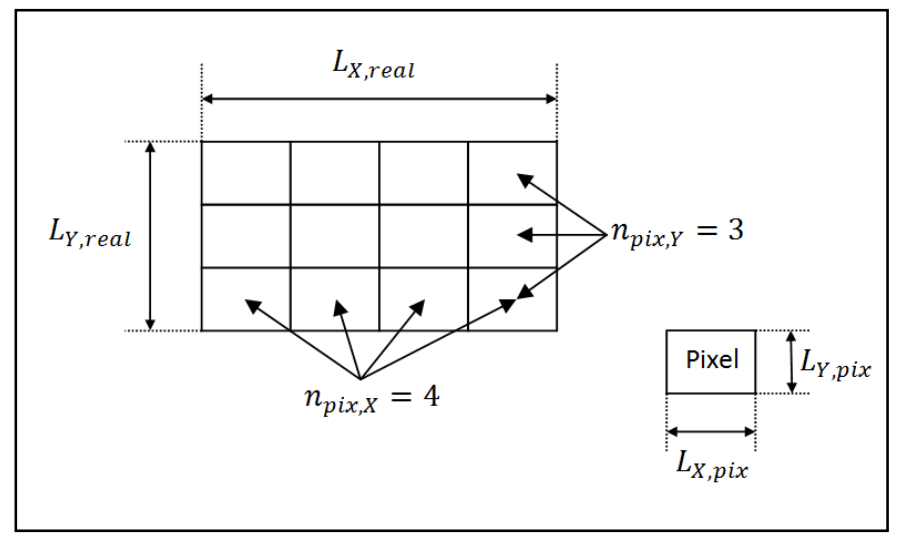

Figura 3.21 - Determinación de las dimensiones de un pixel.

Con las dimensiones del pixel convertidas en $\mathrm{cm}$ lineales (para la longitud) y $\mathrm{cm}^{2}$ (para el área), el programa genera un archivo de Excel con los valores de las coordenadas del centroide, área y perímetro de cada burbuja (plana) de las 500 imágenes, en $\mathrm{cm}$ o $\mathrm{cm}^{2}$ según corresponda.

Se desarrolló un segundo programa, también en la plataforma MATLAB, que permite el cálculo de diámetro, velocidad y frecuencia de las burbujas en función de la altura de lecho, en base a la planilla de Excel generada con los datos de las imágenes 
(sección 2 del Anexo 3.III). En las siguientes secciones se describe el modo en que el programa lleva a cabo los cálculos necesarios.

\subsection{2 - Determinación del diámetro de las burbujas}

Existen en bibliografía diversas formas de expresar el diámetro equivalente de una burbuja en función de la metodología utilizada para medirlas. El trabajo presentado por Karimipour y Pugsley (2011) resume dichas expresiones y utiliza relaciones matemáticas para hacer las conversiones entre ellos. Considerando que el volumen de una burbuja puede definirse como $V_{b}=\frac{\pi}{6} d_{v}^{3}$, los autores buscan relacionar los valores obtenidos según la metodología utilizada para su análisis con el diámetro de una burbuja de volumen equivalente $\left(d_{v}\right)$. En caso de utilizar la metodología de tomografía de capacitancia eléctrica (ECT) o fotografías de las erupciones de burbujas en lechos tridimensionales, el valor obtenido recibe el nombre de diámetro frontal $\left(d_{f}\right)$, que es el diámetro en función de la sección de la burbuja. En caso de trabajar con sensores de fibra óptica o de presión, se obtiene el pierced length $(y)$, y si se utiliza fotografía de rayos-X se obtiene el diámetro vertical $\left(d_{v l}\right)$. Se asume que los diámetros $d_{f}$ y $d_{v l}$ son equivalentes. La siguiente figura permite visualizar los parámetros descriptos:

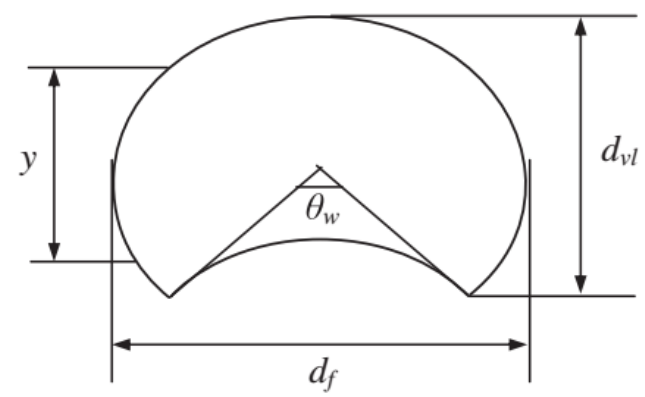

Figura 3.22 - Dimensiones obtenidas según la metodología utilizada para evaluar el diámetro de burbuja. Fuente: Karimipour y Pugsley (2011).

Tal como se mencionó previamente las distintas expresiones del diámetro de burbuja pueden relacionarse mediante conversiones matemáticas:

$$
d_{v}=0,9 d_{f}=1,744 y
$$

Otra forma de evaluar el tamaño de las burbujas es mediante el diámetro de Sauter, $d_{s v}$, definido como el diámetro de una esfera que posee la misma relación entre superficie externa y volumen que la de la burbuja que se desea caracterizar: 


$$
\frac{S_{b}}{V_{b}}=\frac{\pi d_{s v}^{2}}{\frac{\pi}{6} d_{s v}^{3}}=\frac{6}{d_{s v}} \quad \rightarrow \quad d_{s v}=6 \frac{V_{b}}{S_{b}}
$$

donde $S_{b}$ y $V_{b}$ son el área superficial y el volumen de la burbuja real, respectivamente.

En base a estudios preliminares, se observó que el diámetro de Sauter es el que mejor representa los datos obtenidos, por lo tanto, se decidió utilizar la ecuación 3.35 para los cálculos. Se describe a continuación la metodología llevada a cabo para el cálculo de $V_{b}$ y $S_{b}$ en el lecho pseudo-2D.

Debido a que las imágenes obtenidas son bidimensionales, el volumen de cada burbuja se calculó como el volumen de un cilindro, multiplicando el área de la burbuja por la profundidad del lecho (separación entre paredes frontal y posterior):

$$
V_{b}=A_{b} \times e_{\text {lecho }}
$$

donde $A_{b}$ es el área plana de la burbuja obtenida en el tratamiento de imágenes y $e_{\text {lecho }}$ es el espesor del lecho.

Por otro lado, el área superficial de la burbuja se determinó a partir del mismo cilindro, como sigue:

$$
S_{b}=P_{b} \times e_{\text {lecho }}+2 A_{b}
$$

donde $P_{b}$ es el perímetro de la burbuja plana obtenida en el tratamiento de imágenes. En la Figura 3.23 se muestra la forma de la burbuja considerada.

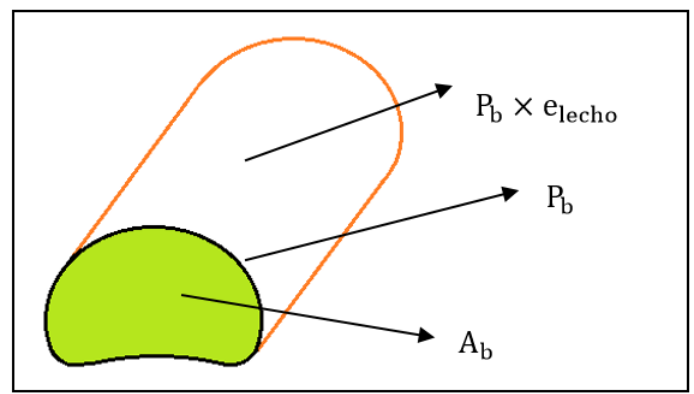

\section{Figura 3.23 - Burbuja en lecho pseudo-2D con sus parámetros geométricos.}

Una vez calculados los valores de $d_{s v}$, se dividió el lecho en intervalos de $1 \mathrm{~cm}$ de altura, desde 0 hasta $28 \mathrm{~cm}$, con el objeto de graficar el diámetro en función de la altura en el lecho. Para cada intervalo $I_{k}$ se determinó la altura media del centro de masa, $\bar{y}_{k}, \mathrm{y}$ el diámetro, ${\overline{d_{s v}}}_{k}$ de las burbujas contenidas en él. 


\subsection{3 - Determinación de la velocidad de las burbujas}

La velocidad de las burbujas se determinó a partir de la diferencia entre los centros de masa de las burbujas en dos imágenes consecutivas, evaluadas con un paso de tiempo de $0,017 \mathrm{~s}$.

$$
u_{b_{i}}=\frac{y_{i, j+1}-y_{i, j}}{\Delta t}
$$

donde $u_{b_{i}}$ es la velocidad de la burbuja $i ; y_{i, j}$ es la altura del centro de masa de la burbuja $i$ en la imagen $j$ con $j=1, \ldots, N-1$, donde $N$ es el número de imágenes analizadas; $y_{i, j+1}$ es la altura del centro de masa de la burbuja $i$ en la imagen $j+1$; y $\Delta t$ es el paso de tiempo entre imágenes $(0,017 \mathrm{~s})$.

Mediante un algoritmo desarrollado en $M A T L A B$, los datos de las burbujas se organizaron en pares. El criterio utilizado para emparejar las burbujas permite un máximo desplazamiento horizontal y vertical de la burbuja en la imagen $j+1$ respecto de la imagen $j$, como así también un máximo crecimiento porcentual de su diámetro.

Como paso previo, se analizaron 10 pares de imágenes, sin la utilización del algoritmo, para determinar:

$\Delta x$ : máximo desplazamiento de la burbuja en la dirección $\mathrm{x}$ (horizontal)

$\Delta y$ : máximo desplazamiento de la burbuja en la dirección y (vertical)

$\Delta d_{s v}$ : fracción máxima de aumento de diámetro de la burbuja en la imagen $j+1$ respecto de la imagen $j$.

El cumplimiento de las siguientes condiciones asegura que se esté analizando la misma burbuja en las dos imágenes consecutivas:

$$
\left\{\begin{array}{c}
x_{i, j+1} \leq x_{i, j} \pm \Delta x \\
y_{i, j+1} \leq y_{i, j}+\Delta y ;(\text { sólo ascendente }) \\
d_{s v_{i, j+1}}<\left(1+\Delta d_{s v}\right) d_{s v_{i, j}}
\end{array}\right.
$$

Finalmente, el programa calcula la velocidad de cada burbuja según la Ecuación 3.38. Una vez analizadas todas las imágenes, para cada intervalo $I_{k}$ se determinó la altura media del centro de masa, $\bar{y}_{k}$, y la velocidad media, $\bar{u}_{b}$ de las burbujas contenidas en dicho intervalo. 


\subsection{4 - Determinación de la frecuencia de burbujas}

Para evaluar la frecuencia de pulsación, se dividió el lecho en secciones transversales a su coordenada axial, distribuidas de forma equidistante y se contabilizó la cantidad de burbujas que atraviesa cada sección durante el período analizado. La misma se calculó teniendo en cuenta la ecuación (3.26). Cabe destacar que una misma burbuja fue tenida en cuenta una única vez en cada sección (es decir, si la misma burbuja permanecía más de un cuadro/imagen en una altura determinada, ésta era contabilizada sólo una vez).

\section{8 - RESULTADOS Y DISCUSIÓN DEL ESTUDIO DE LA FASE BURBUJA}

Siguiendo la línea presentada para el estudio de la pérdida de carga del lecho, las simulaciones se llevaron a cabo utilizando, en una primera fase, el modelo de arrastre de Gidaspow, sin viscosidad friccional y con la condición de borde No Slip para el sólido en la pared. El estudio inicial se llevó a cabo para la velocidad $U=0,35 \mathrm{~m} / \mathrm{s}$.

La Figura 3.24 muestra los resultados obtenidos para el diámetro de burbuja $d_{s v}$ en base a los datos experimentales y obtenidos mediante CFD.

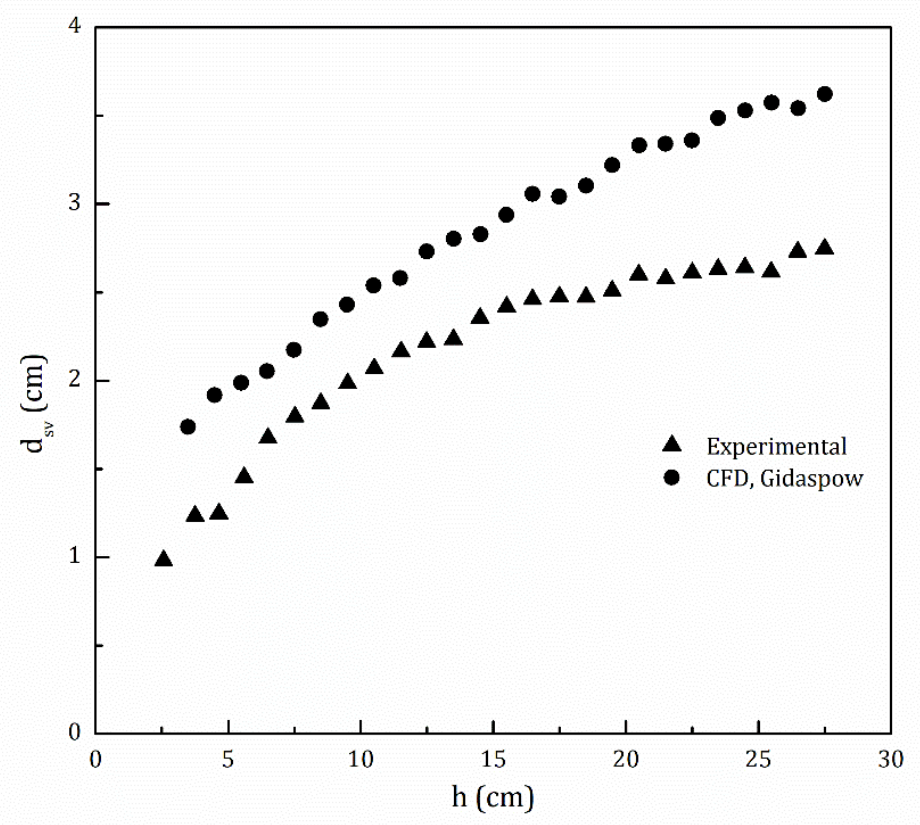

Figura 3.24 - Diámetro de burbuja en función de la altura de lecho. Modelo de arrastre: Gidaspow; condición de borde entre la pared y sólido: No slip. Sin viscosidad friccional. 
Se observa que la simulación sobreestima considerablemente el diámetro de burbuja con los parámetros asignados. Lo mismo ocurre con la velocidad de ascenso de la misma, como puede apreciarse en la Figura 3.25.

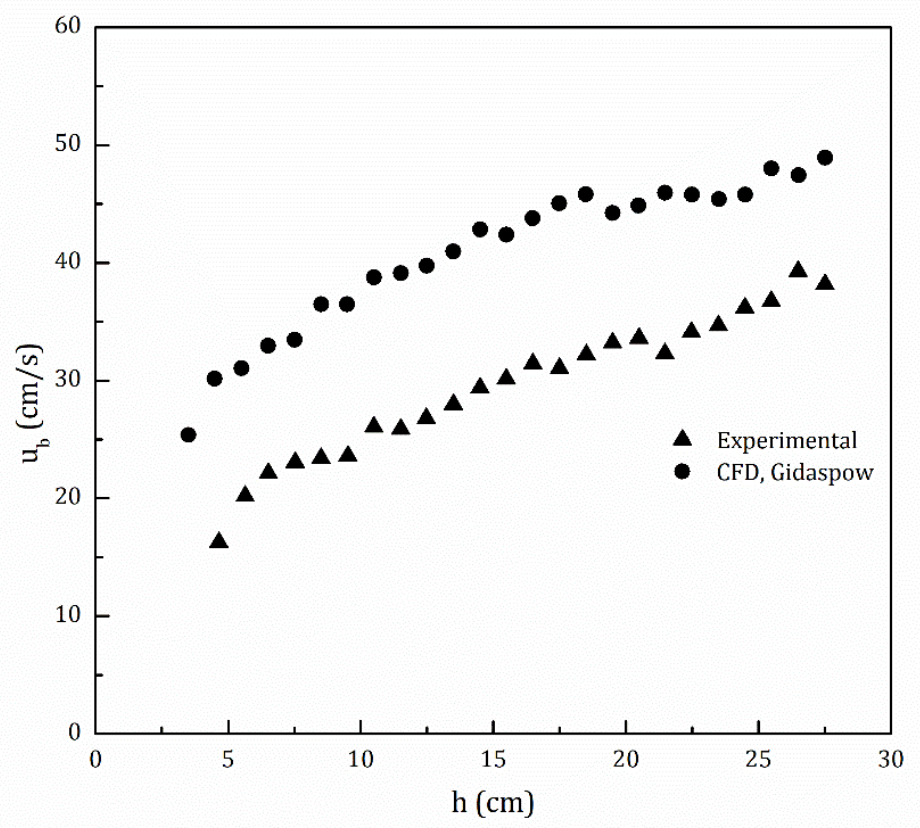

Figura 3.25 - Velocidad de ascenso de las burbujas en lecho. Modelo de arrastre: Gidaspow; condición de borde entre la pared y sólido: No slip. Sin viscosidad friccional.

En base a los resultados obtenidos para este análisis, se concluye que, si bien el modelo de Gidaspow logra una buena representación de la pérdida de carga del lecho y por ende, de la curva de fluidización y velocidad $U_{m f}$, no logra reproducir satisfactoriamente las características y propiedades de la fase burbuja. Por este motivo, se llevó a cabo un estudio exhaustivo, analizando la influencia de los distintos parámetros sobre los resultados de $d_{s v}$ y $u_{b}$. Se realizaron experiencias de simulación modificando el modelo de arrastre, los parámetros que rigen las propiedades de la fase sólida (viscosidad granular y friccional, presión y distribución radial) y las condiciones de borde sobre la pared para la misma fase. La Tabla 3.6 resume los ensayos realizados para decidir el mejor ajuste para las propiedades de la fase burbuja. 
Tabla 3.6 - Ensayos llevados a cabo para el estudio de diámetro y velocidad de ascenso de la fase burbuja. Variaciones en modelo de arrastre, viscosidad friccional y condición de borde para el sólido en la pared. Referencias: GD: Gidaspow y colab. (1992), LUN: Lun y colab. (1984), OGA: Ogawa y colab. (1980), SCH: Schaeffer (1987), SOB: Syamlal y O’Brien (1989), WY: Wen y Yu (1966), SYA: Syamlal y colab. (1993), GIB: Gibilaro (1985).

\begin{tabular}{|c|c|c|c|c|c|c|c|c|}
\hline & Ensayo 1 & \begin{tabular}{|l|} 
Ensayo 2 \\
\end{tabular} & Ensayo 3 & Ensayo 4 & Ensayo 5 & Ensayo 6 & Ensayo 7 & Ensayo 8 \\
\hline \multicolumn{9}{|l|}{ PHASES (solid) } \\
\hline Granular viscosity $(\mu s, k i n-\mu s, c o l)$ & GD & GD & GD & GD & GD & GD & GD & GD \\
\hline Frictional Viscosity $(\mu s, f r)$ & None & $\mathrm{SCH}$ & $\mathrm{SCH}$ & $\mathrm{SCH}$ & $\mathrm{SCH}$ & $\mathrm{SCH}$ & $\mathrm{SCH}$ & $\mathrm{SCH}$ \\
\hline Solids pressure (VPS) & LUN & LUN & LUN & LUN & LUN & LUN & LUN & LUN \\
\hline Radial distribution & OGA & OGA & OGA & OGA & OGA & OGA & OGA & OGA \\
\hline \multicolumn{9}{|l|}{ PAHASES INTERACTION } \\
\hline Drag & GD & GD & GD & GD & GD & GD & SOB & WY \\
\hline \multicolumn{9}{|l|}{ BOUNDARY CONDITIONS } \\
\hline Wall (solid) & No Slip & No Slip & $\phi: 1$ & $\phi: 0,8$ & $\phi: 0,5$ & $\phi: 0,2$ & $\phi: 0,5$ & $\phi: 0,5$ \\
\hline
\end{tabular}

\begin{tabular}{|c|c|c|c|c|c|c|c|}
\hline Ensayo 9 & Ensayo 10 & Ensayo 11 & \begin{tabular}{|l} 
Ensayo 12 \\
\end{tabular} & Ensayo 13 & \begin{tabular}{|l|} 
Ensayo 14 \\
\end{tabular} & \begin{tabular}{|l|} 
Ensayo 15 \\
\end{tabular} & Ensayo 16 \\
\hline GD & GD & GD & GD & GD & SYA & GD & GD \\
\hline $\mathrm{SCH}$ & None & None & $\mathrm{SCH}$ & $\mathrm{SCH}$ & None & None & None \\
\hline LUN & LUN & LUN & LUN & LUN & SYA & LUN & LUN \\
\hline OGA & OGA & OGA & OGA & OGA & SYA & OGA & OGA \\
\hline SOB para & SOB para & GD & GIB & SOB & SOB & SOB & SOB \\
\hline$\phi: 0,5$ & $\phi: 0,5$ & $\phi: 0,5$ & $\phi: 0,5$ & No Slip & No Slip & No Slip & $\phi: 0,5$ \\
\hline
\end{tabular}

A continuación en la Figura 3.26, se presentan los resultados del valor del diámetro de burbuja, $d_{s v}$, en función de la altura, para los diferentes ensayos CFD realizados.

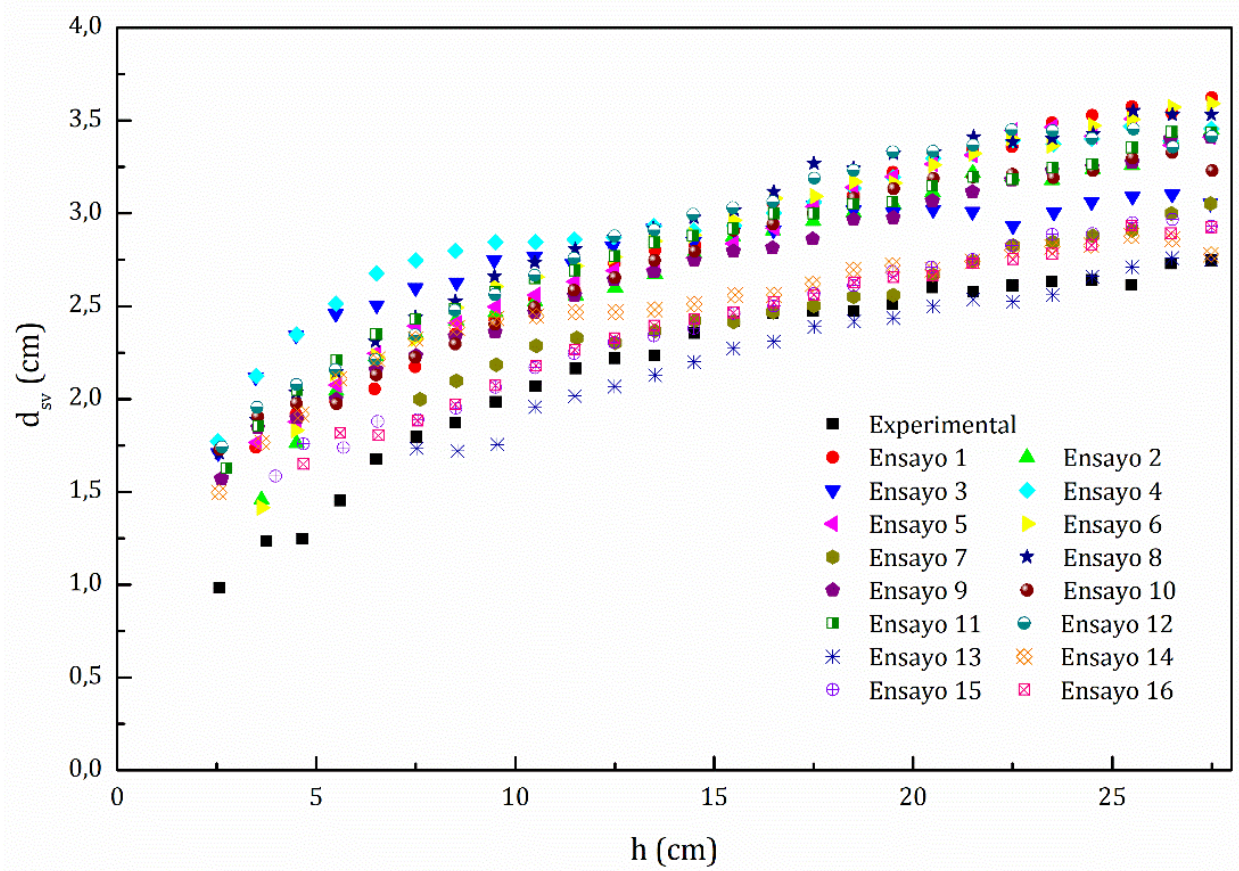

Figura 3.26 - Estudio del diámetro de burbuja en función de la altura para los distintos ensayos modelados. 
Como se observa, los ensayos 7, 13, 15 y 16 presentan los mejores resultados con respecto al valor experimental. Por lo tanto, en primera instancia, el modelo de arrastre de Syamlal O’Brien es el que mejor representa la fluidodinámica del lecho. La Figura 3.27 permite una mejor visualización de los ensayos mencionados y los resultados experimentales.

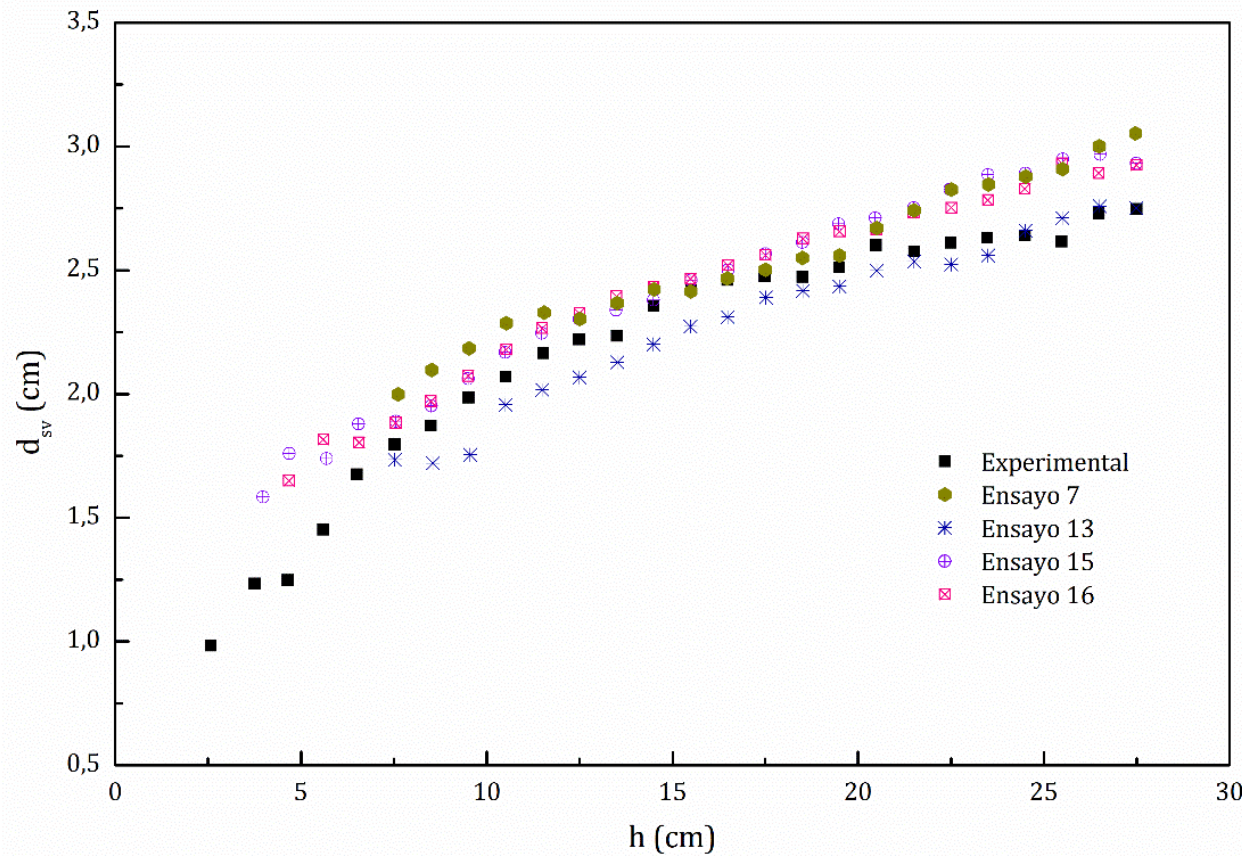

Figura 3.27 - Resultados de diámetro de burbuja para los ensayos con modelo de arrastre SOB.

La diferencia en estos ensayos radica en el modelo para la viscosidad friccional (tiene en cuenta la viscosidad generada por la fricción entre las partículas en lechos densos) y en el coeficiente $\varphi$. De modo complementario se estudió la influencia de los distintos modelos sobre la velocidad de ascenso de las burbujas. Los resultados se presentan en la Figura 3.28. 


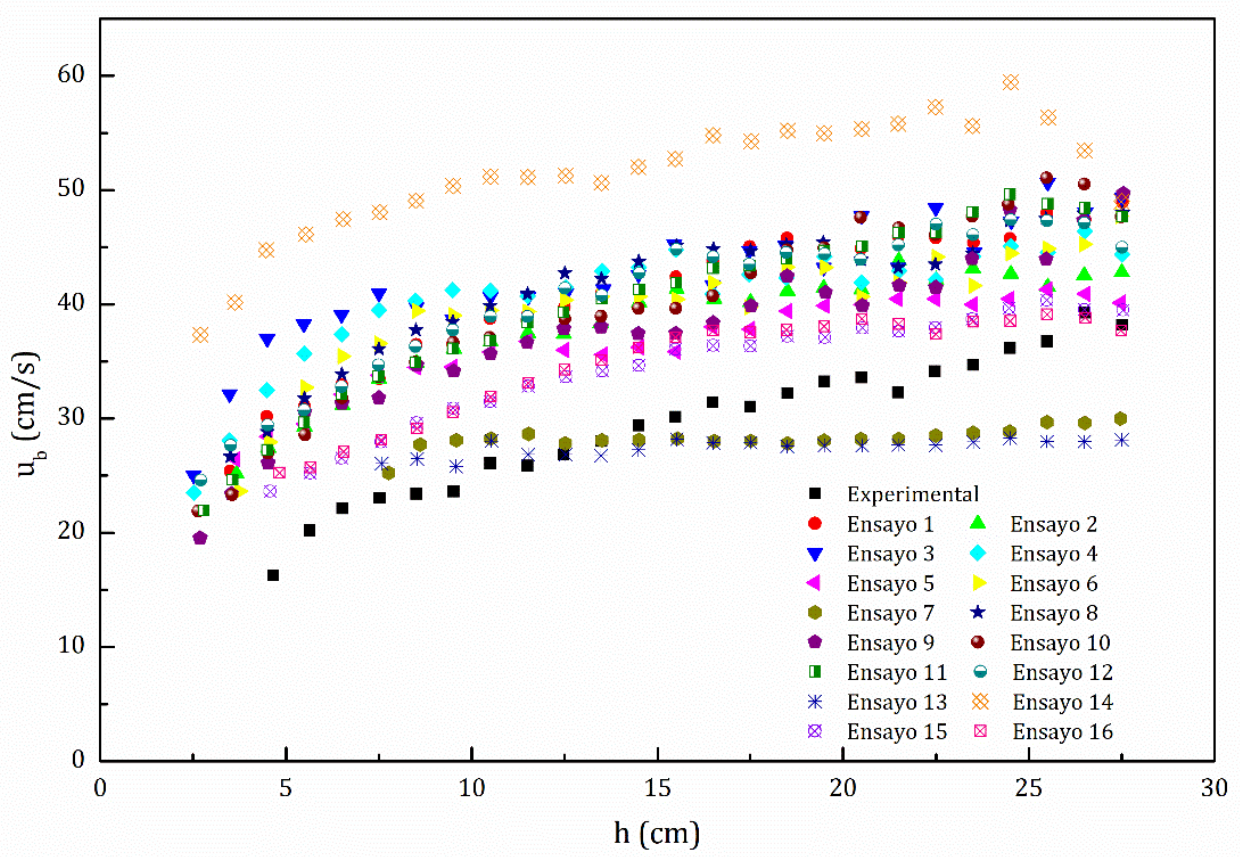

Figura 3.28 - Estudio de la velocidad de ascenso de las burbujas en función de la altura para los ensayos CFD enumerados en la Tabla 3.6.

En función del gráfico es factible concluir que el modelo de arrastre de Syamlal O’Brien también es el que mejor reproduce la velocidad de ascenso de las burbujas. Sin embargo, en este caso existe una gran diferencia en los resultados obtenidos si se selecciona un modelo para la viscosidad friccional o no se utiliza la viscosidad friccional. En el análisis del diámetro de burbuja no se observan diferencias al considerar o no el modelo de viscosidad friccional. Pero en el análisis de velocidad de ascenso de las burbujas la viscosidad friccional hace que la velocidad de las mismas de vea muy limitada, alcanzando un valor aproximado de $25 \mathrm{~cm} / \mathrm{s}$ en todo el rango de alturas.

En la Figura 3.29 se presentan los resultados obtenidos utilizando el modelo de arrastre de Syamlal O'Brien y variando los modelos para viscosidad friccional y la condición de borde en la pared. 


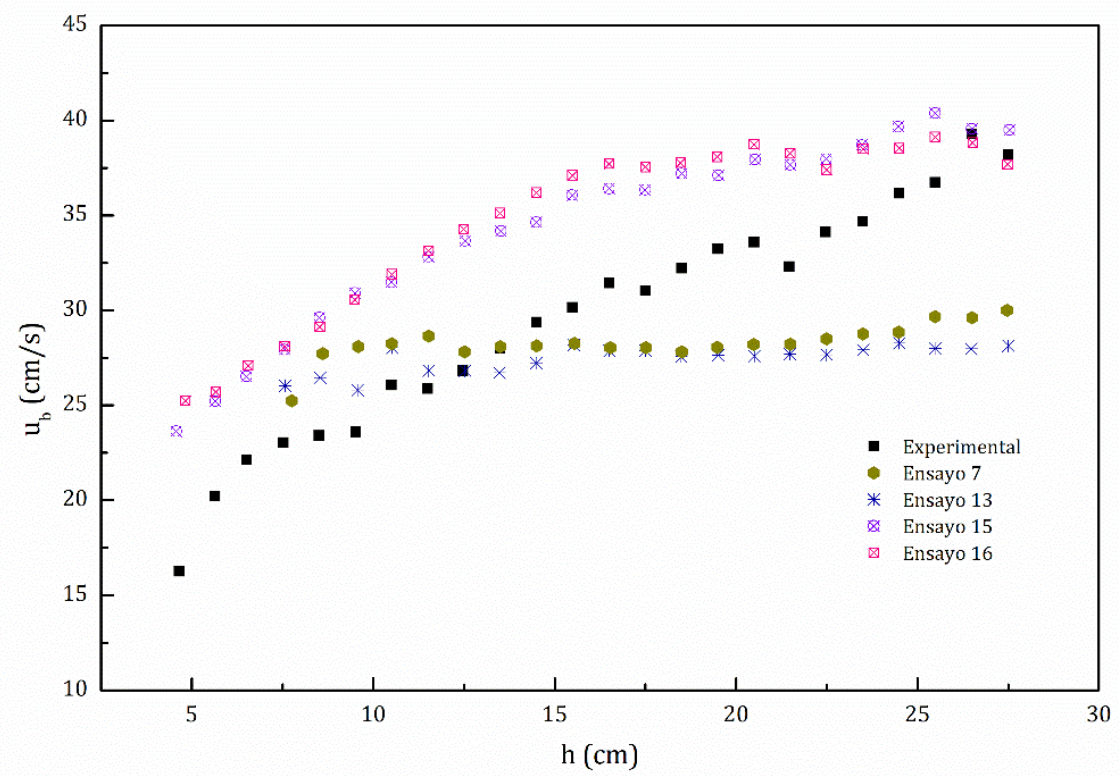

Figura 3.29 - Resultados de velocidad de ascenso de las burbujas para los ensayos con modelo de arrastre SOB.

La diferencia entre considerar o no la condición de borde en la pared para el sólido no provoca diferencias significativas en los resultados. Por lo tanto, del análisis de ambos gráficos se concluye que la simulación debería realizarse con el modelo de arrastre de Syamlal O'Brien, sin viscosidad friccional y con coeficiente $\varphi=0,5$, puesto que de esta manera se tienen en cuenta los efectos de la pared.

En las Figuras $3.30 \mathrm{a}$ y $3.30 \mathrm{~b}$ se presentan los resultados de diámetro $d_{s v} \mathrm{y}$ velocidad $u_{b}$ con el modelo de CFD seleccionado. Los errores relativos promedio son de $7,3 \%$ y $19,5 \%$ respectivamente.

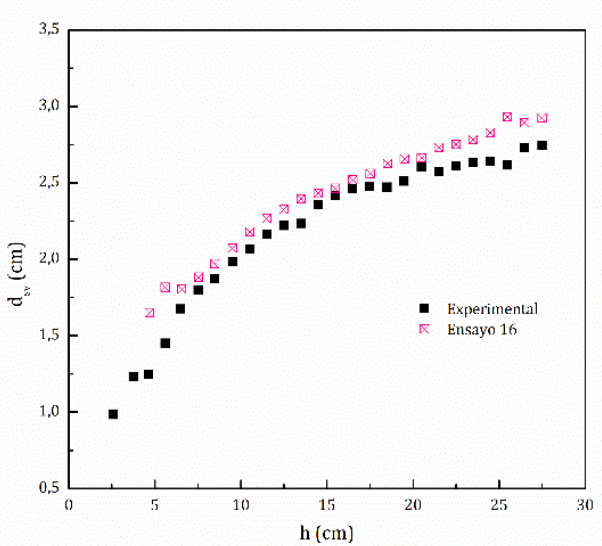

a

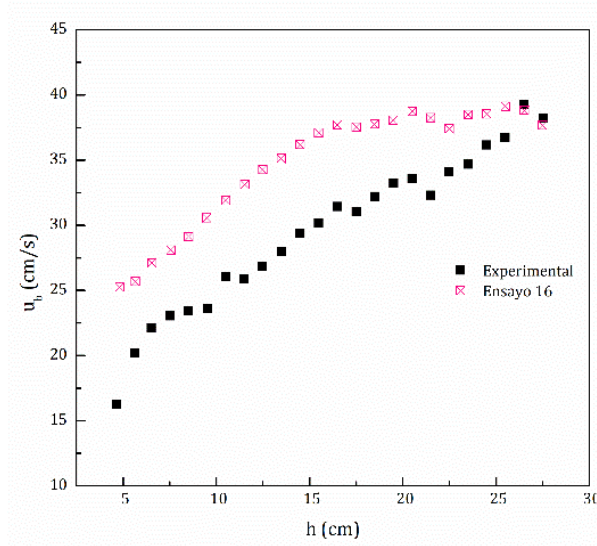

$\mathrm{b}$

Figura 3.30 - Valores de diámetro de burbuja (a) y velocidad de ascenso (b) en función de la altura con el modelo de arrastre de Syamlal O’Brien y coeficiente $\varphi=0,5$. 
Una vez finalizado este análisis, se consideraron los mismos parámetros para estudiar las velocidades $U$ restantes: 0,$40 ; 0,53$ y $0,62 \mathrm{~m} / \mathrm{s}$.

\subsection{1 - Diámetro $d_{s v}$}

En la Figura 3.31 se presentan los resultados para el diámetro de las burbujas en función de la altura desde el distribuidor, $h$, para las distintas velocidades estudiadas, y contrastadas con las correlaciones para su cálculo.
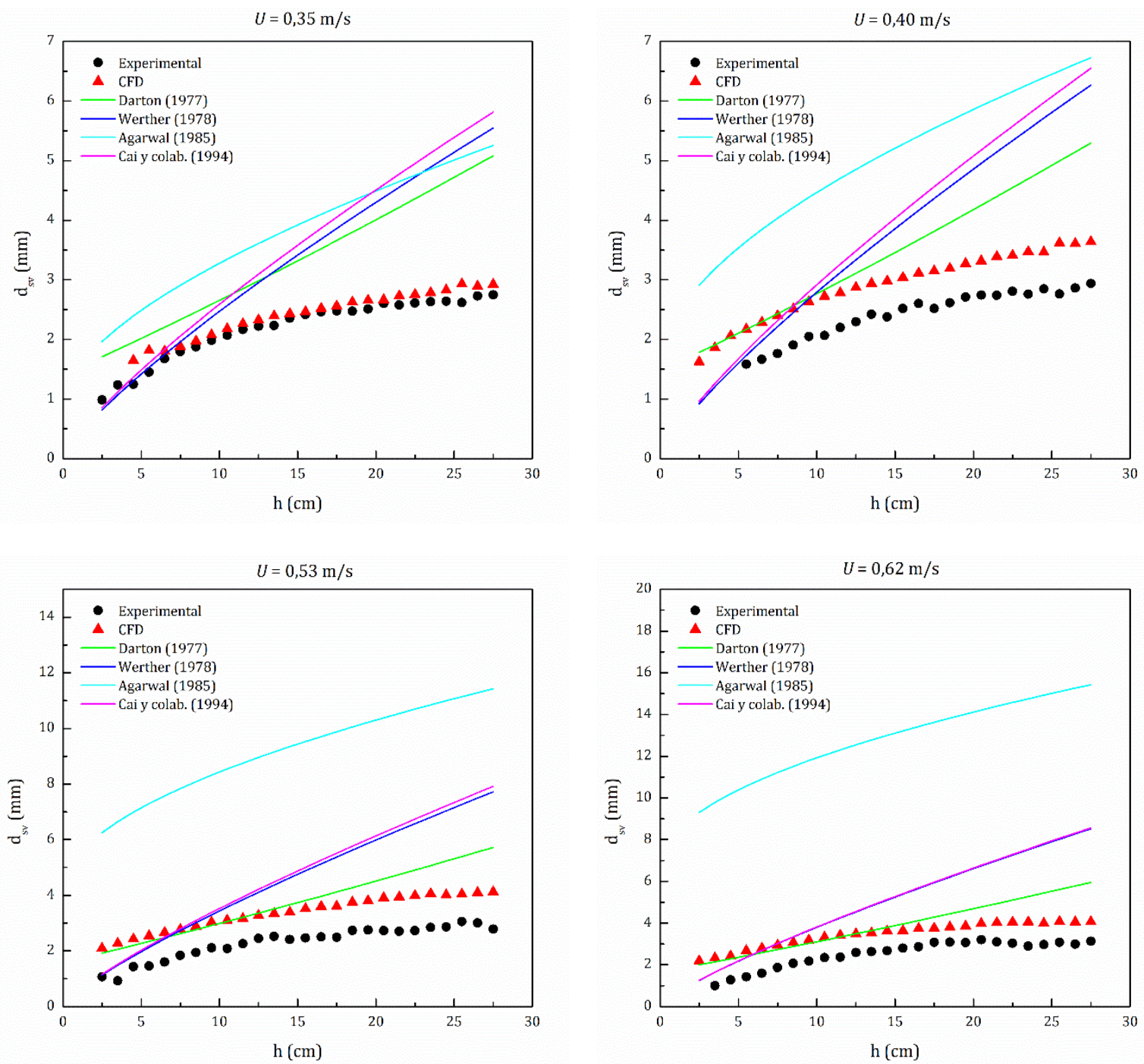

Figura 3.31 - Diámetros de burbuja en función de la altura sobre el distribuidor para resultados experimentales, CFD y correlaciones para las distintas velocidades $U$ estudiadas.

En todos los casos se observa que los diámetros aumentan conforme las burbujas ascienden en el lecho, de acuerdo con el fenómeno de coalescencia de las mismas, que predomina, en promedio, sobre el de splitting. Si bien para la velocidad $U=0,35 \mathrm{~m} / \mathrm{s}$ los resultados experimentales y mediante CFD son coincidentes, para las velocidades 
restantes la CFD sobreestima, en cierto grado, el valor de $d_{s v}$ respecto de los resultados experimentales.

A medida que aumenta la velocidad $U$, los resultados obtenidos mediante la correlación de Darton (1977), que tiene en cuenta la altura $h$, la velocidad de exceso del aire $\left(U-U_{m f}\right)$ y el tipo de distribuidor utilizado, se aproximan a los datos experimentales y los obtenidos mediante CFD. Las correlaciones de Cai y colab. (1994) y de Werther (1978) predicen valores próximos a los datos experimentales y predichos mediante CFD para alturas $h$ inferiores a $20 \mathrm{~cm}$. Ambas correlaciones, si bien consideran la velocidad de exceso del aire y la altura $h$, no tienen en consideración el fenómeno de splitting de las burbujas que tiene mayor peso en la parte superior del lecho. La correlación de Agarwal (1985), al considerar como única variable la altura $h$, se aleja progresivamente de los resultados a medida que aumenta la velocidad de exceso del aire.

\subsection{2 - Velocidad de ascenso $u_{b}$}

En la Figura 3.32 se presentan los resultados de velocidad de ascenso de las burbujas en función de la altura $h$, para una velocidad $U$ de 0,35 m/s. Como puede observarse, $u_{b}$ aumenta en función de $h$ y por lo tanto, en base al análisis realizado en la sección anterior, $u_{b}$ aumenta al incrementarse el diámetro $d_{s v}$ en acuerdo con los resultados reportados por Davidson y Harrison (1963) en base a la TDF.

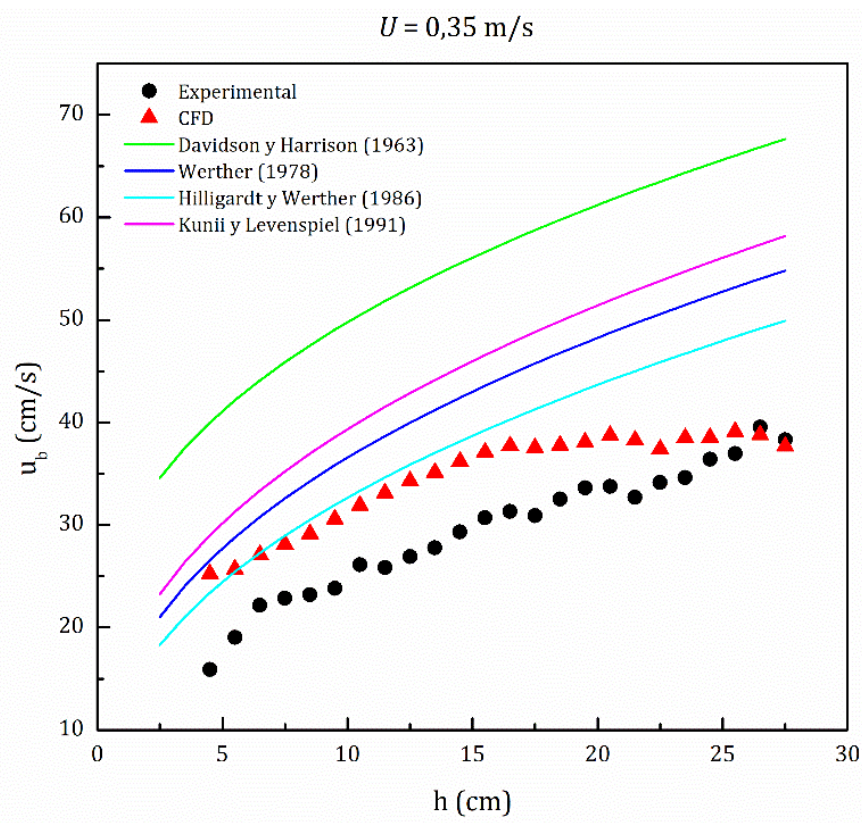

Figura 3.32 - Velocidad de ascenso de las burbujas en función de la altura desde el distribuidor para resultados experimentales, CFD y correlaciones. 
La tendencia de los datos obtenidos mediante CFD es de acompañar los datos experimentales con derivadas similares. Si bien las derivadas en ambos casos son similares a las correspondientes a las correlaciones presentadas, sólo la correlación de Hilligardt y Werther (1986) representa un buen ajuste de los datos en la zona inferior del lecho. La separación de los datos respecto de la correlación en la parte superior del lecho podría deberse al hecho de que la misma no tienen en cuenta el fenómeno de splitting entre las burbujas, de mayor ocurrencia en burbujas grandes, o la influencia de las paredes sobre la velocidad de ascenso.
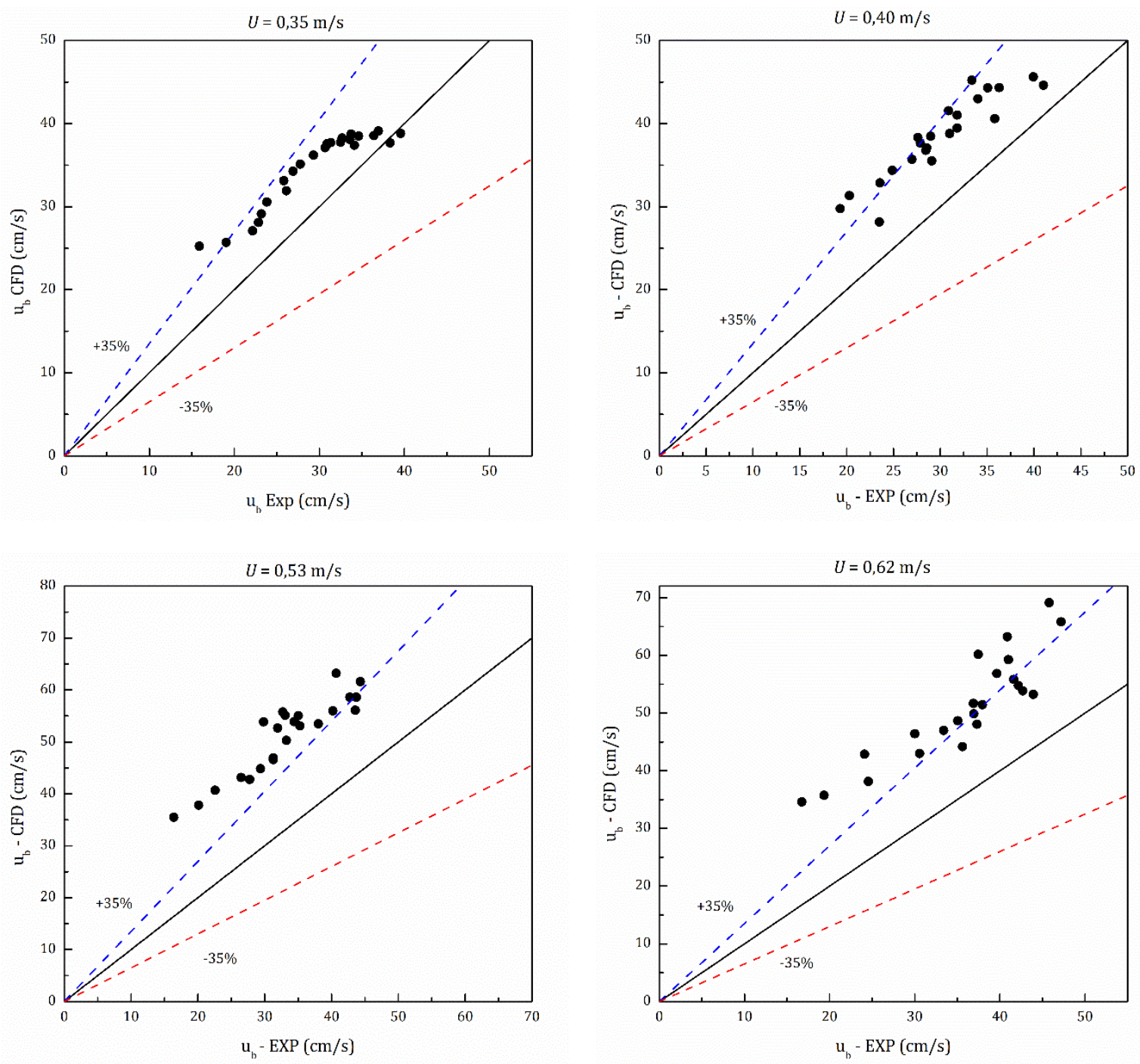

Figura 3.33- Relación entre datos experimentales y mediante CFD para la velocidad de ascenso de burbujas evaluadas a diferentes velocidades U.

Si se analizan los datos la velocidad de burbuja obtenidos mediante CFD con respecto a los resultados experimentales (Figura 3.33), puede observarse que la CFD, en las diversas configuraciones y estructuras de modelado analizados, tiende a sobreestimar 
la propiedad en estudio. Si bien el coeficiente $\varphi$ tiene en cuenta el rozamiento entre los sólidos y la pared, su influencia no resulta significativa al momento de analizar la velocidad de ascenso de las burbujas. Por el contrario, la introducción de la viscosidad friccional en las simulaciones genera una gran disminución de la velocidad de burbuja. Cabe destacar que ANSYS-Fluent cuenta también con el modelo de Johnson y Jackson (1987) para este parámetro, pero en la simulación llevada a cabo con estas condiciones no se logró la generación de burbujas.

\subsection{3 - Factor de forma $\omega$}

En la Figura 3.34 se presentan los resultados obtenidos para el factor de forma $\omega$. Puede observarse que las burbujas mantienen una forma pareja, prácticamente constante, a lo largo del lecho en todos los casos. Los resultados experimentales y mediante CFD tienden a volverse equivalentes conforme se incrementa la velocidad $U$. Sumado a ello, para las velocidades estudiadas más elevadas, en ninguno de los casos el valor de $\omega$ supera el valor de 0,7 , lo que podría deberse al gran desorden existente el lecho y al gran tamaño de las burbujas en esos casos.
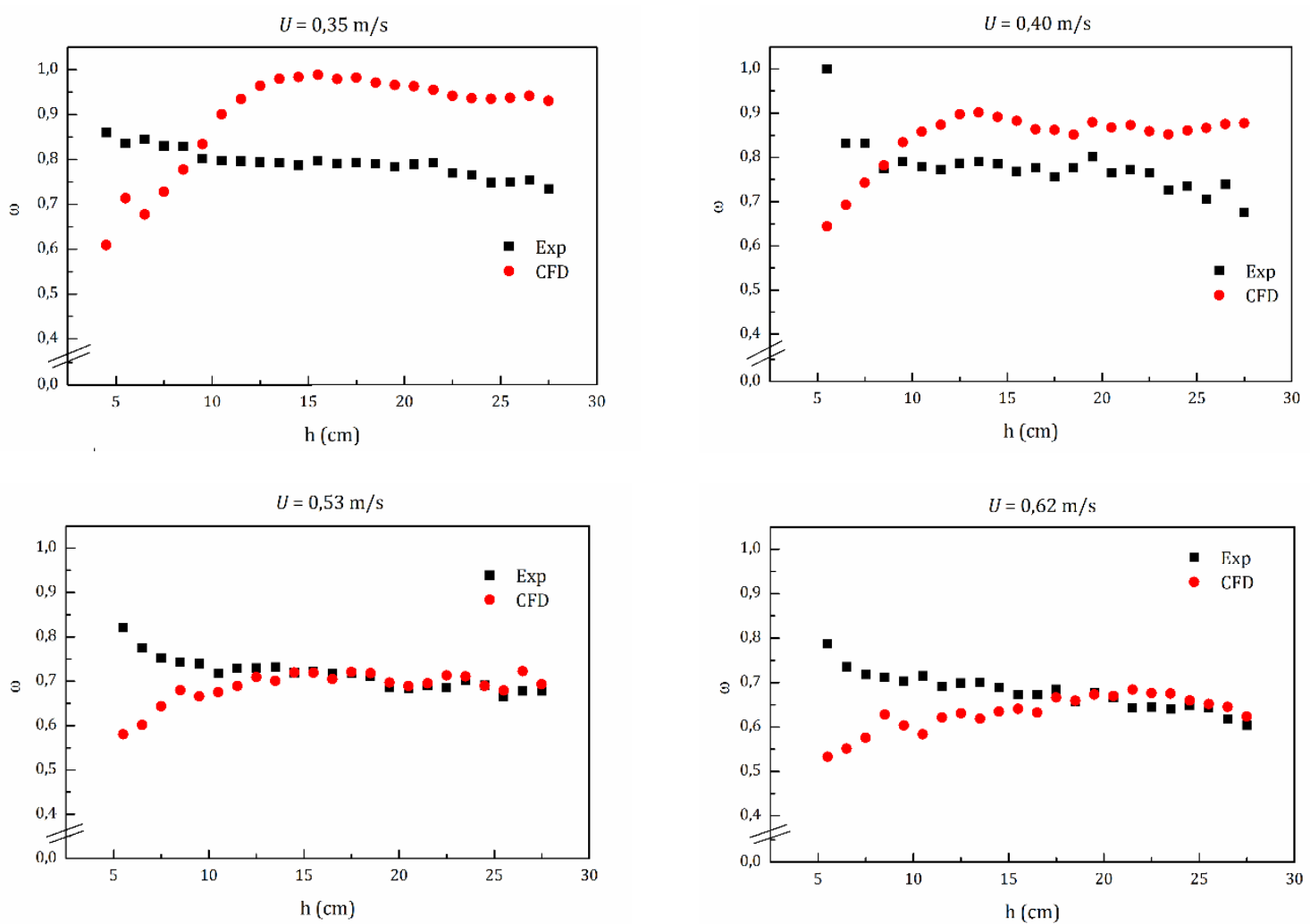

Figura 3.34 - Factor de forma experimental y CFD para las distintas velocidades U estudiadas. 


\subsection{4 - Frecuencia de burbujas}

En la Figura 3.35 se presentan los resultados (experimentales y mediante CFD) para la frecuencia de pulsación de burbujas. Adicionalmente, se incluyen los valores obtenidos mediante la aplicación directa de la TDF (ecuación 3.25) utilizando los valores de diámetro de burbuja resultantes de las experiencias CFD.
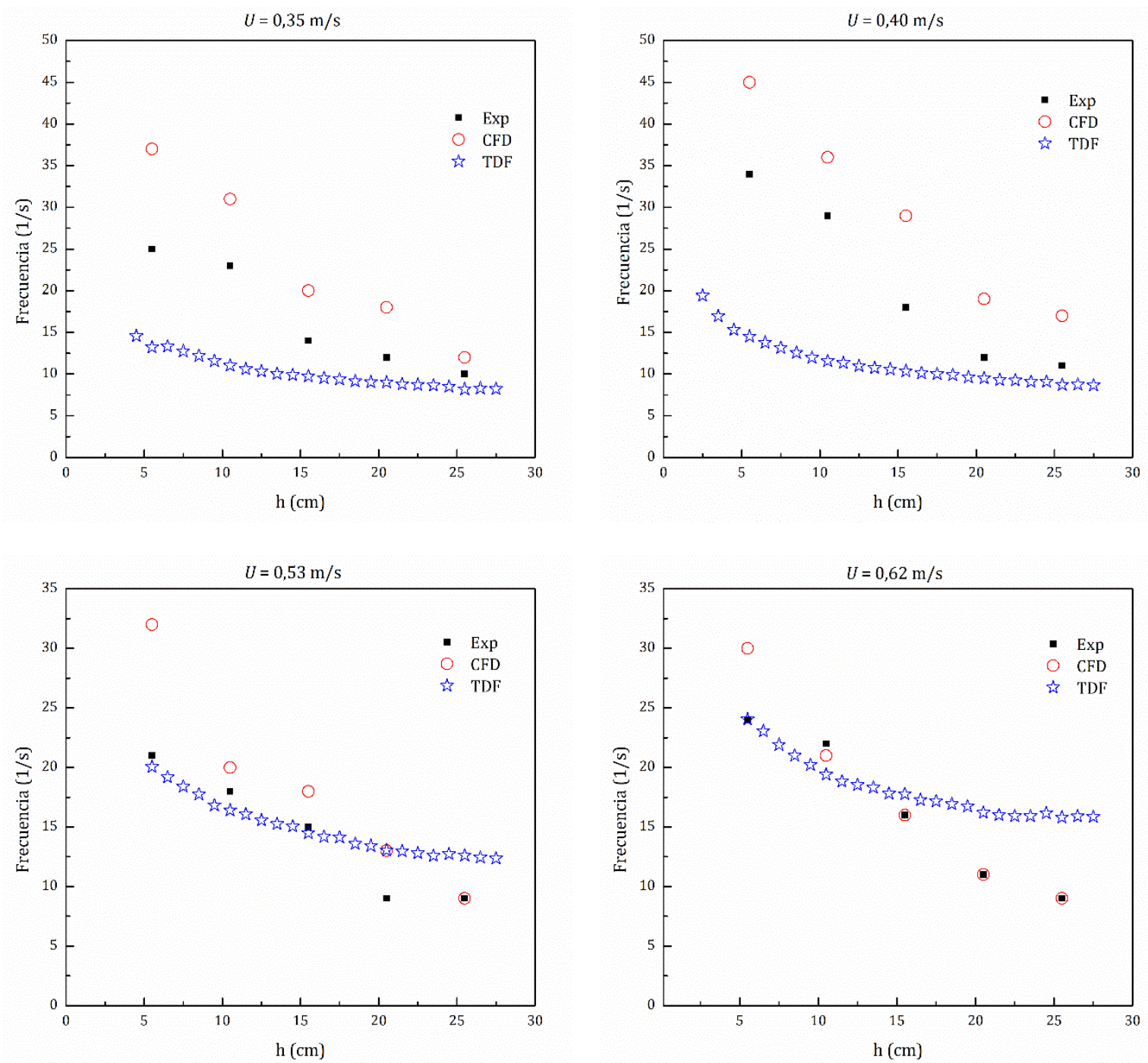

Figura 3.35 - Frecuencia de pulsación de burbujas observadas de modo experimental y mediante CFD, y aplicando la TDF para las distintas velocidades $U$ estudiadas.

En todos los casos se observa que la frecuencia disminuye conforme aumenta la posición vertical de las mismas en el lecho. Esto es consistente con el crecimiento de la burbuja conforme ascienden en el lecho (por la coalescencia predominante), determinando que la cantidad posible de las mismas sea menor. También se observa que 
al aumentar la velocidad $U$, las diferencias halladas entre valores experimentales y obtenidos mediante CFD disminuyen.

A bajas velocidades se observa que los valores obtenidos a partir de la TDF se alejan considerablemente se los resultados experimentales, indicando un pasaje considerable de gas a través de las burbujas, como by-pass.

\section{9 - EXTRAPOLACIÓN A UN LECHO CILÍNDRICO}

Con el objetivo de comparar el régimen de burbujeo bajo la influencia de distintas geometrías del lecho, se estudió, mediante CFD, la fase burbuja de un lecho de arena con geometría cilíndrica y con igual sección transversal y altura de sólidos que el lecho pseudo-2D analizado anteriormente. Se realizó la simulación con una velocidad superficial del aire de 0,35 m/s. Las dimensiones del dominio fueron 0,138 m de diámetro y 0,7 $\mathrm{m}$ de alto. La malla utilizada respetó el tamaño de celda validado $(0,0029 \mathrm{~m})$, alcanzando un total de 444312 elementos. Los parámetros de la simulación fueron los mismos que los utilizados en el Ensayo 16 (Tabla 3.6), que se llevó a cabo utilizando el coeficiente de arrastre de $\operatorname{SOB}$ у $\varphi=0,5$.

Para el estudio de la fase burbuja, se utilizaron las imágenes generadas en $C F D$ Post (programa incluido en el paquete ANSYS). A través de este programa se crearon superficies tridimensionales (llamadas de aquí en adelante "isosuperficies"). De igual modo que en las simulaciones del lecho pseudo-2D, se trabajó con un valor de $\alpha_{g}$ mayor o igual a 0,7 para la fase burbuja, y las isosuperficies se generaron cada 0,017 s.

\subsection{1 - Tratamiento de imágenes del lecho cilíndrico simulado}

Las isosuperficies generadas fueron luego exportadas para ser analizadas con el programa Autodesk 3DS MAX (Figura 3.36).

El programa Autodesk 3DS MAX permite seleccionar cada burbuja de manera individual, y con el uso de la herramienta Measure es posible obtener información del centro de masa, superficie y volumen de cada burbuja en $\mathrm{cm}, \mathrm{cm}^{2}$ y $\mathrm{cm}^{3}$ respectivamente. Los slugs de pared debieron tratarse de forma manual, debido a que el programa no arroja valores confiables cuando la burbuja está en contacto con la pared del lecho. 


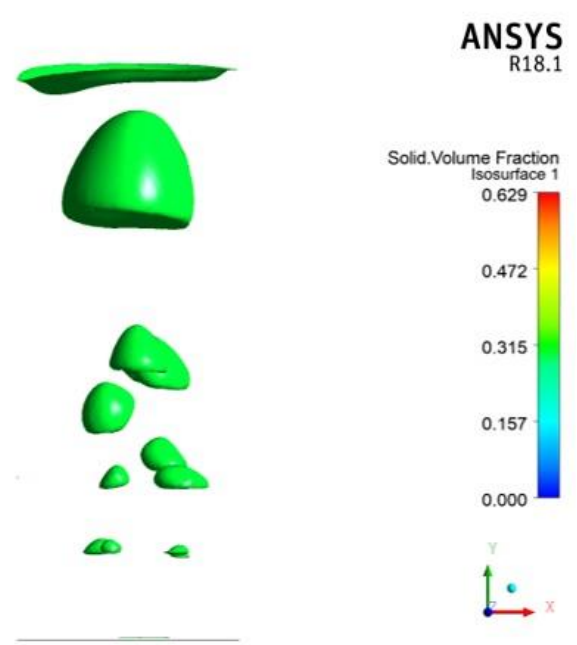

a

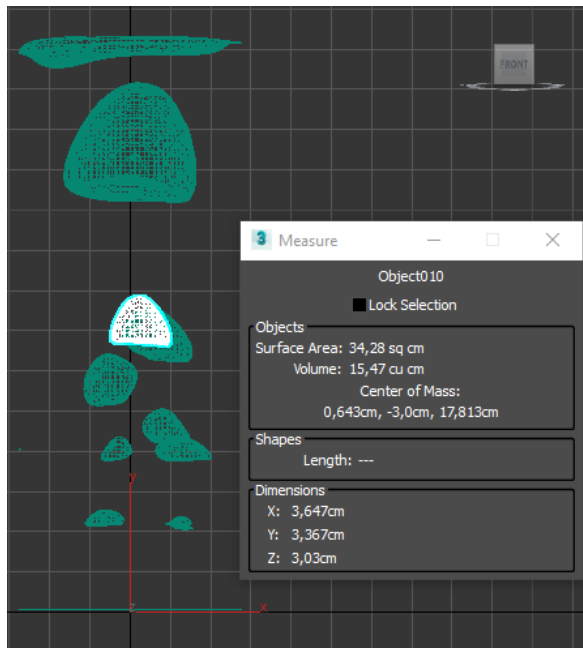

$\mathrm{b}$

Figura 3.36 -: a) Isosuperficie obtenida con CFD-Post y b) la misma imagen de isosuperficie importada en el programa Autodesk 3DS MAX. La ventana derecha de la imagen b indica información del centro de masa, superficie y volumen de la burbuja seleccionada en blanco.

Para realizar el escalado y que las dimensiones mencionadas guardaran correspondencia con los datos reales de la simulación, se utilizó como referencia el diámetro de la sección inferior del lecho.

Mediante un algoritmo desarrollado en el mismo programa, se exportaron los datos de centro de masa (en $\mathrm{x}, \mathrm{y}, \mathrm{z}$ ), superficie $\left(S_{b}\right)$ y volumen $\left(V_{b}\right)$ de todas las burbujas de cada imagen, compilados en un archivo de Excel (sección 3 del Anexo 3.III). Estos datos fueron posteriormente utilizados para el cálculo de diámetro y velocidad de las burbujas, utilizando un algoritmo desarrollado $M A T L A B$, similar al utilizado para el estudio de las burbujas en el lecho pseudo-2D (sección 4 del Anexo 3.III). En el caso del diámetro de burbuja, $d_{s v}$ (ecuación 3.35), el cálculo se llevó a cabo teniendo en cuenta los valores de $S_{b}$ y $V_{b}$ obtenidos. Para el cálculo de la velocidad de burbuja, se consideró una tercera dimensión ( $z$ ) para el desplazamiento, ya que en este caso las burbujas presentan movimiento lateral en los ejes $(x, z)$ y vertical en el eje $(y)$.

\subsection{2 - Resultados y discusión}

En la Figura 3.37 se presentan los valores de diámetro $d_{s v}$ obtenidos por CFD para el lecho cilíndrico (3D) y los correspondientes al lecho pseudo-2D tanto experimentales como CFD, junto con los calculados a partir de las correlaciones de Darton (1977), Werther (1978), Agarwal (1985) y Cai y colab. (1994), en función de la altura. Se 
observa que los diámetros aumentan conforme las burbujas ascienden en el lecho, de acuerdo con el fenómeno de coalescencia, que predomina, en promedio, sobre el de splitting. Sin embargo, los diámetros obtenidos para el lecho cilíndrico son superiores a los obtenidos en el caso pseudo-2D. Esta diferencia se atribuye a la geometría del lecho, que en el caso cilíndrico permite un mayor crecimiento de las burbujas.

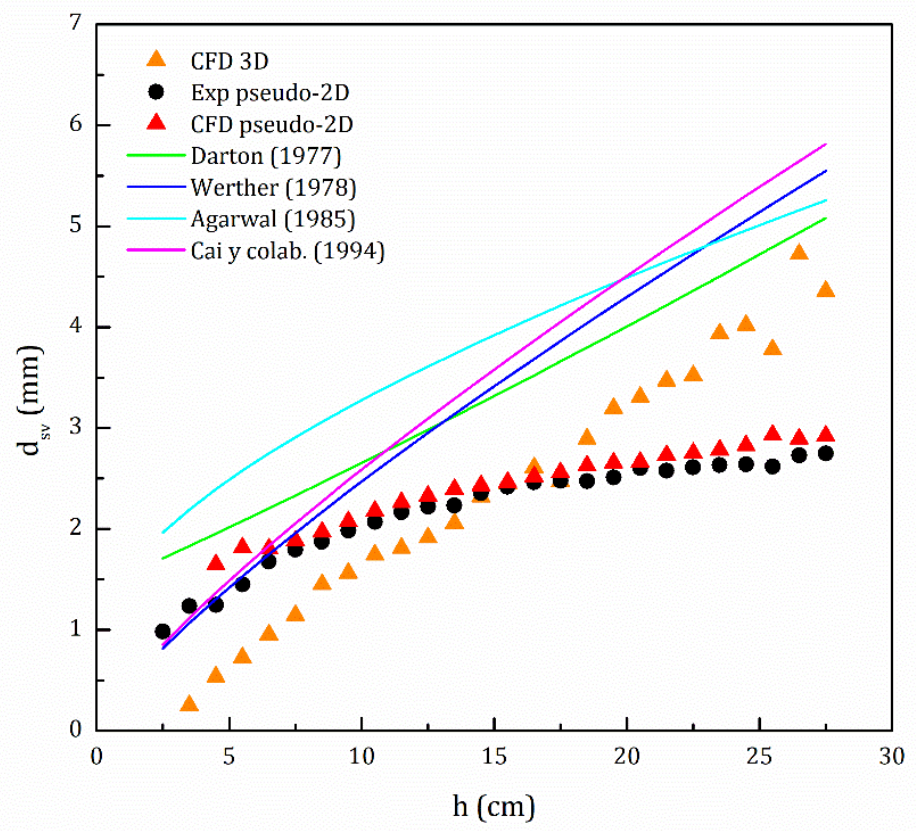

Figura 3.37 - Diámetro de burbuja en función de la altura sobre el distribuidor para simulaciones del lecho cilíndrico y pseudo-2D.

Si bien la correlación de Cai y colab. (1994) predice valores más cercanos a los resultados 3D para la zona cercana al distribuidor, en la parte superior del lecho la correlación de Darton (1977) presenta un mejor ajuste.

La Figura 3.38 muestra los resultados obtenidos para el estudio de la velocidad de ascenso de las burbujas, contrastados contra los valores obtenidos para la geometría pseudo-2D y las correlaciones de Davidson y Harrison (1963), Werther (1978), Hilligardt y Werther (1986) y Kunii y Levenspiel (1991). En este caso, dada la importancia del efecto retardador de las paredes en la velocidad de ascenso las burbujas (observado en la Figura 3.32) y teniendo en cuenta que se cumple con la restricción de $0,125<d_{b} / D<0,6$, se aplicó la correlación de Wallis (1969) para el cálculo de la velocidad de una burbuja individual: 


$$
u_{b r, \text { Wallis }}=\left(0,711 \sqrt{g d_{b}}\right) 1,2 e^{\left(-1,49 d_{b} / D\right)}
$$

Luego, esta velocidad fue considerada para el cálculo de la velocidad de ascenso de burbujas en el lecho mediante la correlación de Kunii y Levenspiel (1991):

$$
u_{b}=0,0032\left(\left(U-U_{m f}\right)+11,3 d_{b}^{0,5}\right) D^{1,35}+u_{b r, \text { Wallis }}
$$

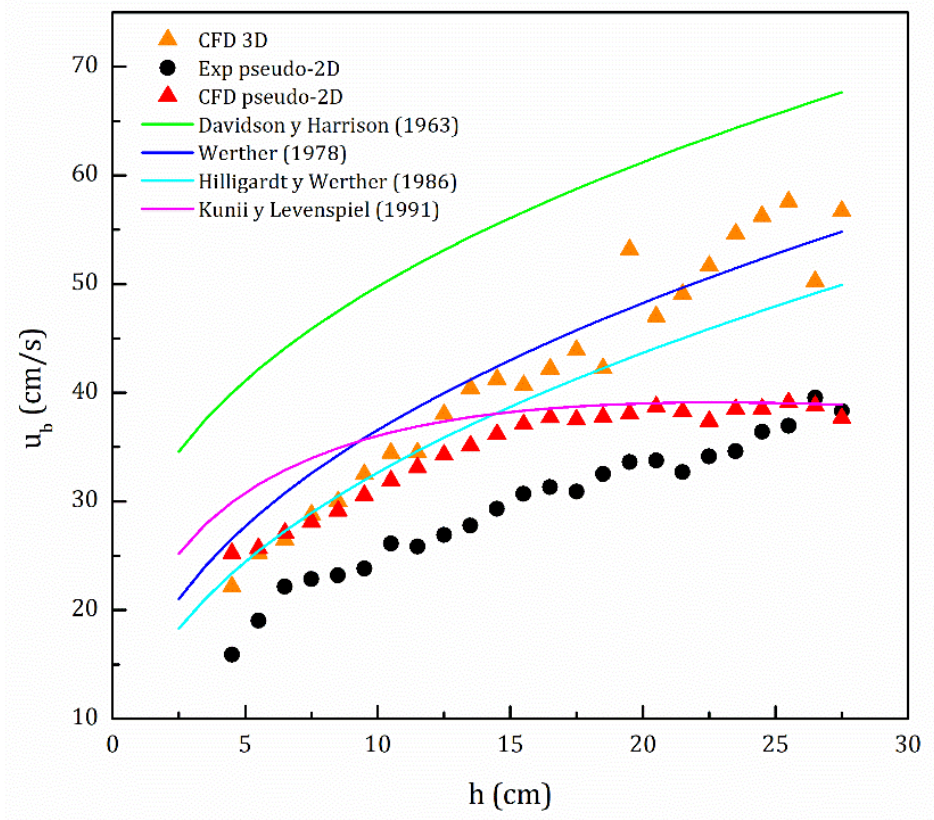

Figura 3.38 - Velocidad de ascenso de las burbujas en función de la altura desde el distribuidor.

Los valores obtenidos mediante la geometría cilíndrica tienen un muy buen ajuste con los obtenidos con la pseudo-2D en la parte inferior del lecho (hasta los $20 \mathrm{~cm}$ aproximadamente). En la parte superior del lecho se observa que los valores obtenidos para la geometría cilíndrica son superiores a aquéllos obtenidos para el lecho pesudo-2D. Las paredes del lecho tienen gran influencia sobre estos resultados, como lo demuestra la correlación de Kunii y Levenspiel (1991) combinada con la correlación de Wallis (1969). Sumado al efecto retardador causado por la fricción de las paredes, las limitaciones en el crecimiento de las burbujas presentadas en el lecho pseudo-2D generan burbujas de menor tamaño y por lo tanto más lentas. En la parte superior del lecho cilíndrico se observaron burbujas grandes que ascienden por el centro del lecho, sin tener contacto con las paredes y generando una velocidad promedio de ascenso superior al caso pseudo2D (donde el contacto de las burbujas con las paredes es constante). Las correlaciones de 
Werther (1978) y Hilligardt y Werther (1986), predicen de manera satisfactoria la velocidad de ascenso de las burbujas en el lecho cilíndrico.

En la Figura 3.39 se observa el ascenso de las burbujas en el lecho. En particular, una de las burbujas fue marcada de modo de poder seguir su movimiento.

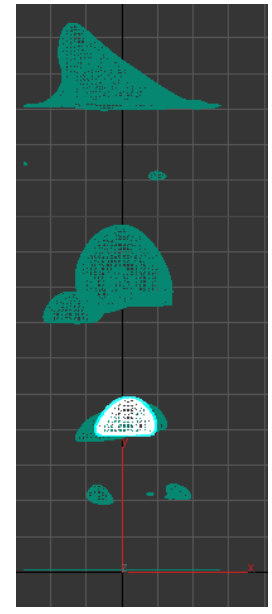

$\mathrm{t}=4,726 \mathrm{~s}$

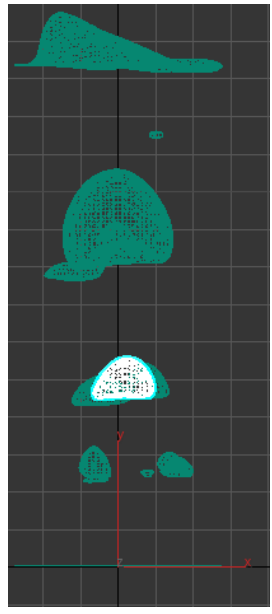

$\mathrm{t}=4,777 \mathrm{~s}$

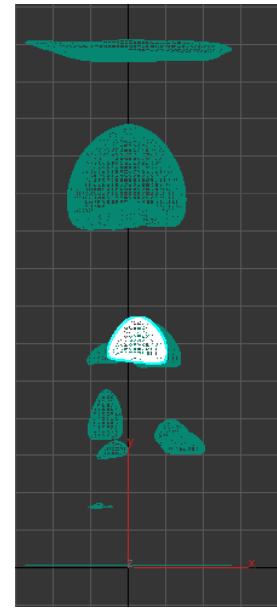

$\mathrm{t}=4,828 \mathrm{~s}$

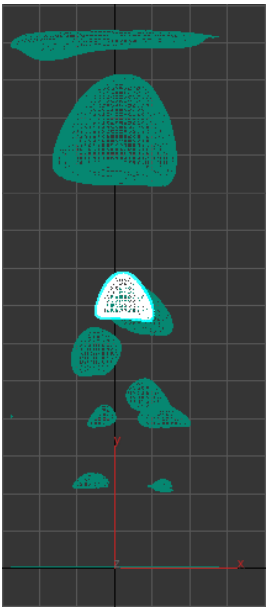

$\mathrm{t}=4,879 \mathrm{~s}$

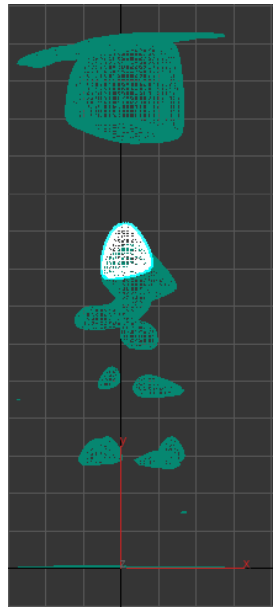

$\mathrm{t}=4,930 \mathrm{~s}$

Figura 3.39 - Imágenes secuenciales de ascenso de las burbujas en el lecho cilíndrico.

En la Figura 3.40 se muestran los valores obtenidos de la frecuencia de pulsación de las burbujas. En ambos casos se observa que la misma disminuye con la posición vertical, lo cual es razonable ya que, debido a la coalescencia, las burbujas aumentan su tamaño al ascender en el lecho y por consiguiente la cantidad posible de burbujas es menor. Se observa, además, que la frecuencia en el lecho pseudo-2D es levemente superior a la del lecho cilíndrico. Esto se debe a que la geometría cilíndrica permite un mayor crecimiento de las burbujas en las coordenadas $(\mathrm{x}, \mathrm{y}, \mathrm{z}) \mathrm{y}$, por lo tanto, puede haber una menor cantidad de burbujas. 


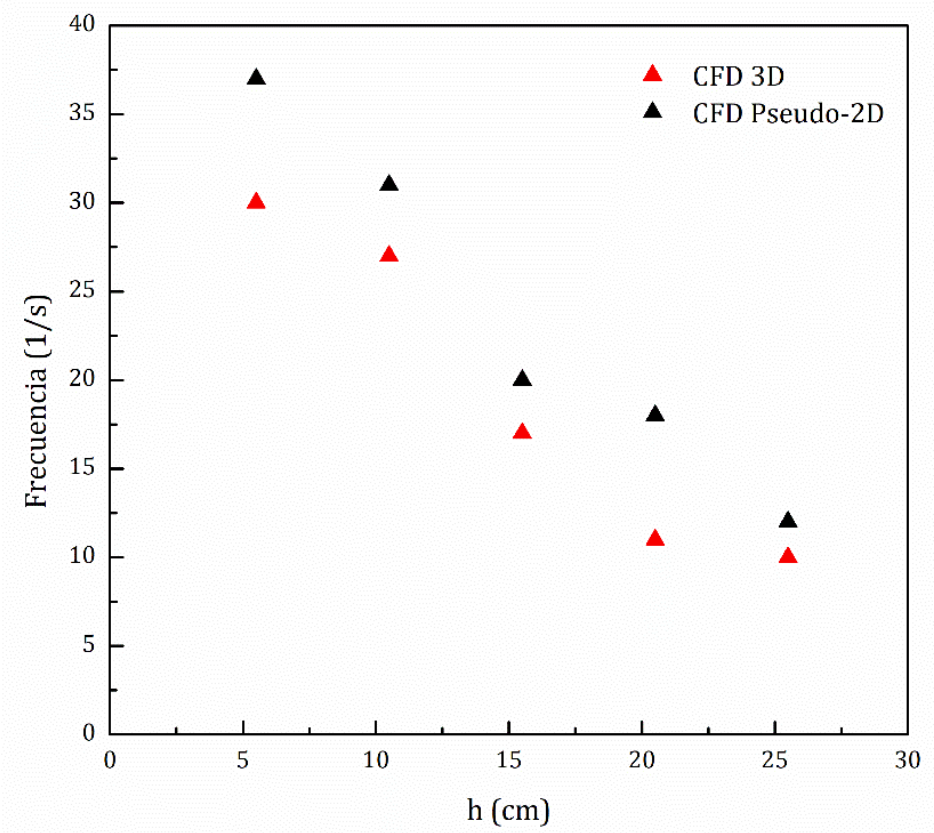

Figura 3.40 - Frecuencia de burbujas en función de h, para los lechos cilíndrico y pseudo-2D.

Finalmente, se analizó en el lecho cilíndrico la esfericidad de las burbujas definida como la relación entre el diámetro de una esfera cuyo volumen es equivalente al de la burbuja $\left(d_{v}\right)$ y el de una esfera con igual área $\left(d_{s}\right)$, ambas elevadas al cuadrado.

$$
\text { Esfericidad }=\left(\frac{d_{v}}{d_{s}}\right)^{2}
$$

De este análisis, se observa que las burbujas mantienen una forma pareja y prácticamente constante a lo largo del lecho (Figura 3.41).

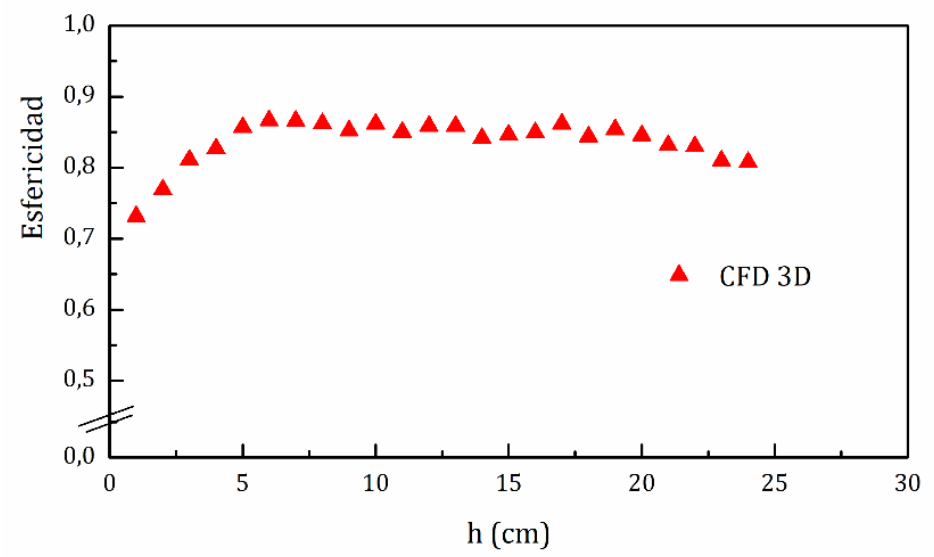

Figura 3.41 - Esfericidad de burbujas en lecho cilíndrico. 


\subsection{0 - ESTUDIO EXPERIMENTAL Y CFD DE UN LECHO FLUIDIZADO DE BASE CÓNICA CON PARTÍCULAS GELDART D}

Con el fin de estudiar el comportamiento de lechos con partículas Geldart D en régimen burbujeante, se realizó un estudio experimental y mediante CFD con partículas de urea, en un lecho fluidizado granulador en escala piloto instalado en PLAPIQUI (CONICET - Universidad Nacional del Sur). En el Anexo 3.I del presente capítulo se describe el equipo experimental, el material utilizado, la metodología aplicada y los resultados obtenidos para las determinaciones experimentales y las simulaciones CFD.

\subsection{1 - CONCLUSIONES DEL CAPÍTULO 3}

Se realizó el estudio de un lecho de partículas Geldart B (arena) fluidizadas por aire, centrando el análisis en el estudio detallado de la fase burbuja y la capacidad del software ANSYS-Fluent de evaluar las diferentes magnitudes que determinan el comportamiento fluidodinámico del lecho y en particular de dicha fase.

Se analizaron los parámetros pérdida de carga y velocidad de mínima fluidización, experimentalmente y mediante simulaciones desarrolladas por CFD. Pudo observarse, para los valores de ambos parámetros, una muy buena concordancia entre ambas metodologías.

Se estudió la influencia de los parámetros y modelos definidos en las simulaciones (modelo de arrastre, viscosidad friccional y coeficiente de especularidad $\varphi$ ), sobre los resultados obtenidos para partículas Geldart B. Este estudio puso de manifiesto que los modelos utilizados tienen mayor influencia en el análisis de la fase burbuja que en el cálculo de la pérdida de carga. En base al análisis de las Figuras 3.26 y 3.28, se seleccionó el modelo de arrastre de SOB, el coeficiente de especularidad $\varphi=0,5$ y decidió trabajar sin viscosidad friccional. Una vez efectuadas las simulaciones, en el equipo con geometría pseudo-2D y para distintas velocidades superficiales de gas $U$, se llevó a cabo la caracterización de la fase burbuja evaluando diámetro, velocidad y frecuencia de burbuja en función de la altura del lecho. Los resultados evidenciaron una buena concordancia entre los valores experimentales y los calculados por CFD.

Los diámetros obtenidos experimentalmente y por CFD fueron comparados con los valores calculados a partir de las correlaciones de Darton (1977), Werther (1978), 
Agarwal (1985) y Cai y colab. (1994). La existencia del fenómeno de coalescencia de las burbujas puede verificarse mediante los resultados de frecuencia de burbuja en función de la altura del lecho. Las velocidades calculadas de ascenso de las burbujas fueron comparadas con las correlaciones de Davidson y Harrison (1963), Werther (1978), Hilligardt y Werther (1986) y Kunii y Levenspiel (1991). Si bien el ajuste con las correlaciones es bueno, las velocidades presentan mayores discrepancias, entre los resultados experimentales y los obtenidos mediante CFD, que los diámetros.

Los parámetros seleccionados para las simulaciones se utilizaron para realizar la simulación en un lecho cargado con las mismas partículas, pero con geometría cilíndrica. Si bien los resultados obtenidos siguen las mismas tendencias que el lecho pseudo-2D, se observan ciertas discrepancias debidas al cambio de geometría, ya que las burbujas tienen mayor sección disponible para poder crecer.

Además, se realizó el estudio de un lecho fluidizado de geometría cónica cargado con partículas Geldart D (Anexo 3.I). Se aplicaron dos métodos alternativos para la evaluación del diámetro de burbujas y se concluyó que con ambas metodologías se puede evaluar el diámetro de las burbujas en función de la altura del lecho y la velocidad de ascenso de las mismas, sin embargo, el método A (equivalente al utilizado para las partículas Geldart B) es más apropiado para el sistema estudiado.

Finalmente, es importante mencionar que se desarrollaron cuatro programas para el análisis de resultados, en los entornos MATLAB y Autodesk 3DSMax, que permitieron analizar un gran volumen de datos en tiempos muy inferiores a los necesarios cuando el análisis se lleva a cabo de forma manual.

A partir de los resultados obtenidos, se puede concluir que el modelado CFD constituye una poderosa herramienta para el análisis y estudio minucioso de lechos burbujeantes de los pares arena-aire y urea-aire. 


\section{ANEXO 3.I}

\section{ESTUDIO DE LA FLUIDIZACIÓN DE PARTÍCULAS DE UREA}

El grupo de partículas Geldart D está conformado por partículas de diámetro superior a 0,5 mm y/o densas, como por ejemplo granos de café, porotos, arvejas, lentejas, partículas de carbón a gasificar, urea granulada y pellets de biomasa (Geldart, 1973). Con este tipo de sólidos, el gas suele canalizarse y se requieren velocidades superficiales de gas elevadas para alcanzar la condición de fluidización. En estos casos, el régimen burbujeante puede lograrse en forma apropiada utilizando lechos de poca altura, lo que permite la operación con velocidades superficiales de gas moderadas. Una alternativa para evitar el slugging consiste en diseñar la parte superior del lecho con área creciente. Por esta razón, frecuentemente los equipos poseen geometría cónica, como el empleado en este trabajo.

Si bien en la literatura abierta se han reportado trabajos sobre la caracterización de la fase burbuja de lechos fluidizados por CFD, éstos se refieren principalmente a las partículas Geldart A y B, observándose una carencia de información referida a la caracterización fluidodinámica de lechos fluidizados de partículas Geldart D.

Lungu y colab. (2016) realizaron simulaciones, utilizando el modelo EulerianoEuleriano con los modelos de arrastre de Gidaspow y Syamlal-0'Brien, de un lecho fluidizado burbujeante de partículas Geldart D. Los datos experimentales fueron tomados de un problema desafío propuesto por el National Energy Technology Laboratory (NETL), con el objetivo de validar los parámetros de simulación. Los autores analizaron tres velocidades superficiales de gas $\left(2 U_{m f}, 3 U_{m f}\right.$ y $\left.4 U_{m f}\right)$ y analizaron diversas variables de interés, concluyendo que ambos modelos sobre-estiman la pérdida de carga en el lecho, mientras que el modelo de Syamlal O'Brien ofrece mejores resultados para la velocidad axial de las partículas. Agrawal y colab. (2018) estudiaron el efecto de los distintos modelos de arrastre en las simulaciones de partículas Geldart 
D mediante simulaciones CFD-DEM. Los resultados experimentales también fueron tomados del problema desafío del NETL y analizaron tres velocidades superficiales $\left(1,25 U_{m f}, 1,5 U_{m f} y 2 U_{m f}\right)$. Entre los modelos de arrastre analizados, se encuentran los de Gidaspow y Syamlal O'Brien.

Venier y colab. (2020) realizaron un análisis cualitativo del burbujeo en un lecho pseudo-2D cargado con partículas de urea y compararon los resultados obtenidos experimentalmente y mediante CFD utilizando los programas comerciales ANSYSFluent y OpenFOAM. Los autores reportaron buena concordancia en los análisis llevados a cabo.

Como se mencionó previamente en el cuerpo principal de la tesis (Capítulo 3), Acosta-Iborra y colab. (2011) realizaron un análisis experimental y simularon en 3D un lecho cilíndrico de partículas Geldart B con el objeto de caracterizar la fase burbuja, aplicando un método basado en el análisis de frecuencias de sondas ópticas en puntos específicos del lecho. En el presente trabajo, se busca utilizar la técnica desarrollada aplicándola al estudio de partículas Geldart D y compararla con los resultados obtenidos mediante el análisis de imágenes tridimensionales obtenidas por CFD.

En este Anexo se presenta el estudio fluidodinámico de un lecho fluidizado cónico de partículas tipo Geldart D. Se realizaron determinaciones la curva de pérdida de carga y de velocidad $U_{m f}$ de modo experimental y mediante CFD. Para el estudio de la fase burbuja, se aplicaron dos métodos alternativos aplicando la técnica de CFD y luego se compararon los resultados obtenidos.

\section{A3.I.1 - EQUIPAMIENTO EXPERIMENTAL}

El equipo de lecho fluidizado de geometría cónica utilizado se encuentra instalado en PLAPIQUI (CONICET-UNS). Los datos experimentales utilizados en esta sección fueron obtenidos por integrantes del grupo de investigación en Ingeniería de Reactores y Procesos Químicos (GIRPQ) del PROBIEN (CONICET-UNCo) durante dos estadías realizadas en el marco de un trabajo en cooperación con el grupo de Tecnología de Partículas del PLAPIQUI que dirige la Dra. V. Bucalá. 
El estudio se centró en el análisis de pérdida de carga y velocidad de mínima fluidización.

El equipo experimental (Figura A3.I.1) consiste en un lecho cónico construido en acero inoxidable de $0,7 \mathrm{~m}$ de altura y diámetros inferior y superior de 0,15 y $0,3 \mathrm{~m}$ respectivamente; el ángulo del cono es $\theta=12,23^{\circ}$.

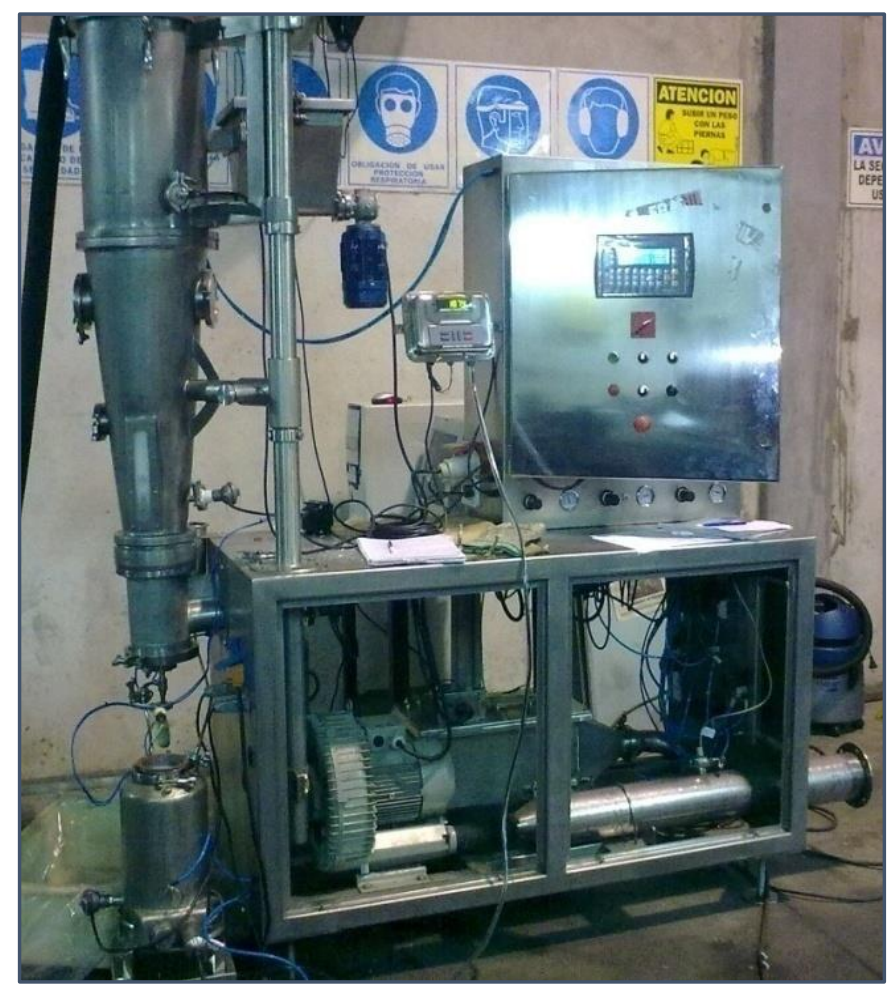

Figura A3.I.1 - Equipo de granulación de urea en escala piloto, ubicado en las instalaciones de PLAPIQUI (CONICET-Universidad Nacional del Sur), Bahía Blanca.

El lecho fluidizado cuenta con dos tomas de presión, una inferior ubicada sobre el distribuidor de gas y otra colocada en la parte superior a $0,37 \mathrm{~m}$ del distribuidor y posee dos ventanas laterales de acrílico (Figura A3.I.2 A), que permiten observar tanto el funcionamiento, como la expansión del lecho y la formación de burbujas sobre la pared del mismo. El distribuidor de gas es un plato perforado con 148 orificios circulares de $3 \mathrm{~mm}$ de diámetro, en arreglo cuadrado (Figura A3.I.2 B), por encima de éste se instaló una malla metálica muy fina, que evita la pérdida de partículas de menor tamaño. Como la función del equipo es la granulación de urea, el lecho-granulador cuenta también con una boquilla de inyección de urea liquida, que está ubicada en el 
centro del distribuidor de gas, termocuplas para la medición de temperaturas y demás instrumental necesario para el proceso de granulación.
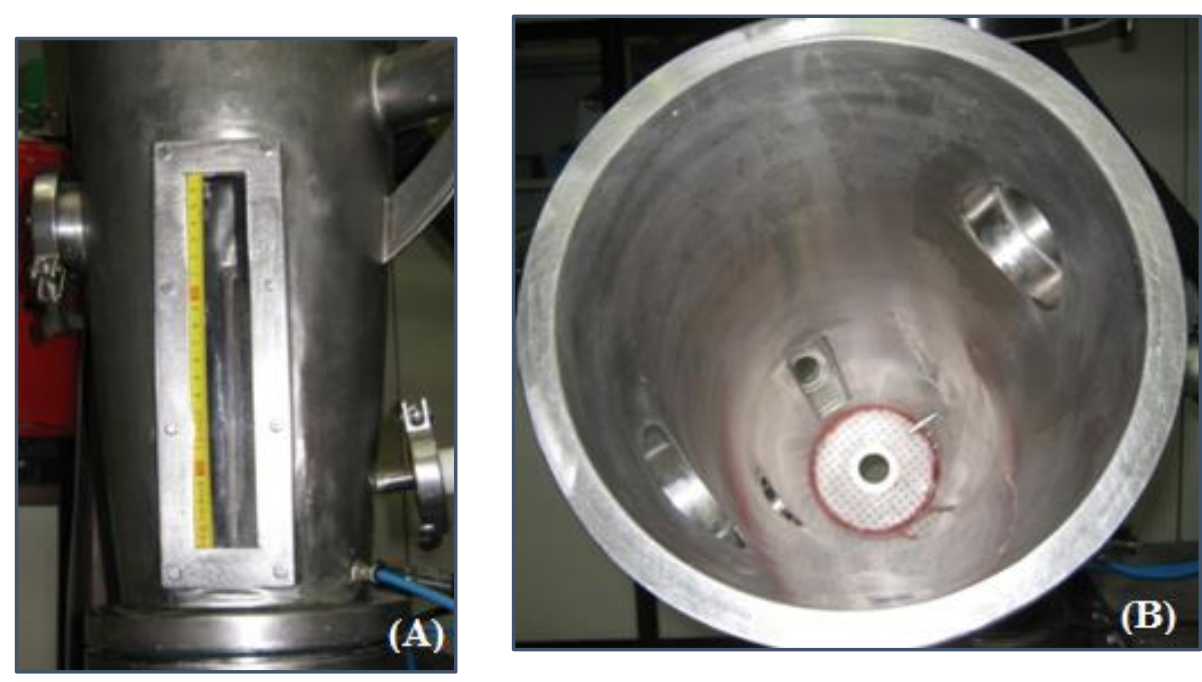

Figura A3.I.2 - (A) Vista frontal del granulador, donde se pueden apreciar una de las ventanas. (B) Vista superior del granulador que permite visualizar el distribuidor.

\section{A3.I.2 - MODELADO POR CFD}

Para la resolución de las ecuaciones diferenciales se utilizó el software ANSYSFluent 18.1. Se trabajó en 3D, con una malla de tipo estructurado, que fue validada con el objeto de determinar el tamaño óptimo que permitiera representar adecuadamente los fenómenos físicos sin incrementar innecesariamente el tiempo de cómputo. La malla seleccionada para llevar a cabo las simulaciones consta de 144.534 elementos.

Al igual que en las simulaciones de los sólidos Geldart B, se utilizó el modelo multifásico Euleriano-Euleriano, con ecuaciones basadas en la Teoría Cinética para Flujo Granular. Zambon y colab. (2011) estudiaron la fluidización de partículas de urea por CFD y reportaron que el modelo de arrastre de Syamlal O'Brien (SOB) permite reproducir adecuadamente la expansión del lecho y la velocidad $U_{m f}$. Asimismo, en el análisis de las imágenes presentado por Agrawal y colab. (2018), puede verse claramente que el modelo de arrastre de Syamlal O'Brien es el que mejor representa la formación y erupción de burbujas a las velocidades estudiadas. En consecuencia, se 
decidió utilizar el modelo de arrastre SOB. En la Tabla A3.I.1 se resumen los parámetros empleados en las simulaciones del lecho y las condiciones operativas aplicadas.

El tiempo de cómputo para cada simulación en la condición de lecho fluidizado fue de 48 horas, para representar la evolución transitoria a lo largo de 12 segundos. Al analizar los resultados, los datos de los primeros tres segundos fueron descartados con el fin de eliminar los efectos iniciales, en acuerdo con lo reportado por Asegehegn y colab. (2011).

Tabla A3.I.1 - Parámetros utilizados en la simulación. Referencias: SOB: Syamlal y O’Brien (1989), LUN: Lun y colab. (1984).

\begin{tabular}{|l|c|}
\hline Parámetro & Valor \\
\hline$\rho_{s}\left[\mathrm{~kg} / \mathrm{m}^{3}\right]$ & 1333,8 \\
\hline$\rho_{g}\left[\mathrm{~kg} / \mathrm{m}^{3}\right]$ & 1,2269 \\
\hline$\mu[\mathrm{Pa} \cdot \mathrm{s}]$ & $1,923 \mathrm{e}-0,5$ \\
\hline$d_{p}[\mathrm{~mm}]$ & 0,0026 \\
\hline$H_{o}[\mathrm{~m}]$ & 0,121 \\
\hline$\alpha_{s}$ & 0,6 \\
\hline Paso de tiempo [s] & 0,001 \\
\hline $\begin{array}{l}\text { Máx. Iteraciones } / \text { paso } \\
\text { de tiempo }\end{array}$ & 20 \\
\hline Criterio de convergencia & 0,001 \\
\hline Condiciones de borde & Valor \\
\hline Wall (aire) & No slip \\
\hline Wall (sólido) & No slip \\
\hline Velocity inlet (aire) [m/s] & 1,9 - 3,9 \\
\hline
\end{tabular}

\begin{tabular}{|l|c|}
\hline \multicolumn{1}{|c|}{ Parámetro } & Valor \\
\hline Viscosidad granular $\left(\mu_{s, \text { kin }}-\mu_{s, \text { col }}\right)$ & SOB \\
\hline Viscosidad granular granel $\left(\lambda_{s}\right)$ & LUN \\
\hline Viscosidad friccional $\left(\mu_{s, f r}\right)$ & None \\
\hline Temperatura granular & Algebraic \\
\hline Presión de sólidos $\left(\nabla P_{S}\right)$ & SOB \\
\hline Distribución radial & SOB \\
\hline Módulo de elasticidad $(G)$ & Derived \\
\hline $\begin{array}{l}\text { Límite de empaquetamiento } \\
\left(\alpha_{s, \text { max }}\right)\end{array}$ & Cte: 0,63 \\
\hline Fuerza de masa virtual & None \\
\hline Modelo de arrastre & SOB \\
\hline Fuerza de sustentación & None \\
\hline Coeficiente de restitución $\left(e_{S S}\right)$ & Cte: 0,9 \\
\hline
\end{tabular}

\section{A3.I.3 - CURVA DE FLUIDIZACIÓN}

En primera instancia se procedió a realizar las simulaciones que permitieran replicar la curva de fluidización experimental mediante CFD. Se realizó la validación de la malla, con el tamaño seleccionado se realizaron las corridas para construir la curva de fluidización (Figura A3.I.3) y finalmente se calculó la velocidad $U_{m f}$, que se comparó con los valores experimentales. Para la obtención de la curva de fluidización y posterior cálculo de la velocidad $U_{m f}$, las experiencias se realizaron siguiendo los lineamientos de la norma ASTM D7743-12. En el caso del análisis mediante CFD, se realizaron simulaciones en estado estacionario y en régimen transitorio. En ambos casos, la 
velocidad $U_{m f}$ se obtuvo mediante la intersección de las curvas correspondientes a lecho fijo y fluidizado, tal como se describió en el Capítulo 3, sección 6.

El valor experimental de la velocidad $U_{m f}$ es de $1,17 \mathrm{~m} / \mathrm{s}$, por lo que el valor obtenido mediante CFD presenta un error relativo de 2,6\%. En la Figura A3.I.3 también puede observarse un muy buen ajuste de los valores de CFD respecto de los experimentales para la pérdida de carga, con un error promedio de $2,5 \%$ para lecho fijo y $3,8 \%$ para la zona fluidizada.

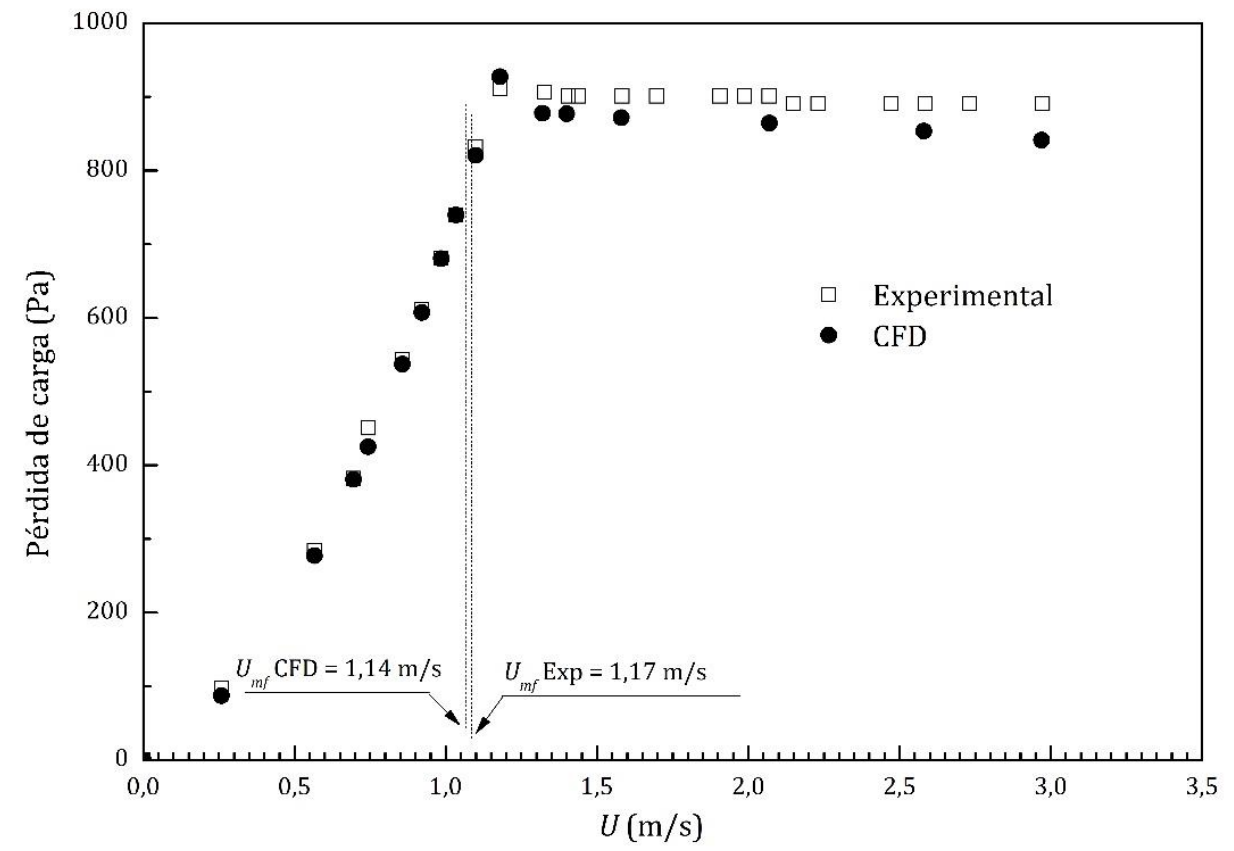

Figura A3.I.3 - Curva de fluidización y velocidad de mínima fluidización.

\section{A3.I.4 - CARACTERIZACIÓN DE LA FASE BURBUJA}

Si bien las características del equipo utilizado no permitían realizar un estudio por imágenes durante las determinaciones experimentales, sí se estudió el comportamiento correspondiente de la fase burbuja por fluidodinámica computacional, en las condiciones de las experiencias llevadas a cabo.

Para caracterizar la fase burbuja, se aplicaron y compararon dos métodos de análisis alternativos (se denominarán métodos A y B), ambos basados en la simulación 
del lecho por CFD. Cabe destacar que se consideraron burbujas aquéllas zonas en las que la fracción volumétrica de sólidos es inferior o igual a 0,2 (valor establecido como umbral).

Método A: Se realizaron las simulaciones por CFD y se generaron imágenes tridimensionales de la fase burbuja correspondientes a distintos tiempos de simulación. Dichas imágenes fueron exportadas al software Autodesk 3DS Max para aislar cada burbuja y obtener datos de su área, volumen y centro de masa. Con esta información, se calculó el diámetro de las burbujas promediado en el tiempo, en función de la altura del lecho y se evaluó la velocidad de ascenso de las mismas.

Método B: A partir de lo reportado por Acosta-Iborra y colab. (2011), en la simulación se incorporaron monitores de fracción de volumen de sólidos y se distribuyeron en el lecho, espaciados en forma vertical a $1 \mathrm{~cm}$ uno de otro y repitiendo el esquema en los cuatro cuadrantes (un monitor es una herramienta del software que permite registrar los valores de una variable seleccionada, en una posición especificada, durante la simulación). Cuando una burbuja atraviesa un monitor, la lectura cae por debajo de 0,2 . Con esta metodología, se evaluó la velocidad de ascenso de la burbuja como la relación existente entre el espaciado de los monitores y el tiempo que demora la burbuja en atravesarlos. El pierced length (y) de las burbujas se calculó como la relación entre su velocidad de ascenso y su tiempo de pasaje (tiempo durante el cual el monitor de fracción volumétrica de sólidos arroja un valor inferior a 0,2). Finalmente se calculó el diámetro de una burbuja de volumen equivalente $\left(d_{v}\right)$ en base a dicho valor.

Para realizar el análisis mediante el Método A, se siguió un procedimiento equivalente al descripto en el Capítulo 3, sección 9. Se registraron 10 archivos de datos por segundo, a partir de los cuales se generaron las iso-superficies (Figura A3.I.4), con una fracción volumétrica de sólidos inferior o igual a 0,2 . 

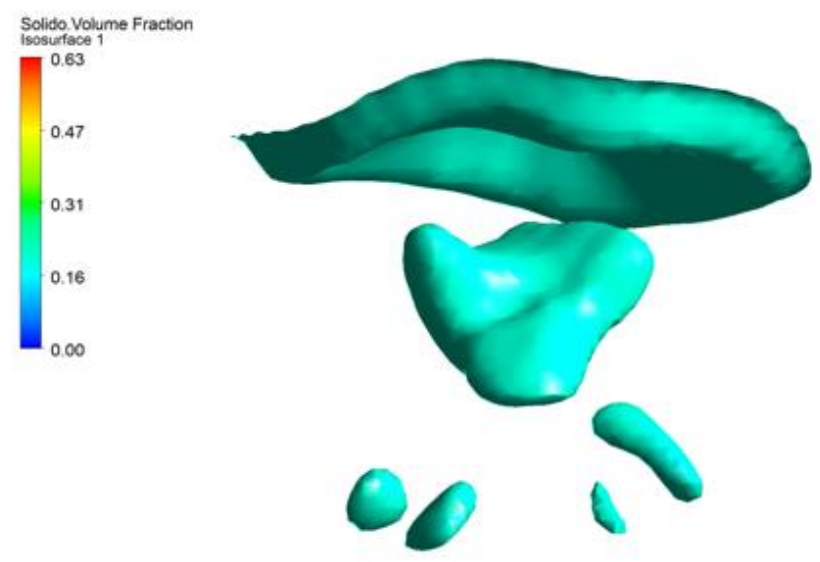

ANSYS

R18.1

Figura A3.I.4 - Iso-superficie obtenida utilizando ANSYS CFD Post versión 18.1.

Las iso-superficies se exportaron al programa Autodesk 3DS Max y se obtuvieron los datos de centro de masa, área superficial y volumen de cada burbuja (Figura A3.I.5). Con esa información, se calculó el diámetro en función del volumen, $d_{v}$, y el diámetro de Sauter, $d_{s v}$, para las burbujas. Los valores de centro de masa permitieron conocer a qué altura de lecho se encuentra cada burbuja.

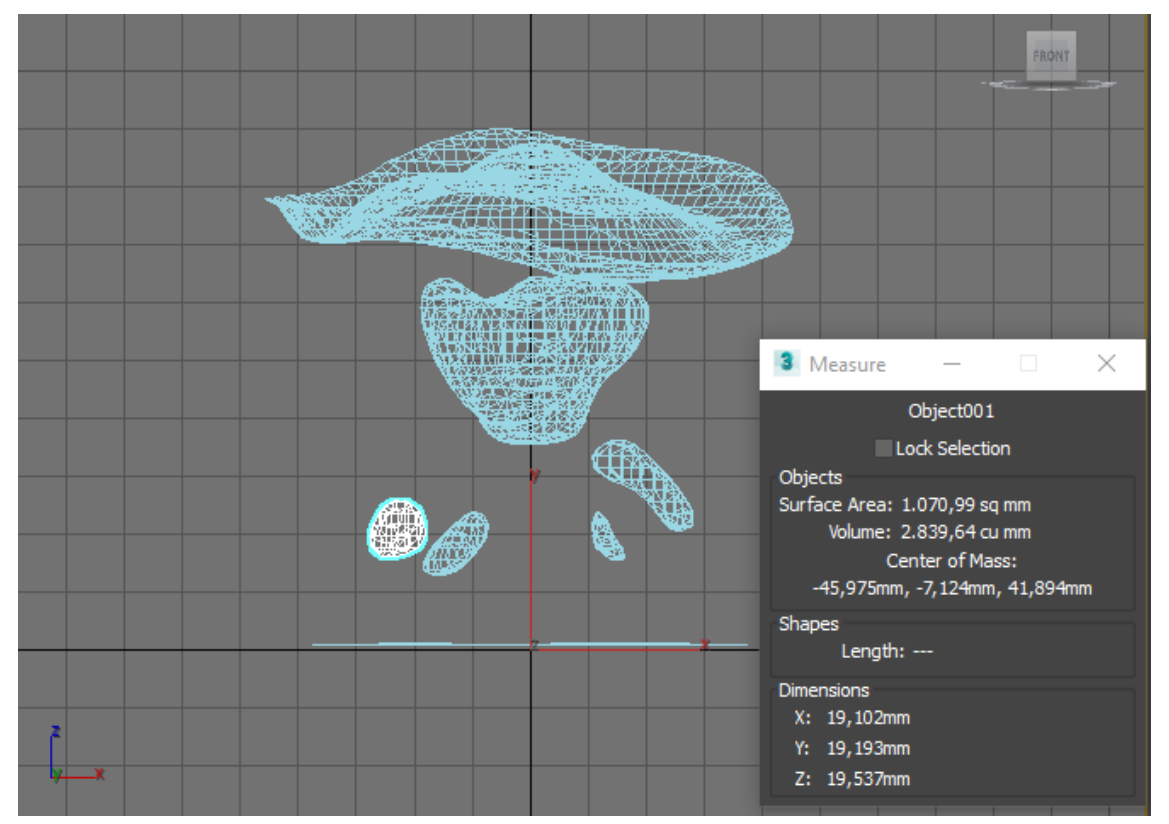

Figura A3.I.5 - Imágenes de burbujas analizadas mediante el Método A. 
Aplicando el Método B, se obtuvieron curvas de fracción de volumen en función del tiempo de simulación, para cada uno de los ocho monitores generados. En la Figura A3.I.6 se muestra el análisis realizado para el primer cuadrante, donde los puntos 1-1 y 1-2 corresponden a los monitores colocados a 11 y $12 \mathrm{~cm}$ de la base del lecho, respectivamente. En la misma se puede observar la presencia de tres burbujas entre los segundos 7 y 8 de la simulación.

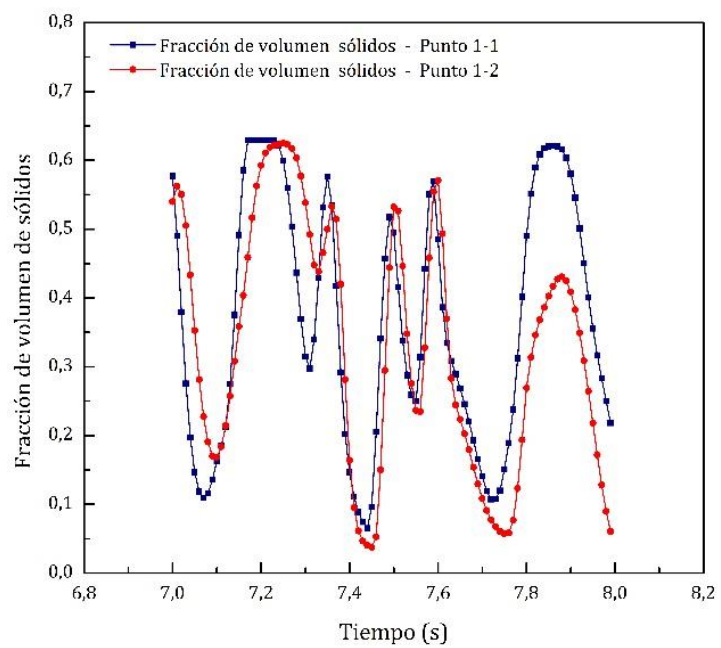

Figura A3.I.6 - Método B: Fracción de volumen de sólidos en función del tiempo, reportados en el primer cuadrante.

Para evaluar el tiempo de pasaje $\left(\Delta t_{p}\right)$ se consideraron los valores de tiempo medio entre los cuáles el monitor de fracción de volumen arroja valores inferiores a 0,2. Para la evaluación del tiempo que demora la burbuja en atravesar los monitores $\left(\Delta t_{s}\right)$, se calculó previamente la diferencia de tiempo entre el instante en que la burbuja comenzó a pasar por el primer monitor y el instante en que comenzó a pasar por el segundo monitor (valor denominado $\Delta_{t i}$ en la Figura A3.I.7). Se repitió este cálculo, pero referido al instante en que la burbuja terminó de pasar por los monitores $\left(\Delta_{t f}\right)$. Luego se promediaron $\Delta_{t i}$ y $\Delta_{t f}$ y se obtuvo el valor de tiempo buscado.

$$
\Delta t_{s}=\frac{\Delta_{t i}+\Delta_{t f}}{2}
$$




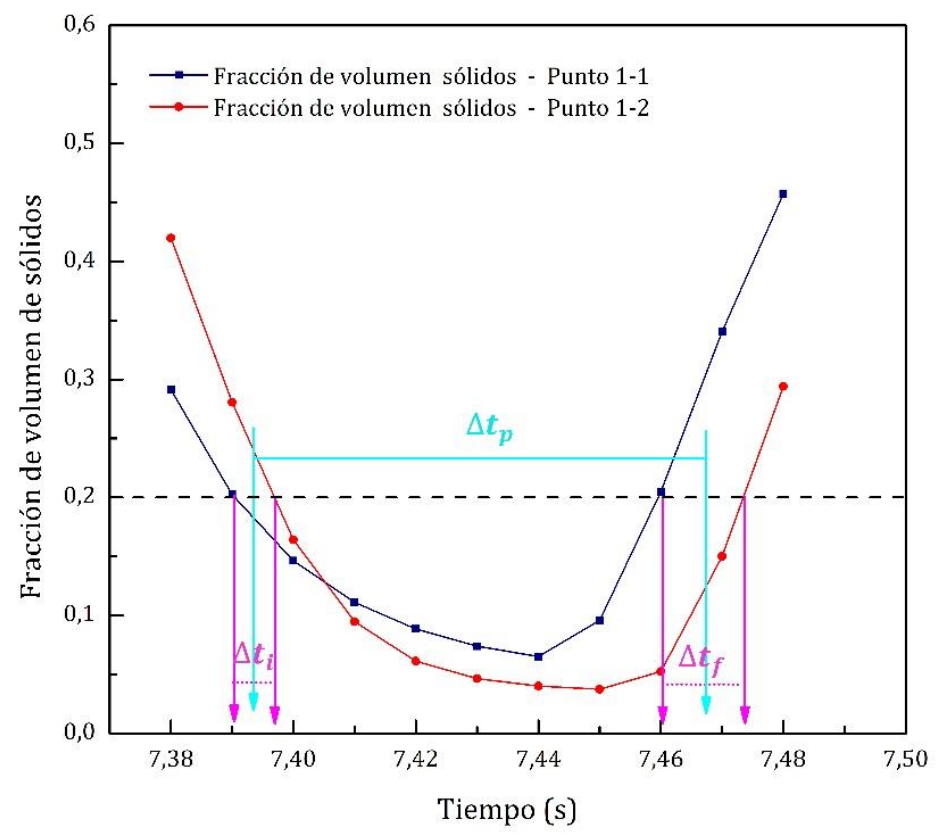

Figura A3.I.7 - Tiempo de pasaje de la burbuja.

La velocidad de ascenso de la burbuja se calculó teniendo en cuenta el valor de $\Delta t_{s}$ y el espaciado entre monitores:

$$
u_{b}=\frac{1 \mathrm{~cm}}{\Delta t_{s}}
$$

Luego, teniendo en cuenta dicha velocidad y el tiempo de pasaje $\left(\Delta t_{p}\right)$ se calculó el pierced length $(y)$ de la burbuja, que puede relacionarse con el diámetro de una burbuja de volumen equivalente como $d_{v}=1,744$ y (explicado en la sección 3.7.2 del Capítulo 3).

$$
d_{v}=1,744\left(u_{b} \cdot \Delta t_{p}\right)
$$

La Figura A3.I.8 muestra los valores de diámetro de burbuja para una velocidad $U$ de $1,58 \mathrm{~m} / \mathrm{s}$. El diámetro de burbuja fue estimado mediante los dos métodos descriptos anteriormente. Con el Método B, se trabajó a una única altura (los monitores fueron colocados a 11 y $12 \mathrm{~cm}$ desde la base del lecho), mientras que con el Método A se realizó el análisis para diferentes valores de la coordenada vertical. En ambos casos el análisis de realizó en un lapso de tiempo de 1 segundo. 


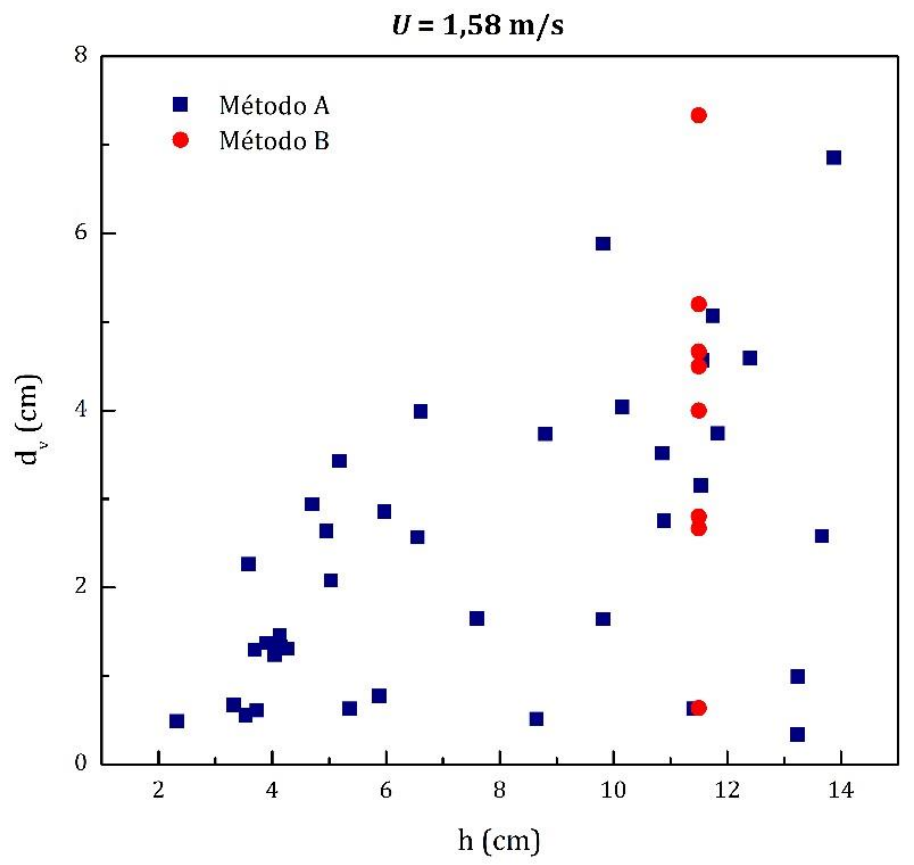

Figura A3.I.8 - Diámetro de las burbujas en función de la altura del lecho.

Si bien ambos métodos predicen valores similares de diámetros, el Método B no considera la excentricidad de las burbujas con respecto al monitor ni las deformaciones de las mismas. Esta característica es crítica cuando se trabaja con partículas Geldart D, ya que las burbujas se alejan marcadamente de geometría esférica (Venier y colab., 2020). Además, con dicho método, si la burbuja no pasa exactamente por el sitio en el que se encuentra localizado el monitor, no es detectada. Por lo tanto, para poder realizar un estudio minucioso de las burbujas con el Método B, debería colocarse una gran cantidad de monitores distribuidos axial y radialmente, de modo de poder realizar un barrido completo del lecho. Si bien esto es factible, el análisis de los monitores resultaría extremadamente complejo, restando practicidad a la metodología.

Por las razones expuestas, se decidió realizar el análisis completo de la fase burbuja utilizando el Método A.

\section{A3.I.4.1 - Diámetro de burbuja}

Siguiendo la metodología descripta en el Capítulo 3, se trabajó con el diámetro de Sauter para las burbujas $\left(d_{s v}\right)$. Los resultados se expresan en función de la altura 
sobre el distribuidor para tres velocidades $U$ distintas. Los valores obtenidos de las simulaciones fueron contrastados con las correlaciones de Darton (1977), Werther (1978) y Cai y colab. (1994), descriptas en Capítulo 3, sección 3.3.
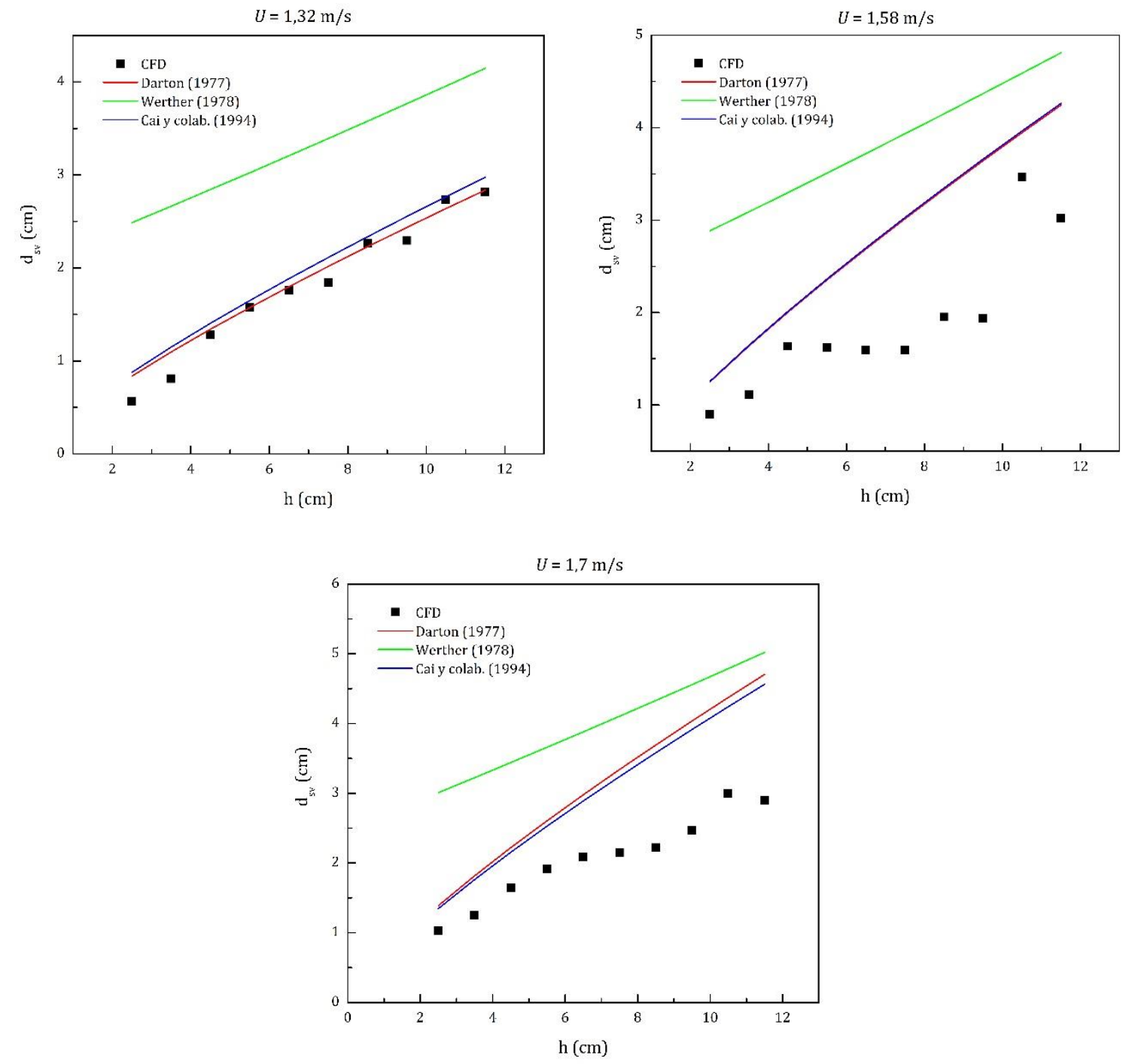

Figura A3.I.9 - Diámetro de las burbujas en función de la altura del lecho para distintas velocidades $U$.

Las correlaciones de Darton (1977) y Cai y colab. (1994) predicen el diámetro en forma precisa para la velocidad $U=1,32 \mathrm{~m} / \mathrm{s}$, pero se aprecian discrepancias crecientes a medida que la velocidad superficial del gas se incrementa. Este comportamiento puede deberse a que las correlaciones presentadas ignoran potenciales fenómenos de splitting de las burbujas, el cual incrementa su efecto a 
mayores velocidades de gas. No obstante, debe señalarse que los valores de diámetro de burbuja obtenidos mediante CFD presentan un buen ajuste con las correlaciones para alturas cercanas al distribuidor para las velocidades $U$ estudiadas. La correlación de Werther (1978) sobreestima los valores para todas las velocidades estudiadas.

\section{A3.I.4.2 - Velocidad de ascenso de burbujas}

En base al procedimiento descripto en el Capítulo 3, se calculó la velocidad de ascenso de las burbujas. En este caso, el estudio de la velocidad de ascenso de las mismas se realizó para una única velocidad superficial de gas. Para el estudio, el acople de burbujas se llevó a cabo de forma manual, comparando una imagen y la inmediatamente posterior. Se compararon las burbujas presentes en las dos imágenes, se registraron sus centros de masa y se obtuvo el desplazamiento vertical para cada burbuja en todos los pares analizados. Se presenta a continuación la velocidad de ascenso de las burbujas en función de la altura del lecho, para una velocidad $U=1,7$ m/s, comparada con las correlaciones de Davidson y Harrison (1963) y Hilligardt y Werther (1986). Debe destacarse que ambas correlaciones fueron modificadas respecto de las ecuaciones presentadas en la sección 3.3.4 del Capítulo 3, para considerar el tratamiento de sólidos Geldart D.

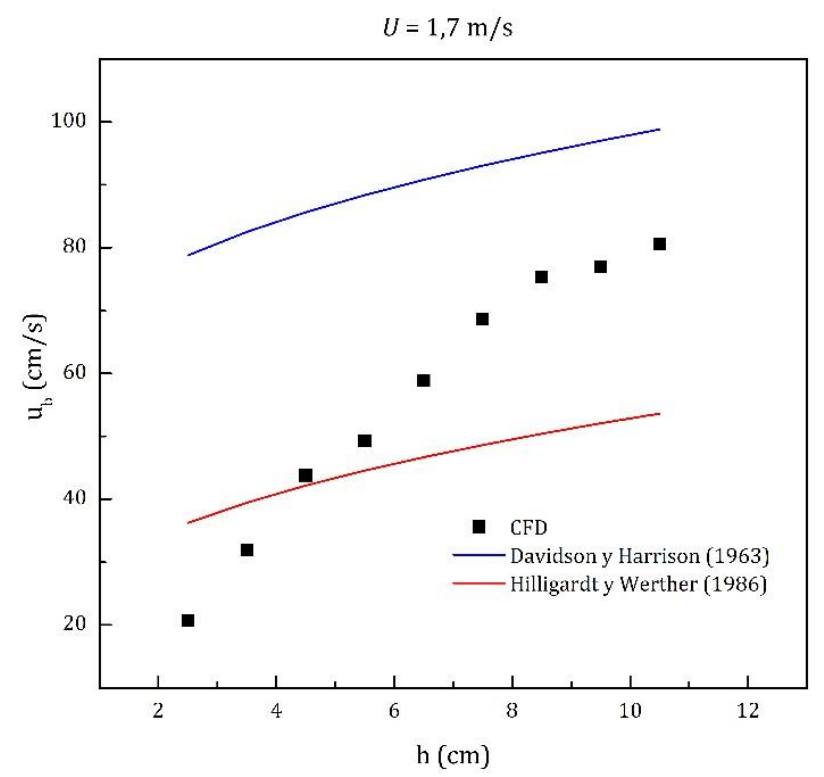

Figura A3.I.10 - Velocidad de ascenso de burbujas en función de la altura desde el distribuidor. 
La velocidad $u_{b}$ aumenta en función de la altura del lecho, al igual que en el análisis anterior lo hace el diámetro, $d_{s v}$, en acuerdo con los resultados reportados por Davidson y Harrison (1963) en base a la TDF. Si bien el aumento en la velocidad $u_{b}$ es pronunciado en la zona inferior del lecho, su derivada comienza a disminuir en la zona superior del lecho. Esto se debe a que la velocidad superficial del gas disminuye con la altura al aumentar la sección del lecho cónico, causando que el caudal promedio en burbujas, sea menor y genere un menor efecto de "empuje" sobre la burbuja, haciendo más lento su ascenso. Este efecto es predominante en la región superior del lecho. Las correlaciones de Davidson y Harrison (1963) y Hilligardt y Werther (1986) no logran reproducir satisfactoriamente la velocidad de ascenso de las burbujas, pero la misma se encuentra comprendida entre ambas correlaciones.

\section{A3.I.5 - CONCLUSIONES}

La metodología presentada para el análisis de la fase burbuja fue estudiada y validada en el Capítulo 3 para las partículas de arena. En el caso de urea, el análisis de las fotografías tomadas en el lecho pseudo-2D y analizadas con el programa desarrollado en MATLAB, no permitió obtener datos confiables de la fase burbuja. Esto se debe a que la gran expansión del lecho aleja entre sí a las partículas que conforman el contorno de las burbujas, dificultando el reconocimiento de las mismas.

Los resultados obtenidos para el diámetro de burbuja presentan excelente ajuste con las correlaciones de Darton (1977) y Cai y colab. (1994), para la velocidad $U=1,32 \mathrm{~m} / \mathrm{s}$, pero los errores aumentan al incrementarse $U$. La velocidad de ascenso de las burbujas no logró ser ajustada satisfactoriamente mediante correlaciones.

Es de gran importancia poder realizar un estudio experimental que permita validar los parámetros utilizados en la simulación. Una alternativa sería colocar sensores ópticos o de presión en el lecho cónico y de este modo analizar la fase burbuja, teniendo en cuenta que esta metodología sólo permite el estudio en puntos específicos del lecho. 


\section{ANEXO 3.II}

\section{FLUIDODINÁMICA COMPUTACIONAL (CFD)}

Para llevar a cabo las simulaciones por CFD, se utilizó el paquete ANSYS-Fluent, en su versión Académica 18.1. A continuación se describen las ecuaciones y modelos utilizados en el presente trabajo.

Los lechos fluidizados, comprendidos en la categoría de flujos gas-sólido, se encuentran dentro de los llamados flujos multifásicos. Para el modelado de este tipo de flujos existen diferentes estrategias, dentro de las que se encuentra la aproximación Euleriana-Euleriana (Taghipour y colab., 2005; Busciglio y colab., 2009; Li y colab., 2010; Acosta-Iborra y colab., 2011; Zhao y colab., 2013; Loha y colab., 2013; Sobrino y colab., 2015; Bakshi y colab., 2015; Altantzis y colab., 2015; Lee y colab., 2017; Haghgoo y colab., 2018) En esta aproximación, las diferentes fases son tratadas matemáticamente como continuas e interpenetrantes, y se introduce el concepto de fracción volumétrica de la fase $\left(\alpha_{q}\right)$, dado que el volumen de una de ellas no puede ser ocupado por otra. Las leyes de conservación de la masa y cantidad de movimiento se cumplen para cada fase por separado y $\alpha_{q}$ representa el espacio ocupado por cada una de ellas. Se resuelve un conjunto de ecuaciones de continuidad y cantidad de movimiento para cada fase, acopladas mediante la presión (compartida por todas las fases) y un coeficiente de intercambio en interfase. Para el caso específico de fluidos granulares (fluido-sólido), las propiedades se obtienen mediante la aplicación de la teoría cinética. 


\section{A3.II.1 - ECUACIONES DE CONSERVACIÓN}

Se presentan a continuación las ecuaciones generales de conservación, a partir de las que se derivan las ecuaciones resueltas por ANSYS-Fluent.

\section{A3.II.1.1 - Conservación de materia}

La ecuación de conservación de materia para la fase "q" (fase primaria) se escribe de la siguiente forma:

$$
\frac{\partial}{\partial t}\left(\alpha_{q} \rho_{q}\right)+\nabla \cdot\left(\alpha_{q} \rho_{q} \overrightarrow{v_{q}}\right)=\sum_{p=1}^{n}\left(m_{p q}-m_{q p}\right)+S_{q}
$$

donde $\alpha_{q}$ y $\rho_{q}$ representan la fracción volumétrica y densidad de la fase "q", $\overrightarrow{v_{q}}$ representa su velocidad y $m_{p q}$ la transferencia de materia de la fase " $q$ " a la fase " $p$ ". El término $S_{\mathrm{q}}$ representa la masa incorporada a la fase primaria proveniente de una segunda fase o alguna otra fuente. Por defecto, el término $S_{q}$ es nulo. La ecuación (A3.II.1) es válida tanto para flujos compresibles como incompresibles.

\section{A3.II.1.2 - Conservación de la cantidad de movimiento}

La ecuación general de conservación de la cantidad de movimiento para un marco de referencia inercial (sin aceleración) está dada por:

$$
\begin{gathered}
\frac{\partial}{\partial t}\left(\alpha_{q} \rho_{q} \vec{v}_{q}\right)+\nabla \cdot\left(\alpha_{q} \rho_{q} \vec{v}_{q} \vec{v}_{q}\right)= \\
-\alpha_{q} \nabla p+\nabla \cdot \overline{\bar{\tau}}_{q}+\alpha_{q} \rho_{q} \vec{g}+\sum_{p=1}^{n}\left(\vec{R}_{p q}+\dot{m}_{p q} \vec{v}_{p q}-\dot{m}_{q p} \vec{v}_{q p}\right)+\vec{F}
\end{gathered}
$$

donde $p$ es la presión estática, $\overline{\bar{\tau}}_{q}$ es el tensor esfuerzo de corte, $\vec{R}_{p q}$ es la fuerza de interacción entre las fases y, por último, los términos $\rho \overrightarrow{\mathrm{g}}$ y $\overrightarrow{\mathrm{F}}$ representan la fuerza gravitatoria que actúa sobre el cuerpo y las fuerzas externas aplicadas al mismo respectivamente.

El tensor $\overline{\bar{\tau}}_{q}$ puede escribirse de la siguiente forma: 


$$
\overline{\bar{\tau}}_{q}=\alpha_{q} \mu_{q}\left(\nabla \vec{v}_{q}+\nabla \vec{v}_{q}^{T}\right)+\alpha_{q}\left(\lambda_{q}-\frac{2}{3} \mu_{q}\right) \nabla \cdot \vec{v}_{q} \overline{\bar{I}}
$$

donde $\mu_{q} \mathrm{y} \lambda_{q}$ son la viscosidad de corte y bulk del fluido, e $\overline{\bar{I}}$ es el tensor unitario.

Las ecuaciones de balance de cantidad de movimiento se acoplan mediante expresiones apropiadas de la fuerza $\vec{R}_{p q}$, que depende de la fricción, presión, cohesión y debe cumplirse que $\vec{R}_{p q}=-\vec{R}_{q p}$ y $\vec{R}_{q q}=0$. Para modelar esta fuerza, se utiliza la siguiente ecuación:

$$
\sum_{p=1}^{n} \vec{R}_{p q}=\sum_{p=1}^{n} K_{p q}\left(\vec{v}_{p}-\vec{v}_{q}\right)
$$

donde $K_{p q}=K_{q p}$ es el coeficiente de intercambio de cantidad de movimiento entre las fases.

\section{A3.II.1.3 - Conservación de la energía}

Para describir la conservación de la energía en flujos multifásicos, la ecuación de entalpía para cada fase se escribe del siguiente modo:

$$
\begin{gathered}
\frac{\partial}{\partial t}\left(\alpha_{q} \rho_{q} h_{q}\right)+\nabla \cdot\left(\alpha_{q} \rho_{q} \vec{u}_{q} h_{q}\right)= \\
\alpha_{q} \frac{d p_{q}}{d t}+\overline{\bar{\tau}}_{q}: \nabla \vec{u}_{q}-\nabla \cdot \vec{q}_{q}+S_{q}+\sum_{p=1}^{n}\left(Q_{p q}+\dot{m}_{p q} h_{p q}-\dot{m}_{q p} h_{q p}\right)
\end{gathered}
$$

donde $h_{q}$ es la entalpía específica de la fase "q", $\overrightarrow{q_{q}}$ representa el flujo de calor, $S_{q}$ es un término fuente que incluye fuentes de entalpía (por ejemplo reacciones químicas o radiación), $Q_{p q}$ es la intensidad del intercambio de calor entre la fase "q" a la fase "p", y $h_{p q}$ es la entalpía de la interfase (por ejemplo, en el caso de la evaporación sería la entalpía del vapor a la temperatura de las gotas). El intercambio de calor entre las fases debe cumplir con las condiciones del balance local: $Q_{p q}=-Q_{q p}$ y $Q_{q q}=0$. 


\section{A3.II.2 - ECUACIONES AUXILIARES}

\section{A3.II.2.1 - Coeficiente de intercambio de cantidad de movimiento}

Para flujos granulares, este coeficiente puede definirse como:

$$
K_{s g}=\frac{\alpha_{s} \rho_{s} f}{\tau_{s}}
$$

donde $s$ y $g$ hacen referencia al sólido y gas respectivamente, $\alpha_{s}$ es la fracción volumétrica de sólido (obtenida mediante la ecuación de continuidad), $\rho_{s}$ es la densidad del sólido, $\tau_{s}$ es un tiempo de relajación (que depende directamente de la densidad y diámetro del sólido y en forma inversa de la viscosidad del fluido) y $f$ es una función que depende del modelo de arrastre utilizado. Entre los distinos modelos de arrastre disponibles en ANSYS-Fluent para sistemas fluido-sólido, se encuentran:

$\checkmark$ Syamlal-O’brien (1989): apropiado cuando las tensiones de corte de los sólidos se definen utilizando las correlaciones de Syamlal y colab. (1993).

$\checkmark$ Syamlal-0'brien parametrizado: sólo es apropiado para partículas tipo Geldart B y está restringido a flujos gas-sólido en los que la fase gaseosa es la primaria.

$\checkmark$ Wen y Yu (1966): recomendado para sistemas diluidos.

$\checkmark$ Gidaspow y colab. (1992): recomendado para lechos fluidizados densos. Este modelo es una combinación del modelo de Wen y Yu (1966) y la ecuación de Ergun (1952).

$\checkmark$ Gibilaro (1985).

En el presente trabajo, se utilizan los modelos de Syamlal O’brien y Gidaspow. En el modelo de Syamlal - O’brien (1989), la función $f$ se define como

$$
f=\frac{C_{D} R e_{s} \alpha_{g}}{24 v_{r, s}^{2}}
$$

y la función de arrastre, $C_{D}$, se deriva de la ecuación de Dalla Valle (1960):

$$
C_{D}=\left(0,63+\frac{4,8}{\sqrt{\operatorname{Re}_{s} / v_{r, s}}}\right)^{2}
$$


que está basada en mediciones de la velocidad terminal de las partículas en un proceso de fluidización o de sedimentación, donde $\mathrm{Re}_{\mathrm{s}}$ es el número de Reynolds relativo (depende de ambas fases) y $\mathrm{v}_{\mathrm{r}, \mathrm{s}}$ se calcula en base a una correlación para velocidad terminal (Garside y Al-Dibouni, 1977).

En el modelo de Gidaspow y colab. (1992), por tratarse de una combinación de dos modelos, el coeficiente de intercambio toma distintas expresiones según sea el valor de $\alpha_{g}$.

$$
\begin{aligned}
& \checkmark \alpha_{g}>0,8 \\
& K_{s g}=\frac{3 C_{D} \alpha_{s} \alpha_{g} \rho_{g}\left|\overrightarrow{v_{s}}-\overrightarrow{v_{g}}\right| \alpha_{g}^{-2,65}}{4 d_{s}} \\
& C_{D}=\frac{24}{\alpha_{g} R e_{s}}\left[1+0,15\left(\alpha_{g} R e_{s}\right)^{0,687}\right] \\
& \checkmark \alpha_{g} \leq 0,8
\end{aligned}
$$

En caso de tener más de una fase sólida, como en las mezclas binarias, debe tenerse en cuenta además un coeficiente de intercambio entre fases sólidas $K_{l s}$, cuya expresión es:

$$
K_{l s}=\frac{3\left(1+e_{l s}\right)\left(\frac{\pi}{2}+C_{f r, l s} \frac{\pi^{2}}{8}\right) \alpha_{s} \rho_{s} \alpha_{l} \rho_{l}\left(d_{l}+d_{s}\right)^{2} g_{0, l s}}{2 \pi\left(\rho_{l} d_{l}^{3}+\rho_{s} d_{s}^{3}\right)}\left|\vec{v}_{l}-\vec{v}_{s}\right|
$$

donde $e_{l s}$ es el coeficiente de restitución para la colisión de partículas, $C_{f r, l s}$ es el coeficiente de fricción entre las fases sólidas, $d_{l}$ es el diámetro de las partículas de sólido de la fase $l$ y $g_{0, l s}$ es la función de distribución radial (se describe en la sección A3.II.2.3).

\section{A3.II.2.2 - Presión de sólidos}

Cuando la fracción volumétrica de los sólidos es inferior al máximo valor permitido, puede decirse que el flujo granular se encuentra en régimen compresible. En 
estos casos se calcula una presión de sólidos de forma independiente y se utiliza en el gradiente $\nabla p$ de la ecuación de cantidad de movimiento. La presión de sólidos está compuesta por un término cinético y un término asociado a las colisiones entre partículas. Para definir esta presión, hay diversas opciones disponibles en la literatura, entre ellas se encuentra la ecuación propuesta por Lun y colab. (1984):

$$
p_{s}=\alpha_{s} \rho_{s} \Theta_{s}+2 \rho_{s}\left(1+e_{s s}\right) \alpha_{s}^{2} g_{0, s s} \Theta_{s}
$$

donde $e_{s s}$ es el coeficiente de restitución para la colisión de partículas, $g_{0, s s}$ es la función de distribución radial y $\Theta_{s}$ es la temperatura granular (proporcional a la energía cinética de las partículas en movimiento). Otra opción es la ecuación propuesta por Syamlal y colab. (1993):

$$
p_{s}=2 \rho_{s}\left(1+e_{s s}\right) \alpha_{s}^{2} g_{0, s s} \Theta_{s}
$$

\section{A3.II.2.3 - Función de distribución radial}

Se trata de un factor de corrección que modifica la probabilidad de colisión entre granos cuando la fase sólida se vuelve densa. Puede interpretarse como la distancia no dimensional entre esferas:

$$
g_{0}=\frac{s+d_{p}}{s}
$$

donde $s$ es la distancia entre granos. Cuando la fase es diluida, $s \rightarrow \infty$ y $g_{0} \rightarrow 1$, mientras que $s \rightarrow 0$ y $g_{0} \rightarrow \infty$ cuando la fase se vuelve densa o compacta. En la literatura existe una amplia variedad de ecuaciones para representar esta función. Se presentan aquí las ecuaciones utilizadas en el presente trabajo:

$\checkmark$ Ogawa y colab. (1980), citado por Lun y colab. (1984):

$$
g_{0}=\left[1-\left(\frac{\alpha_{s}}{\alpha_{s, \max }}\right)^{1 / 3}\right]^{-1}
$$

donde $\alpha_{s, \max }$ es el límite de empaquetamiento de los sólidos. Esta ecuación es empírica y debe modificarse cuando se tiene más de una fase sólida presente en el sistema. 
$\checkmark$ Syamlal y colab. (1993), para los casos en los que se tiene más de una fase sólida:

$$
g_{0, k l}=\frac{1}{1-\alpha_{s}}+\frac{3 \sum_{k=1}^{N} \frac{\alpha_{k}}{d_{k}}}{\left(1-\alpha_{s}\right)^{2}\left(d_{j}+d_{k}\right)} d_{k} d_{l}
$$

\section{A3.II.2.4 - Tensiones de corte de la fase sólida}

El tensor de tensiones $(\overline{\bar{\tau}})$ de la fase sólida está compuesto por las viscosidades de corte $\mu_{s}$ y bulk $\lambda_{s}$ provenientes del intercambio de cantidad de movimiento debido a traslación y colisiones, pero también puede incluir una componente friccional que tenga en cuenta la transición visco-plástica que ocurre cuando la fase sólida alcanza la fracción de volumen máxima. De este modo, la viscosidad de corte toma la siguiente forma:

$$
\mu_{s}=\mu_{s, \text { col }}+\mu_{s, k i n}+\mu_{s, f r}
$$

\section{A3.II.2.4.1 - Viscosidad bulk}

Este parámetro considera la resistencia a la compresión y expansión de las partículas de la fase granular. Se le puede asignar un valor nulo (como en el presente trabajo), o modelarse mediante una ecuación.

\section{A3.II.2.4.2 - Viscosidad por colisiones}

Se modela según Gidaspow y colab. (1992) y Syamlal y colab. (1993):

$$
\mu_{s, \mathrm{col}}=\frac{4}{5} \alpha_{s} \rho_{s} d_{s} g_{0, s s}\left(1-e_{s S}\right)\left(\frac{\Theta_{s}}{\pi}\right)^{1 / 2} \alpha_{s}
$$

\section{A3.II.2.4.3 - Viscosidad cinética}

Puede estimarse mediante las siguientes alternativas:

$\checkmark$ Syamlal y colab. (1993):

$$
\mu_{s, k i n}=\frac{\alpha_{s} \rho_{s} d_{s} \sqrt{\Theta_{s} \pi}}{6\left(3-e_{s s}\right)}\left[1+\frac{2}{5}\left(1-e_{s s}\right)\left(3 e_{s s}-1\right) \alpha_{s} g_{0, s s}\right]
$$


$\checkmark$ Gidaspow y colab. (1992):

$$
\mu_{s, k i n}=\frac{10 \rho_{s} d_{s} \sqrt{\Theta_{s} \pi}}{96 \alpha_{s}\left(1+e_{s s}\right) g_{0, s s}}\left[1+\frac{4}{5} g_{0, s s} \alpha_{s}\left(1+e_{s s}\right)\right]^{2} \alpha_{s}
$$

\section{A3.II.2.4.4 - Viscosidad friccional}

Cuando la fracción volumétrica de sólidos es cercana al packing limit (límite máximo de empaquetamiento de los sólidos), la fricción entre partículas genera el mayor aporte a la generación de tensiones. La viscosidad friccional puede modelarse entonces aplicando la ecuación de Schaeffer (1987):

$$
\mu_{s, f r}=\frac{p_{s} \sin \phi}{2 \sqrt{I_{2 D}}}
$$

donde $p_{s}$ es la presión de sólidos, $\phi$ es el ángulo de fricción interna e $I_{2 D}$ es la segunda invariante del tensor de tensiones.

\section{A3.II.2.4.5 - Temperatura granular}

La temperatura granular de cada fase sólida es proporcional a la energía cinética debida al movimiento aleatorio de sus partículas (Goldhirsch, 2008; Huan y Liu, 2008; Wang y colab., 2013). Puede expresarse como:

$$
\Theta_{s}=\frac{1}{3} u_{s, i} u_{s, i}
$$

donde $u_{s, i}$ representa la componente $i$ de la velocidad de fluctuación de los sólidos en coordenadas cartesianas.

\section{A3.II.3 - MODELO DEL MEDIO POROSO}

El modelo de medio poroso puede ser utilizado en una amplia variedad de problemas, incluyendo lechos rellenos. Este modelo considera la adición de un término fuente de momento a las ecuaciones estándar del flujo de fluidos, que representa las fuerzas de resistencia del material sólido en el gas. El término fuente está formado por dos partes: un término de pérdidas viscosas (ley de Darcy), y un término de pérdidas inerciales. 


$$
S_{i}=-\left(\sum_{j=1}^{3} D_{i j} \mu v_{j}+\sum_{j=1}^{3} C_{i j} \frac{1}{2} \rho v v_{j}\right)
$$

donde $\boldsymbol{S}_{\boldsymbol{i}}$ es el término fuente para la ecuación de momento " $\boldsymbol{i}$ " (con $\boldsymbol{i}=\boldsymbol{x}, \boldsymbol{y}$ o $z$ ), $\boldsymbol{D}$ о $\boldsymbol{C}$ son matrices establecidas y $\boldsymbol{v}_{\boldsymbol{j}}$ son las componentes de la velocidad. Este sumidero de momento contribuye al gradiente de presión en las celdas porosas, creando una caída de presión que es proporcional a la velocidad del fluido en la celda.

Para el caso más simple de medio poroso homogéneo:

$$
S_{i}=-\left(\frac{\mu}{\alpha} v_{i}+C_{2} \frac{1}{2} \rho|v| v_{i}\right)
$$

Donde $\boldsymbol{\alpha}$ es la permeabilidad del medio poroso y $\boldsymbol{C}_{2}$ el factor de resistencia inercial.

En flujos laminares a través de medios porosos, la caída de presión es generalmente proporcional a la velocidad y la constante $\boldsymbol{C}_{2}$ puede ser considerada igual a cero. Ignorando la aceleración convectiva y la difusión, el modelo de medio poroso se reduce a la ley de Darcy:

$$
\nabla p=-\frac{\mu}{\alpha} \vec{v}
$$

A velocidades de flujo altas, la constante $\boldsymbol{C}_{2}$ en la ecuación (A3.II.24) provee una corrección para las pérdidas inerciales en el medio poroso. Esta constante puede ser vista como un coeficiente de pérdida por unidad de longitud a lo largo de la dirección de flujo, permitiendo a la pérdida de carga ser especificada como una función de las cargas de velocidad. Para problemas en los que la permeabilidad es elevada (banco de tubos, placas perforadas), el término de pérdidas viscosas puede ser omitido en la ecuación (A3.II.23).

Existen diferentes alternativas para estimar los valores de $\boldsymbol{\alpha}$ y $\boldsymbol{C}_{2}$ para un lecho fijo, dependiendo del tipo de información con que se cuente. Un modo es a partir de datos experimentales de pérdida de carga en función de la velocidad superficial del agente fluidizante, es decir, datos experimentales de la curva de lecho fijo. 
Partiendo de los datos experimentales de la curva correspondiente a la región de lecho fijo, se realiza un ajuste de mínimos cuadrados mediante una función polinómica de segundo grado:

$$
\Delta P=A U_{0}{ }^{2}+B U_{0}
$$

siendo $\boldsymbol{A}$ y $\boldsymbol{B}$ los valores que surgen del ajuste. Comparando las ecuaciones (A3.II.26) y (A3.II.24), se obtiene:

$$
\begin{gathered}
C_{2}=\frac{2 A}{\rho \Delta n} \\
\alpha=\frac{\mu \Delta n}{B}
\end{gathered}
$$

donde $\Delta n$ es la altura del medio poroso, que en este caso es la altura inicial del sólido en el lecho fijo.

\section{A3.II.4 - DISCRETIZACIÓN DE LAS ECUACIONES DE TRANSPORTE}

Para que un programa CFD pueda resolver las ecuaciones diferenciales que describen a un flujo de fluido, éstas deben ser transformadas en expresiones algebraicas. Dicha transformación se denomina proceso de discretización numérica. Existen diversas técnicas de discretización, dependiendo de los principios en que se basen. Las más utilizadas son: diferencias finitas (DF), volúmenes finitos (VF), y elementos finitos (EF).

Los primeros programas de CFD utilizaron DF. La mayor desventaja de este método es que está limitado a grillas estructuradas, las cuales son difíciles de aplicar a sistemas con geometrías complejas. Los métodos de VF y EF soportan tanto grillas estructuradas como no-estructuradas y por lo tanto pueden ser aplicados a geometrías más complejas. El método de EF es en general más preciso que el de VF, pero el de VF aplica la ecuación de continuidad a cada volumen de control, resultando en un balance de materia más exacto. VF es más apropiado para flujo de fluidos, mientras que EF es utilizado extensamente en cálculos de sistemas sometidos a tensión, donde satisfacer la ecuación de continuidad en forma local es menos importante. 
El software ANSYS-Fluent se basa en el método numérico VF, en el que el dominio se divide en un determinado número de volúmenes de control y las ecuaciones diferenciales de transporte se integran sobre cada uno de dichos volúmenes. Luego, se define la fórmula de interpolación entre dos puntos sucesivos de la grilla y se discretizan las ecuaciones para generar un sistema de ecuaciones algebraicas (Patankar, 1980). Las ecuaciones discretizadas obtenidas de esta forma expresan el principio de conservación, para cada variable analizada, en un volumen de control infinitesimal. Finalmente, las ecuaciones algebraicas son resueltas numéricamente para generar el campo de solución de las variables del sistema en estudio.

La integración sobre el volumen de control de las ecuaciones de conservación requiere calcular los valores de las variables escalares en las caras de cada volumen de control o celda, para determinar los flujos convectivos y difusivos. Para ello se interpola el valor de la variable escalar del centro de cada celda a la cara de la misma celda. Existen diferentes esquemas de interpolación. La aplicación de un esquema específico para una variable depende, entre otros, del alineamiento del mallado al campo de flujo. Los esquemas de interpolación de mayor orden presentan una mayor precisión, ya que los esquemas de primer orden introducen dispersión numérica cuando el flujo de fluido es oblicuo al alineamiento del mallado. Sin embargo, los esquemas de interpolación de orden mayor presentan un proceso de solución menos estable.

\section{A3.II.5 - PROCEDIMIENTO DE RESOLUCIÓN POR MEDIO DEL SOFTWARE}

El paquete de software de CFD, ANSYS-Fluent, se encuentra estructurado alrededor de algoritmos numéricos que pueden abordar problemas de flujo de fluidos. Para que el software pueda comenzar a resolver numéricamente las ecuaciones del modelo junto a las condiciones de contorno e iniciales, debe diseñarse la geometría y el mallado (etapa de pre-procesamiento). Una vez resueltas las ecuaciones de conservación por medio de Fluent, se puede realizar el análisis de los resultados empleando el software CFD-Post de la misma firma. A esta última etapa se la denomina pos-procesamiento. 


\section{A3.II.5.1 - Pre-procesamiento}

Creación del dominio:

Mediante el programa ANSYS-Design Modeler se dibuja la geometría del lecho a estudiar, creando el dominio para la resolución numérica de las ecuaciones de conservación.

Mallado:

En esta etapa se realiza la discretización del dominio computacional en pequeños volúmenes de control no superpuestos, utilizando para ello el programa ANSYS-Meshing. Esta herramienta consigue un alto grado de automatización de la técnica de mallado haciendo posible la generación de diferentes tipos de mallas, clasificadas en estructuradas y no estructuradas. En este trabajo se utilizarán mallas estructuradas, constituidas por celdas cuadriláteras en 2D y hexaédricas en 3D. En los mallados estructurados, cada punto de la malla está inequívocamente identificado por los índices $i, j, k$, en las coordenadas utilizadas (en los mallados no estructurados, las celdas y los nodos de la malla no tienen un orden particular). La Figura A3.II.1 muestra los diferentes tipos de elementos disponibles para la generación de la malla.
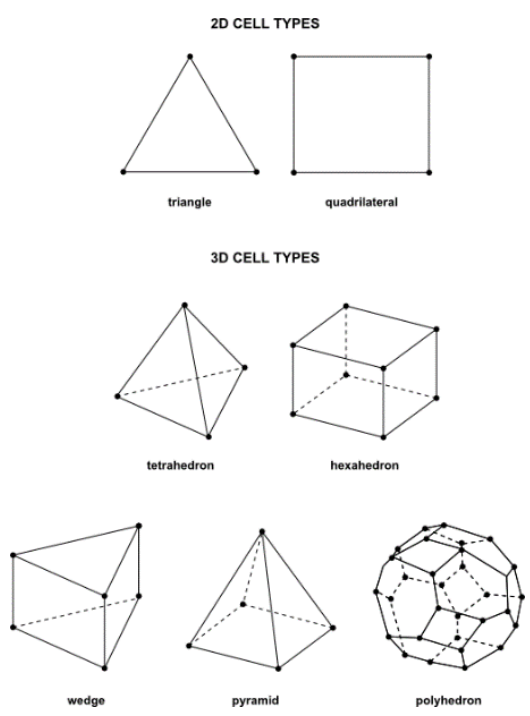

Figura A3.II.1 -Elementos que pueden emplearse para generar la malla. (Fuente: ANSYSFluent User's Guide 18.1, 2020 - ANSYS, Inc.) 
Uno de los problemas a determinar en lo que respecta a la malla es el refinamiento adecuado para el problema a simular por CFD. Para su determinación, se realiza el proceso de validación de malla.

En esta etapa también se definen las zonas correspondientes a las condiciones de borde necesarias para la resolución del problema (velocity-inlet, pressure-outlet, wall, interior-fluid).

\section{A3.II.5.2 - Resolución}

Validación del mallado:

Debido a que el proceso de resolución implica el cálculo de las ecuaciones de gobierno en cada uno de los volúmenes de control, los resultados pueden ser altamente dependientes del tamaño y cantidad de volúmenes de control. Debe destacarse que si bien la precisión en los resultados aumenta con el incremento de la cantidad de volúmenes de control (menor tamaño de cada uno de ellos), también lo hace el esfuerzo computacional y el tiempo de cómputo necesario. El proceso de validación de la malla tiene como objetivo evaluar el grado de refinamiento requerido de modo de asegurar que los resultados sean independientes del número de elementos de la malla.

\section{Resolución:}

Una vez generada la malla, se procede a la etapa de resolución estricta. Para ello se establecen las condiciones de contorno fijando valores a ciertas variables en los límites del dominio (condiciones Dirichlet o de Von Neumann), condiciones iniciales (en caso de no estacionario), propiedades del fluido y sólido que intervienen en la simulación, modelos de turbulencia, métodos de resolución y parámetros de convergencia.

\section{A3.II.5.3 - Post-procesamiento}

En esta etapa se lleva a cabo la visualización de los resultados obtenidos. A diferencia de los métodos experimentales, la simulación por CFD proporciona datos de presión, velocidad, densidad y otras variables de interés en todos los puntos del 
dominio de flujo simulado, por lo tanto, al finalizar la simulación se debe realizar el tratamiento de estos datos, con el fin de seleccionar aquellos que tienen relevancia práctica en el estudio realizado. ANSYS cuenta con una serie de herramientas para la visualización de resultados, entre las que se incluyen diagramas de contorno, de presión, fracción de sólidos, diagramas vectoriales del campo de velocidades y trazado de superficies en dos y tres dimensiones. Además, en el presente trabajo se utilizan, como herramientas de post-procesamiento adicionales, los programas MATLAB y Autodesk 3DS MAX. 


\section{ANEXO 3.III}

\section{PROGRAMACIÓN AUXILIAR}

Las imágenes bidimensionales se analizaron utilizando dos programas desarrollados con la herramienta MATLAB. Se trabajó, en primera instancia, con un programa que permite analizar cada imagen y obtener datos de área, perímetro, centro de masa y longitud máxima y mínima de cada burbuja en cada imagen. Luego se trabajó con el segundo programa, que calcula valores totales y promedio de diámetro, centro de masa y esfericidad; éste último permite, adicionalmente, acoplar las burbujas entre imágenes consecutivas y realizar el cálculo de su velocidad de ascenso. Este programa también incluye el cálculo de diámetros y velocidades de burbuja aplicando diferentes correlaciones.

Las imágenes tridimensionales (isosuperficies) fueron tratadas con dos programas diferentes. En primera instancia se trabajó con el programa de diseño AutoDesk 3DSMax, que permite obtener datos de posición (centro de masa), superficie y volumen de cada burbuja. El programa arroja los valores mencionados para el bloque completo que compone la isosuperficie. El proceso de aislar cada burbuja (detach elements) y eliminar imágenes innecesarias (al exportar las imágenes desde ANSYS CFD Post, se genera también la escala de colores para referencia) se llevó a cabo de modo manual, pero se desarrolló un programa dentro del programa 3DSMax que permite exportar los datos obtenidos a un archivo de texto. Luego, se genera una planilla de Excel con los archivos de texto obtenidos y finalmente, se llevan a cabo los cálculos de diámetro y velocidad de las burbujas utilizando un tercer algoritmo, desarrollado en Matlab, que además permite descartar datos espúreos (slugs de pared, base del lecho y freeboard).

\section{A3.III.1 - ANÁLISIS DE IMÁGENES BIDIMENSIONALES}

El programa que se presenta a continuación lee cada una de las imágenes y permite la generación de una matriz de datos cuyas unidades son píxeles. Mediante 
referencias incluidas en las imágenes, el programa permite convertir la matriz obtenida a sistema métrico.

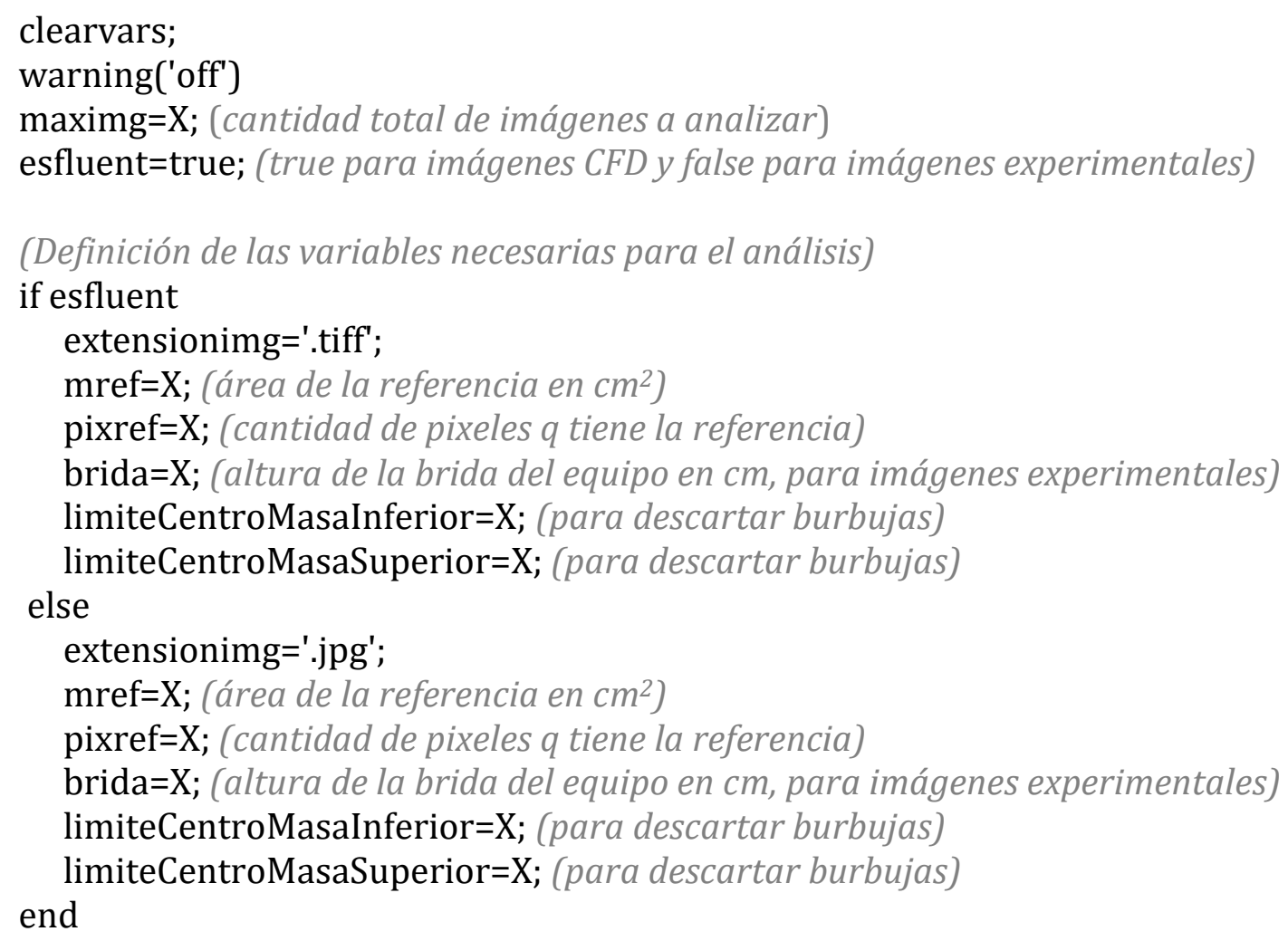

MatrizTotal=[]; (se genera la variable, para optimizar tiempos de cómputo)

for numberFile $=1$ :maximg stringFile=strcat(num2str(numberFile),extensionimg); (se arma el nombre del archivo, concatenando un numero con ".tiff")

original=imread(stringFile); (se lee la imagen)

figure,imshow(original),title('Original');

if esfluent

crop=imcrop(burbuja,[284 70 675-284 659-70]); (se recorta la imagen para dejar solo la parte de interés)

figure,imshow(crop),title('crop');

else

crop=imcrop(burbuja,[470 192 1251-470 900-192]);

figure,imshow(crop),title('crop');

end

gris=rgb2gray(crop); (se convierte la imagen a escala de grises) 


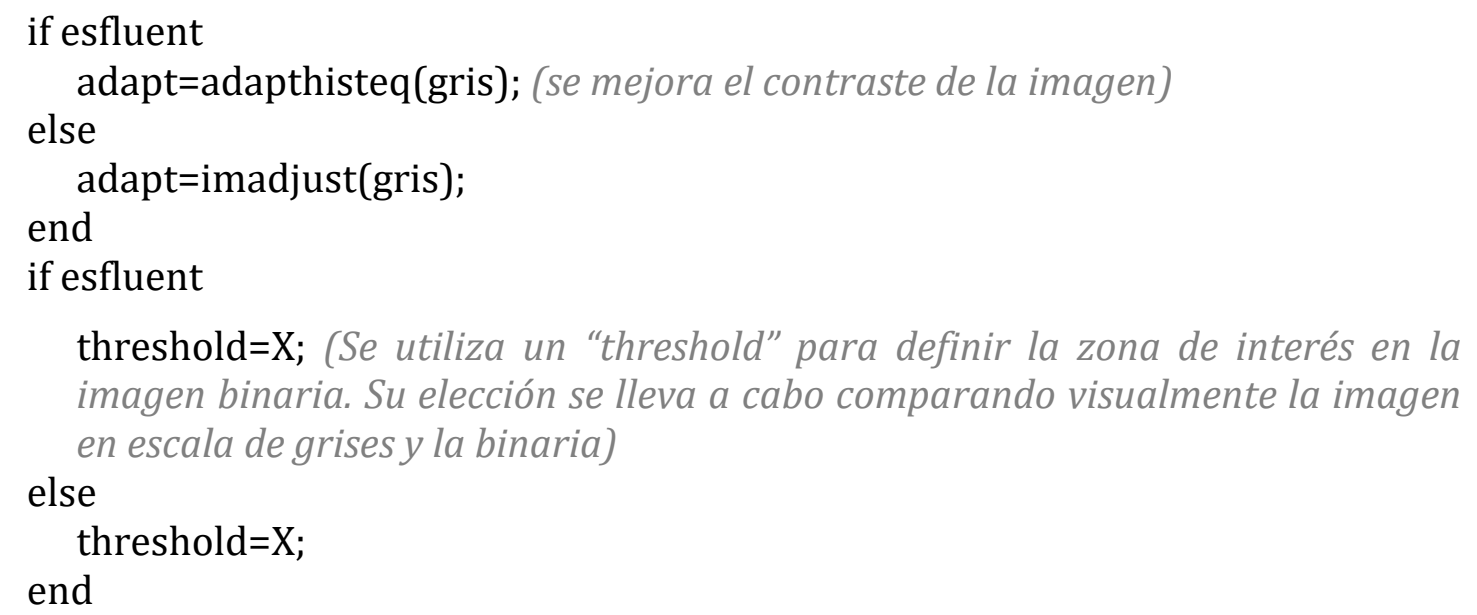

bw = im2bw(bub_adapt,threshold); (se convierte la imagen a binaria)

bw2=imcomplement(bw); (en caso de necesitar el complemento de bw)

bw3 = bwareaopen(bw,50); (se eliminan los objetos con menos de 50 pixels - ruido)

$[\mathrm{B}, \mathrm{L}, \mathrm{N}, \mathrm{A}]=$ bwboundaries(bw3,8,'noholes');

(Se rastrean los contornos de las regiones en la imagen binaria:

$B$ : muestras los contornos externos de los objetos.

L: es la matriz que representa los objetos de interés (label matrix). Las dimensiones de la matriz son LargoxAncho de la imagen

$N$ : corresponde a la cantidad de objetos encontrados.

A: es la matriz de adyacencia, cuyas filas y columnas corresponden a las posiciones de los contornos almacenados en $B$

close all (se cierra la figura una vez guardada)

imagenRGB=label2rgb(L, @jet, [.5 .5 .5],'shuffle'); (se representa a la matriz L como una imagen en colores)

figure(numberFile),imshow(imagenRGB)

hold on

for $\mathrm{k}=1$ :length(B) (se asignan números a cada objeto. Su posición en la imagen es al azar y su tamaño, color y fuente son definidos por el usuario)

boundary $=\mathrm{B}\{\mathrm{k}\}$;

plot(boundary(:,2), boundary(:,1),'w','LineWidth',2);

rndRow $=\operatorname{ceil}\left(\right.$ length $($ boundary $\left.) /\left(\bmod \left(\operatorname{rand}^{*} \mathrm{k}, 7\right)+1\right)\right)$;

col = boundary $($ rndRow, 2$)$; row = boundary $(\operatorname{rndRow}, 1)$;

$\mathrm{h}=\operatorname{text}(\mathrm{col}+1$, row-1, num2str(L(row,col)));

set(h,'Color','k','FontSize',8,'FontWeight','bold');

if $\mathrm{k}==$ length(B),

print('-djpeg100',numberFile); (se guarda la imagen RGB con los números asignados a cada objeto)

end

end

Página A3.III.3 


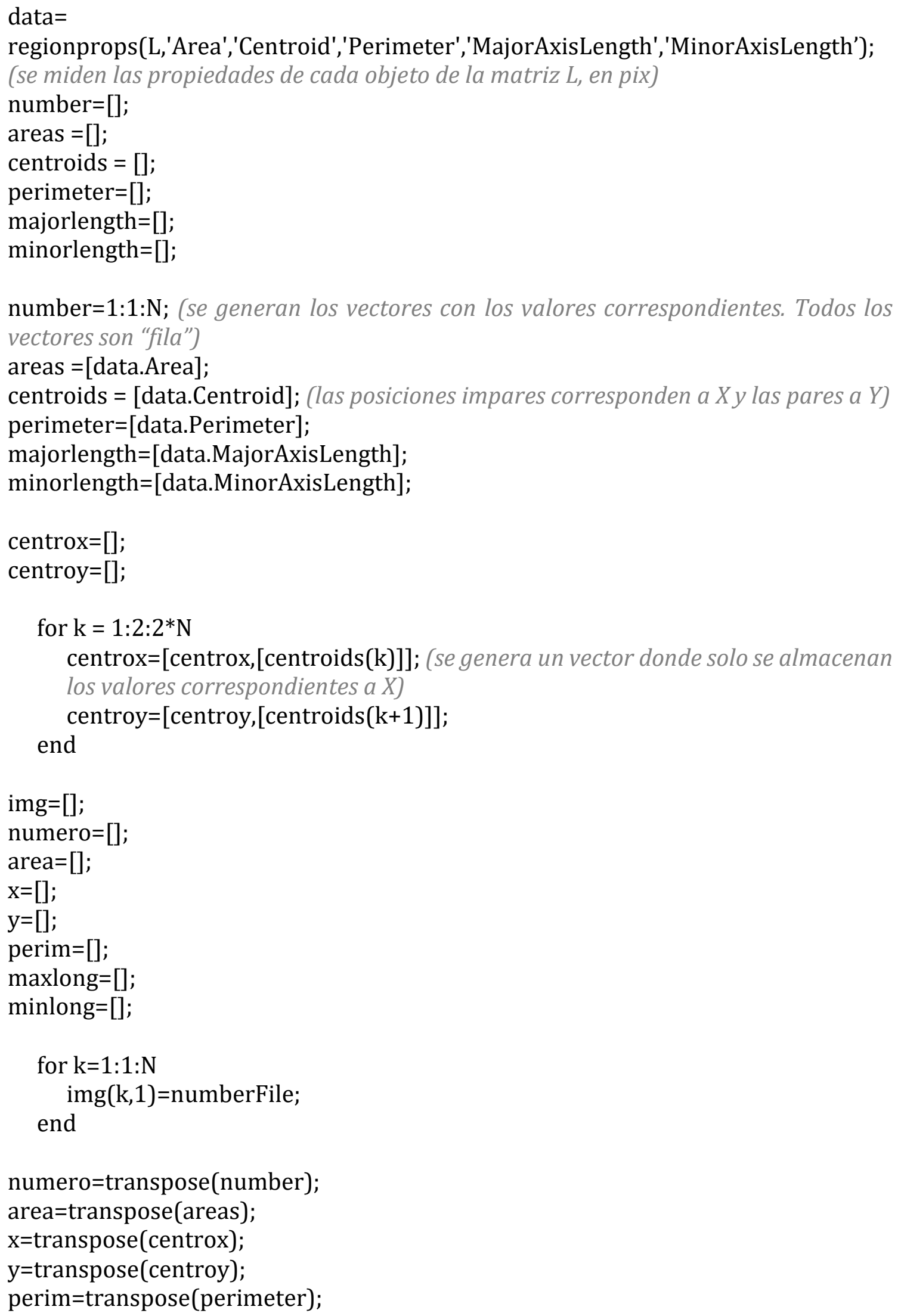


maxlong=transpose(majorlength);

minlong=transpose(minorlength);

MatrizParcial=[];

MatrizParcial=[img,numero,area, $\mathrm{x}, \mathrm{y}$, perim,maxlong,minlong];

MatrizTotal=vertcat(MatrizTotal,MatrizParcial);

end

sizeN=size(MatrizTotal);

$\mathrm{N}=\operatorname{sizeN}(1,1)$;

apix=mref/pixref; (área de 1 pix en $\mathrm{cm}^{2}$ )

longpix=sqrt(apix); (longitud 1 pix en $\mathrm{cm}$ )

$\mathrm{a}=[]$

sizeL=size(L); (La matriz L tiene como dimensiones el Alto $x$ Ancho de la imagen, por lo tanto, al informar su tamaño, se puede leer el alto y ancho del lecho directamente)

alturapix=sizeL(1,1); (altura del lecho en pix)

anchopix=sizeL(1,2); (ancho del lecho en pix)

for $\mathrm{i}=1: \mathrm{N}$ (se convierten los datos obtenidos en pix a unidades del sistema métrico, $\mathrm{cm}$ )

$\mathrm{a}(\mathrm{i}, 1)=$ MatrizTotal $(\mathrm{i}, 1)$;

$\mathrm{a}(\mathrm{i}, 2)=$ MatrizTotal $(\mathrm{i}, 2)$;

$\mathrm{a}(\mathrm{i}, 3)=$ MatrizTotal $(\mathrm{i}, 3)^{*}$ apix;

a(i,4)=MatrizTotal(i,4)*longpix;

$\mathrm{a}(\mathrm{i}, 5)=($ alturapix-MatrizTotal $(\mathrm{i}, 5)) *$ longpix+brida;

$\mathrm{a}(\mathrm{i}, 6)=$ MatrizTotal $(\mathrm{i}, 6) *$ longpix;

a(i,7)=MatrizTotal $(\mathrm{i}, 7) *$ longpix;

a(i,8)=MatrizTotal $(\mathrm{i}, 8)^{*}$ longpix;

$\mathrm{a}(\mathrm{i}, 9)=\operatorname{sqrt}(($ MatrizTotal(i,3)*apix)*4/pi); (diámetro - usado como cálculo preliminar para descartar elementos)

end

$\mathrm{b}=[]$;

$\mathrm{j}=1$;

for $\mathrm{i}=1: \mathrm{N}$

if a(i,4)-a(i,9)/2) $>0$ (se eliminan slug pared izquierda)

if $\mathrm{a}(\mathrm{i}, 4)+\mathrm{a}(\mathrm{i}, 9) / 2$ ) <anchopix*longpix (se eliminan slug pared derecha)

if $\mathrm{a}(\mathrm{i}, 5)>=$ limiteCentroMasaInferior (se eliminan elementos cercanos al distribuidor)

if $\mathrm{a}(\mathrm{i}, 5)<$ limiteCentroMasaSuperior (se eliminan elementos cercanos al freeboard)

$\mathrm{b}(\mathrm{j}, 1)=\mathrm{a}(\mathrm{i}, 1)$; (imagen $)$ 


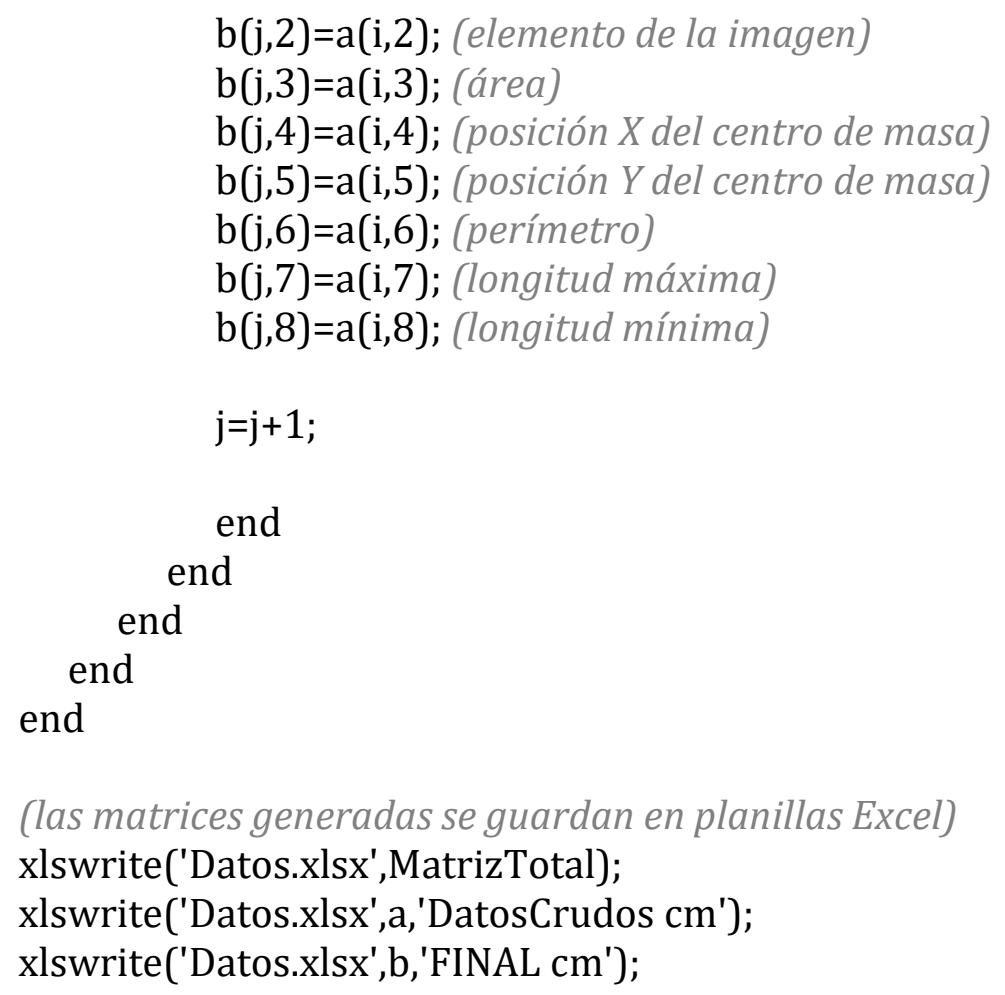

\section{A3.III. 2 - CÁLCULOS PARA IMÁGENES BIDIMENSIONALES}

El programa para realizar los cálculos fue desarrollado para el análisis de imágenes bidimensionales y tridimensionales. Se presenta a continuación el programa para imágenes bidimensionales.

b=xlsread('1-Datos.xls','FINAL cm');

tamano=size(b);

filab=tamano(1,1);

colb=tamano $(1,2)$;

(Definición de parámetros)

maximg=X;

espesorlecho=X; (espesor del lecho experimental en $\mathrm{cm}$ )

rango=X; (cantidad de alturas para estudiar diámetro y velocidad promedios)

deltax=X; (máximo desplazamiento en eje X, para acoplar burbujas en análisis velocidad. Depende de la velocidad superficial del gas y se encuentra haciendo un análisis manual para una cierta cantidad de imágenes)

deltay $=\mathrm{X}$;

aumento=X; (fracción de aumente de diámetro entre imágenes consecutivas)

uo=X; (velocidad superficial del aire, en $\mathrm{cm} / \mathrm{s}$ )

umf=X; (velocidad de mínima fluidización, en $\mathrm{cm} / \mathrm{s}$ ) 
$\mathrm{dt}=\mathrm{X}$; (tiempo entre imágenes consecutivas, en segundos)

grav=981; (aceleración de la gravedad, en $\mathrm{cm} / \mathrm{s}^{2}$ )

Ao=X;

Diam=X; (diámetro del lecho, en $\mathrm{cm}$ )

titahw=0.2*sqrt(Diam); (para correlación Hiligardt y Werther, partículas Geldart B) titaw $=0.254 * \operatorname{Diam}^{\wedge} 0.4$; (para correlación Werther, partículas Geldart B)

\section{A3.III.2.1 - Análisis de diámetro}

for $\mathrm{i}=1$ :filab

$\mathrm{b}(\mathrm{i}, \mathrm{colb}+1)=\operatorname{sqrt}\left(\mathrm{b}(\mathrm{i}, 3)^{*} 4 / \mathrm{pi}\right)$; (diámetro de una esfera de igual área proyectada, $\mathrm{cm}$ ) $\mathrm{b}(\mathrm{i}, \mathrm{colb}+2)=6 /((2 /$ espesorlecho $)+(\mathrm{b}(\mathrm{i}, 6) / \mathrm{b}(\mathrm{i}, 3))) ;$ (diámetro de una esfera de superficie por unidad de volumen equivalente, $\mathrm{cm})$

$\mathrm{b}(\mathrm{i}, \mathrm{colb}+3)=\left(4^{*} \mathrm{pi}^{*} \mathrm{~b}(\mathrm{i}, 3) /\left(\mathrm{b}(\mathrm{i}, 6)^{\wedge} 2\right)\right) ;($ factor de forma $)$ end

for $\mathrm{k}=1$ :rango

$\mathrm{j}=0$;

$\mathrm{c} 1=[]$

c2=[];

c3=[];

c4=[];

for $\mathrm{i}=1$ :filab

if $\mathrm{b}(\mathrm{i}, 5)>=\left(1^{*}(\mathrm{k}-1)\right) \& \& \mathrm{~b}(\mathrm{i}, 5)<\left(1+1^{*}(\mathrm{k}-1)\right)$, (se ordenan los datos agrupándolos según un rango determinado de alturas)

$\mathrm{j}=\mathrm{j}+1$;

$\mathrm{c} 1(\mathrm{j}, 1)=\mathrm{b}(\mathrm{i}, 5) ;$ (altura)

$\mathrm{c} 2(\mathrm{j}, 1)=\mathrm{b}(\mathrm{i}, \mathrm{colb}+1) ;\left(d_{a}\right)$

$\mathrm{c} 3(\mathrm{j}, 1)=\mathrm{b}(\mathrm{i}, \mathrm{colb}+2) ;\left(d_{s v}\right)$

$\mathrm{c} 4(\mathrm{j}, 1)=\mathrm{b}(\mathrm{i}, \mathrm{colb}+3)$; (factor de forma)

end

end

$\mathrm{d} 1=$ mean(c1); (altura media)

$\mathrm{d} 2=\operatorname{mean}(\mathrm{c} 2)$;

d3=mean (c3);

$\mathrm{d} 4=$ mean (c4);

sigma2 = std(c2); (desvío estándar)

sigma3=std(c3);

cantburbujas=size(c1); (cantidad de burbujas en el rango)

if isempty(d1) (Si d1 NO esta vacío, se vuelcan los datos promedios a la matriz f. De este modo se evitan errores cuando en un rango de alturas no hay datos)

$\mathrm{f}(\mathrm{k}, 1)=\mathrm{d} 1 ;$ (altura media)

$\mathrm{f}(\mathrm{k}, 2)=\mathrm{d} 2 ;($ da medio $)$ 


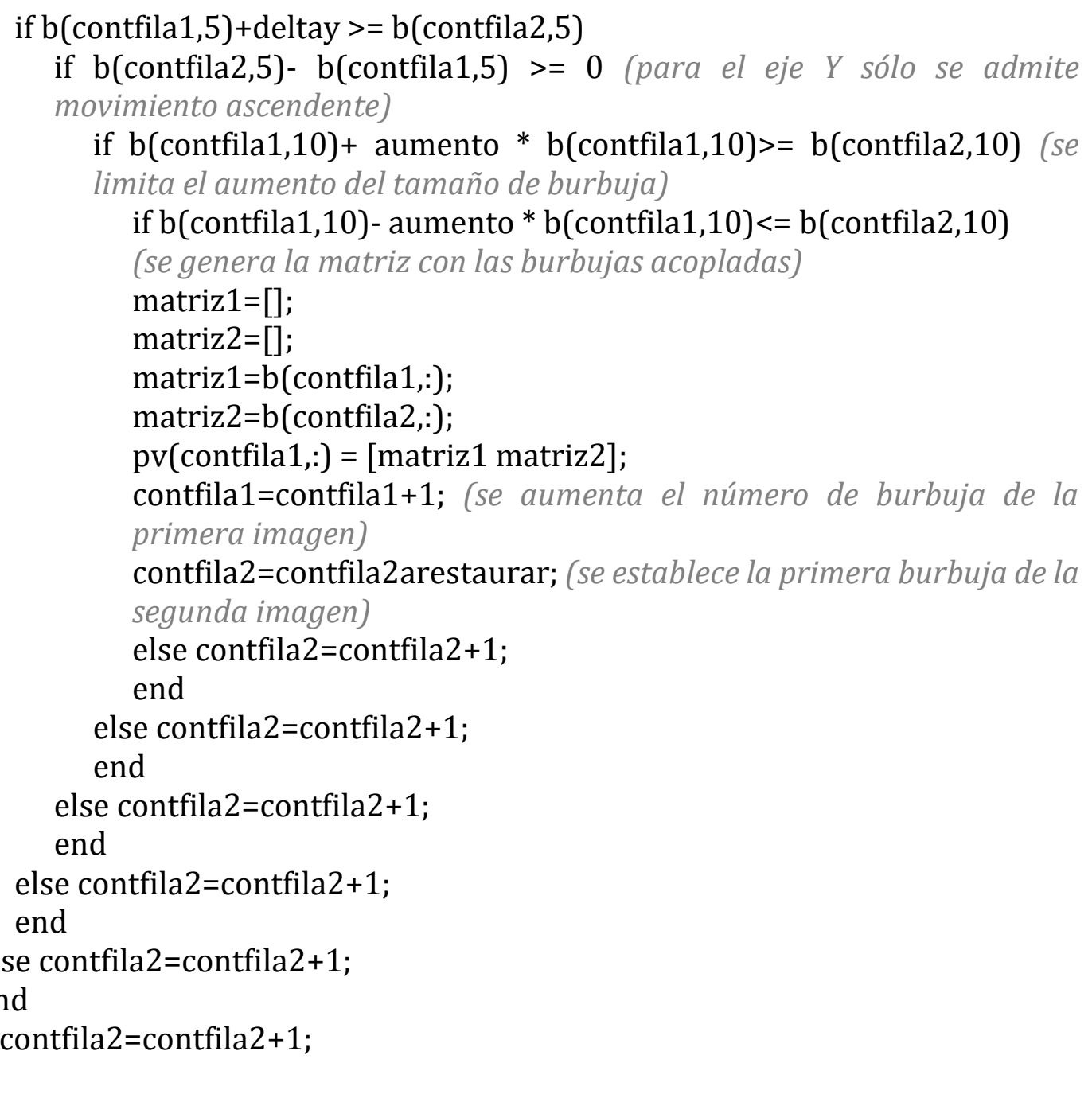

if $\mathrm{b}$ (contfila1,1)+2==b(contfila2-1,1) (si se alcanza este punto es porque la burbuja de la primer imagen no fue acoplada con ninguna de la imagen consecutiva) pv(contfila1,:) = zeros $\left(1,2^{*}(\operatorname{colb}+3)\right) ;($ en caso de no acoplarse ninguna burbuja, se completa la fila de la matriz con ceros)

contfila1 $=$ contfila $1+1$

contfila2 $=$ contfila2arestaurar;

end

if $\mathrm{b}$ (contfila1,1)==maximg- 1 \&\& contfila2>maxfila (si se alcanza este punto es porque la burbuja de la primer imagen no fue acoplada con ninguna de la imagen consecutiva) (CASO ESPECIAL: es el último par de imágenes a analizar) pv(contfila1,:) = zeros $\left(1,2^{*}(\operatorname{colb}+3)\right) ;($ en caso de no acoplarse ninguna burbuja, se completa la fila de la matriz con ceros)

contfila1=contfila $1+1$

contfila2 $=$ contfila2arestaurar; 


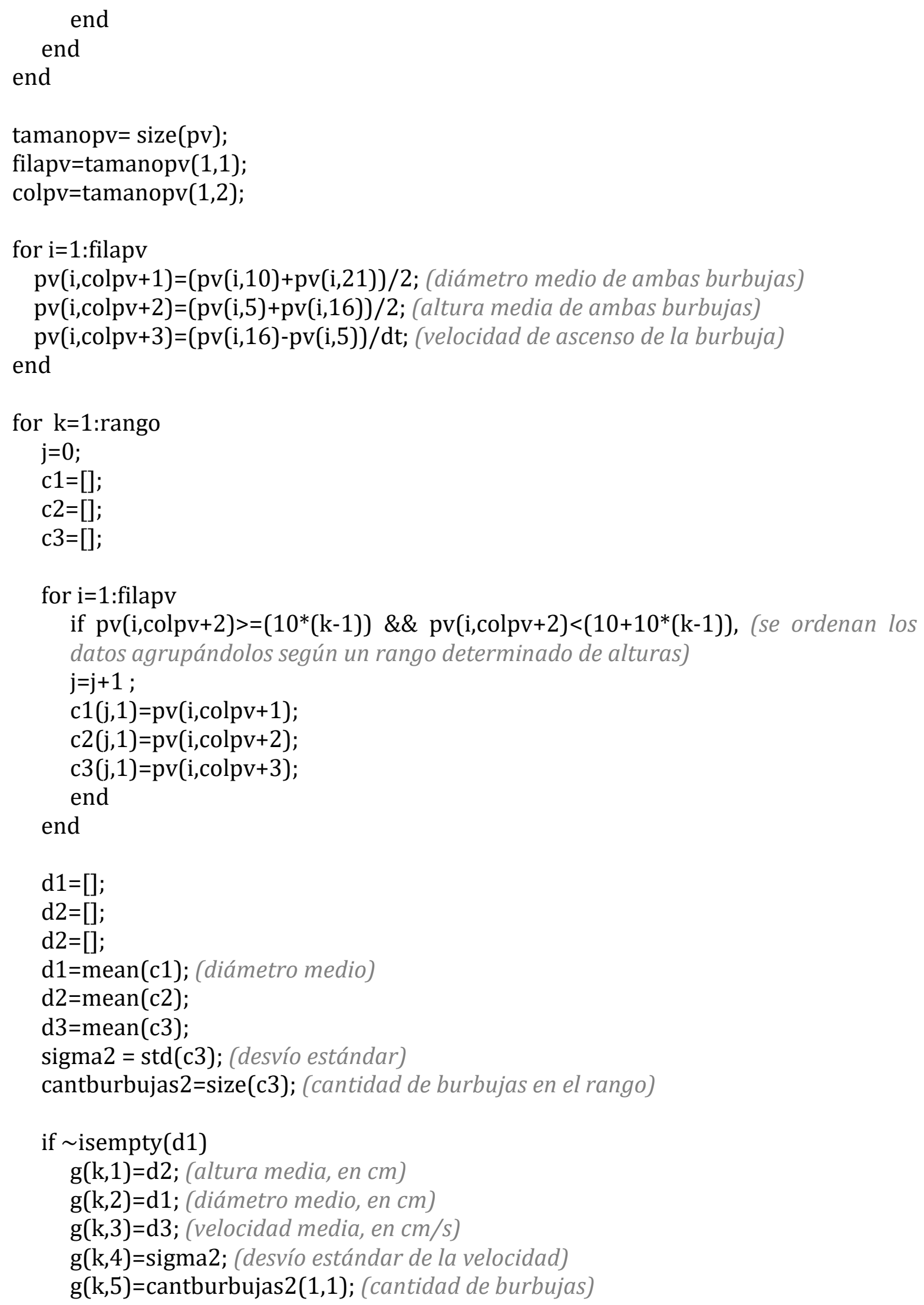


(Velocidad de ascenso de burbujas, según distintas correlaciones, en cm/s)

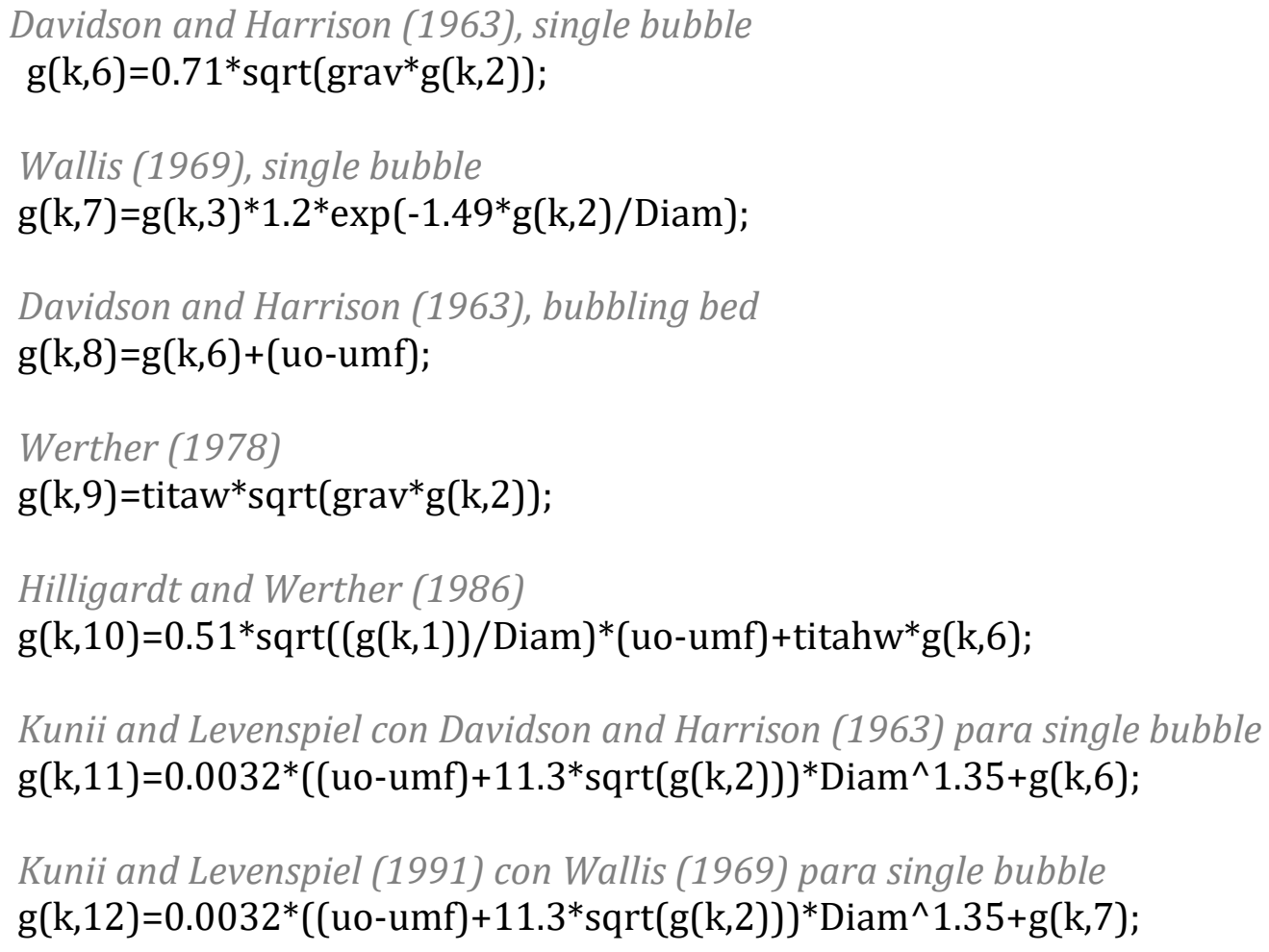

end

end

xlswrite('Calculos.xlsx',b,'Diametro');

xlswrite('Calculos.xlsx',f,'Diametro Promedio');

xlswrite('Calculos.xlsx',pv,'Pares Velocidad');

xlswrite('Calculos.xlsx',g,'Velocidad Promedio');

\section{A3.III.3 - GENERACIÓN DE ARCHIVOS DE DATOS 3D}

Se presenta a continuación el programa para generar archivos de texto con los datos obtenidos del programa 3DSMax. Debe destacarse que este programa, además transforma los datos obtenidos de unidades genéricas (las utilizadas por el programa) a sistema métrico, tomando como referencia la sección correspondiente a la base del lecho, que es un valor conocido.

rollout CreateTxtVolume "Create volume txt file" width:160 height:120

( 


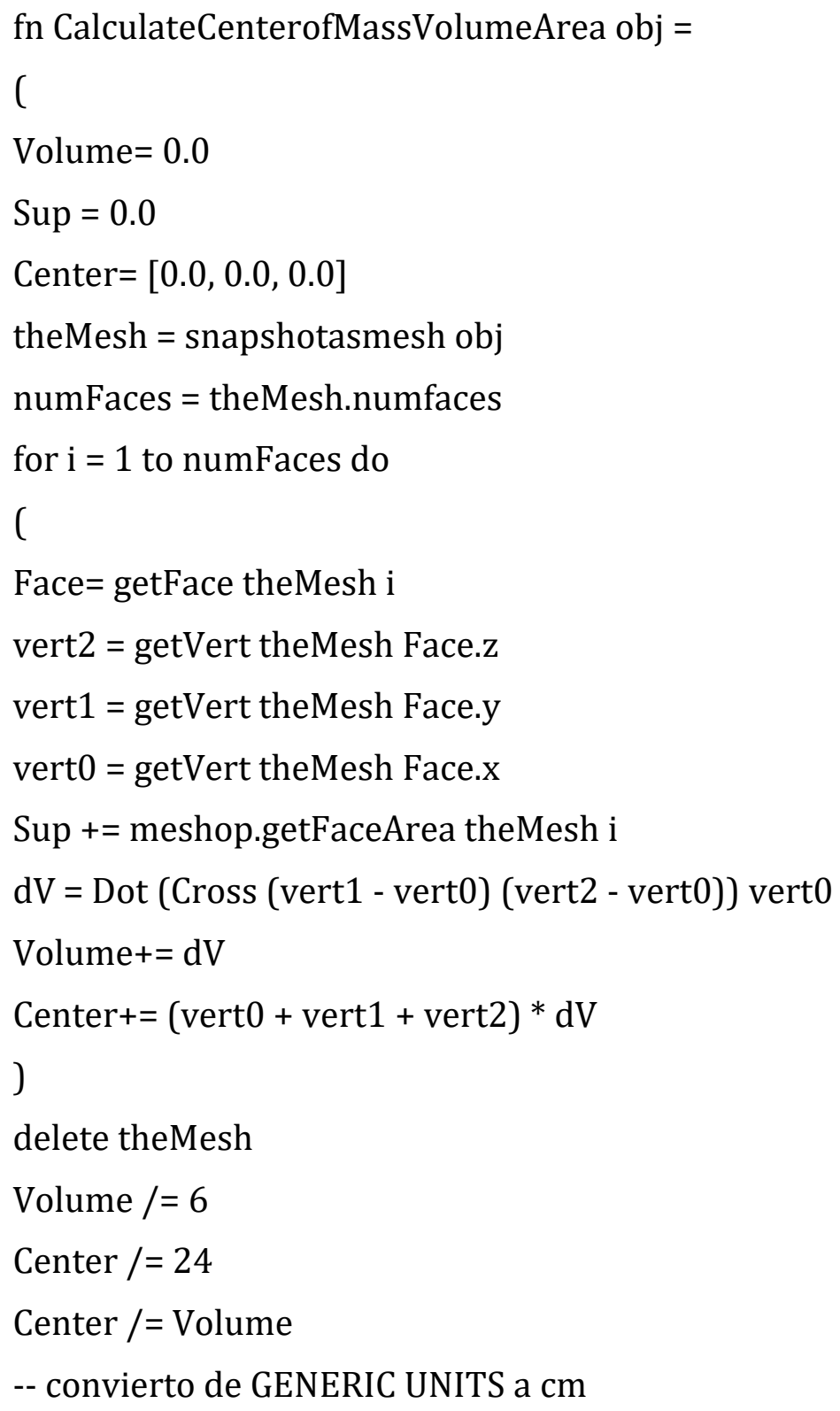

Sup $/=0.3937^{\wedge} 2$

Volume $/=0.3937^{\wedge} 3$

Center $/=0.3937$

\#(Center,Volume,Sup)

)

button btn2 "Create txt from scene" pos:[8,8] width:143 height:33 label lbl2 "Florencia Toschi" pos:[8,96] width:144 height:16 
on btn2 pressed do

(

CtvPath = getSaveFileName caption:"Save txt file as:" filename:"c:/test/test.txt" types:"Text(*.txt)|*.txt|All|*.*|"

if CtvPath != undefined then

(

btn2. caption $=$ filenameFromPath CtvPath

CtvSelection $=\$ *$ as array

out_file $=$ createfile CtvPath

for item in CtvSelection do

(

$\operatorname{tryc}$

format "\%\t\%\n" item.name

(CalculateCenterofMassVolumeArea item)[1,2,3] to:out_file

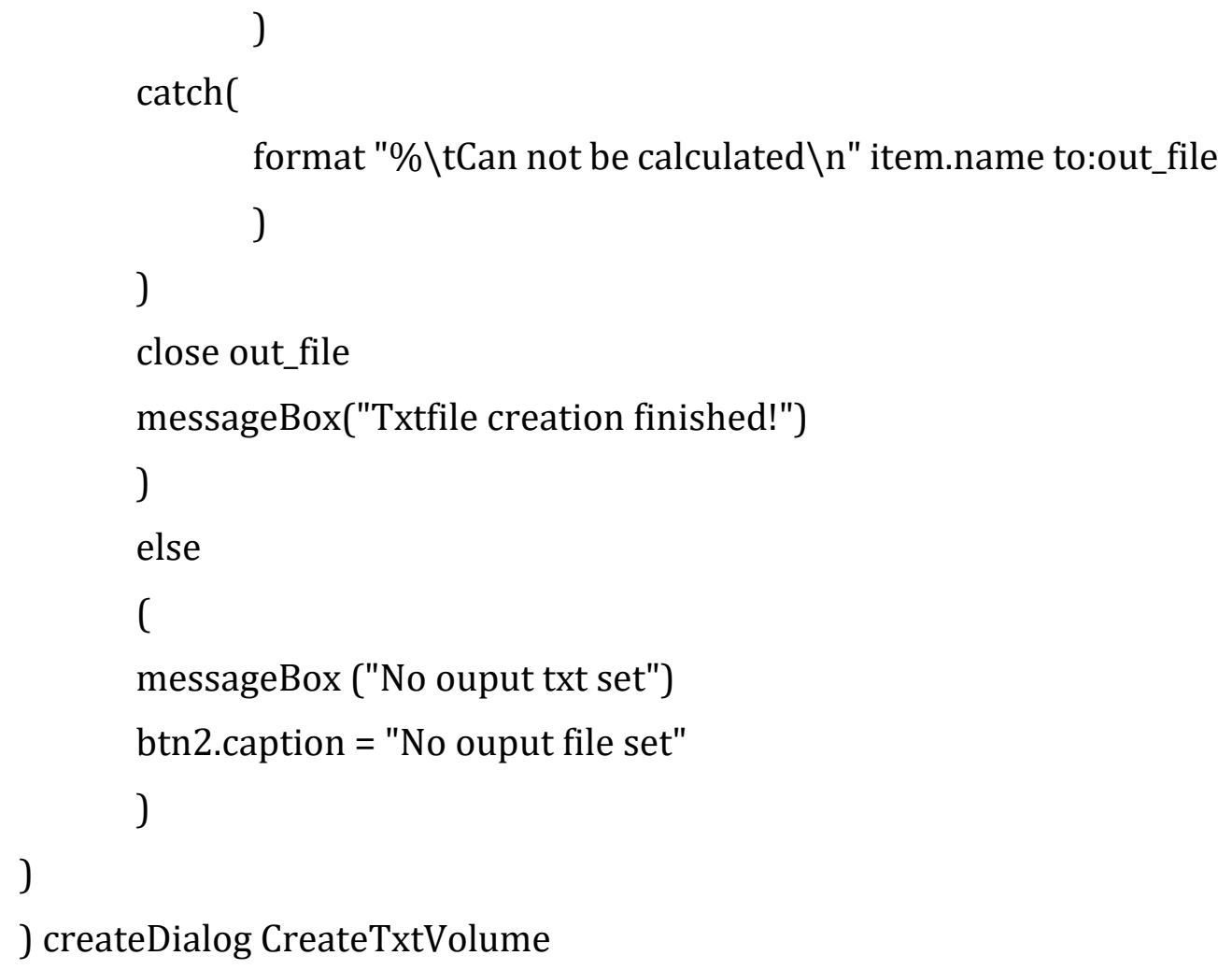




\section{A3.III.4 - CÁLCULOS PARA DATOS DE ISOSUPERFICIES}

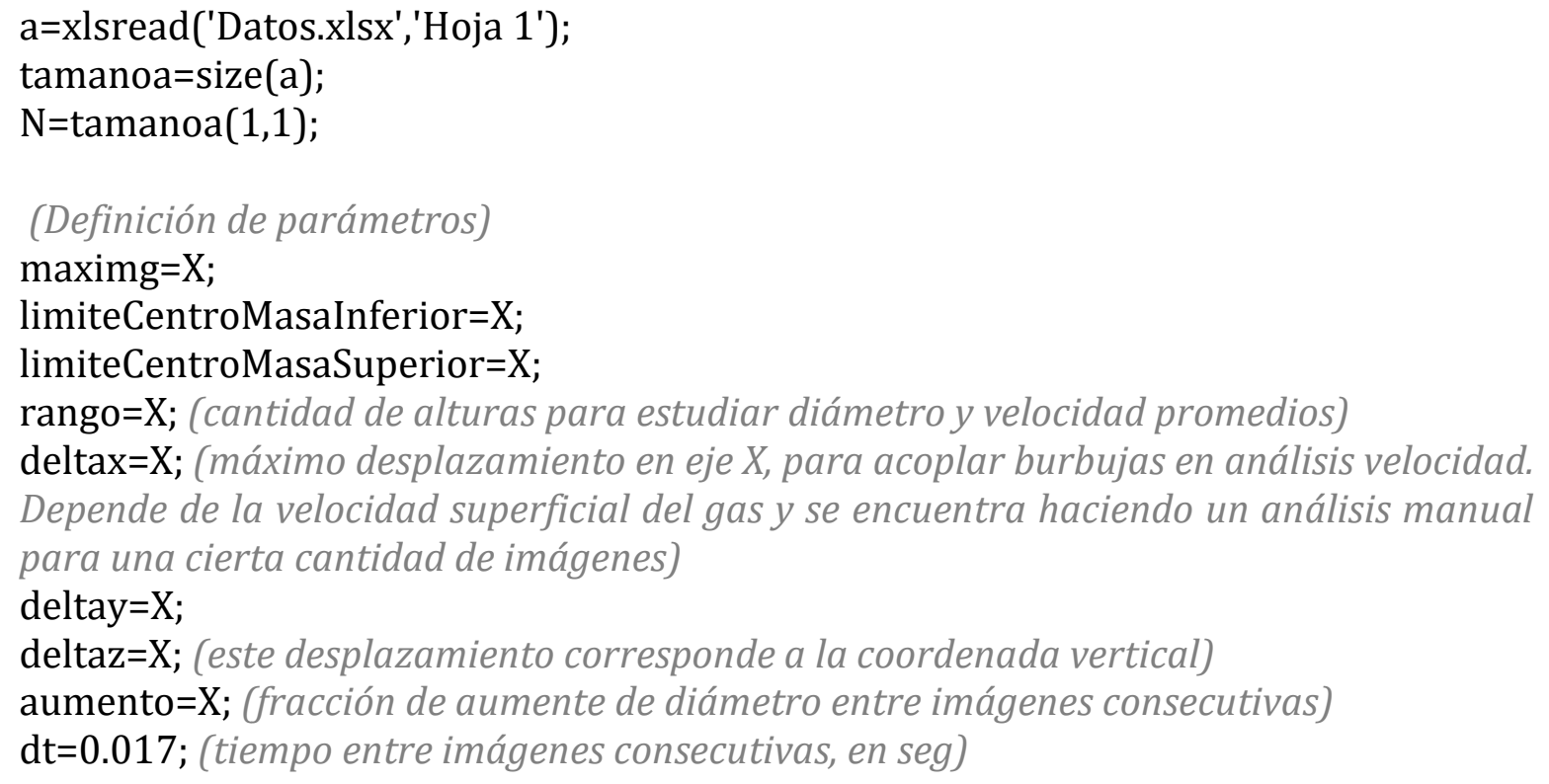

\section{A3.III.4.1 - Análisis de diámetro}

$\mathrm{b}=[]$;

$j=1$;

for $\mathrm{i}=1: \mathrm{N}$

Descarto slugs y freeboard por tener volumen NEGATIVO (todo lo que toca la pared en el programa 3DSMax, por defecto queda con volumen negativo o vol*) if $\mathrm{a}(\mathrm{i}, 8)<0$

$$
\begin{aligned}
& \text { if } \mathrm{a}(\mathrm{i}, 7)>=\text { limiteCentroMasaInferior } \\
& \text { if } \mathrm{a}(\mathrm{i}, 7)<\text { limiteCentroMasaSuperior } \\
& \mathrm{b}(\mathrm{j}, 1)=\mathrm{a}(\mathrm{i}, 1) \text {; (imagen) } \\
& \mathrm{b}(\mathrm{j}, 2)=\mathrm{a}(\mathrm{i}, 2) ; \text { (altura total, cm) } \\
& \mathrm{b}(\mathrm{j}, 3)=\mathrm{a}(\mathrm{i}, 3) ; \text { (dimensión } Z \text { de freeboard, cm) } \\
& \mathrm{b}(\mathrm{j}, 4)=\mathrm{a}(\mathrm{i}, 4) ;(\text { burbuja) } \\
& \mathrm{b}(\mathrm{j}, 5)=\mathrm{a}(\mathrm{i}, 5) ;(\text { centro de masa en } X, \mathrm{~cm}) \\
& \mathrm{b}(\mathrm{j}, 6)=\mathrm{a}(\mathrm{i}, 6) ;(\text { centro de masa en } Y, \mathrm{~cm}) \\
& \mathrm{b}(\mathrm{j}, 7)=\mathrm{a}(\mathrm{i}, 7) ;(\text { centro de masa en } Z, \mathrm{~cm}) \\
& \mathrm{b}(\mathrm{j}, 8)=\mathrm{a}(\mathrm{i}, 8) ;\left(\text { volumen, } \text { cm }^{3}\right. \text { ) } \\
& \mathrm{b}(\mathrm{j}, 9)=\mathrm{a}(\mathrm{i}, 9) ;\left(\text { área superficial, } \mathrm{cm}^{2}\right. \text { ) }
\end{aligned}
$$




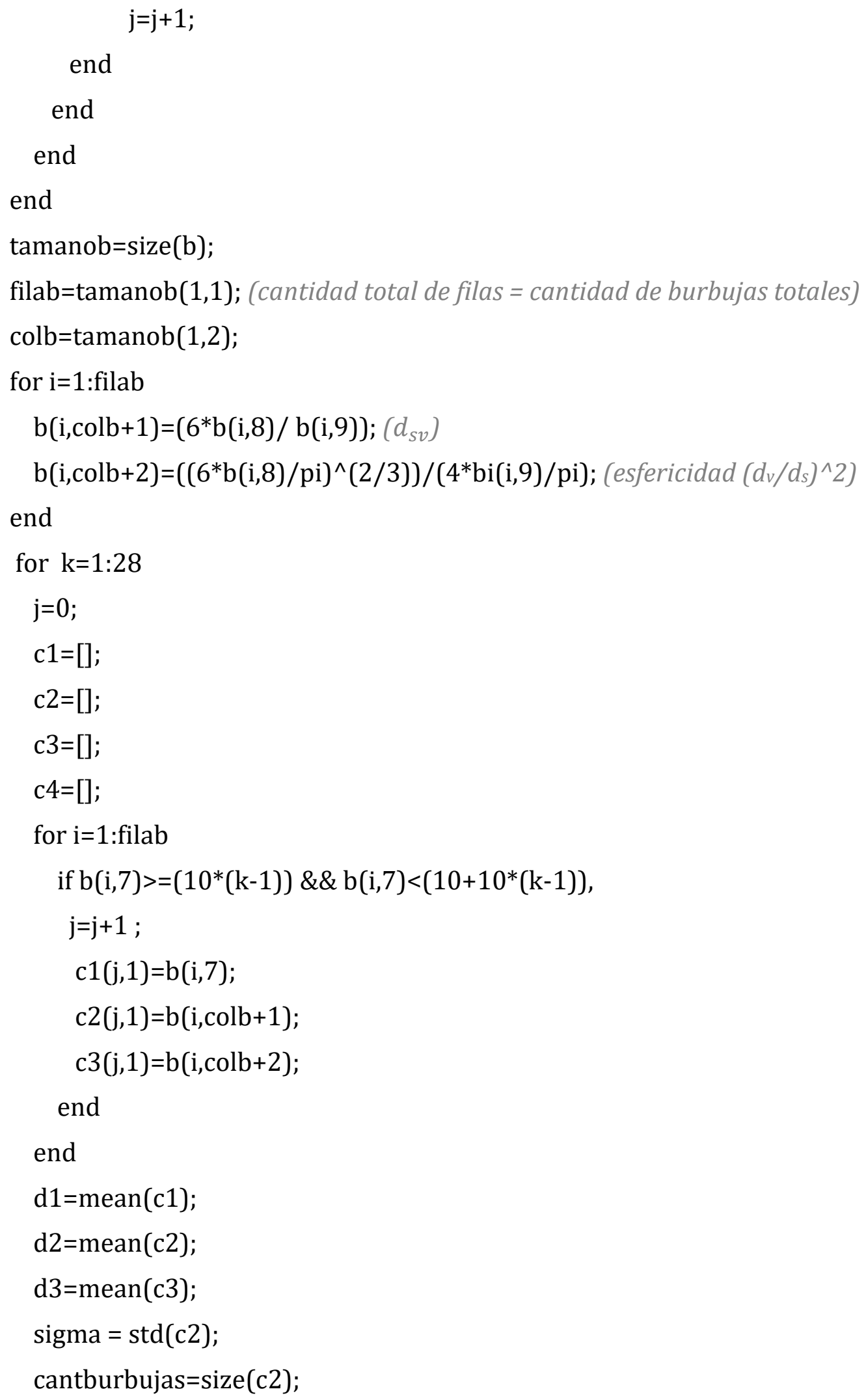



la matriz f)

if isempty(d1) (si d1 NO esta vacío, entonces se vuelcan los datos promedios a

$\mathrm{f}(\mathrm{k}, 1)=\mathrm{d} 1 / 10$; (altura promedio del rango, en $\mathrm{cm}$ )

$\mathrm{f}(\mathrm{k}, 2)=\mathrm{d} 2 / 10 ;\left(d_{s v}\right.$ promedio, en $\left.\mathrm{cm}\right)$

$\mathrm{f}(\mathrm{k}, 3)=\mathrm{d} 3$; (esfericidad promedio)

$\mathrm{f}(\mathrm{k}, 4)=$ sigma; (desvío estándar para el vector de $d_{s v}$ )

$\mathrm{f}(\mathrm{k}, 5)=$ cantburbujas(1,1); (cantidad de burbujas en el rango)

end

end

\section{A3.III.4.2 - Análisis de velocidad de burbuja}

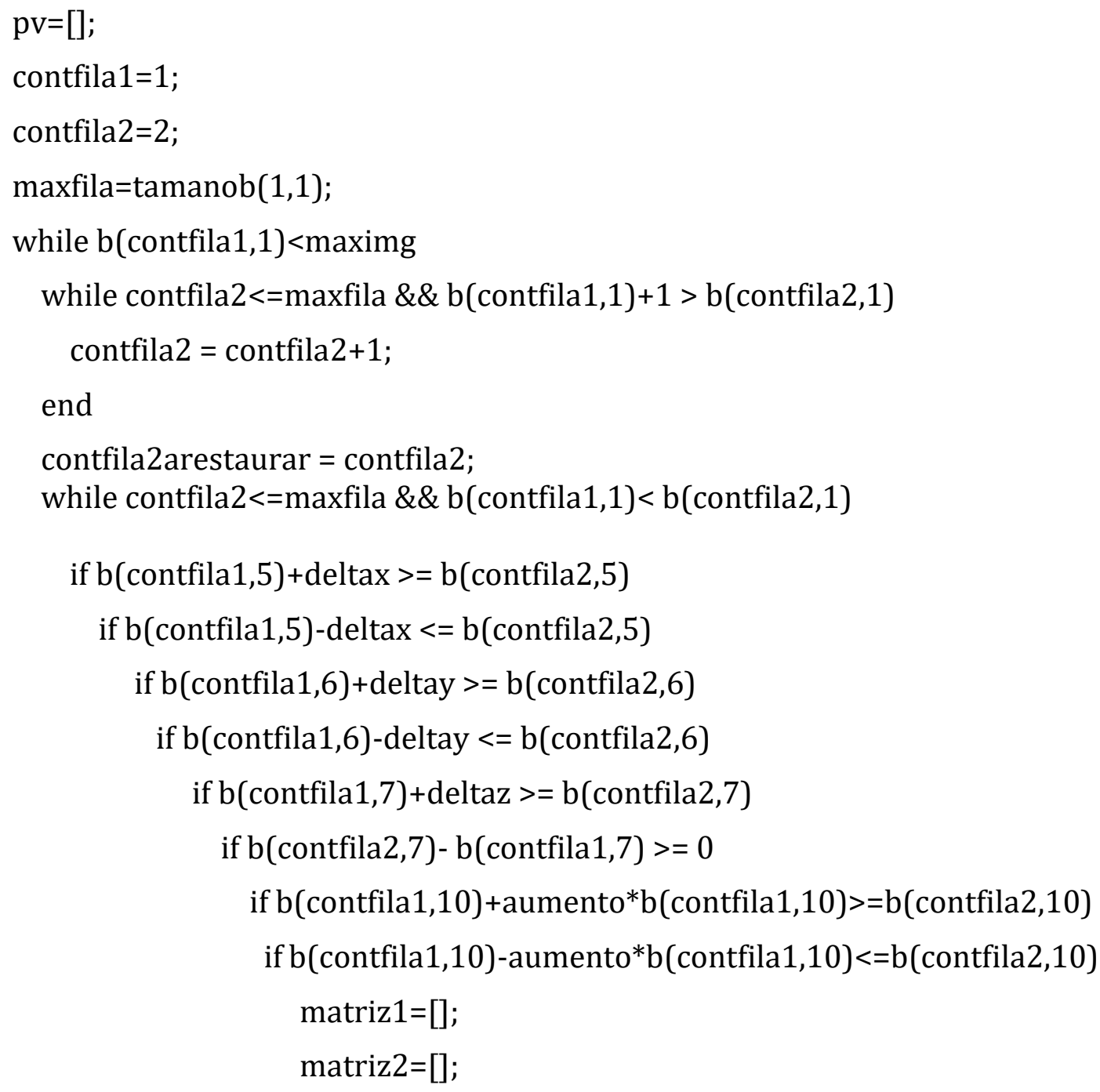




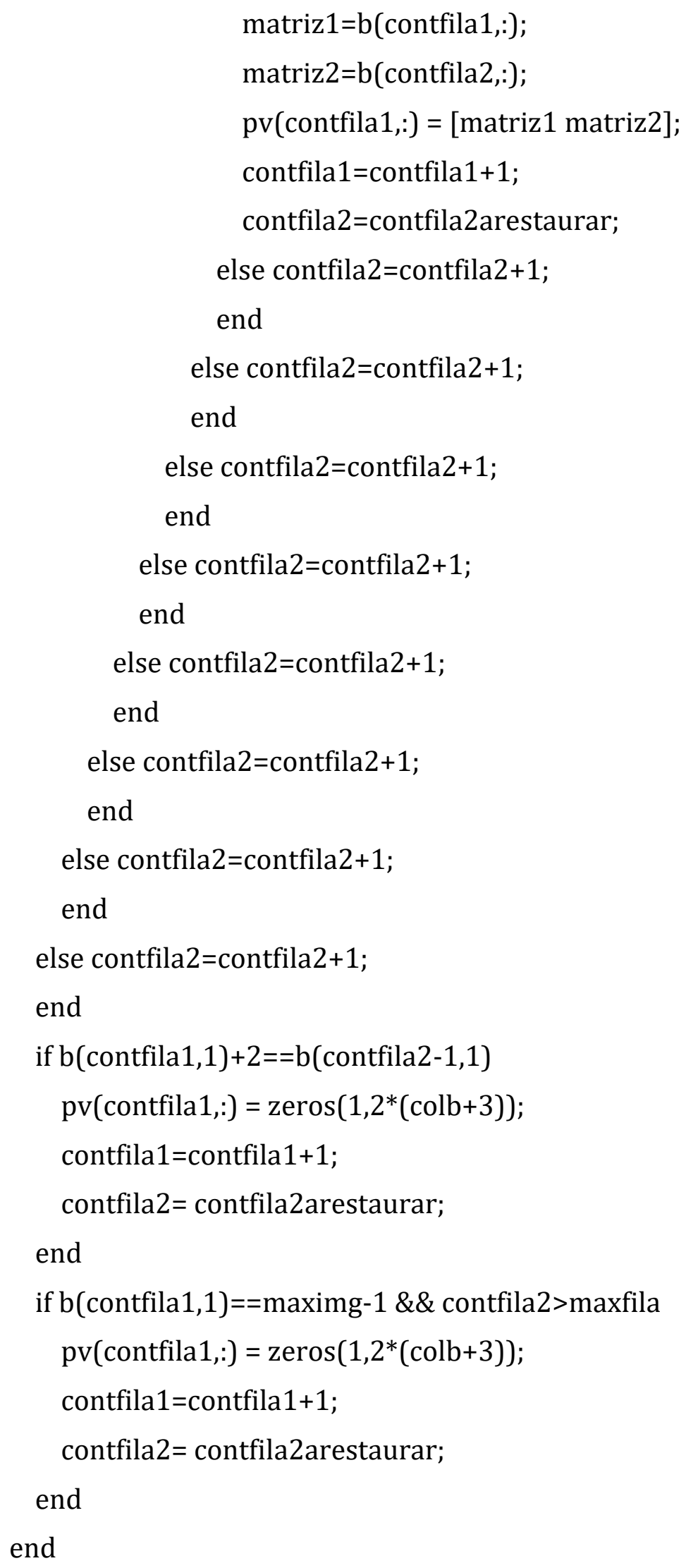




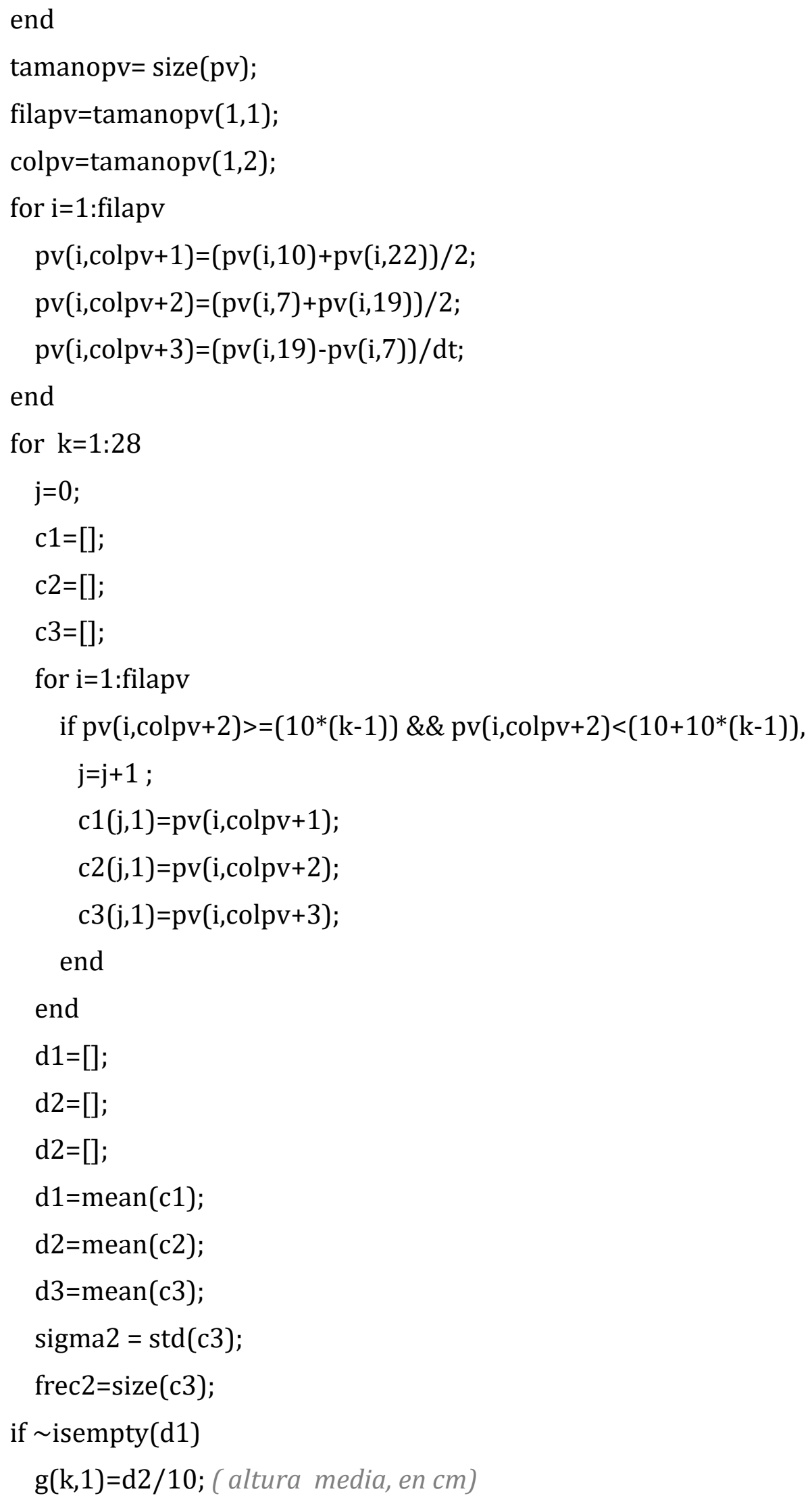




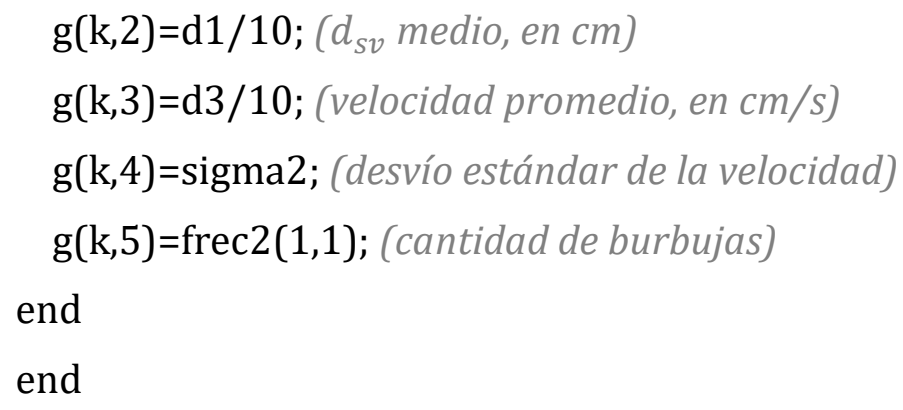




\section{CAPITULO 4}

\section{FLUIDIZACIÓN EN RÉGIMEN SLUG}

\section{INTRODUCCIÓN}

4.1 - RÉGIMEN SLUG: ASPECTOS GENERALES

4.2 - COMPORTAMIENTO FLUIDODINÁMICO DE SÓLIDOS GELDART A

\section{3 - ECUACIONES Y VARIABLES FUNDAMENTALES}

4.3.1 - Altura mínima requerida (umbral para el inicio de la formación de slugs axiales)

4.3.2 - Expansión del lecho

4.3.3 - Longitud y frecuencia de slugs

4.3.4 - Velocidad de ascenso de slugs

4.4 - DESCRIPCIÓN DE LAS FUENTES DE INFORMACIÓN EXPERIMENTAL

4.4.1 - Esquema experimental de Reyes Urrutia y colab. (2016)

4.4.2 - Esquema experimental de Kong y colab. (2017)

\section{5 - MODELADO POR CFD}

4.5.1 - Simulación del sistema correspondiente a los resultados publicados por Reyes Urrutia y colab. (2016).

4.5.2 - Simulación del sistema correspondiente a los resultados publicados por Kong y colab. (2017).

4.6 - DISCUSIÓN DE RESULTADOS 
4.6.1. - Resultados de la simulación y comparación con resultados experimentales de Reyes Urrutia y colab. (2016)

4.6.1.1 - Presencia de slugs en el lecho

4.6.1.2 - Influencia de los slugs en la transferencia de calor paredsuspensión

4.6.1.3 - Discretización axial del dominio analizado

4.6.2 - Resultados de la simulación y comparación con resultados experimentales de Kong y colab. (2017)

4.6.2.1 - Longitud de slugs

4.6.2.2 - Frecuencia de slugs

4.6.2.3 - Velocidad de slugs

4.7 - CONCLUSIONES

ANEXO 4.I: MODELADO NUMÉRICO DEL FLUJO MULTIFÁSICO

ANEXO 4.II: PROGRAMACIÓN PARA ANÁLISIS DE IMÁGENES

A4.II.1 - ANÁLISIS DE IMÁGENES

A4.II.2 - CÁLCULOS

A4.II.2.1 - Análisis de longitud de slug

A4.II.2.2 - Análisis de velocidad de ascenso de slug 


\section{INTRODUCCIÓN}

En el Capítulo 3 se trató en profundidad el régimen de fluidización burbujeante, para sólidos Geldart B y D. En ambos casos la relación de aspecto (H/D) era baja. Cuando el proceso de fluidización se lleva a cabo en lechos profundos, con elevada relación de aspecto (H/D superior a dos), la coalescencia puede llevar a la formación de burbujas con diámetros cercanos al del lecho llamadas slugs (Yates, 1983).

En la actualidad, los sistemas fluidizados circulantes con burbujeo con elevada relación de aspecto, son empleados en estudios de captación de energía solar concentrada en tubos de pared opaca. En particular, estos sistemas están constituidos por partículas Geldart A con propiedades térmicas adecuadas (capacidad calorífica y conductividad térmica elevada) que circulan por el interior de tubos de acero. En estos sistemas, las partículas conforman un vector de energía térmica cíclico capaz de captar energía para posteriormente ser utilizada en la generación de energía eléctrica (Flamant y colab., 2013, Reyes y colab., 2016).

La velocidad de ascenso de los slugs es considerablemente menor a la de una burbuja del mismo tamaño (Kong y colab., 2017), disminuyendo considerablemente el efecto sobre el mezclado de sólidos. Debido a que la elevada transferencia de calor en los lechos fluidizados se encuentra estrechamente relacionada al mezclado de sólidos generado por las burbujas, el régimen de slug incide desfavorablemente, en forma marcada con respecto a dispositivos sumergidos. En este capítulo se presenta un modelo fluidodinámico para estudiar y caracterizar los slugs, tomando como base de información experimental de dos fuentes. En primer lugar, se utilizaron los datos experimentales obtenidos en un colector solar en régimen circulante denso instalado en el laboratorio de PROMES (Reyes Urrutia y colab., 2016) en el cual se fluidizaron partículas de SiC (Geldart A). En segundo lugar, se emplearon los datos reportados por Kong y colab. (2017), quienes desarrollaron experimentos en un lecho cautivo de acrílico, de 0,05 m de diámetro interno y $2 \mathrm{~m}$ de altura, con partículas de cristobalita (Geldart A) en régimen de burbujeo y slug. 
En la sección 4.1 de este capítulo se presentan las características principales del régimen slug mientras que en la sección 4.2 se detalla el comportamiento específico de los sólidos Geldart A (que serán los analizados en el presente Capítulo). Luego, en la sección 4.3 se presentan las ecuaciones fluidodinámicas que caracterizan a los slugs. En la sección 4.4 se describen las fuentes que se toman para llevar a cabo los análisis: Reyes y colab. (2016) y Kong y colab. (2017). Posteriormente, en la sección 4.5 se detallan los parámetros considerados para las simulaciones de ambos casos: longitud, velocidad y frecuencia de los slugs y en la sección 4.6 se discuten los resultados obtenidos. Finalmente, en la sección 4.7 se vuelcan las conclusiones alcanzadas. El Capítulo cuenta además, con los Anexos 4.I y 4.II donde se describen las ecuaciones de modelado y los programas desarrollados en MATLAB para el análisis de imágenes respectivamente.

\section{1 - RÉGIMEN SLUG: ASPECTOS GENERALES}

Las características de los slugs se encuentran estrechamente relacionadas con el tipo de sólidos que se esté fluidizando. Este fenómeno tiene lugar en sistemas gassólido, así como también en sistemas líquido-sólido. En el caso de polvos finos de baja densidad, como los son los sólidos tipo Geldart A, se forman slugs axiales (Figura 4.1 a) y los sólidos caen por las paredes equiparando la velocidad de ascenso de dichos slugs. Cabe destacar que en la fluidización gas-líquido también se forman este tipo de slugs (Kunii y Levenspiel, 1991).

Cuando las paredes del recipiente presentan cierta rugosidad o los sólidos son angulares, los slugs tienden a adherirse a las mismas, como puede observarse en la Figura 4.1 b, formando los llamados slugs de pared. En la actualidad, los estudios en tubos con alta relación de aspecto, revelan que el régimen de slugs de pared ocurre a una altura menor a la que ocurre el régimen de slugs axiales, con una zona de transición entre ambos y una región inferior de burbujas (Sabatier y colab., 2020)

En la fluidización de sólidos de gran tamaño y densidad, tipo Geldart D, se forman los llamados slugs planos (Figura $4.1 \mathrm{c}$ ). En este caso el lecho se divide en porciones de emulsión separadas por gas que ascienden en el lecho, mientras se produce una lluvia de sólidos entre dichas porciones (Kunii y Levenspiel, 1991). 


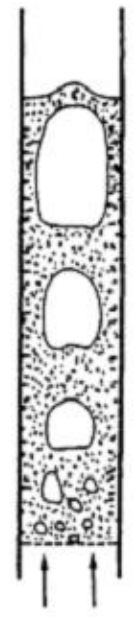

a

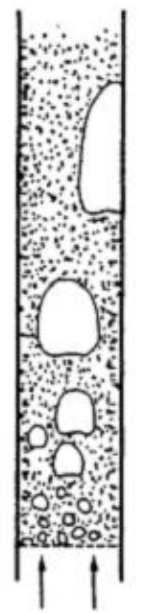

b

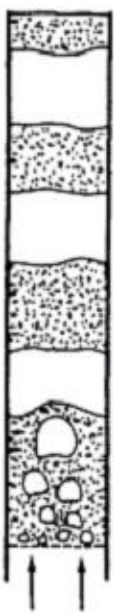

C

Figura 4.1 - Tipos de slugs presentes en lechos fluidizados: a- axial, b- de pared, cplano. (Fuente: Kunii y Levenspiel, 1991).

\section{2 - COMPORTAMIENTO FLUIDODINÁMICO DE SÓLIDOS GELDART A}

Si bien los sólidos de mayor tamaño y densidad también forman slugs, en el presente trabajo se hace foco en aquellos formados por polvos Geldart A. Estos sólidos son de interés debido, por un lado, a su uso como catalizador en reactores de lecho fluidizado (Kunii y Levenspiel, 1991), y por otro, a su aplicación como vector de térmico en colectores solares con tubos cilíndricos de bajo diámetro (Flamant y colab., 2013).

Para los sólidos Geldart A, a diferencia de lo que ocurre con partículas Geldart B, las velocidades $U_{m f}$ y de mínimo burbujeo $\left(U_{m b}\right)$ no resultan coincidentes, como puede observarse en la Figura 4.2. Los lechos cargados con estos sólidos se expanden significativamente para velocidades entre $U_{m f}$ y $U_{m b}$. Superando $U_{m b}$ comienza el burbujeo, y la altura del lecho disminuye debido a que la formación de burbujas reduce la porosidad del lecho $\left(\varepsilon_{m b}<\varepsilon_{m f}\right)$. Al aumentar aún más la velocidad $U$, se produce un incremento neto de la altura del lecho, las burbujas se rompen y re-coalescen, alcanzando un tamaño máximo de burbuja o formando slugs en lechos de diámetro pequeño. Para velocidades aún mayores, se operará en régimen turbulento y luego en un sistema circulante (Kong y colab., 2017). 


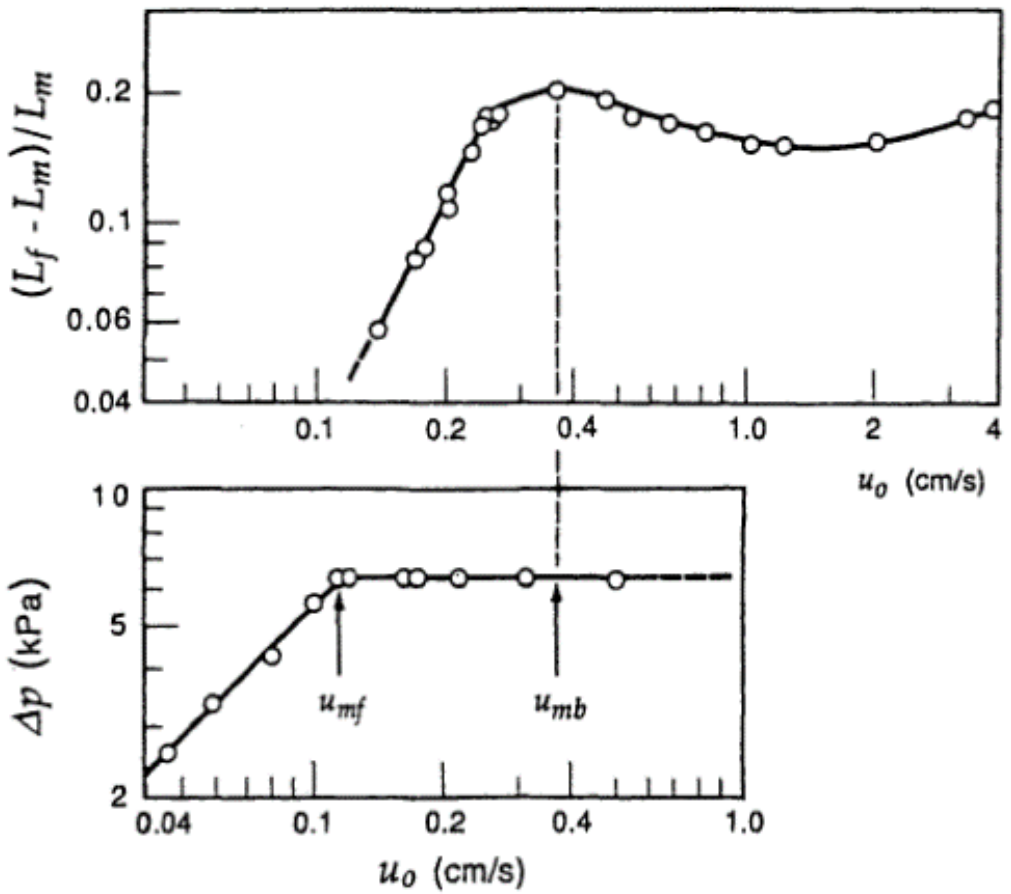

Figura 4.2 - Expansión del lecho y velocidades características $U_{m f}$ y $U_{m b}$ para partículas Geldart A. (Fuente: Kunii y Levenspiel, 1991).

\section{3 - ECUACIONES Y VARIABLES FUNDAMENTALES}

A continuación, se realiza una descripción de las ecuaciones y variables relevantes para el análisis del régimen de slugs.

\subsection{1 - Altura mínima requerida (umbral para el inicio de la formación de} slugs axiales)

Según el estudio realizado por Baeyens y Geldart (1974), cuando los lechos profundos operan a velocidades superficiales de gas superiores a las de mínima fluidización, existen tres zonas: (I) burbujeante, (II) slugs que van creciendo por coalescencia y (III) se completa la coalescencia de slugs y se establece un espaciado estable entre los mismos. Los autores proponen la siguiente ecuación para calcular la altura del lecho necesaria para alcanzar esta zona estable:

$$
H_{L}=60 D^{0,175}
$$

donde el diámetro, $D$, se expresa en $\mathrm{cm}$. 


\subsection{2 - Expansión del lecho}

Los lechos con presencia de slugs presentan oscilaciones en su superficie debido a su erupción. Basados en la teoría de las dos fases, Matsen y colab. (1969) desarrollaron la ecuación de expansión:

$$
\frac{\left(H_{\max }-H_{m f}\right)}{H_{m f}}=\frac{\left(U-U_{m f}\right)}{0,35 \sqrt{g D}}
$$

Realizando un balance de materia de sólidos y gas, puede calcularse la longitud de los slugs del siguiente modo (Yang, 2003):

$$
L_{s}=\frac{\left(U-U_{m f}\right) N_{T} \sqrt{D}}{0,35 \sqrt{g}}
$$

donde $N_{T}$ es la cantidad de diámetros de lecho entre la parte inferior de un slug y la punta del slug siguiente, valor que debe ser determinado de modo experimental. En caso que haya presencia de slugs de pared, Kong y colab. (2017) proponen la siguiente ecuación:

$$
L_{s}=\frac{\left(U-U_{m f}\right) N_{T} \sqrt{D}}{0,7 \sqrt{g}}
$$

La frecuencia de slugs puede expresarse como:

$$
f_{s}=\frac{\left(U-U_{m f}\right)}{L_{s}}=\frac{0,35 \sqrt{g}}{N_{T} \sqrt{D}}
$$

Puede observarse, teniendo en cuenta la ecuación 4.3, que el cálculo de frecuencia $f_{s}$ no depende de la velocidad superficial del gas $(U)$.

Considerando trabajos previos (Baeyens y Geldart (1974), Yamazaki y colab. (1985), Weimer y Quarderer (1985)) y resultados experimentales propios, Kong y colab. (2017) proponen un valor de $N_{T}=1,4 / D^{0,35}$, pero además consideran que el factor $0,35 \sqrt{g}$ es válido para slugs axiales, mientras que para slugs de pared dicho valor debe ser reemplazado por $0,7 \sqrt{g}$. 


\subsection{4 - Velocidad de ascenso de slugs}

Al igual que en el caso de las burbujas, la velocidad de ascenso de los slugs es importante ya que tiene gran influencia en el contacto entre los sólidos y el gas, y en el caso de tratarse de un lecho con reacción química esto se ve traducido directamente en la conversión de dicho proceso (Müller y colab., 2007).

Según Stewart y Davidson (1967), la velocidad de ascenso de un slug axial está dada por:

$$
u_{S}=0,35 \sqrt{g D}
$$

En el caso de los slugs de pared, Birkhoff y Carter (1975) asumieron que se comportan como un slug axial pero en un lecho de dos dimensiones, por lo que su velocidad de ascenso es $\sqrt{2}$ veces superior. Kong y colab. (2017), basados en trabajos previos de Baeyens y Geldart (1974), proponen que la velocidad de los slugs de pared está dada por:

$$
u_{S}=0,7 \sqrt{g D}
$$

Se entiende, en cambio, que la velocidad de ascenso de los slugs planos es inferior a la de los axiales y Rudolph y Judd (1985) proponen la ecuación:

$$
u_{S}=0,18 \sqrt{g D}
$$

En el caso de lechos en los que hay una formación continua de slugs axiales, debe sumarse la velocidad de exceso a aquélla de un único slug, al igual que en el caso de lechos burbujeantes (Müller y colab., 2007), de modo que se obtiene la expresión:

$$
u_{S}=\left(U-U_{m f}\right)+0,35 \sqrt{g D}
$$

En el caso de tener formación continua de slugs de pared, le expresión propuesta por Kong y colab. (2017) es:

$$
u_{S}=\left(U-U_{m f}\right)+0,7 \sqrt{g D}
$$




\section{4 - DESCRIPCIÓN DE LAS FUENTES DE INFORMACIÓN EXPERIMENTAL}

\subsection{1 - Esquema experimental de Reyes Urrutia y colab. (2016)}

Reyes Urrutia y colab. (2016) llevaron a cabo el modelado mediante CFD de la transferencia de calor entre la pared de un tubo colector solar de pared opaca y una suspensión densa de partículas de $\mathrm{SiC}$ utilizada como vector de calor. Las partículas, de 0,064 mm de diámetro (Figura 4.3) corresponden a la clasificación Geldart A. El tubo, ubicado en el foco de un horno solar de $1 \mathrm{MW}$, forma parte de un prototipo experimental (Figura 4.4) perteneciente al laboratorio PROMES-CNRS, Font-Romeu, Pirineos Orientales, Francia. El lecho del sistema ((1) en la Figura 4.5) está constituido por una suspensión densa de partículas Geldart A. El tubo tiene una longitud de 2,6 m y un diámetro interno $D=0,036 \mathrm{~m}$. La suspensión circula por este tubo en sentido ascendente debido a la diferencia de presión. Flamant y colab. (2013) presentaron una descripción detallada del sistema.

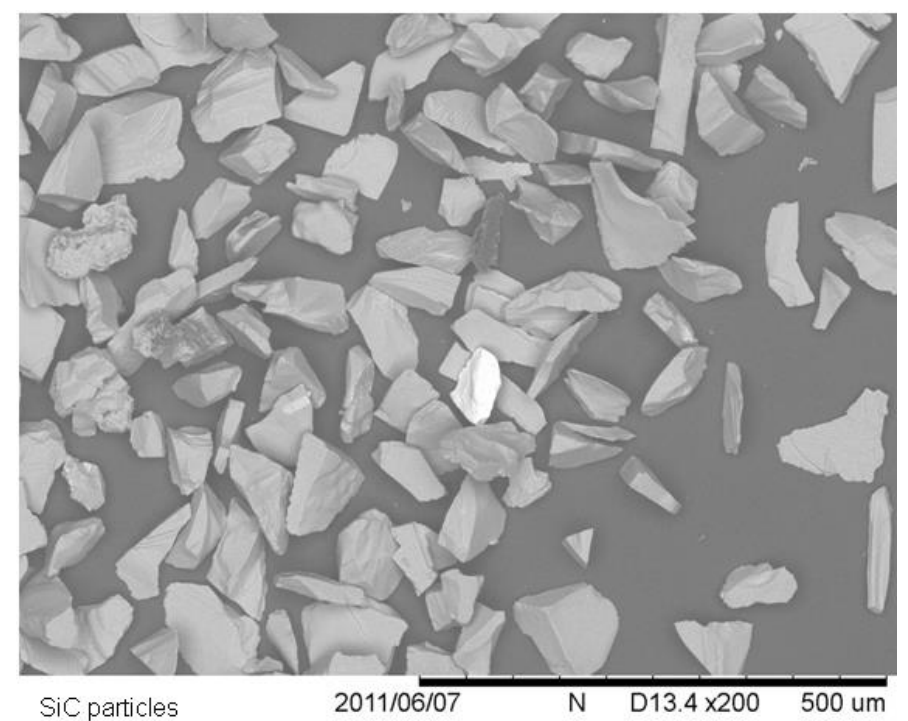

Figura 4.3 - Imagen de las partículas de SiC tomada con microscopio de barrido electrónico SEM (PROMES-CNRS, Francia). 


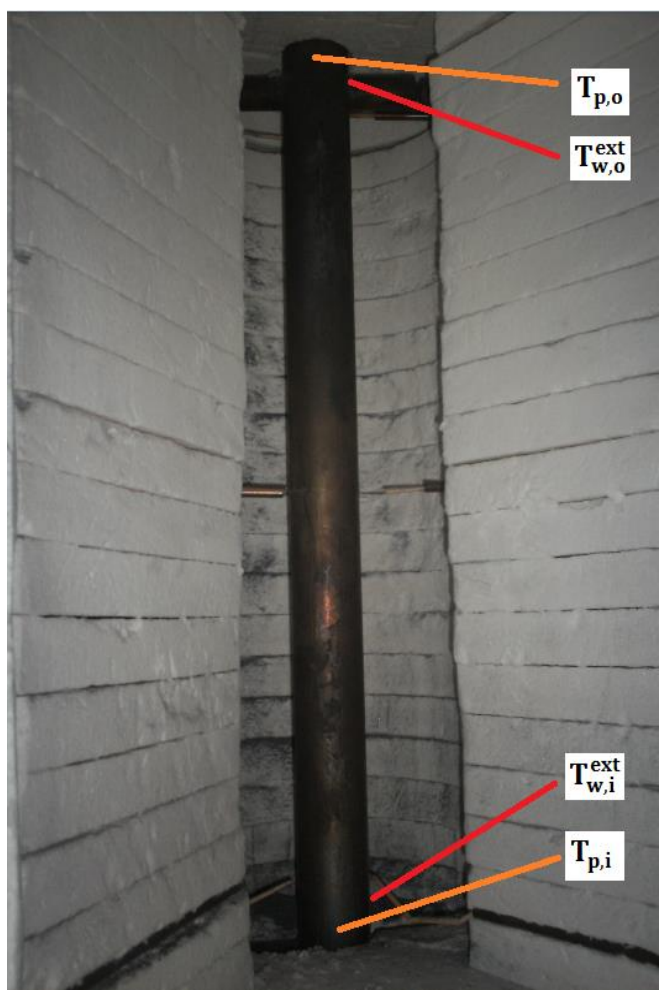

Figura 4.4 - Imagen de la región del tubo receptora de energía solar concentrada. Tp,i es la temperatura de la suspensión SiC-aire al ingresar a la zona de transferencia de calor, $\mathrm{T}_{\mathrm{p}, \mathrm{o}}$ es la temperatura a la salida. Las $\mathrm{T}_{\mathrm{w}}^{\mathrm{ext}}$ a son las temperaturas medidas en la cara externa del tubo en la parte baja y alta.

Una parte del lecho (1) recibe la energía solar concentrada en el foco de la gran parábola del horno solar del laboratorio PROMES. En la Figura 4.4 se muestra la zona de recepción de 0,5 $\mathrm{m}$ de largo. $\mathrm{T}_{\mathrm{p}, \mathrm{o}}$, es la temperatura a la que la emulsión abandona la zona de transferencia de calor; $\mathrm{T}_{\mathrm{p}, \mathrm{i}}$ corresponde al valor de temperatura de la emulsión en el ingreso a la zona de transferencia. El valor de $\mathrm{T}_{\mathrm{p}, \mathrm{i}}$ es muy superior al valor de la temperatura en el lecho fluidizado (2), indicado en la Figura 4.5, lo que revela la existencia de una gran recirculación de material sólido hacia región inferior del sistema. 


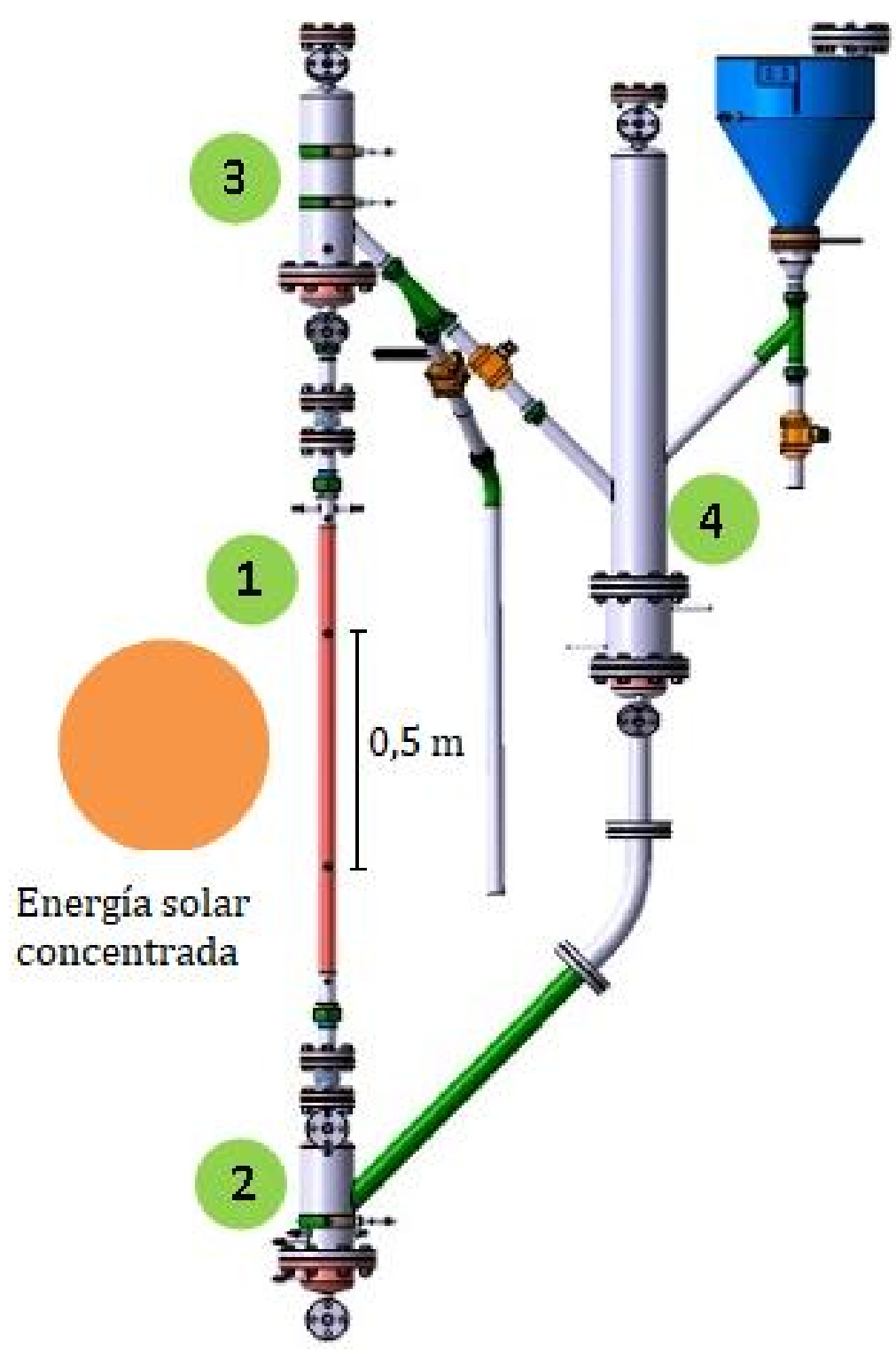

Figura 4.5 - Vista esquemática del sistema de recepción (Flamant y colab., 2013): (1) tubo metálico receptor de energía; (2) lecho fluidizado generador del flujo ascendente de la suspensión; (3) lecho fluidizado receptor; (4) lecho fluidizado con camisa externa para la generación de vapor.

En la Tabla 4.1 se presentan las propiedades termofísicas de las partículas empleadas. 
Tabla 4.1 - Propiedades físicas de las partículas de SiC utilizadas en las experiencias del Laboratorio PROMES.

\begin{tabular}{|c|c|}
\hline Parámetro & Valor \\
\hline$d_{p}[\mathrm{~mm}]$ & 0,064 \\
\hline$\psi$ & 0,77 \\
\hline$\rho_{s}\left[\mathrm{~kg} / \mathrm{m}^{3}\right]$ & 3210 \\
\hline$C_{p, s}[\mathrm{~J} / \mathrm{kgK}]$ & $-2,31+2,73 \mathrm{~T}_{\mathrm{p}}-1,6 \times 10^{-3} \mathrm{~T}_{\mathrm{p}}^{2}$ \\
\hline$k_{p, o}[\mathrm{~W} / \mathrm{mK}]$ & $194,7-0,4 \mathrm{~T}_{\mathrm{p}}+3,3 \times 10^{-4} \mathrm{~T}_{\mathrm{p}}^{2}-1,5 \times 10^{-7} \mathrm{~T}_{\mathrm{p}}^{3}+2,5 \times 10^{-11} \mathrm{~T}_{\mathrm{p}}^{4}$ \\
\hline$\varepsilon_{m f}$ & 0,57 \\
\hline$\varepsilon_{m b}$ & 0,59 \\
\hline$U_{m f}[\mathrm{~m} / \mathrm{s}]$ & 0,005 \\
\hline$U_{m b}[\mathrm{~m} / \mathrm{s}]$ & 0,0066 \\
\hline
\end{tabular}

\subsection{2 - Esquema experimental de Kong y colab. (2017)}

Kong y colab. (2017) desarrollaron experimentos en un lecho cautivo de acrílico, de 0,05 m de diámetro interno y $2 \mathrm{~m}$ de altura, con partículas Geldart A. En el estudio, se observó la formación de slugs los cuales fueron analizados mediante tres metodologías. En primer lugar, en los experimentos se observó la superficie del lecho, donde en lugar de las erupciones aleatorias debidas a un patrón burbujeante se generaron erupciones periódicas del tipo pistón. A partir de registrar el tiempo entre las erupciones, se evaluó la frecuencia. Por otro lado, se analizaron las fluctuaciones de presión colocando un sensor sobre el distribuidor (en esta zona se producen grandes fluctuaciones de presión cuando explotan las burbujas o los slugs en la superficie del lecho). Por último, se iluminó el lecho desde su parte posterior y se colocó una escala milimétrica sobre la pared exterior del lecho, obteniéndose imágenes a contraluz mediante una cámara de alta velocidad. Estas imágenes fueron analizadas para obtener registros de velocidad, longitud y frecuencia de slugs a determinados valores de altura del lecho, así como también datos de porosidad. 
En la Tabla 4.2 se muestran las propiedades de las partículas empleadas, características del sistema fluidizado y condiciones fluidodinámicas reportadas por Kong y colab. (2017).

Tabla 4.2 - Resumen de parámetros experimentales (Kong y colab., 2017).

\begin{tabular}{|l|c|}
\hline \multicolumn{1}{|c|}{ Parámetro } & Valor \\
\hline$d_{p}[\mathrm{~mm}]$ & 0,075 \\
\hline$\rho_{s}\left[\mathrm{~kg} / \mathrm{m}^{3}\right]$ & 2720 \\
\hline$\rho_{\text {bulk }}\left[\mathrm{kg} / \mathrm{m}^{3}\right]$ & 1388 \\
\hline $\mathrm{D}[\mathrm{m}]$ & 0,05 \\
\hline $\mathrm{H}[\mathrm{m}]$ & 2,0 \\
\hline$U_{m f}[\mathrm{~m} / \mathrm{s}]$ & 0,006 \\
\hline$U_{m b}[\mathrm{~m} / \mathrm{s}]$ & 0,0095 \\
\hline$H_{m f}[\mathrm{~m}]$ & 0,75 \\
\hline$H_{m b}[\mathrm{~m}]$ & 0,964 \\
\hline
\end{tabular}

\section{5 - MODELADO POR CFD}

En esta sección se describe la metodología adoptada para la simulación CFD de los sistemas descriptos en las sub-secciones 4.4.1 y 4.4.2. Las simulaciones se realizaron con el software ANSYS-Fluent, aplicando el enfoque multifase Euleriano-Euleriano.

De acuerdo a lo descripto en el Anexo 3.II, del Capítulo 3, en primer lugar, se construyó la geometría de los sistemas a simular en el entorno ANSYS-Design Modeler y se procedió al mallado correspondiente. Luego, cada sistema requiere la utilización de un conjunto apropiado de las ecuaciones descriptas también en el Anexo 3.II, atendiendo a los requerimientos de los fenómenos involucrados. Las particularidades de cada conjunto simulado se describen en las siguientes sub-secciones. En el Anexo 4.I se incluye el desarrollo de ecuaciones específicas utilizadas en este Capítulo. 


\subsection{1 - Simulación del sistema correspondiente a los resultados publicados por Reyes Urrutia y colab. (2016).}

El trabajo de modelado presentado previamente Reyes Urrutia y colab. (2016), se centraba en la zona de transferencia de calor del tubo. En el presente trabajo, se incluye la parte baja aislada del sistema experimental de 0,8 $\mathrm{m}$ de longitud. De esta forma, los efectos de la recirculación hacia la región aislada inferior del lecho también son incluidos en el modelo CFD.

El objetivo específico de esta sección del trabajo es caracterizar en detalle el comportamiento de las fases gas y sólido granular en el lecho presentado en la Figura 4.5. Para ello, se realizaron simulaciones con y sin transferencia de calor entre la pared del lecho y la suspensión densa de partículas de SiC. Para validar el modelo, los resultados proporcionados por la simulación se comparan con resultados experimentales obtenidos en el prototipo expuesto en la Figura 4.5.

En la Figura 4.6a se presenta el dominio adoptado para desarrollar las diferentes simulaciones junto a las condiciones de borde adoptadas. En el caso de las simulaciones con transferencia de calor, el azul corresponde a regiones aisladas del tubo. En rojo, se indica la región del tubo posicionada en el foco de la gran parábola de PROMES. La zona baja corresponde a la región comprendida entre el lecho fluidizado inferior y el ingreso a la zona expuesta a la energía solar concentrada. La región azul superior, corresponde a la porción del tubo posterior a la zona de transferencia de calor. La finalidad de la incorporación de este tramo de tubo es poder resolver de manera adecuada la eventual recirculación de sólido granulado desde esta parte del dominio hacia la región de transferencia de energía.

También se llevó a cabo una simulación sin transferencia de calor. En este caso no fue necesario resolver el balance de energía. 


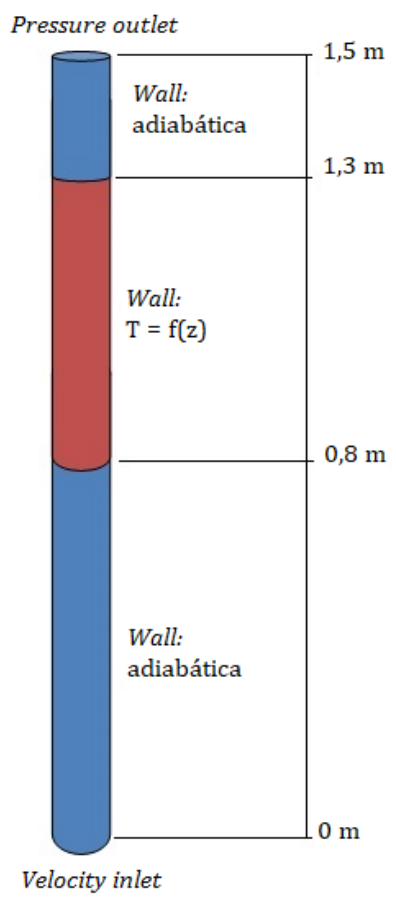

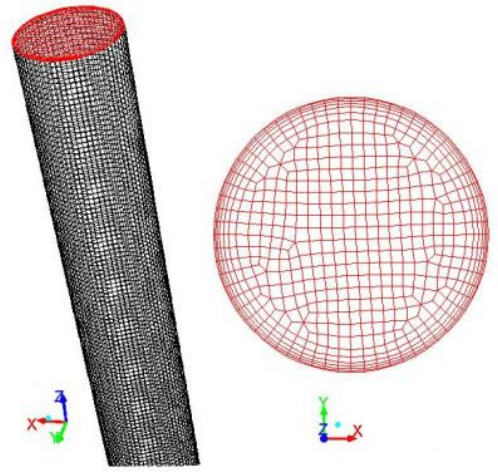

$\mathrm{b}$

Figura 4.6 - Dominio adoptado en la simulación mediante CFD (a) y mallado estructurado utilizado en las simulaciones (b): vista lateral del tubo y sección transversal del mismo.

\section{Malla utilizada}

La discretización del dominio se llevó a cabo empleando una malla estructurada, refinada en la región próxima a la pared del tubo, que consta de un total de 531000 elementos hexaédricos (Figura 4.6b).

Condiciones de borde

a. Base del tubo (Velocity inlet):

$\checkmark$ Energía: ingresan aire y partículas de SiC a la temperatura promedio determinada experimentalmente $\mathrm{T}_{\mathrm{p}, \mathrm{cold}}$.

$\checkmark$ Cantidad de movimiento: ingresa sólido con velocidad lineal $u_{p} \mathrm{y}$ fracción $\varepsilon_{p}$, correspondientes a los valores medios determinados a partir del caudal de sólido y la pérdida de carga de cada ensayo experimental. Para el gas la velocidad intersticial es $u_{g}=u_{p}+u_{m f}$. La 
dirección de la velocidad de ambas fases se supone perpendicular al plano de ingreso.

Los valores de temperatura y velocidad para cada fase empleados en las simulaciones se muestran en la Tabla 4.3. Las simulaciones 1 y 2 corresponden a caudales másicos de SiC 42,35 kg/h y 87,80 kg/h, respectivamente. Para la simulación a temperatura ambiente, las condiciones de ingreso de ambas fases coinciden con las de alto caudal con transferencia de calor.

Tabla 4.3 - Condiciones de borde empleadas en la entrada del tubo.

\begin{tabular}{|c|c|c|c|c|c|}
\hline Run & $u_{p}[\mathrm{~m} / \mathrm{s}]$ & $u_{g}[\mathrm{~m} / \mathrm{s}]$ & $\varepsilon_{p}$ & $\mathrm{~T}_{\mathrm{p}, \text { cold }}[\mathrm{K}]$ & $\mathrm{T}_{\mathrm{g}, \text { cold }}[\mathrm{K}]$ \\
\hline 1 & 0,012 & 0,025 & 0,31 & 300,53 & 300,53 \\
\hline 2 & 0,024 & 0,039 & 0,31 & 317,28 & 317,28 \\
\hline 3 & 0,024 & 0,039 & 0,31 & ----- & ----- \\
\hline
\end{tabular}

b. Paredes del tubo (Wall):

$\checkmark$ Energía: para las simulaciones con transferencia de calor, la región del tubo expuesta a la energía solar concentrada fue considerada como una pared con un perfil de temperatura a lo largo de la coordenada $z$ (h), definido a partir de los valores medios de temperatura de pared determinados experimentalmente. La función de temperatura de pared interna en función de la altura $h$ fue programada en lenguaje $\mathrm{C}++\mathrm{e}$ incorporada al algoritmo de la simulación. En la Tabla 4.4 se muestra dicha función. Las paredes de las regiones previa y posterior a la zona de transferencia de energía se consideraron adiabáticas. Las simulaciones a temperatura ambiente no requieren especificar esta condición.

$\checkmark$ Cantidad de movimiento: la condición de no deslizamiento (No slip) fue aplicada a ambas fases en toda la pared para todas las simulaciones. 
Tabla 4.4 - Funciones de temperaturas de pared interna utilizadas en la simulación.

\begin{tabular}{|c|c|c|}
\hline$\dot{\mathrm{m}}_{\mathrm{SiC}}[\mathrm{kg} / \mathrm{h}]$ & Intervalo & $\mathrm{T}_{\mathrm{w}, \mathrm{h}}^{\text {int }}[\mathrm{K}]$ \\
\hline \multirow{2}{*}{42,35} & $0,8 \mathrm{~m}<\mathrm{h} \leq 1,05 \mathrm{~m}$ & $401,84+196,92 \mathrm{~h}$ \\
& $1,05 \mathrm{~m}<\mathrm{h}<1,3 \mathrm{~m}$ & $616,97-7,96 \mathrm{~h}$ \\
\hline \multirow{2}{*}{87,80} & $0,8 \mathrm{~m}<\mathrm{h} \leq 1,05 \mathrm{~m}$ & $326,30+223,16 \mathrm{~h}$ \\
& $1,05 \mathrm{~m}<\mathrm{h}<1,3 \mathrm{~m}$ & $558,69+1,84 \mathrm{~h}$ \\
\hline
\end{tabular}

c. Parte superior del tubo (Pressure outlet):

Se fijó un valor nulo de la presión manométrica. Solo es admitido el retroflujo de gas en dirección perpendicular a la superficie del plano de salida.

\section{Condiciones iniciales}

Las simulaciones se iniciaron con un lecho fijo de partículas $\mathrm{SiC}$, con altura $H=$ $0,2 \mathrm{~m}$ y porosidad $\varepsilon=0,4$. Para las simulaciones con transferencia de calor, la temperatura del sistema coincide inicialmente con la de la emulsión que ingresa por el fondo $\left(\mathrm{T}_{\mathrm{p}, \text { cold }}\right)$.

Todas las simulaciones se llevaron a cabo en estado transitorio, adoptándose un paso de tiempo de 0,001 segundos, con 40 iteraciones por paso, lo que aseguró la convergencia adecuada durante las simulaciones. Se seleccionó el método de resolución Pressure based. La discretización espacial de los términos convectivos presentes en las ecuaciones de resolución se realizó mediante un esquema de segundo orden.

Las simulaciones con transferencia de calor muestran que en primera instancia se logra una pérdida de carga que alcanza un valor estable (y por lo tanto una fracción de sólido promedio estable). Luego se alcanzó el estado pseudo-estacionario térmico en el que la temperatura de la suspensión oscila en torno a un valor medio constante a diferentes alturas del dominio.

El tiempo de cómputo para la simulación a temperatura ambiente fue de 50 días y, para las simulaciones con transferencia de calor, los tiempos de simulación 
fueron de 60 días, para alto caudal másico de sólido y 80 días para la condición de bajo caudal.

\subsection{2 - Simulación del sistema correspondiente a los resultados publicados por Kong y colab. (2017).}

Para partículas Geldart A, como se ha señalado previamente, la ausencia de resultados satisfactorios suele atribuirse a que la mayoría de las simulaciones desprecia la existencia de fuerzas cohesivas inter-partícula y sólo tiene en cuenta las colisiones entre las mismas (McKeen y Pugsley, 2003). Si bien en las partículas Geldart B las fuerzas cohesivas son despreciables, en las A son significativas. Krishna y Van Baten (2001) plantearon el uso de pseudo-fluidos debido a que los modelos TFM (EulerEuler) no representan satisfactoriamente las relaciones inter-partícula. Sin embargo, este planteo desprecia los fenómenos de splitting y coalescencia, que son característicos de los sólidos tipo A.

Las fuerzas de arrastre representan un aspecto fundamental en las ecuaciones de gobierno de los modelos Euler-Euler. Diversos autores (Li y Kwauk, 2001, 2003; Beetstra y colab., 2006, Ma y colab., 2006) han reportado que los modelos de arrastre estándar no tienen en cuenta las meso-estructuras burbuja/cluster características en las partículas pequeñas y livianas. Por lo tanto, implementar ecuaciones realistas para representar estos sólidos representa un gran desafío. Vashisth y colab. (2015) proponen que debido a que las fuerzas cohesivas inter-partícula tienen gran peso sobre la fluidización de sólidos tipo A, es necesario realizar modificaciones sobre los modelos de arrastre. La estrategia más ampliamente utilizada para dicha modificación plantea el uso de un factor de corrección. Este factor puede ser una constante que disminuye la función de arrastre, una correlación empírica o un método de escalado. Una de las modificaciones más ampliamente utilizada es el factor de corrección constante. En este estudio, se utilizó el modelo de arrastre modificado de Gibilaro (Gibilaro y colab., 1985), con un valor de C = 0,3 (ver Anexo 4.I).

Se consideró la influencia de la viscosidad friccional en las simulaciones, aplicando el modelo de Schaeffer (1987). 


\section{Malla utilizada}

Se trabajó con una malla estructurada, como en el caso anterior, con 66304 elementos. Su imagen se muestra en la Figura 4.7.
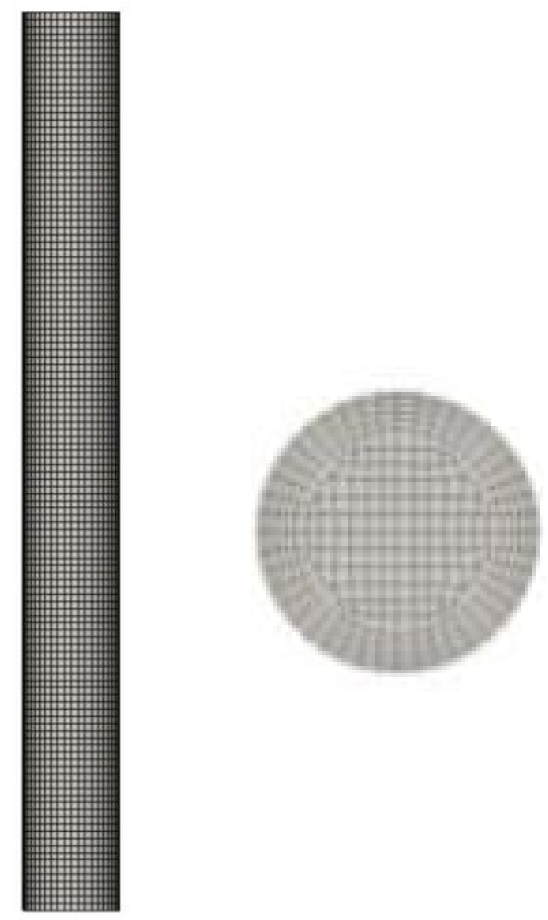

Figura 4.7 - Malla estructurada usada en las simulaciones (vista lateral y transversal). Fuente: Venier y colab. (2020).

Condiciones de borde

En este caso, las simulaciones no tuvieron en cuenta contemplaciones térmicas, por lo que no se consideraron condiciones de energía en las simulaciones.

a. Base del tubo (Velocity inlet):

Se consideraron diferentes velocidades superficiales de gas $(0,12 \mathrm{~m} / \mathrm{s}, 0,15$ $\mathrm{m} / \mathrm{s}, 0,17 \mathrm{~m} / \mathrm{s}$ y $0,23 \mathrm{~m} / \mathrm{s}$ ). La dirección de la velocidad se supone perpendicular al plano de ingreso.

b. Paredes del tubo (Wall):

La condición de coeficiente de especularidad nulo $(\varphi=0)$ fue aplicada para el sólido en toda la pared para todas las simulaciones.

c. Parte superior del tubo (Pressure outlet): 
Se fijó un valor nulo de la presión manométrica. Sólo es admitido el retroflujo de gas en dirección perpendicular a la superficie del plano de salida.

Condiciones iniciales

Para inicializar la solución se debe indicar la altura del lecho $(0,63 \mathrm{~m})$. Este valor se calculó teniendo en cuenta la densidad del lecho, $\rho_{\text {bulk }}$, y un valor característico de porosidad de mínima fluidización para sólidos tipo Geldart A de $\varepsilon_{m f}=0,57$. La fracción volumétrica del sólido $\left(\alpha_{s}=0,51\right)$, fue calculada a partir de los datos de densidad $\rho_{\text {bulk }}$ y densidad de las partículas $\rho_{s}$.

Las simulaciones se llevaron a cabo utilizando esquemas de discretización espacial de segundo orden (Second Order Upwind) para las ecuaciones de momento y de primer orden para la fracción volumétrica (First Order Upwind), mientras que el tiempo se discretizó usando un esquema de segundo orden (Second Order Implicit). Se empleó el esquema de resolución Phase Coupled SIMPLE para resolver la ecuación de presión y velocidad. Se utilizó el esquema de resolución SIMPLE, único disponible en el software, para sistemas multifase.

\section{6 - DISCUSIÓN DE RESULTADOS}

\subsection{1. - Resultados de la simulación y comparación con resultados experimentales de Reyes Urrutia y colab. (2016)}

En esta sección se presentan los resultados para las tres simulaciones presentadas en la Tabla 4.3. La Tabla 4.5 contiene datos experimentales de las experiencias en el tubo colector de pared opaca del laboratorio PROMES. Para el caudal másico de 87,80 kg/h de $\mathrm{SiC}$, se efectuaron simulaciones con y sin transferencia de calor. 
Tabla 4.5 - Resultados experimentales empleados en el modelado mediante CFD.

\begin{tabular}{|c|c|c|c|c|c|c|c|c|}
\hline $\begin{array}{c}\dot{\mathrm{m}}_{\mathrm{SiC}} \\
{[\mathrm{kg} / \mathrm{h}]}\end{array}$ & $\begin{array}{c}\mathrm{T}_{\mathrm{p}, \text { cold }} \\
{[\mathrm{K}]}\end{array}$ & $\begin{array}{c}\mathrm{T}_{\mathrm{p}, \mathrm{i}} \\
{[\mathrm{K}]}\end{array}$ & $\begin{array}{c}\mathrm{T}_{\mathrm{p}, \mathrm{o}} \\
{[\mathrm{K}]}\end{array}$ & $\begin{array}{c}\mathrm{T}_{\mathrm{w}, \mathrm{h}}^{\mathrm{inti}} \\
{[\mathrm{K}]}\end{array}$ & $\begin{array}{c}\mathrm{T}_{\mathrm{w}, \mathrm{h}}^{\mathrm{intm}} \\
{[\mathrm{K}]}\end{array}$ & $\begin{array}{c}\mathrm{T}_{\mathrm{w}, \mathrm{h}}^{\text {int,o }} \\
{[\mathrm{K}]}\end{array}$ & $\alpha_{\mathrm{s}}$ & $\begin{array}{c}\mathrm{h} \\
{\left[\mathrm{w} / \mathrm{m}^{2} \mathrm{~K}\right.}\end{array}$ \\
\hline 42,35 & 300,53 & 455,78 & 548,83 & 556,17 & 604,41 & 606,62 & 0,31 & 450,00 \\
\hline 87,80 & 317,28 & 389,62 & 495,83 & 504,83 & 560,62 & 561,08 & 0,31 & 628,56 \\
\hline 87,80 & ---- & ---- & ---- & ---- & ---- & ---- & 0,39 & --- \\
\hline
\end{tabular}

La simulación sin transferencia de calor en la pared, fue empleada para analizar las posibles diferencias en el comportamiento fluidodinámico con los sistemas a temperatura elevada.

En la Figura 4.8 se muestra la evolución de la pérdida de carga en función del tiempo, a partir de la situación de lecho en reposo, para las tres simulaciones realizadas. Como es de esperar, los valores de la variable crecen sostenidamente conforme el material granulado ingresa al tubo para finalmente estabilizarse cuando el SiC alcanza la salida del sistema en estudio. La zona horizontal de cada curva es empleada para determinar la fracción de sólidos promedio en el tubo en condición pseudoestacionaria. La Figura 4.8 muestra que existe una clara diferencia entre la pérdida de carga del sistema a elevada temperatura (Run 2) y a temperatura ambiente (Run 3). En los sistemas con transferencia de calor, la expansión del aire debida a las elevadas temperaturas, genera un menor valor promedio de la fracción de sólidos en el tubo y como consecuencia, la pérdida de carga total es menor a la del sistema frío. 


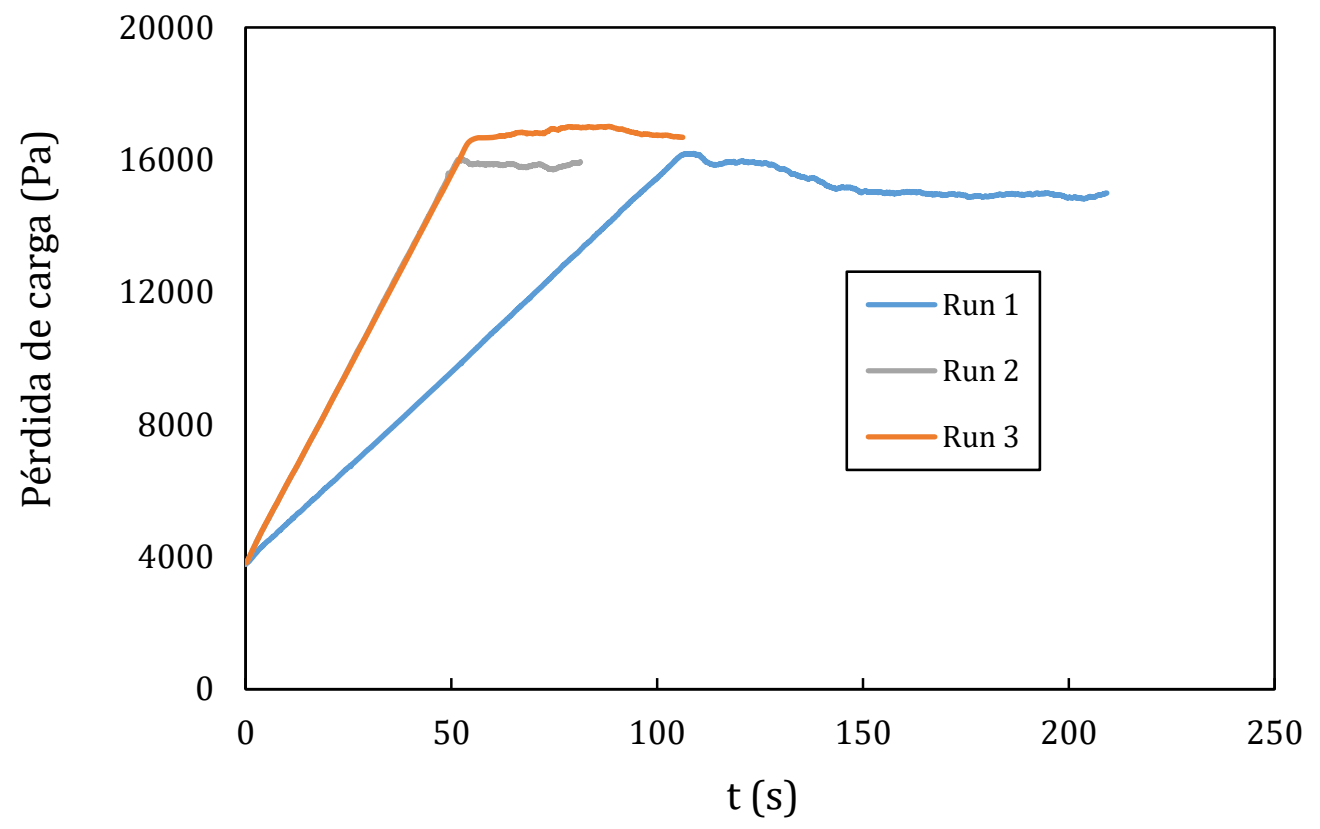

Figura 4.8 - Pérdida de carga en el tubo completo en función del tiempo para las tres simulaciones.

En la Figura 4.9 se muestran los valores de flujo de energía sobre la pared receptora del tubo, en función del tiempo. En primera instancia, cuando en la zona de transferencia hay sólo aire, el flujo de energía es muy bajo. Luego, cuando el sólido alcanza dicha región, el flujo de energía crece para finalmente alcanzar la pseudoestabilidad. La simulación de elevado caudal alcanza la pseudo-estabilidad en términos de flujo de energía en un tiempo considerablemente menor al necesario para el sistema de bajo caudal. 


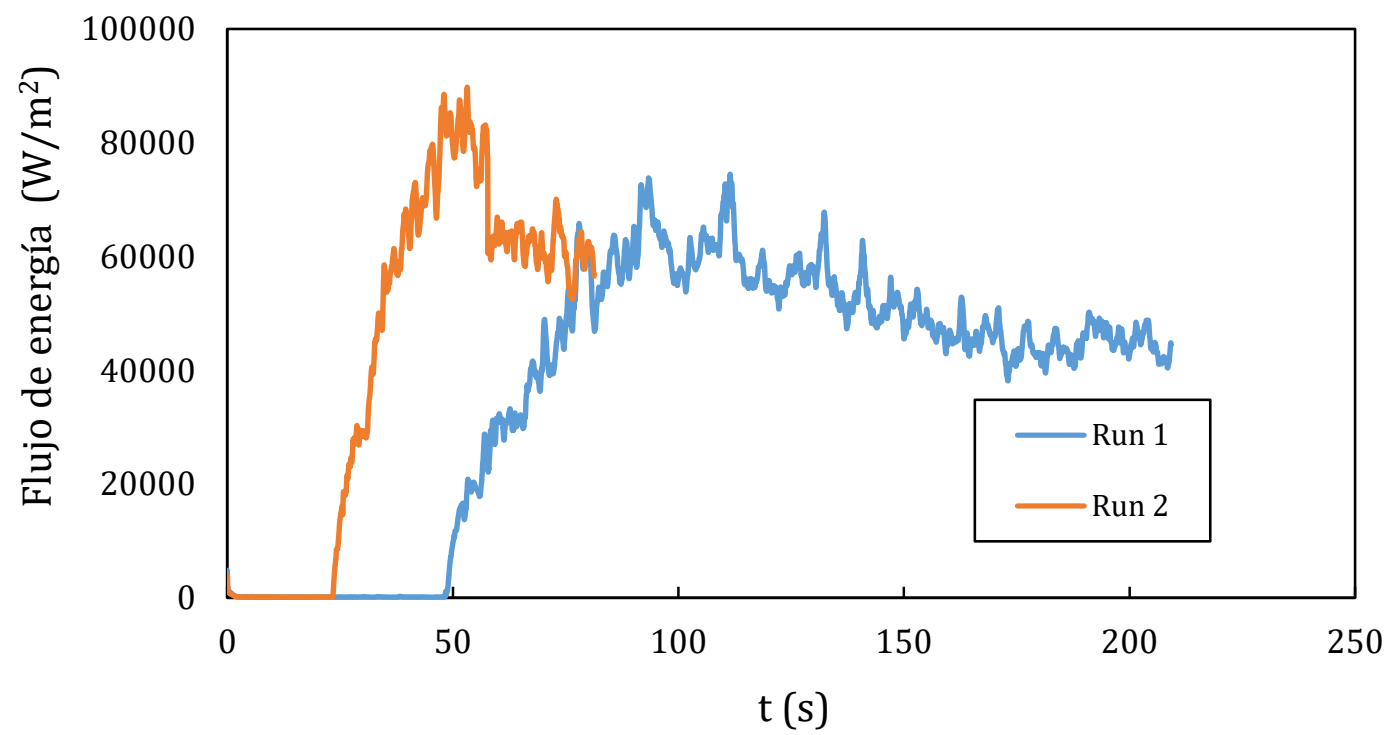

Figura 4.9 - Flujo medio instantáneo de energía sobre la pared caliente para las dos simulaciones con transferencia de calor.

En las Figuras 4.10a y 4.10b se muestran los valores medios de la temperatura de las partículas en planos ubicados en el ingreso y a la salida de la zona de transferencia en función del tiempo. La Figura 4.10a corresponde a la simulación con bajo caudal de SiC (Run 1) y la Figura 4.10b a la simulación con alto caudal de fluido térmico (Run 2).

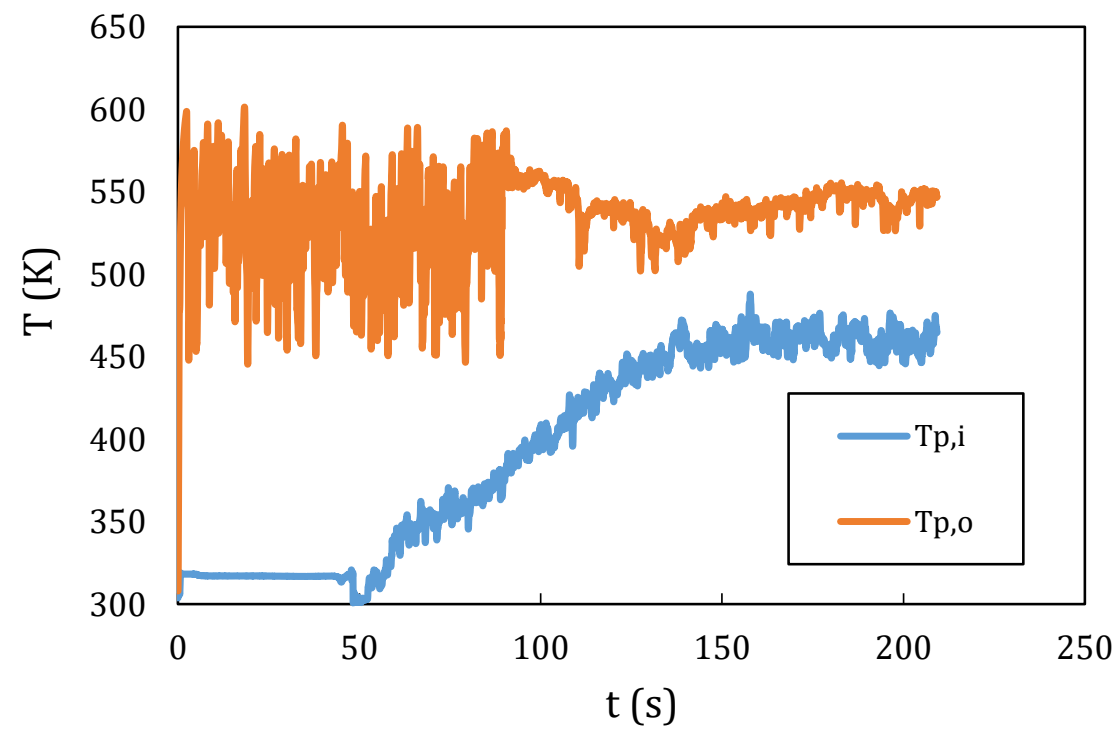

Figura 4.10a - Evolución de los valores medios de la temperatura de las partículas $\mathrm{T}_{\mathrm{p}}$ para Run 1 en planos ubicados en el ingreso y en la salida de la zona de transferencia de calor del sistema. $\mathrm{T}_{\mathrm{p}, \mathrm{i}}$ corresponde al plano ubicado en el ingreso y $\mathrm{T}_{\mathrm{p}, \mathrm{o}}$ corresponde a la salida. 


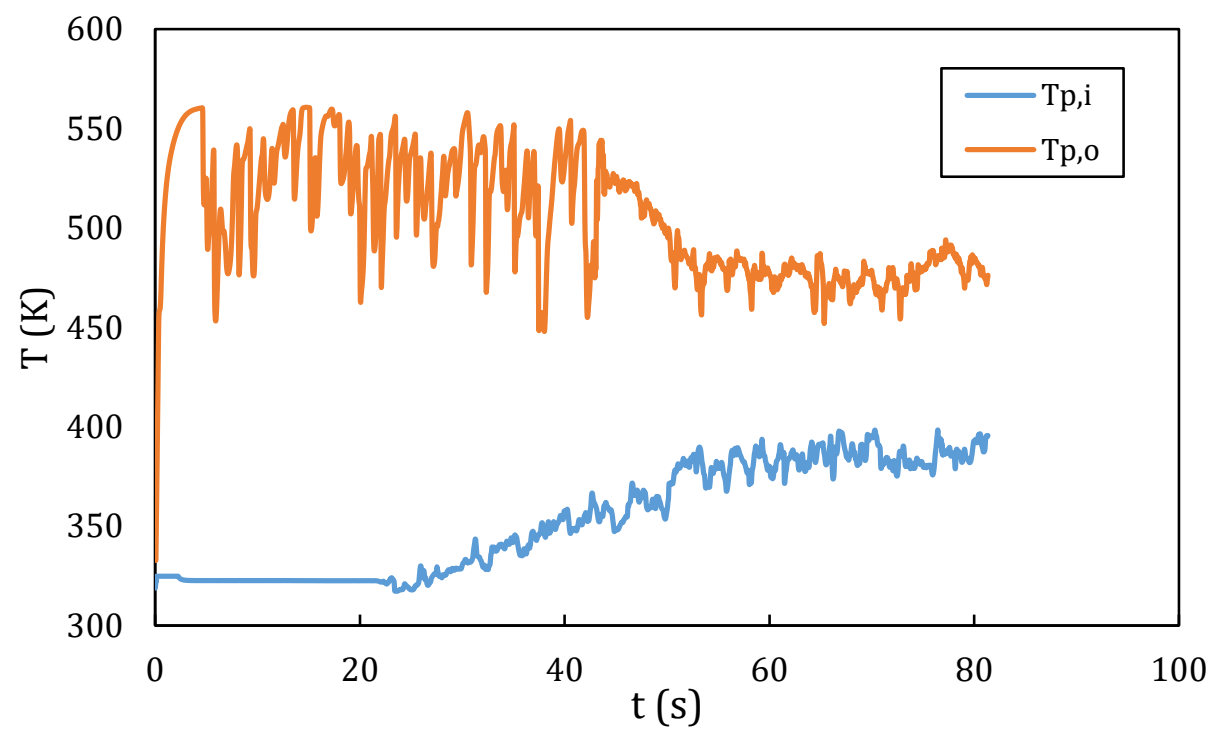

Figura 4.10b - Evolución de los valores medios de T para la Run 2.

En ambas simulaciones, inicialmente el valor medio de la temperatura en el plano ubicado en el ingreso a la zona de transferencia de calor se mantiene constante e igual al de la condición de borde. Este comportamiento se mantiene hasta los 50 segundos, en la simulación con bajo caudal másico de $\mathrm{SiC}$, y hasta los 20 segundos para la simulación con alto caudal de material granulado. Luego, la temperatura de la mezcla crece sostenidamente como resultado de la recirculación de sólido desde la zona de transferencia de calor hacia la parte baja del tubo. Finalmente se alcanza la condición de pseudo-estabilidad de la temperatura, a partir de los 150 segundos para la simulación de bajo caudal de SiC (Run 1) y 50 segundos para la simulación con mayor caudal de SiC (Run 2).

En la Tabla 4.6 se resumen los resultados promedio, en estado pseudoestacionario, de las variables: fracción de sólidos (determinados a partir de la ecuación 4.10); flujo de energía a través de la pared y temperaturas de las partículas de SiC en los planos de entrada y salida a la región de transferencia (considerando el equilibrio térmico entre el aire y las partículas). 


$$
\alpha_{s}=\frac{\Delta P_{\text {lecho }}}{\left(\rho_{p}-\rho_{g}\right) H g}
$$

Tabla 4.6 - Resultado de la simulación por CFD en estado pseudo-estacionario. Valores medios de variables de interés.

\begin{tabular}{|c|c|c|c|c|}
\hline Run & $\alpha_{s}$ & $\dot{\mathrm{Q}}\left[W / m^{2}\right]$ & $\mathrm{T}_{\mathrm{p}, \mathrm{i}}[\mathrm{K}]$ & $\mathrm{T}_{\mathrm{p}, \mathrm{o}}[\mathrm{K}]$ \\
\hline 1 & 0,32 & 44562,82 & 460,82 & 545,47 \\
\hline 2 & 0,34 & 61424,51 & 385,50 & 476,23 \\
\hline 3 & 0,37 & ----- & ----- & $-\cdots---$ \\
\hline
\end{tabular}

En la Tabla 4.7 se comparan valores de la fracción de sólido obtenidos por CFD, en las condiciones operativas analizadas, con los resultados experimentales.

Tabla 4.7 - Comparación entre los resultados experimentales y los obtenidos con la simulación.

\begin{tabular}{|c|c|c|c|}
\hline Run & $\alpha_{s}$ (Exp) & $\alpha_{s}$ (CFD) & e (\%) $\alpha_{s}$ \\
\hline 1 & 0,31 & 0,32 & 3,23 \\
\hline 2 & 0,31 & 0,33 & 6,45 \\
\hline 3 & 0,39 & 0,38 & 2,56 \\
\hline
\end{tabular}

De la comparación entre las Tablas 4.5 y 4.6 se puede concluir que el modelo reproduce adecuadamente los valores de temperaturas de las partículas de $\mathrm{SiC}$ en el ingreso a la zona de transferencia de calor en ambas condiciones. A bajo caudal, también el modelo CFD reproduce la temperatura a la salida de la zona de transferencia. Por otro lado, a elevado caudal, el modelo predice una temperatura de salida de la zona de transferencia 19,6 K menor a la experimental. Esta diferencia podría atribuirse a la cercanía de la condición de borde, posicionada 0,2 m por encima del plano de medición, diferente a los 1,13 m del prototipo experimental. La salida cercana empleada en el modelado impide la recirculación de partículas en la zona superior del sistema la cual permitiría aprovechar la fuerza impulsora aún existente en la condición de caudal másico elevado. A bajo caudal, el movimiento a menor velocidad de la emulsión, genera 
que la fuerza impulsora para la transferencia de calor a la salida de la zona de intercambio de calor sea muy baja. Por esta razón, la cercanía de la condición de borde, no produce el efecto observado a alto caudal másico de SiC y la temperatura obtenida mediante el modelo concuerda con el valor experimental de la variable. Por otro lado, la Tabla 4.7 muestra que modelo reproduce de manera adecuada la fracción de sólidos $\left(\alpha_{s}\right)$ promedio experimental en el lecho del sistema en estudio.

\subsubsection{1 - Presencia de slugs en el lecho}

Las simulaciones revelaron la presencia de slugs de pared en el lecho para todas las condiciones de operación analizadas. Con relación a este fenómeno, recientemente Kong y colab. (2017), en sus experiencias realizadas a temperatura ambiente, atribuyen la formación de slugs de pared en perjuicio de la formación de slugs axiales a la intensa recirculación de partículas que fuerza a las burbujas a desplazarse desde el centro del tubo hacia la pared del mismo.

En la Figura 4.11a se muestran isosuperficies del dominio con fracción volumétrica de aire $\alpha_{g}=0,8$ (Run 2). Este valor de porosidad, asignado a la interfase burbuja (o slug)-fase densa, es tomado como referencia a partir del trabajo de Lu y colab. (2015) quienes caracterizaron las burbujas en un lecho fluidizado burbujeante a partir de los resultados obtenidos por simulación CFD empleando un método discreto. Los slugs se generan sobre la cara interna de la pared, a una cierta altura del ingreso al lecho (círculo azul), manteniendo un tamaño relativamente pequeño en comparación al que adquieren al alcanzar la zona de transferencia de calor, donde pasan a ocupar gran parte de la superficie interna del tubo.

En la Figura 4.11b se muestra la fracción de sólido (Run 2), en cortes transversales tomados a distintas alturas y distintos tiempos con el objeto de seguir la evolución de un slug. Es importante señalar la influencia de la temperatura, tanto en el tamaño como en el espesor del slug. Con relación al tamaño, en la zona caliente los slugs cubren regiones extensas del perímetro interno del tubo alcanzando a ocupar aproximadamente un 50 \% del mismo. Con respecto al espesor de los slugs, en la región 
aislada, el espesor promedio es de $2 \mathrm{~mm}$ mientras que en la zona de intercambio se observan espesores comprendidos entre 4 y $6 \mathrm{~mm}$.
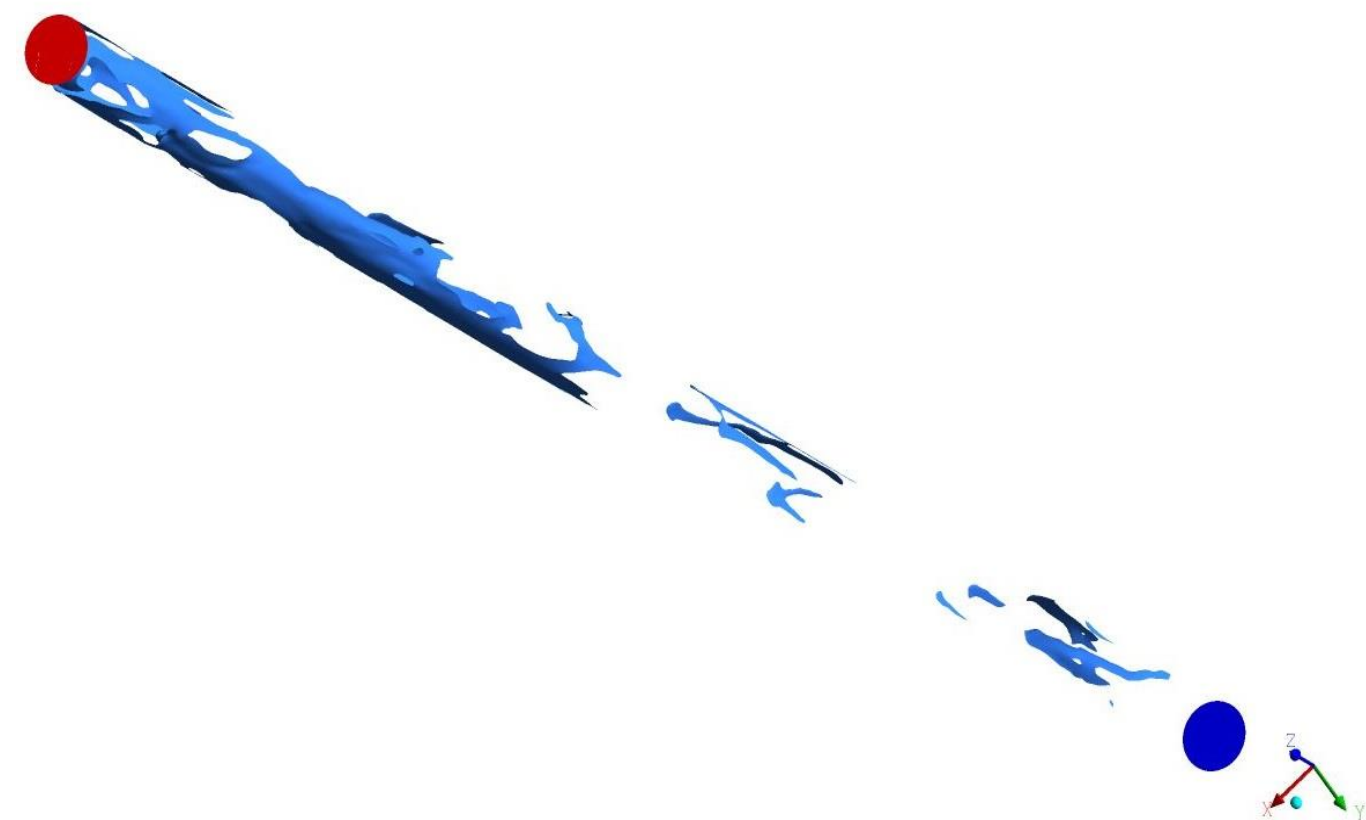

Figura 4.11a - Presencia de slugs sobre la zona adyacente a la pared del tubo. En azul, el plano de ingreso de la emulsión al dominio; en rojo el plano de salida.

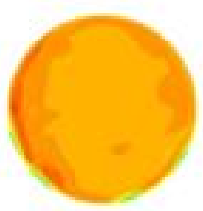

$0,55 \mathrm{~m}$ $58 \mathrm{~s}$

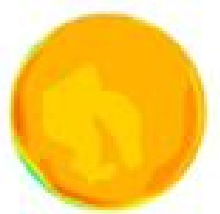

$0,70 \mathrm{~m}$ $58,5 \mathrm{~s}$

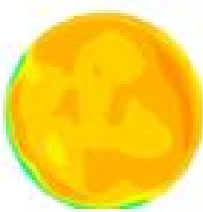

$0,85 \mathrm{~m}$ $59 \mathrm{~s}$

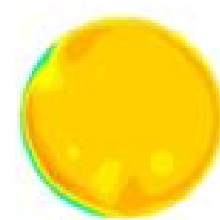

$1,00 \mathrm{~m}$ $59,5 \mathrm{~s}$

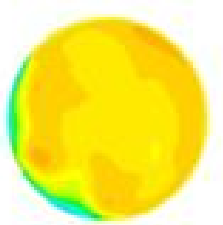

$1,15 \mathrm{~m}$ $60 \mathrm{~s}$

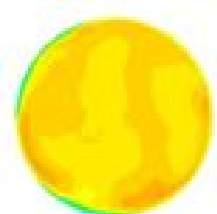

$1,30 \mathrm{~m}$ $60,5 \mathrm{~s}$

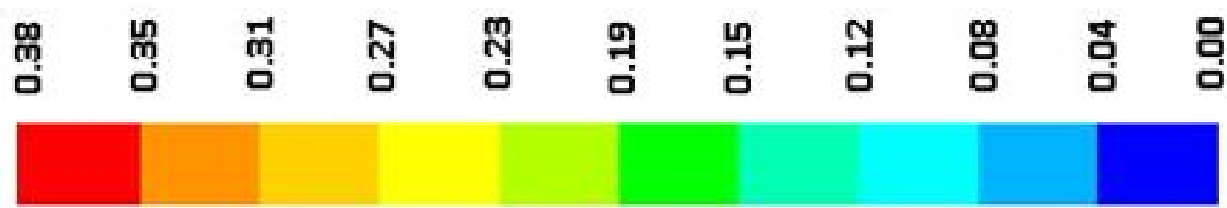

Fracción volumétrica de sólidos

Figura 4.11b - Seguimiento de un slug de pared para la Simulación 2. 


\subsubsection{2 - Influencia de los slugs en la transferencia de calor pared-suspensión}

Para estudiar la presencia de este fenómeno y su influencia en la transferencia de calor a lo largo de la pared de intercambio se llevó a cabo la discretización axial de la pared del tubo en tres porciones de $5 \mathrm{~cm}$ de longitud (Figura 4.12). La primera de ellas, ubicada en la zona inferior del tubo, la segunda en el centro y la restante ubicada en la zona previa a la salida. Sobre estas porciones de tubo se analizó el flujo de calor transferido y la fracción de superficie interior del tubo cubierta por slugs

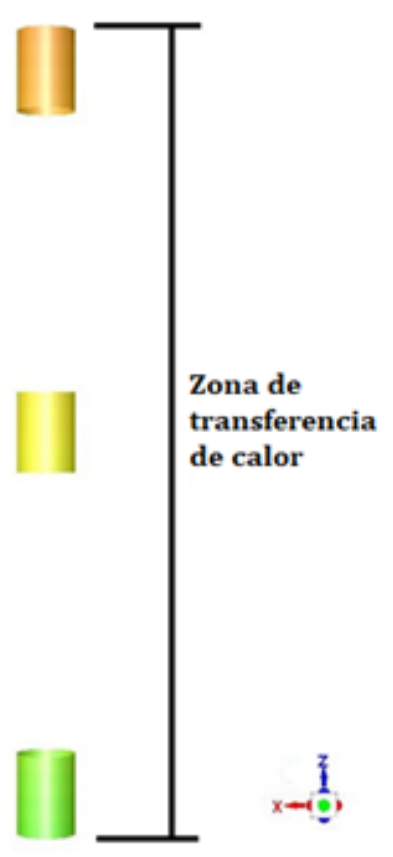

Figura 4.12 - Discretización sobre la zona de transferencia de calor para analizar el flujo de energía sobre la pared caliente.

En las Figuras 4.13a y 4.13b se muestran los valores promedio de flujo de energía sobre cada una de las porciones de pared indicadas en la Figura 4.12, junto con el porcentaje del área interna de pared del tubo cubierta por slugs. 


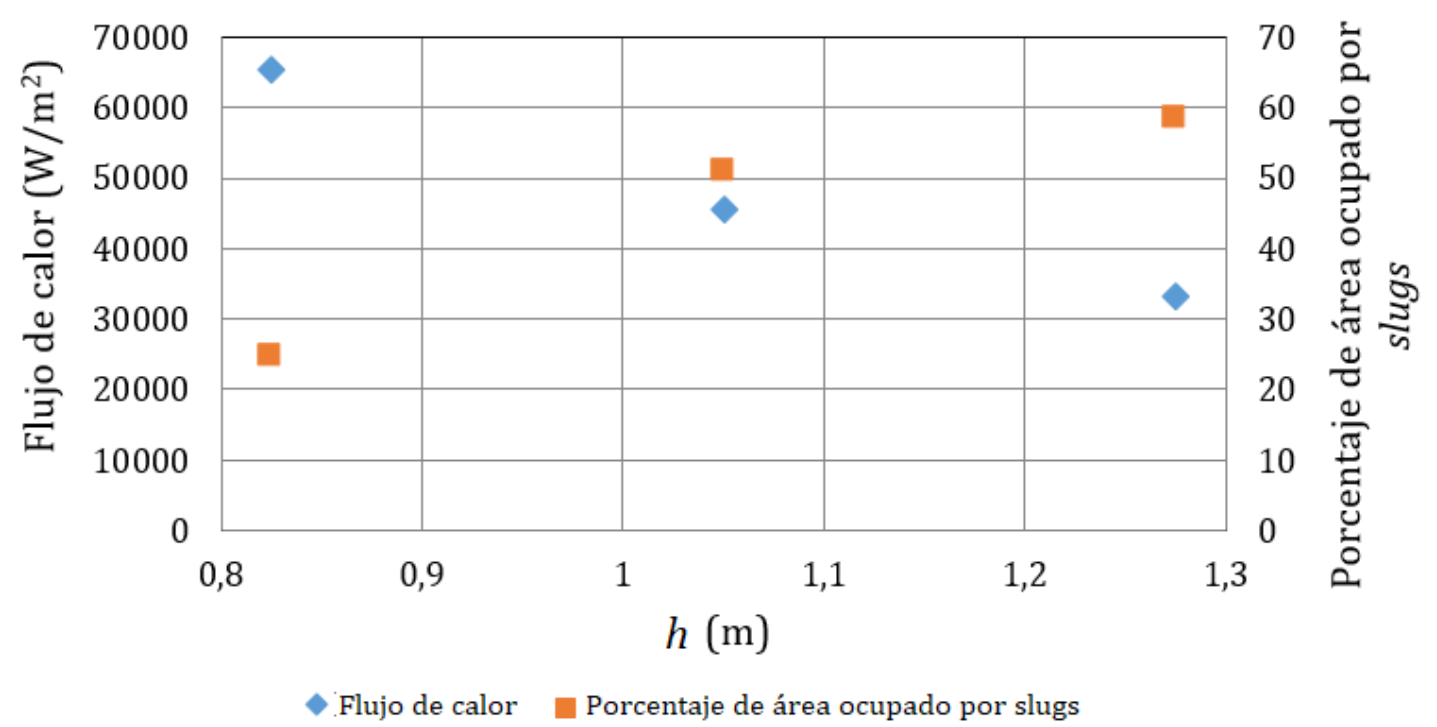

Figura 4.13a - Run 1. Flujo de energía sobre la pared y fracción de pared interna cubierta por slugs.

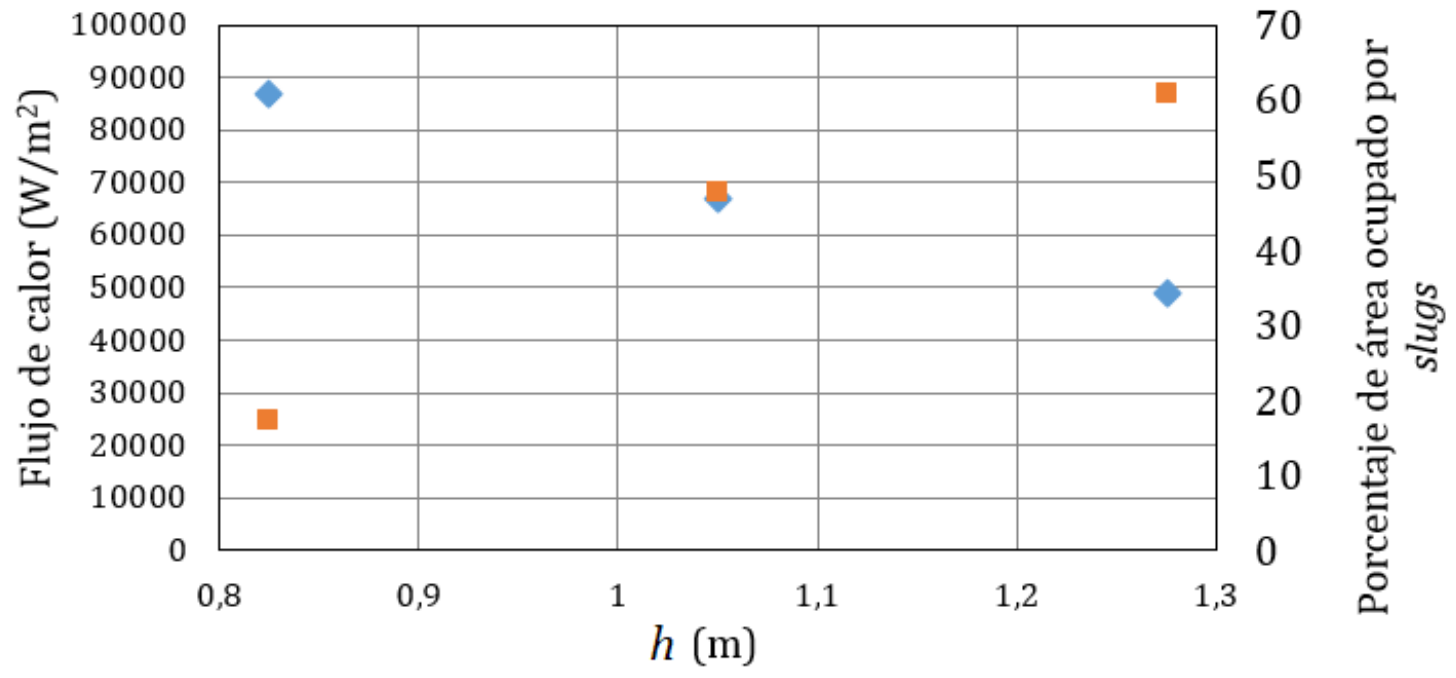

- Flujo de calor a Porcentaje de área ocupado por slugs

Figura 4.13b - Run 2. Flujo de energía sobre la pared y fracción de pared interna cubierta por slugs.

A partir de las Figuras 4.13a y 4.13b puede observarse que en ambas simulaciones el flujo de energía es elevado en la zona inferior del tubo y disminuye con la altura. De esta manera, se puede concluir que la disminución del flujo de energía con 
la altura se debe a dos efectos, por un lado, a la disminución de la fuerza impulsora para la transferencia de calor, y por otro, a la presencia de slugs sobre la región adyacente a la cara interna de la pared del tubo caliente. Con relación a este último factor, la capacidad de transferir calor de las burbujas es mucho menor que la correspondiente a la de fase densa, fundamentalmente debido a la diferencia de capacidades caloríficas del sólido y del gas (Chandran y Chen, 1985; Mazza, 1993), por esta razón, los slugs actúan como resistencias para la transferencia de calor causando bajos valores de flujo de energía.

La disminución de flujo de energía con la altura observada en las Figuras 4.13a y 4.13b tiene relación con el perfil axial de temperatura de pared del tubo determinado experimentalmente (Tabla 4.5) En la Figura 4.14 se presenta una imagen de la zona caliente inmediatamente después de la finalización de uno de los ensayos. La parte baja de la zona referida es la de mayor enfriamiento de la pared por parte de la emulsión (altos flujos de energía pared-emulsión), mientras que la incandescencia de la zona superior evidencia la escasa transferencia de calor hacia la emulsión en esa región del tubo.

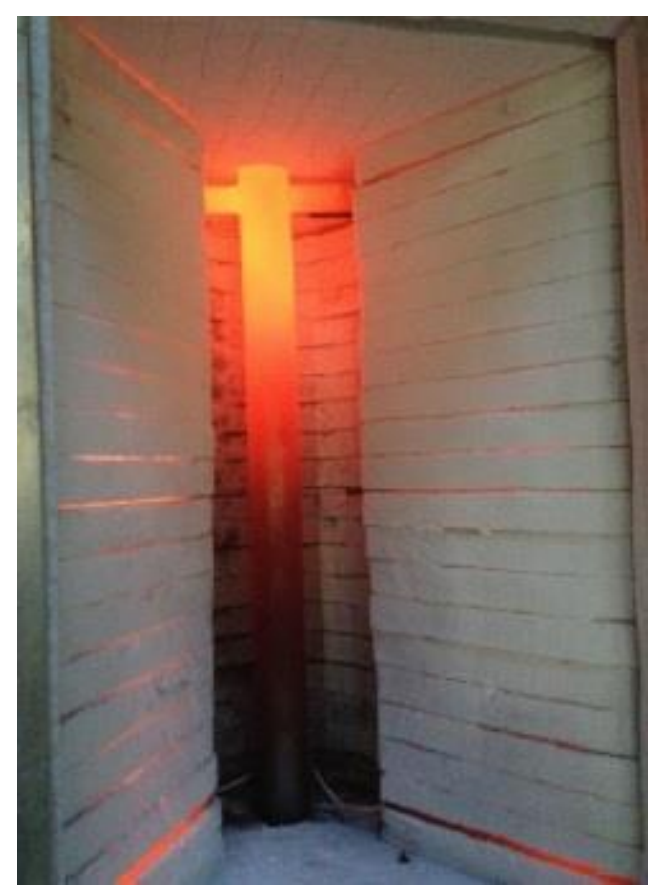

Figura 4.14 - Fotografía de la cavidad y del tubo al concluir uno de los ensayos en el prototipo experimental del laboratorio PROMES. 


\subsubsection{3 - Discretización axial del dominio analizado}

Mediante el esquema de discretización mostrado en la Figura 4.15, se analizaron los perfiles axiales de la temperatura de las partículas y de la fracción de sólidos. Se construyeron planos perpendiculares al flujo de partículas. En la región del tubo previa a la zona caliente, los planos se ubicaron cada $20 \mathrm{~cm}$ mientras que, en la zona expuesta al flujo de energía solar concentrada, la distancia entre planos es de 10 $\mathrm{cm}$.

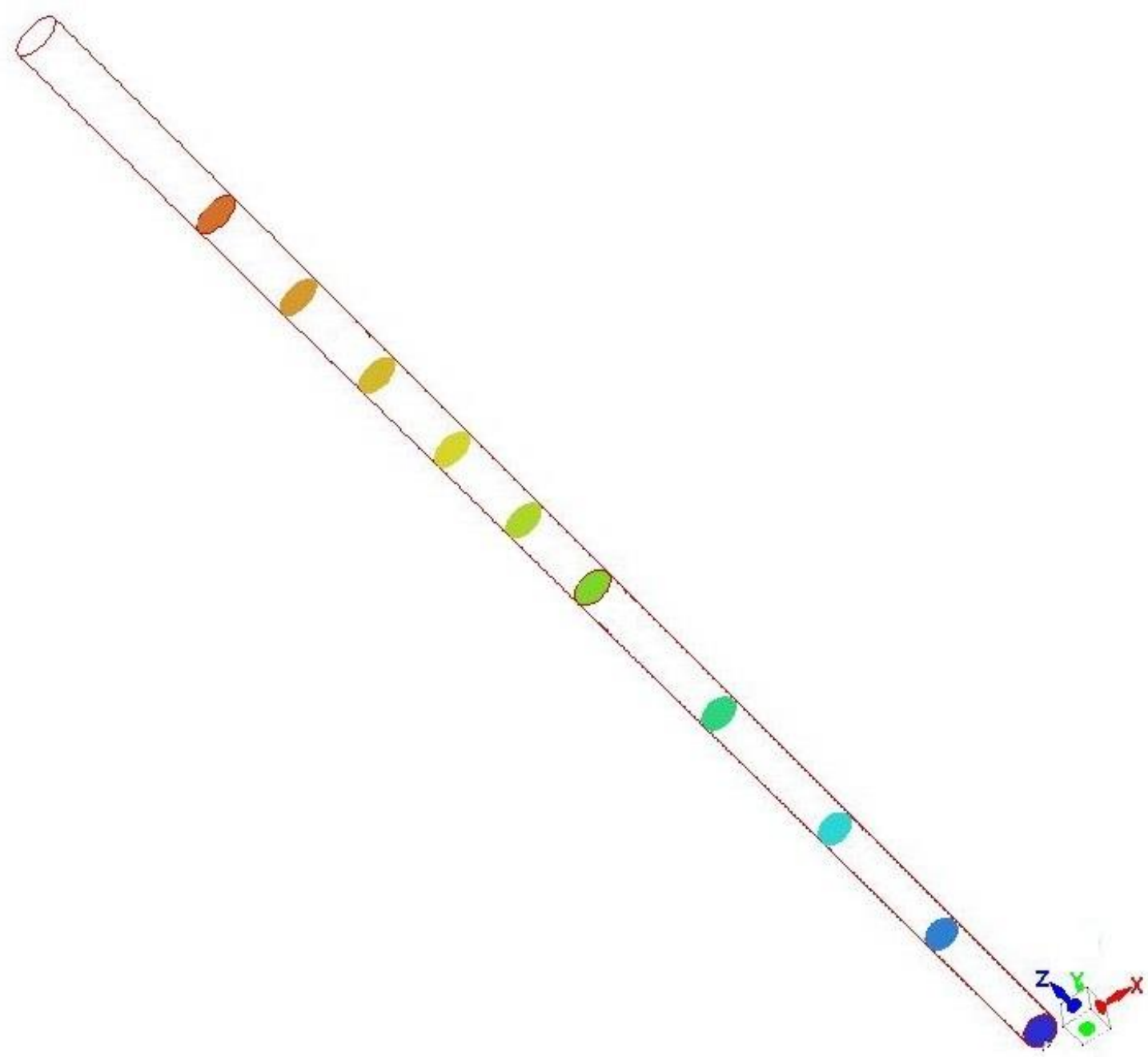

Figura 4.15 - Discretización axial empleada en el análisis de variables de interés.

La Figura 4.16 se representan los valores medios de fracción volumétrica de sólidos en diferentes alturas. Por debajo de los 0,2 m, existe una zona de leve aumento de la variable para todos los casos analizados. Luego de los 0,6 m, el efecto del aumento 
de la temperatura con la altura causa la expansión del aire de fluidización y consecuentemente la disminución de los valores de la variable para los casos con transferencia de calor. Para la simulación en frío, la fracción de sólidos se mantiene casi constante con la altura a partir de $0,2 \mathrm{~m}$.

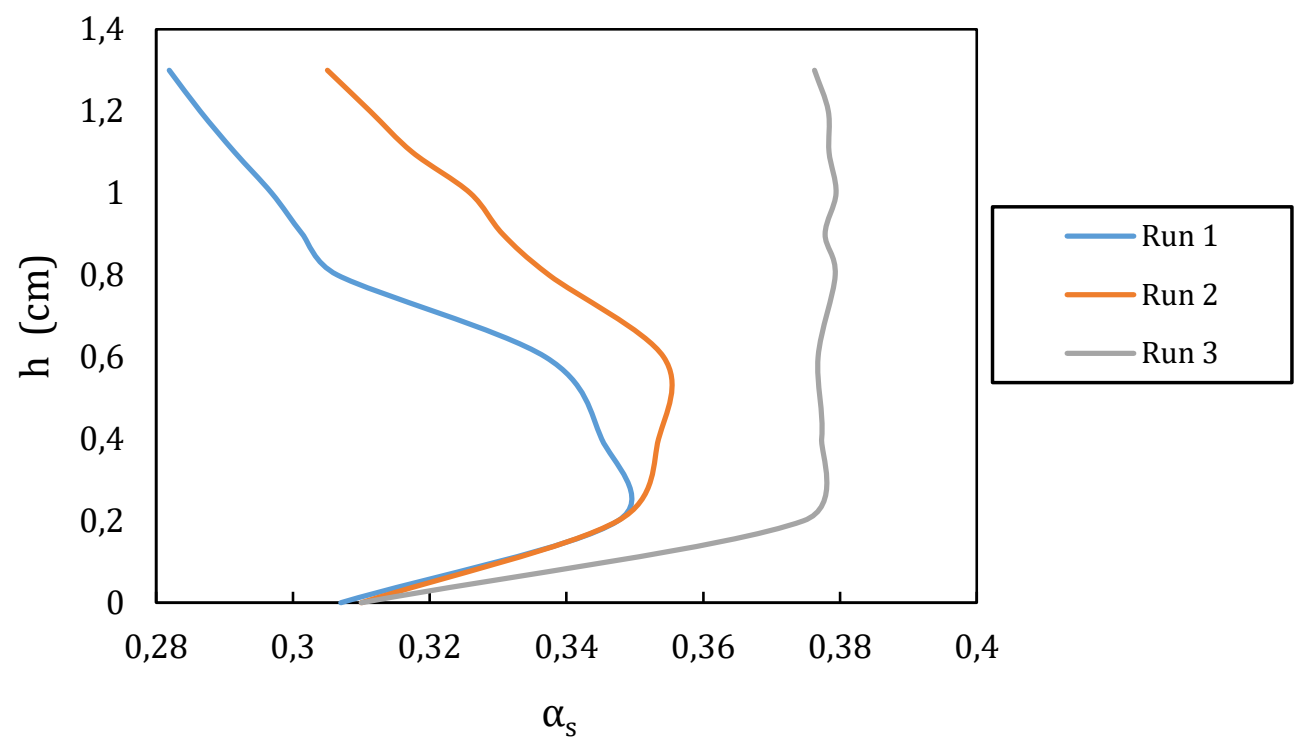

Figura 4.16 - Fracción volumétrica ocupada por las partículas de SiC para diferentes posiciones de la coordenada axial h.

En la Figura 4.17 se representa la temperatura de las partículas en función de la posición axial. La recirculación intrínseca del sistema fluidizado permite la transferencia de calor convectiva a prácticamente toda la región aislada del lecho. El aumento en la temperatura de las partículas con la altura se hace más importante a partir de los $0.4 \mathrm{~m}$ para los dos casos con transferencia de calor estudiados. 


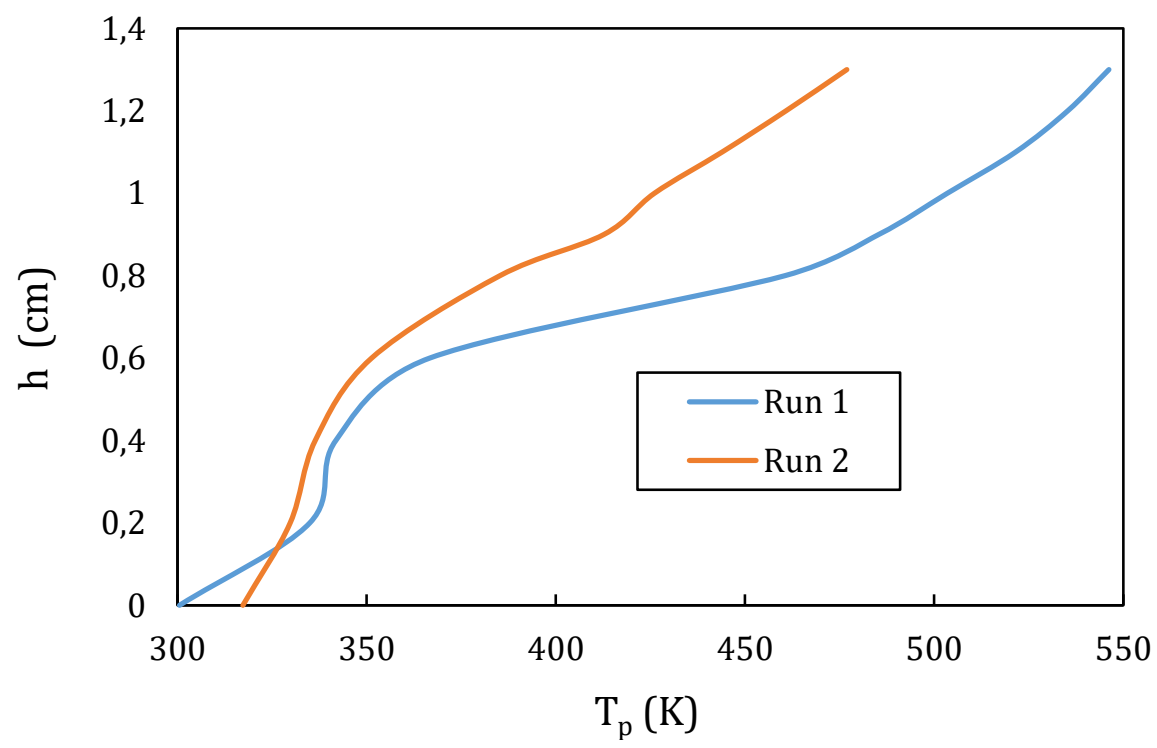

Figura 4.17 - Temperatura media de las partículas de SiC para diferentes posiciones de la coordenada axial h.

\subsection{2 - Resultados de la simulación y comparación con resultados} experimentales de Kong y colab. (2017)

En esta sección se presentan los resultados para el análisis de slugs realizado mediante CFD y se los compara con los resultados obtenidos por Kong y colab. (2017). Cabe destacar que para el análisis de las imágenes y el cálculo de los parámetros estudiados, se utilizó un programa desarrollado en $M A T L A B$, que se presenta en el Anexo 4.II.

\subsubsection{1 - Longitud de slugs}

La Figura 4.18 muestra los resultados hallados para la longitud característica de los slugs mediante CFD y comparada con los resultados obtenidos con Kong y colab. (2017). Los datos fueron analizados en función de la velocidad $U$ para una altura desde el distribuidor de 0,8 m. Se observa que su tamaño aumenta al incrementarse la velocidad, presentando una relación lineal. Para bajas velocidades se obtiene buena concordancia en los resultados, pero para alta velocidad $(U=0,23 \mathrm{~m} / \mathrm{s})$ se presenta discrepancia con el valor reportado experimental de Kong y colab. (2017). En este caso debería considerarse cambiar el modelo de arrastre utilizado. La altura del lecho a la 
cual se llevó a cabo el análisis determina la longitud $L_{s}$ ya que los slugs crecen conforme ascienden en el lecho debido a la fenómeno de coalescencia.

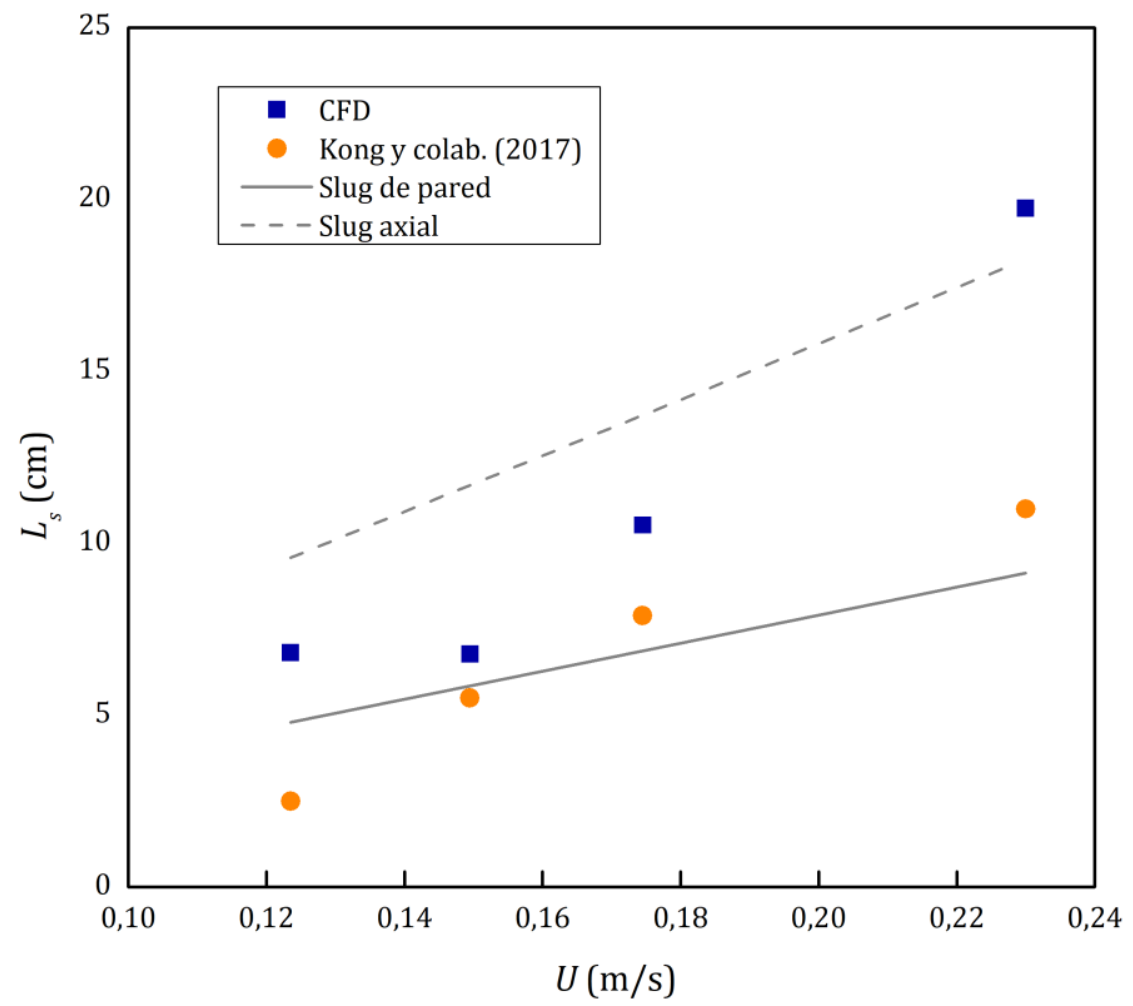

Figura 4.18 - Longitud de slugs en función de la velocidad $U$ y correlaciones correspondientes a slug axial y de pared.

Adicionalmente, en la Figura 4.18, los resultados son comparados con los valores obtenidos a partir de las ecuaciones para el cálculo de la longitud de slugs (Ecuaciones 4.3a y 4.3b). Los resultados experimentales presentados por Kong y colab. (2017) tienen buen ajuste con la correlación para slugs de pared en todo el rango de velocidades estudiadas. Sin embargo, el valor obtenido mediante CFD para $U=0,23 \mathrm{~m} / \mathrm{s}$ se aproxima claramente al predicho por la correlación para slug axial (esperable a dicha velocidad).

\subsubsection{2 - Frecuencia de slugs}

En la Figura 4.19, se muestran los resultados obtenidos para la frecuencia de slugs para el valor de velocidad $U=0,15 \mathrm{~m} / \mathrm{s}$. En ambos casos se observa que la 
frecuencia disminuye conforme los slugs ascienden en el lecho. Si bien la CFD sobreestima los valores de frecuencia, la tendencia se mantiene a lo largo del lecho. A diferencia de los resultados experimentales, en las simulaciones se observa presencia de slugs a alturas más bajas, pero no se observan slugs por encima de los 0,85 $\mathrm{m}$ de altura, lo que podría indicar una subestimación de la expansión mediante la CFD.

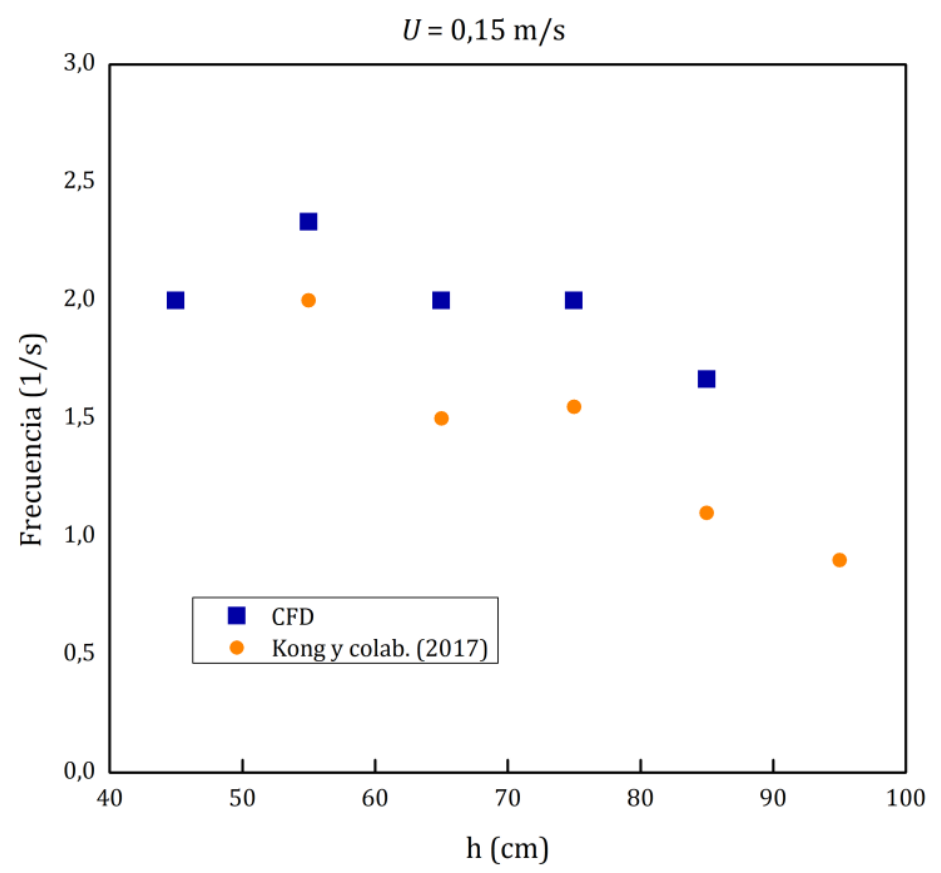

Figura 4.19 - Frecuencia de slugs en función de la altura desde el distribuidor.

\subsubsection{3 - Velocidad de slugs}

Los resultados obtenidos para el estudio de la velocidad de slugs se presentan en la Figura 4.20. En ambos casos se observa un incremento de la velocidad de ascenso de los slugs al aumentar la velocidad $U$. Para la velocidad más baja estudiada, tanto la CFD como los resultados experimentales presentan valores similares. A medida que aumenta la velocidad $U$, los valores obtenidos mediante CFD siguen la tendencia de los valores obtenidos con la correlación de slug axial. Por el contrario, los valores experimentales tienden a la correlación de slugs de pared al aumentar la velocidad $U$. 


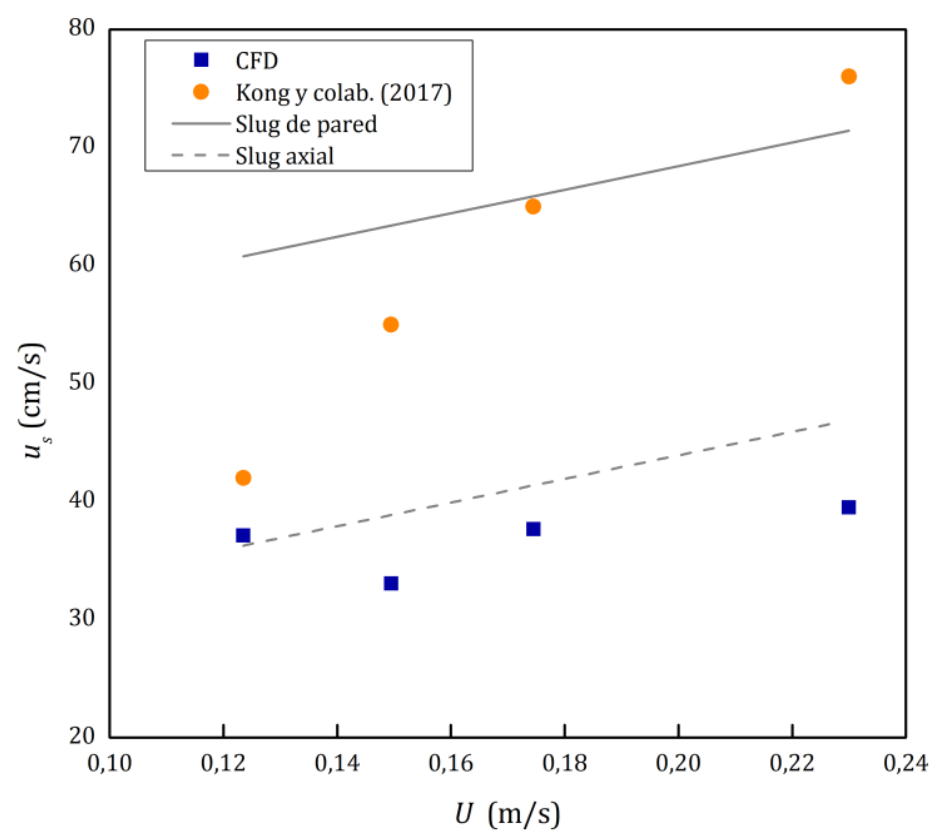

Figura 4.20 - Velocidad de slug en función de la velocidad $U$.

La discrepancia en las velocidades experimentales y CFD tiene su fundamento en que las frecuencias obtenidas por CFD, si bien respetan la tendencia de los valores experimentales, son prácticamente el doble de éstos. Ello implica una cantidad superior de burbujas para un mismo caudal volumétrico de gas, reduciendo directamente las velocidades resultantes (debido a la presencia burbujas más pequeñas).

Se realizaron pruebas modificando el coeficiente C del modelo de Gibilaro y colab. (1985) pero el sistema no presentó suficiente sensibilidad a los mismos. La observación de los resultados lleva a concluir que debería apelarse a un modelo discreto (simulación individual por partículas) para las partículas Geldart A insertas en el dominio, lo que conduce a un esfuerzo computacional significativo. El uso de un modelo como el aquí utilizado, requeriría, a su vez, una búsqueda exhaustiva de nuevos modelos de arrastre específicos.

\subsubsection{4 - Fracción de sólidos y fracción de burbuja}

En la siguiente figura se presentan los resultados obtenidos para la fracción de sólidos en el lecho $\left(\alpha_{s}\right)$ y la fracción de burbujas $\left(\varepsilon_{b}\right)$. Los resultados experimentales de 
$\alpha_{s}$ fueron obtenidos mediante datos de $\Delta P / \rho_{S}$, los resultados obtenidos mediante CFD se calcularon teniendo en cuenta la siguiente ecuación

$$
\alpha_{s}=\frac{m}{\rho_{\text {solidos }} A H_{\text {Lecho }}}
$$

donde la masa de sólidos $m$ se calculó en base a los datos de mínima fluidización.

La fracción $\varepsilon_{b}$ se calculó en base a los datos de expansión del lecho como:

$$
\varepsilon_{b}=1-\frac{H}{H_{o}}
$$

donde $H_{o}$ es la altura inicial del lecho $(0,63 \mathrm{~m})$.

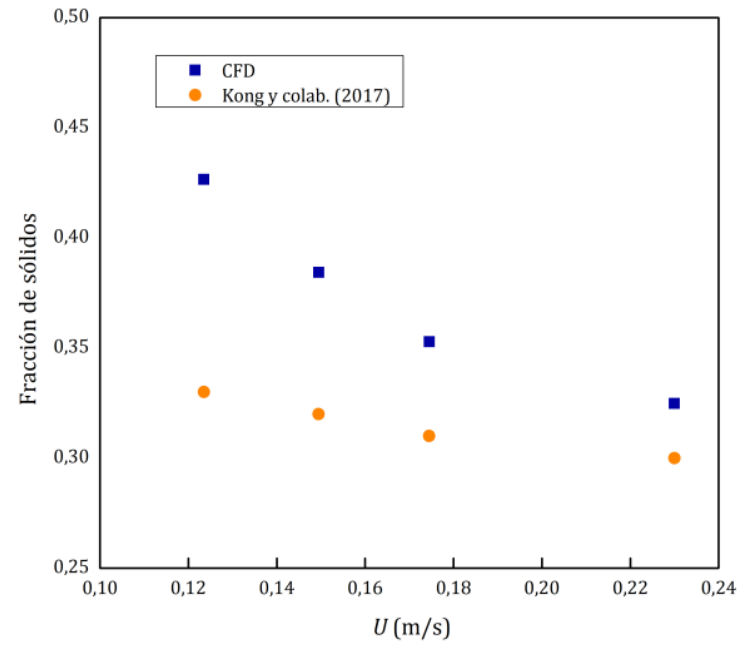

a

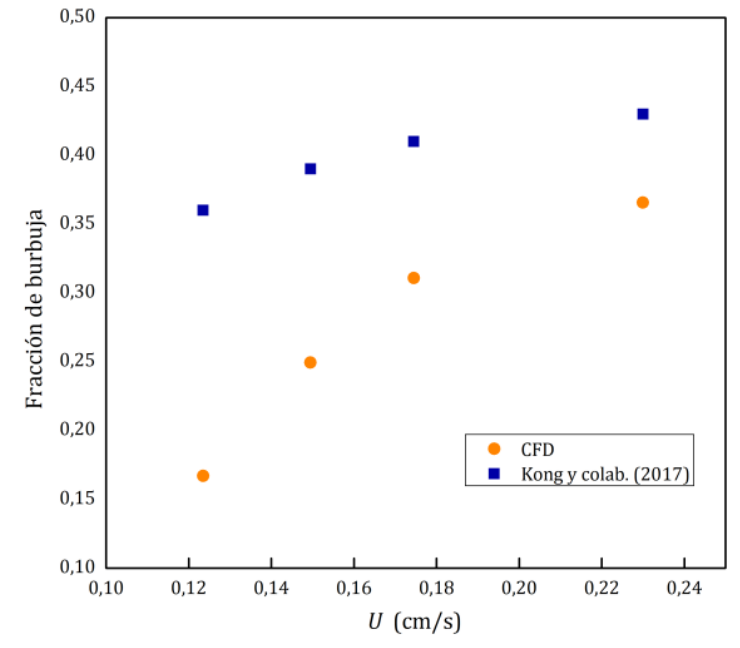

$\mathrm{b}$

Figura 4.21 - Fracción de sólidos (a) y fracción de burbuja (b) en función de la velocidad $U$.

Si bien la CFD sobreestima los valores experimentales a bajas velocidades, a medida que aumenta el valor de $U$ las diferencias entre los resultados disminuyen, tanto para $\alpha_{s}$ como para $\varepsilon_{b}$. A medida que el lecho se expande (con el incremento de $U$ ) la $\alpha_{s}$ disminuye considerablemente, mientras que la tendencia es opuesta para $\varepsilon_{b}$. Al igual que en los resultados de frecuencia de slug, las diferencias entre valores experimentales y CFD para $\varepsilon_{b}$ (teniendo en cuenta la ecuación 4.12, utilizada para su cálculo) podrían estar indicando una subestimación de la expansión del lecho mediante CFD. 


\section{7 - CONCLUSIONES}

Se desarrolló la simulación y comparación con resultados experimentales de un sistema circulante en emulsión densa de partículas Geldart A (Reyes Urrutia y colab., 2016) y de un sistema con generación de slugs (Kong y colab., 2017) en la plataforma ANSYS-Fluent de CFD.

En primer lugar, se llevó a cabo el modelado mediante CFD de una suspensión densa de partículas de SiC fluidizadas con aire, con y sin transferencia de calor a través de la pared del lecho. Las condiciones empleadas en las simulaciones son idénticas a las utilizadas en un prototipo experimental perteneciente al laboratorio PROMES-CNRS, Francia.

El modelo CFD reproduce de manera adecuada la porosidad del sistema experimental. También, a partir de los resultados obtenidos para la temperatura de las partículas en el ingreso a la zona de intercambio, se concluye que el modelo reproduce la recirculación de las partículas de SiC entre la zona de intercambio y la zona baja del lecho.

Un aspecto relevante de los resultados obtenidos es que el modelo pone en evidencia la formación de slugs de pared en los casos con y sin transferencia de calor. Se ha analizado la importancia del fenómeno sobre la transferencia de calor desde la pared caliente hacia la suspensión. En este trabajo se han presentado perfiles axiales de diferentes variables para conocer el comportamiento del sistema en diversas condiciones operativas. Es importante destacar el efecto de la pared caliente sobre el tamaño de los slugs. La presencia de la pared caliente genera el aumento de su espesor y también causa la ocupación de gran parte de la superficie interna de intercambio del tubo.

En segundo lugar, se llevó a cabo el modelado mediante CFD de un lecho de 0,05 m de diámetro interno, operando en régimen slug y se estudiaron sus características fluidodinámicas.

Si bien el modelado CFD reproduce la tendencia de los datos de frecuencia de slugs, fracción de sólidos y fracción de burbujas en el lecho, los resultados de longitud y 
velocidad de ascenso presentan diferencias considerables. Se observó que las simulaciones arrojan valores inferiores de expansión del lecho, lo que podría influir en las diferencias observadas en todos los resultados.

Tanto para la longitud de slug como para su velocidad de ascenso, los valores obtenidos mediante CFD presentan valores cercanos a la correlación presentada para slug axial, mientras que los datos experimentales tienden a la correlación de slugs de pared.

Para el caso de $u_{s}$, las diferencias observadas entre los resultados experimentales y los obtenidos por CFD está relacionada con la frecuencia de slug obtenida por CFD, que, si bien respeta la tendencia de los valores experimentales, prácticamente los duplica. Ello implica la presencia de una cantidad superior de burbujas para un mismo caudal volumétrico de gas, reduciendo directamente las velocidades $u_{s}$ resultantes. Asimismo, esta discrepancia puede estar relacionada con el modelo friccional utilizado en las simulaciones que tiene una fuerte influencia sobre el modelado del movimiento de las partículas (tal como pudo observarse en el análisis llevado a cabo en el Capítulo 3 para la velocidad de ascenso de las burbujas). 


\section{ANEXO 4.I}

\section{MODELADO NUMÉRICO DEL FLUJO MULTIFÁSICO}

El modelo multifásico empleado es el modelo Euler-Euler disponible en el software ANSYS-Fluent 18.1, ampliamente empleado en el modelado de sistemas fluidizados (Pain y colab., 2001; Taghipour y colab., 2005; Kuipers y colab., 1992; Armstrong y colab., 2010)

Las ecuaciones fundamentales para el modelado de flujo multifásico fueron descriptas en el Anexo 3.II del Capítulo 3. En el presente Anexo se presentan las ecuaciones utilizadas para el modelado térmico y las modificaciones llevadas a cabo en los modelos de arrastre para la simulación de sólidos Geldart A, ya que tal como se explicó en el cuerpo del Capítulo 4, la mayoría de los modelos estándar no tienen en cuenta las meso-estructuras burbuja/cluster características en las partículas pequeñas y livianas.

En el primer caso presentado (basado en el trabajo de Reyes y colab., 2016) se utilizó el modelo de arrastre de Syamlal y O’Brien (1987) para resolver el intercambio de cantidad de movimiento entre las fases, presentado en la Tabla A4.I.1. En la ecuación A4.I.5, los coeficientes $\mathrm{C}_{1}$ y $\mathrm{C}_{2}$, característicos dicho modelo fueron determinados a partir de los valores de la velocidad y porosidad en la condición de mínima fluidización del par sólido-gas en estudio.

Para el estudio fluidodinámico del régimen de slug del segundo caso presentado (basado en el trabajo de Kong y colab., 2017), se aplicó el modelo de arrastre Gibilaro modificado (Gibilaro y colab., 1985). Tal como se dijo en la subsección 4.5.2 del Capítulo 4, una de las estrategias más utilizadas para la modificación de los modelos de arrastre es el uso de factores de corrección contantes. El ejemplo más característico de factor constante es la modificación propuesta por McKeen y Pugsley (2003) sobre el modelo de arrastre de Gibilaro (Gibilaro y colab., 1985), mostrado en la ecuación A4.I.6 de la Tabla A4.I.1. En este caso se utiliza una constante C, basada en la 
fluidización homogénea, para disminuir el coeficiente de arrastre. El valor de C suele encontrarse entre 0,1 - 0,3 dependiendo de las características del sistema a modelar (McKeen y Pugsley, 2003; Ye y colab., 2008). En base a pruebas preliminares llevadas a cabo en el GIRPQ (PROBIEN), se decidió trabajar con un valor de $\mathrm{C}=0,3$. Valores superiores al indicado, generan la expansión homogénea del lecho sin formación de burbujas, mientras que valores inferiores, no permiten la fluidización del lecho, dando como resultado un lecho pseudo-fijo con escaso movimiento de las partículas.

Tabla A4.I. - Coeficientes de intercambio de cantidad de movimiento.

\section{Syamlal y O’Brien (1987)}

$$
\begin{gathered}
K_{s g}=\frac{3}{4} \frac{\alpha_{s} \alpha_{g} \rho_{g}}{v_{t, s}^{2} d_{p, e f f}} C_{D}\left(\frac{R e_{s}}{v_{t, s}}\right)\left|\vec{v}_{s}-\vec{v}_{g}\right| \\
d_{p, e f f}=\phi_{s}{ }^{n} d_{p} \quad n=2,53 \\
C_{D}=\left(0,63+\frac{4,8}{\sqrt{R e_{s} / v_{t, s}}}\right)^{2} \\
v_{t, s}=0,5\left(A-0,06 R e_{s}\right. \\
\left.+\sqrt{\left(0,06 e_{s}\right)^{2}+0,12 e_{s}(2 B-A)+A^{2}}\right) \\
A=\alpha_{g}^{4,14} \\
B=C_{1} \alpha_{g}^{1,28} \text { para } \alpha_{g} \leq 0,85 \\
B=\alpha_{g}^{C_{2}} \text { para } \alpha>0,85 \\
\text { Con } C_{1}=0,8 \text { y } C_{2}=2,65
\end{gathered}
$$

\section{Gibilaro y colab. (1985)}

$$
K_{s g}=C\left[\left(\frac{18}{R e}+0,33\right) \frac{\rho_{g}\left|v_{s}-v_{g}\right|}{d_{p}} \alpha_{s} \alpha_{g}^{-1,8}\right]
$$

En el estudio térmico presentado en el Capítulo 4, debe evaluarse el intercambio de calor convectivo entre las fases. La ecuación general de conservación de 
la energía fue presentada en el Anexo II del Capítulo 3 (sección A3.II.1.3). Se asume que el coeficiente de intercambio de calor es una función de la diferencia de temperaturas y del área interfasial, $A_{i}$ :

$$
Q_{s g}=h_{s g} A_{i}\left(T_{s}-T_{g}\right)
$$

donde $h_{s g}\left(=h_{g s}\right)$ es el coeficiente volumétrico de transferencia de calor entre las fases sólida y gaseosa. El coeficiente de transferencia de calor puede ser calculado en base a la definición del número de Nusselt mediante:

$$
h_{s g}=\frac{k_{g} N u_{s}}{d_{p}}
$$

donde $k_{g}$ es la conductividad térmica de la fase gaseosa y $d_{p}$ es el diámetro de partícula.

Entre los distintos métodos disponibles en ANSYS-Fluent para determinar coeficiente volumétrico de transferencia de calor, $h_{s g}$, se encuentra en modelo de Gunn (Gunn, 1978), que establece que en flujos granulares con un rango de porosidades entre 0,35 - 1,0 y números de Reynolds hasta $10^{5}$, el número de $N u_{s}$ puede calcularse como:

$$
\begin{aligned}
& N u_{s}=\left(7-10 \alpha_{g}+5 \alpha_{g}^{2}\right)\left(1+0,7 \operatorname{Re}_{s}^{0,2} \operatorname{Pr}^{1 / 3}\right) \\
& +\left(1,33-2,4 \alpha_{g}+1,2 \alpha_{g}^{2}\right) \operatorname{Re}_{s}^{0,7} \operatorname{Pr}^{1 / 3}
\end{aligned}
$$

donde el número de Prandtl se define como:

$$
\operatorname{Pr}=\frac{c p_{g} \mu_{g}}{k_{g}}
$$

La naturaleza intrínseca continua del modelo Euler-Euler genera una sobrestimación de la energía transferida entre la pared y la emulsión densa de partículas (Reyes Urrutia y colab., 2015). Para la resolución correcta de la transferencia de calor pared-emulsión es necesario incorporar modelos de conductividad efectiva para ambas fases. La Tabla A4.I.2 contiene las ecuaciones del modelo de Zehner y Schlünder (1970) empleado en este trabajo. 


\section{Tabla A4.I.2 - Ecuaciones del modelo de Zehner y Schlünder (1970).}

Conductividad efectiva de la suspensión densa

$$
k_{b}=k_{b, g}+k_{b, s}
$$

Conductividad efectiva del gas:

$$
k_{b, g}=\left(1-\sqrt{1-\alpha_{g}}\right) k_{g, o}
$$

Conductividad efectiva del medio granular:

$$
\begin{gathered}
k_{b, s}=\sqrt{1-\alpha_{g}}[\omega A+(1-\omega) \Gamma] k_{g, o} \\
\omega=7,26 \times 10^{-3} \\
\Gamma=\frac{2}{\left(1-\frac{B}{A}\right)}\left\{\frac{(A-1)}{\left(1-\frac{B}{A}\right)^{2}} \frac{B}{A} \ln \left(\frac{A}{B}\right)-\frac{(B-1)}{\left(1-\frac{B}{A}\right)}-\frac{1}{2}(B+1)\right\} \\
B=1,25\left(\frac{\left(1-\alpha_{g}\right)}{\alpha_{g}}\right)^{10 / 9} \quad A=\frac{k_{p, o}}{k_{g, o}}
\end{gathered}
$$




\section{ANEXO 4.II}

\section{PROGRAMACIÓN PARA ANÁLISIS DE IMÁGENES}

Las imágenes se analizaron utilizando dos programas desarrollados con la herramienta MATLAB, similares a los utilizados en el Capítulo 3. El primero de ellos permite analizar cada imagen y obtener datos de área, perímetro, centro de masa y longitudes máxima y mínima de cada slug en cada imagen. El segundo programa calcula valores totales y promedio de diámetro, centro de masa y esfericidad; adicionalmente, permite acoplar slugs de imágenes consecutivas y realizar el cálculo de velocidad de ascenso.

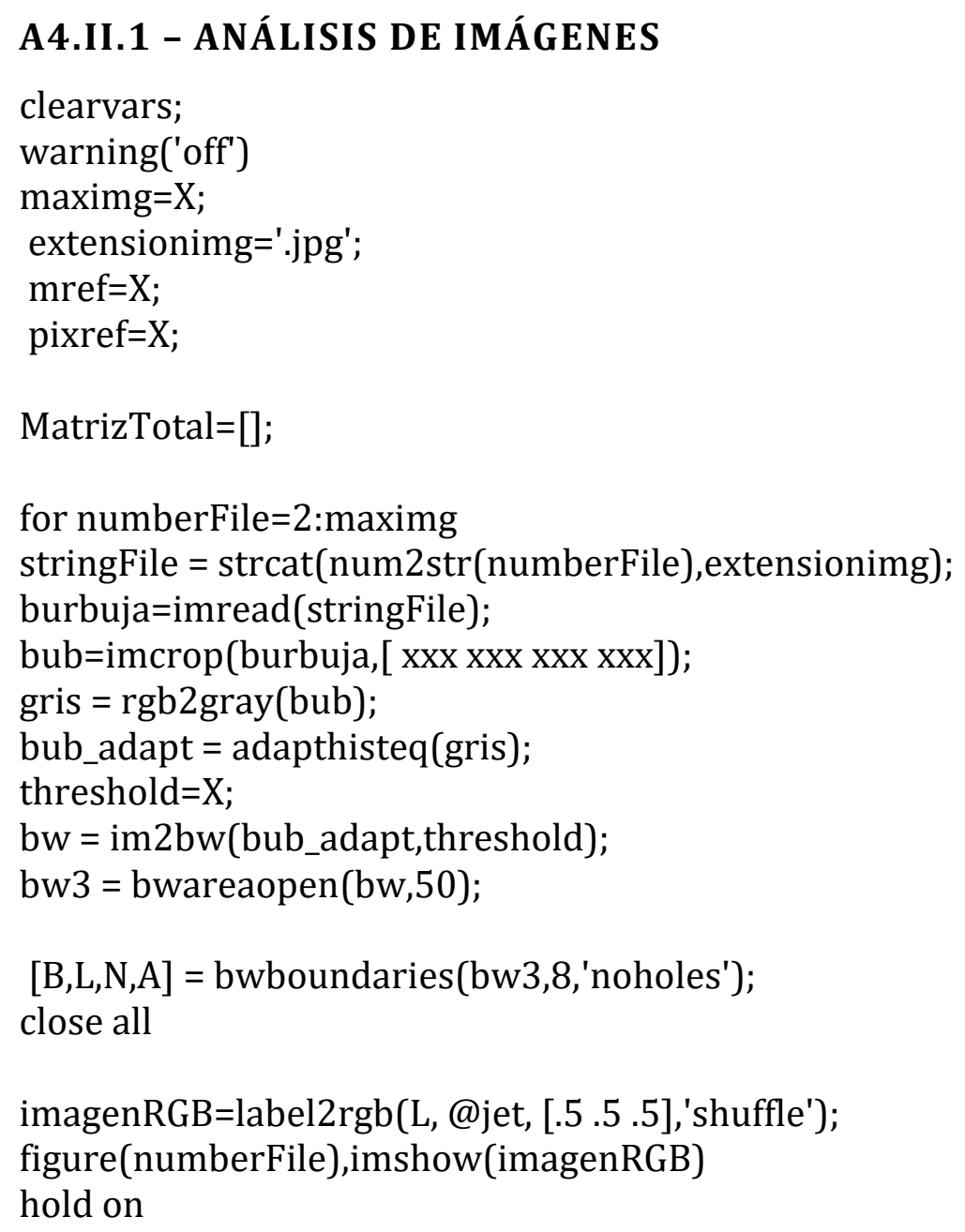




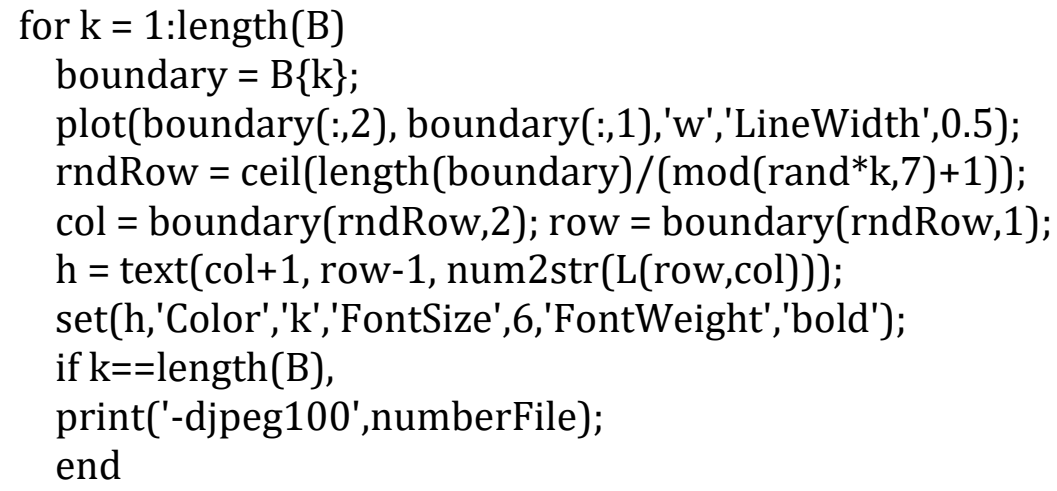

end

bubbledata = regionprops(L,'Area','Centroid','MajorAxisLength'); 


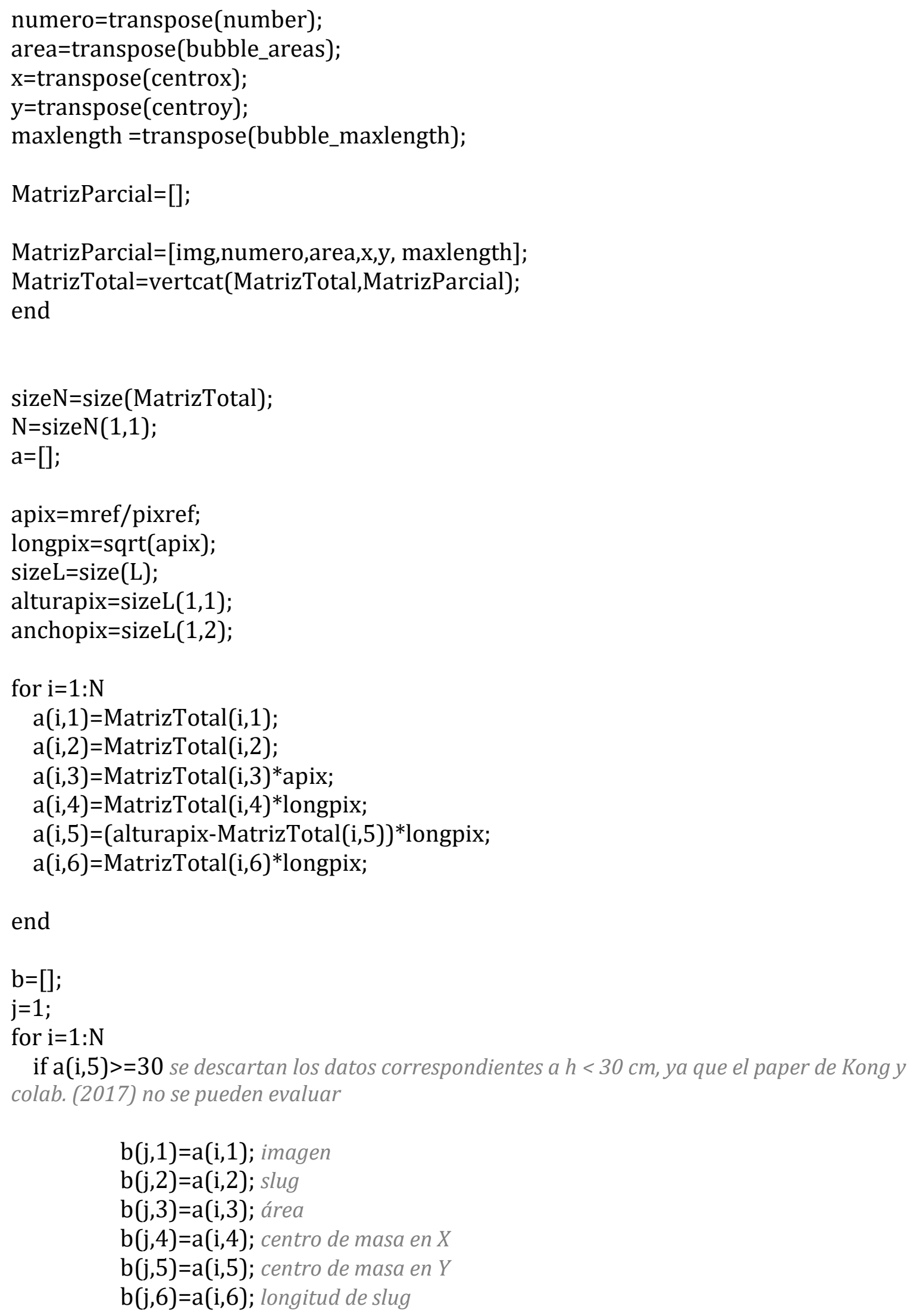




$$
\begin{aligned}
& \mathrm{j=j+1} \text {; } \\
& \text { end } \\
& \text { end }
\end{aligned}
$$

xlswrite('Datos.xls',MatrizTotal);

xlswrite('Datos.xls',a,'DatosCrudos cm');

xlswrite('Datos.xls',b,'FINAL cm');

\section{A4.II. 2 - CÁLCULOS}

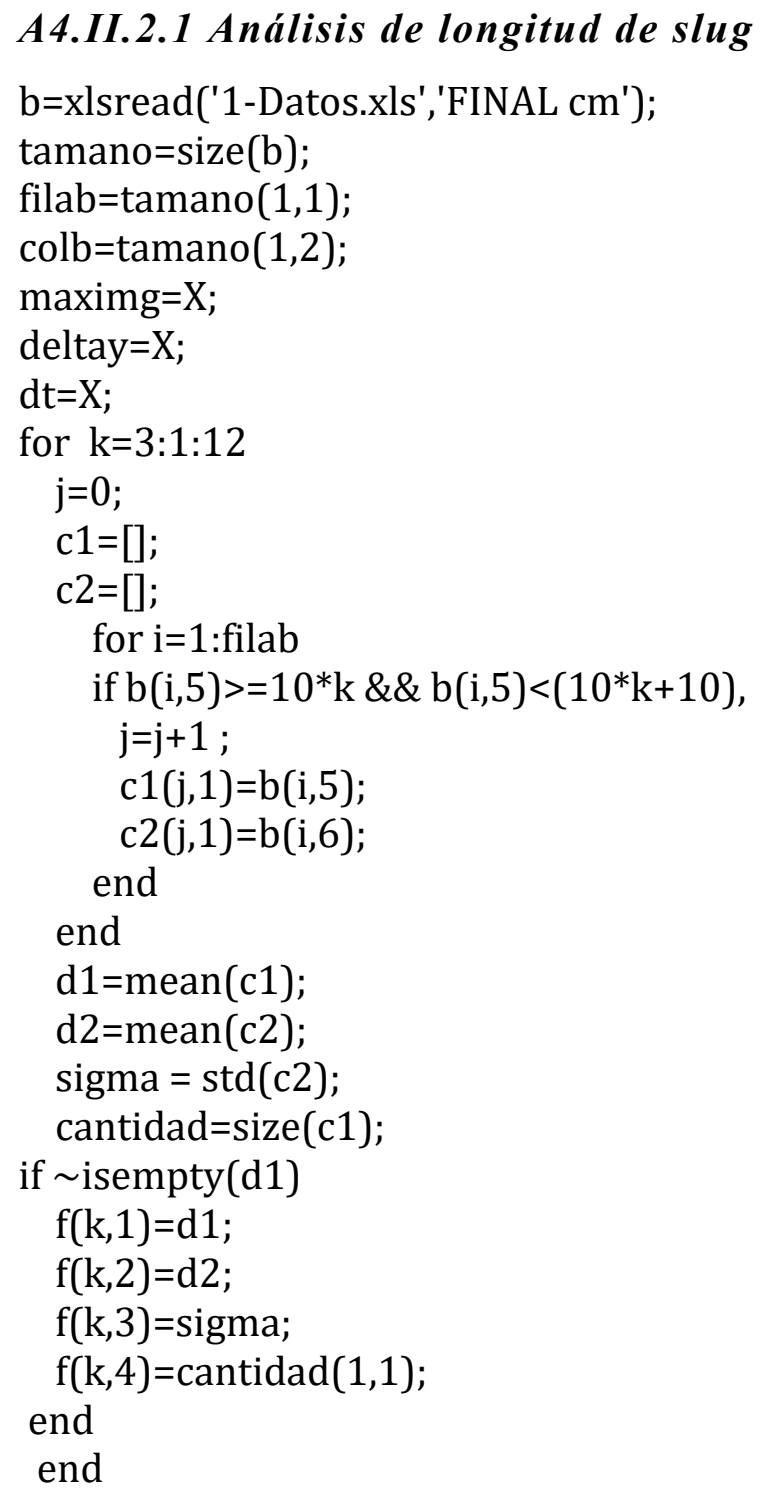




\section{A4.II.2.2 Análisis de velocidad de ascenso de slug}

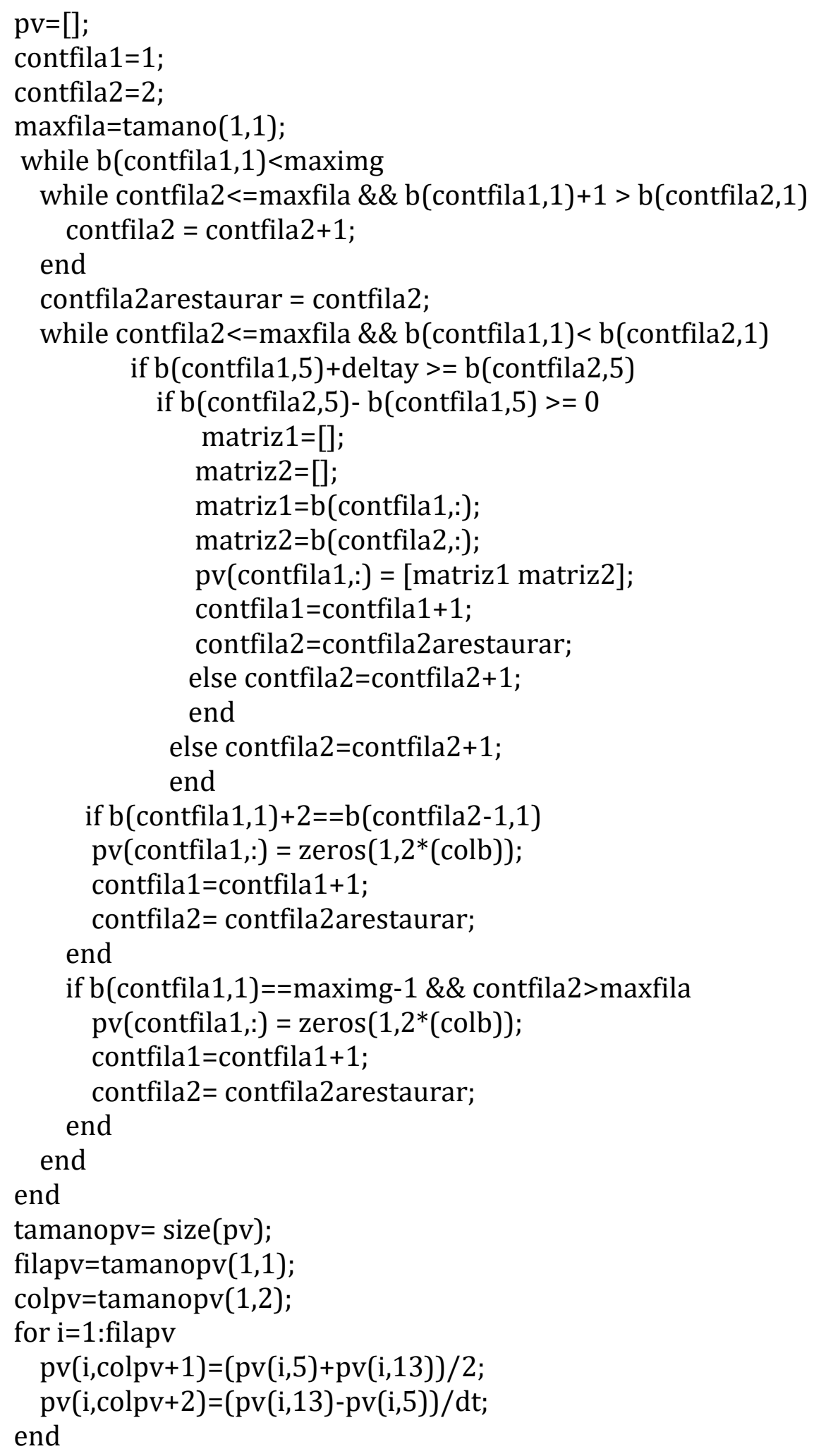




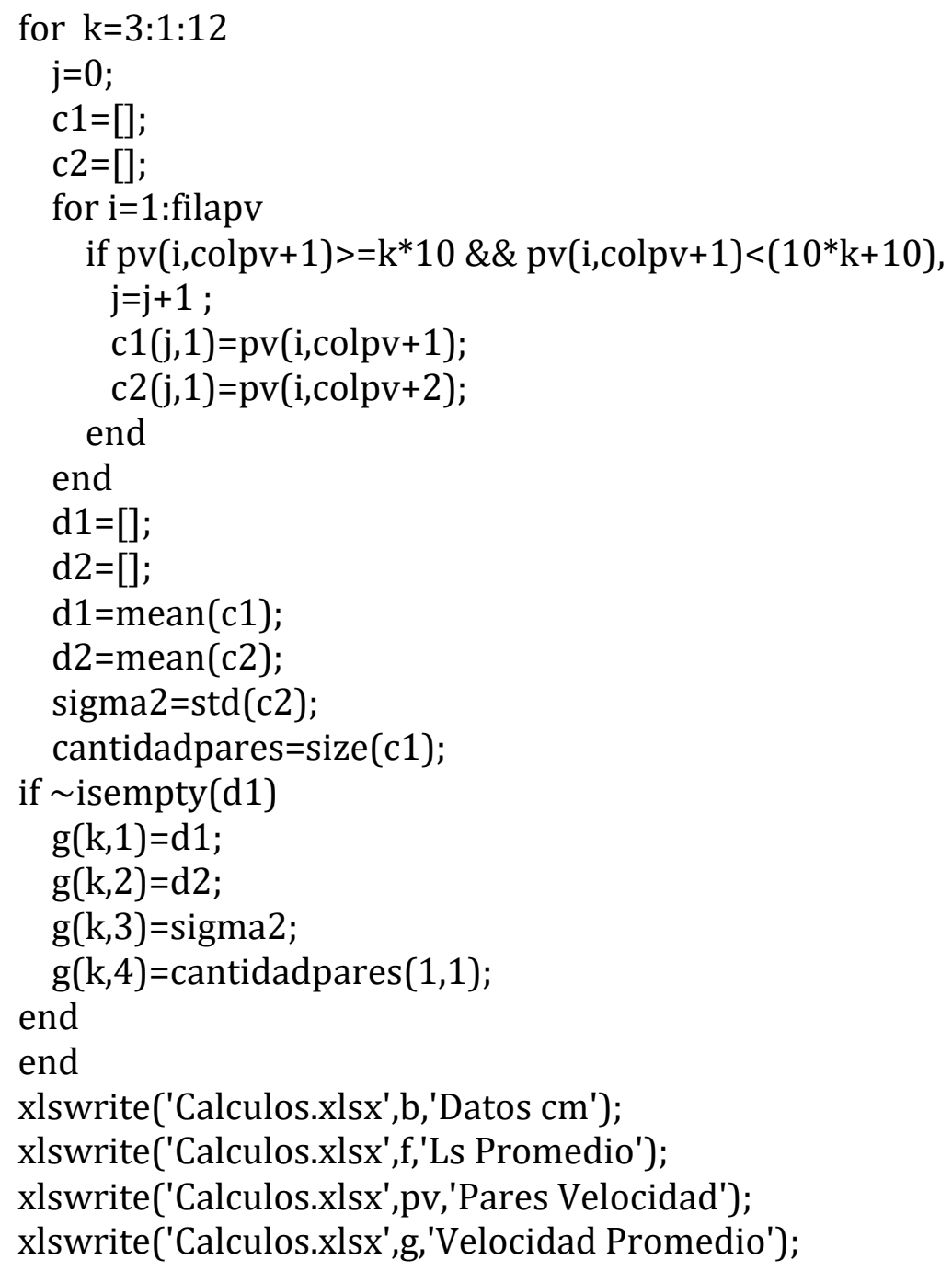




\section{CAPÍTULO 5}

\section{FLUIDIZACIÓN DE BIOMASA}

INTRODUCCIÓN

5.1 - OBTENCIÓN DE ENERGÍA A PARTIR DE BIOMASA

5.1.1 - Gasificación y lechos fluidizados

5.2 - MATERIALES Y EQUIPAMIENTO

5.2.1 - Caracterización de las partículas

5.2.2 - Análisis de bioresiduos: poder calorífico superior (PCS) e inferior (PCI), contenido de lignina, celulosa y hemicelulosa

5.2.3 - Procedimiento Experimental

5.3 - MODELADO POR CFD

5.4 - RESULTADOS Y DISCUSIÓN

5.4.1 - SISTEMA 1 (aserrín- arena)

5.4.1.1 - Lecho de partículas de arena

5.4.1.2 - Lecho de partículas de aserrín

5.4.1.3 - Mezclas binarias aserrín-arena

5.4.2 - SISTEMA 2 (bagazo de manzana - esferas de vidrio)

5.4.2.1 - Lecho de esferas de vidrio

5.4.2.2 - Lecho de bagazo de manzana

5.4.2.3 - Mezclas binarias bagazo-esferas de vidrio

5.5 CONCLUSIONES DEL CAPÍTULO 5

ANEXO 5.I : VALIDACIÓN DE LAS MALLAS DE LAS MEZCLAS BINARIAS

GENERACIÓN DEL DOMINIO, MALLADO Y VALIDACIÓN 


\section{INTRODUCCIÓN}

Los combustibles fósiles fueron convirtiéndose, desde fines del siglo XIX y durante el siglo XX, en la principal fuente de energía utilizada en el sistema socioproductivo global. Uno de sus rasgos fundamentales radica en el hecho de ser no renovables, por lo que es imprescindible prever su agotamiento. Ante este escenario, se debe disponer de fuentes de energía primaria, renovables, que avancen en su sustitución; siendo la biomasa una de ellas.

En primer lugar, se debe definir el concepto de biomasa: en su acepción más general es el conjunto de toda la materia orgánica del reino vegetal y animal. En términos de la IUPAC, la biomasa se define como el material producido por crecimiento biológico (microorganismos, plantas, animales, etc.) (Nagel y colab., 1992). A diferencia de los combustibles sólidos, la biomasa requiere un tiempo relativamente breve para su desarrollo. En base a estas definiciones, la biomasa puede clasificarse en (Cossu y colab., 2020):

Material virgen, expresamente generado para producción de energía (madera, maíz, etc.)

$\checkmark$ residuos agroforestales e industriales (paja, bagazos, excrementos, etc.);

$\checkmark$ fracciones biodegradables de residuos (residuos alimentarios, lodos urbanos, aceites agotados, etc.)

$\checkmark$ biomasa cosechada (cultivos y algas) cultivada mediante el uso de residuos líquidos

La biomasa es considerada, progresivamente, como una fuente estratégica para generar energías alternativas renovables, reduciendo el uso de recursos fósiles de base carbonosa.

En el marco de la enumeración anterior, el término biomasa, dentro del campo de su utilización como fuente de energía, hace referencia a cultivos energéticos, cuyo único fin es obtener energía, y residuos orgánicos como los agroindustriales, agrícolas, forestales y urbanos (fracción orgánica de los mismos) (Energías renovables 2008 Energía biomasa, Secretaría de Energía Argentina, 2008). Para la biomasa en aplicaciones energéticas, surgen distintas clasificaciones arbitrarias, siendo una de ellas la distinción entre biomasa húmeda y biomasa seca. Los procesos para obtener energía a partir de la 
biomasa húmeda son mayormente procesos físicos o bioquímicos, y para la biomasa seca son procesos termoquímicos, que se basan en el suministro de energía térmica para generar reacciones químicas que conducirán a la transformación de la biomasa inicial. De esta manera se pueden obtener compuestos gaseosos, líquidos y sólidos que servirán como materias primas para generar derivados útiles para la industria, síntesis de productos químicos y generación de energía.

En la zona cordillerana de la región del Comahue, se generan grandes cantidades de residuos forestales (aserrín, ramas, residuos de podas), mientras que en la región del Alto Valle se generan residuos provenientes de industrias jugueras o sidreras o vínicas (bagazo de manzana y pera, orujo y escobajo de uva), todos con potencial para ser destinados a la generación de energía. La utilización de esta biomasa como fuente alternativa de energía también aportaría una conveniente solución al problema del manejo y disposición de estos voluminosos residuos (Van de Velden y colab., 2008; Dai y colab., 2015; Fernandez y colab., 2018, Sette y colab., 2020).

Los sistemas más utilizados y eficientes de generación de energía a partir de biomasa emplean el proceso de gasificación en reactores de lecho fluidizado. Este proceso permite la generación de energía con múltiples ventajas frente a los tratamientos térmicos en operaciones convencionales. Las burbujas presentes en este tipo de lechos proporcionan un excelente contacto gas-sólido y favorecen la ocurrencia de elevadas velocidades de transferencia de calor y masa (Baeyens y Geldart 1980; Venier y colab., 2020). Una gran cantidad de biomasa es generada anualmente mediante fotosíntesis absorbiendo $\mathrm{CO}_{2}$ de la atmósfera, y al ser tratada termoquímicamente libera $\mathrm{CO}_{2}$ sin incrementar la cantidad presente en la atmósfera (el balance de emisiones de $\mathrm{CO}_{2}$ es neutro). Es importante destacar que el $C$ liberado proveniente de combustibles fósiles es el que está fijo a la tierra hace millones de años (Basu, 2010).

Los residuos biomásicos, debido a su forma, tamaño y densidad, presentan dificultades para su fluidización en forma casi excluyente. Para mejorar la operación, se puede incorporar un material inerte apropiado, tal como arena o perlas de vidrio. Al cofluidizar bioresiduos incluyendo un inerte, se logra mejorar la calidad de la fluidización, incrementar el mezclado y la calidad de burbujeo del lecho, además de obtenerse una disminución en la velocidad de mínima fluidización. Por otra parte, en el proceso de gasificación se observará una mejora en la velocidad de transferencia de calor debido a la 
incorporación de un sólido con mayor capacidad calorífica (Proenza Perez y colab., 2017). Girimonte y colab. (2019), llevaron a cabo un estudio respecto de la influencia que tiene la granulometría del material inerte en el proceso de obtención de energía a partir de residuos de la industria del aceite de oliva. Para ello utilizaron carozos de oliva como bioresiduo, y diferentes tamaños de inertes (arena y perlas de vidrio), analizando las curvas de fracción de gas y las velocidades de fluidización. De los tamaños de arena estudiados, concluyeron que aquélla cuyo diámetro medio era de $340 \mu \mathrm{m}$ promueve en mayor medida el mezclado de sólidos y mejora la distribución de biomasa a lo largo del lecho.

Las correlaciones convencionales para la determinación de la velocidad $U_{m f}$, frecuentemente arrojan resultados erróneos en el caso de mezclas binarias, por lo que se han realizado estudios específicos de las mismas para la estimación de la velocidad de mínima fluidización. Paudel y Feng (2013) estudiaron experimentalmente la fluidización de mezclas de biomasa y distintos sólidos inertes con aire. Utilizaron mazorca de maíz y cáscaras de nuez (biomasa), y arena, perlas de vidrio y alúmina como inertes, cubriendo un rango de porcentajes en peso entre 0-100 \% de biomasa. Propusieron una nueva correlación para predecir la velocidad de mínima fluidización de partículas de inerte, de biomasa y mezclas de inerte-biomasa en base a su porcentaje en peso. Zhang y colab. (2011) realizaron un detallado estudio experimental de la fluidización de mezclas de biomasa pelletizada y arena en tres tamaños diferentes reportando que el inerte favorece la fluidización de la biomasa, disminuyendo marcadamente el valor de $U_{m f}$.

Ma y Zhao (2018) estudiaron la influencia de un inerte con forma esférica en la fluidización de biomasa (pellet). Llevaron a cabo experiencias y simulaciones mediante CFD-DEM (método de elementos discretos) de cinco sistemas variando la fracción volumétrica de biomasa. Observaron una disminución de $U_{m f}$ al aumentar la proporción de inerte. En el mismo sentido, Wang y Zong (2019) reportaron resultados obtenidos experimentalmente y mediante simulaciones CFD-DEM para mezclas arena-biomasa en un lecho fluidizado. Los autores analizaron la influencia de la densidad y tamaño de las partículas de biomasa sobre la calidad de fluidización a tres velocidades superficiales de gas. Observaron un buen mezclado de partículas cuando la relación de tamaños era inferior a 4 y predijeron valores de $U_{m f}$ utilizando correlaciones empíricas previamente desarrolladas. 
Sousa Sant'Anna y colab. (2017) llevaron a cabo simulaciones CFD del comportamiento de un gasificador de lecho burbujeante para un sistema compuesto gasbiomasa-arena. Utilizando CFD acoplada con planificación factorial, identificaron los ensayos en los que el sistema alcanzó la fluidización burbujeante mediante los perfiles longitudinales de las fracciones volumétricas de arena, gas y biomasa. Observaron que se presentaba segregación del medio particulado en aquellos ensayos para los que la relación másica biomasa/arena era superior a 1 y la relación entre fracciones volumétricas de biomasa y arena en el lecho era inferior o igual a 0,5. También concluyeron que la variable con mayor incidencia en la ecuación de modelado era el tamaño de la partícula de biomasa.

Thapa y Halvorsen (2013) aplicaron el modelo Euleriano para predecir las propiedades de fluidización de partículas de cuarzo de 0,5 mm fluidizadas con vapor y esferas de vidrio de 0,35 mm fluidizadas con aire, y compararon sus comportamientos. Predijeron la velocidad $U_{m f}$ utilizando la desviación estándar de la presión y validaron los resultados con mediciones experimentales. La caída de presión a lo largo del lecho obtenida mediante CFD fue aproximadamente la misma para ambos casos y los resultados se desviaron en un $18 \%$ respecto de las mediciones experimentales en condiciones de mínima fluidización.

Pese a los aportes mencionados, no se ha logrado de modo totalmente satisfactorio, describir el comportamiento fluidodinámico de las mezclas binarias. Es por ello que se propone realizar el estudio fluidodinámico de mezclas binarias de bagazo de manzana y perlas de vidrio, y de aserrín con arena, en todos los casos fluidizadas con aire, con el fin de lograr un conocimiento exhaustivo de su comportamiento, abarcando los principales indicadores tales como velocidad de mínima fluidización y pérdida de carga del lecho, para distintas proporciones de inerte y biomasa. La completa interpretación de la fluidodinámica de estos materiales es una etapa previa e indispensable para lograr la simulación completa de su proceso de gasificación en lecho fluidizado. Los resultados experimentales son utilizados para la validación del modelado mediante CFD.

En este Capítulo se aplica la técnica de CFD para desarrollar una metodología eficiente para simular la fluidización de mezclas binarias biomasa-inerte, utilizando aire como agente fluidizante, con el objetivo de predecir la velocidad $U_{m f}$ y tener un conocimiento exhaustivo de su comportamiento fluidodinámico. Se trabajó con dos 
muestras de biomasa diferentes: aserrín y bagazo de manzana, provenientes de industrias de la zona, y como inerte se utilizó arena en el primer caso y esferas de vidrio en el segundo. En la sección 5.1 se resumen las principales formas de obtención de energía a través de biomasa. En la sección 5.2 se presenta la caracterización de los sólidos utilizados y el procedimiento experimental llevado a cabo para obtener las curvas de $\Delta P$ y el cálculo de las velocidades $U_{m f}$; y en la sección 5.3 se describe la metodología aplicada para obtener los datos mediante CFD. Luego, en la sección 5.4, se presentan los resultados obtenidos para los sólidos puros y para los sistemas conformados por aserrín-arena y bagazo de manzana- esferas de vidrio. Finalmente, en la sección 5.5 se vuelcan las conclusiones del capítulo. Este capítulo cuenta con un breve anexo (Anexo 5.I) donde se describe la validación de las mallas utilizadas.

\section{1 - OBTENCIÓN DE ENERGÍA A PARTIR DE BIOMASA}

Como se mencionó en la Introducción, los procesos termoquímicos conducen a la transformación de la biomasa seca en compuestos gaseosos, líquidos o sólidos, que pueden ser utilizados como materias primas para, por ejemplo, la generación de energía. Estos procesos de conversión pueden clasificarse en cuatro grandes grupos (Basu, 2010; Energías renovables 2008 - Energía biomasa, Secretaría de Energía Argentina, 2008):

Combustión: es el proceso más sencillo y el más ampliamente usado. Permite obtener energía térmica, ya sea para uso doméstico o industrial. Durante la combustión, la biomasa (combustible) es quemada en presencia de exceso de aire para producir calor. Permite generar vapor en elementos sumergidos, que luego dan lugar a la producción de energía eléctrica al expandirlo en una turbina adosada a un generador eléctrico.

$\checkmark$ Pirólisis: se realiza una degradación controlada de la biomasa bajo atmósfera inerte, para obtener como producto una combinación variable de combustibles sólidos, líquidos y gaseosos, en función de la temperatura y de la velocidad de calentamiento.

$\checkmark$ Licuefacción: es un proceso de conversión termoquímico en medio acuoso complejo. Cobra progresivamente mayor interés, ya que las condiciones de presión y temperatura bajo las cuales se desarrollan las reacciones son 
moderadas, permitiendo obtener un biocombustible líquido con mayor eficiencia energética que con otros procesos.

$\checkmark$ Gasificación: consiste en la transformación de biomasa sólida en forma controlada y en presencia de oxígeno deficitario, de manera de producir un gas combustible denominado gas pobre, debido a que su poder calorífico es menor que el del gas natural. La gasificación se realiza en un recipiente cerrado llamado gasificador en el cual se introduce el combustible sólido y una cantidad de aire u otro agente gasificador que provea una cantidad de oxígeno menor que la que se requeriría para una combustión completa. El gas obtenido puede utilizarse luego en un quemador para obtener energía térmica, en una caldera para producir vapor, o ser enfriado y acondicionado para su uso en un motor de combustión interna que produzca luego energía mecánica. Es una fuente apropiada de gas de síntesis (mezcla de hidrógeno y monóxido de carbono), materia prima para numerosos procesos químicos de generación de productos de alto valor.

\subsection{1 - Gasificación y lechos fluidizados}

La gasificación y combustión son dos procesos termoquímicos estrechamente relacionados, pero hay una diferencia importante entre ellos, la gasificación almacena la energía en los enlaces químicos del producto gaseoso mientras que durante la combustión se rompen esos enlaces para liberar energía directamente.

La gasificación tiene lugar a altas temperaturas y en un rango de presiones que pueden ir desde 1 a 33 atm (Ruiz y colab., 2013). A continuación, se listan las diferentes etapas del proceso de gasificación, aunque debe aclararse que no hay un límite claro entre las etapas, y las mismas suelen solaparse.

Secado: la biomasa generalmente está acompañada por un elevado contenido de humedad, lo que disminuye la eficiencia del proceso, ya que la energía utilizada en evaporar el agua se pierde. Por esto, previo a ingresar al gasificador, la biomasa debe secarse hasta alcanzar niveles máximos de humedad del 10 al 15\%.

$\checkmark$ Pirólisis: ocurre a temperaturas superiores a $150^{\circ} \mathrm{C}$ y deriva en la formación de un residuo sólido carbonoso conocido como char, junto con la emisión de algunos gases y un líquido que contiene condensables y agua (bio-aceite). 
$\checkmark$ Oxidación: también llamada combustión parcial de algunos gases, vapores y el char por un agente de gasificación. Parte de estos compuestos se convierten en $\mathrm{CO}, \mathrm{CO}_{2}$ y $\mathrm{H}_{2} \mathrm{O}$. La energía necesaria para las etapas de pirolisis y gasificación es generada en esta etapa.

$\checkmark$ Gasificación: en esta etapa el char producido durante la pirolisis es convertido principalmente en $\mathrm{CO}, \mathrm{H}_{2}$ y $\mathrm{CH}_{4}$.

Las últimas dos etapas requieren de un medio como vapor, aire, $\mathrm{CO} 2$, u oxígeno para ordenar la estructura de la materia prima, con el fin de convertirla en un gas; pudiéndose también añadir hidrógeno al producto. Estos agentes gasificantes reaccionan con el carbono sólido e hidrocarburos más pesados para convertirlos en gases de bajo peso molecular como $\mathrm{CO}, \mathrm{H}_{2} \mathrm{y} \mathrm{CH}_{4}$.

En las reacciones de gasificación, interactúa el char producido en la pirólisis con los gases del entorno. El char generado a partir de biomasa es muy reactivo dado que su porosidad se encuentra en el rango de 40 a $50 \%$, lo que le da una gran superficie de contacto con el gas (Encinar y colab., 2001).

Según Van der Drift y colab. (2001) la tecnología de gasificación en lecho fluidizado es considerada una de las técnicas más adecuadas para convertir termoquímicamente diferentes combustibles en energía utilizable posteriormente. En este tipo de reactor la alimentación fresca de partículas de biomasa entra en contacto con un lecho caliente de sólidos, que, gracias a la agitación, lleva rápidamente a las nuevas partículas a la temperatura donde puede comenzar la pirólisis, produciendo el char y los respectivos gases inherentes al proceso. El alto grado de mezclado de los sólidos ayuda a mantener una temperatura relativamente uniforme en todo el reactor. Otra ventaja de este tipo de gasificador es que su mezclado vigoroso favorece a las fragmentaciones de la biomasa dando lugar al desprendimiento inicial de los volátiles y a la formación del char.

La agitación permite además gasificar diferentes tipos de biomasa (dependiendo la disponibilidad de esta con, por ejemplo, las estaciones del año). Es por esto que es una de las tecnologías preferidas para plantas de gasificación de biomasa a gran escala. 


\section{2 - MATERIALES Y EQUIPAMIENTO}

\subsection{1 - Caracterización de las partículas}

Se utilizaron dos bioresiduos de diferente procedencia. Por un lado, aserrín, proveniente del aserradero "Abra Ancha”, localizado en Aluminé, provincia de Neuquén, y por otro lado bagazo de manzana, proveniente de la empresa "Sidrera La Delicia SRL", situada en Cipolletti, provincia de Río Negro. Como material inerte, se empleó arena y esferas de vidrio. Se trabajó con dos tipos de muestras binarias: aserrín-arena (SISTEMA 1) y bagazo- esferas de vidrio (SISTEMA 2).

Los materiales mencionados fueron tamizados para su clasificación, utilizando una torre de tamizado (Tamices y Equipo Vibrador ZONYTESTMR).

En el SISTEMA 1, se utilizó la arena descripta en el Capítulo 3 y la fracción de aserrín retenida en las mallas 30 y 40, que representa un 53,89\% del total de la biomasa tamizada (80,67 g sobre un total de 149,68 g de muestra). La Tabla 5.1 muestra un resumen de sus propiedades.

En el caso del SISTEMA 2, con el objetivo de utilizar una distribución de tamaño de partícula que permitiera la posterior separación de los sólidos y que perteneciera a la clasificación B de Geldart, se trabajó con la muestra retenida en la malla 60 para el material vidrio y en las mallas 18, 20, 25 y 30 para la biomasa (representando un 44,39\% del total de la muestra). Sus propiedades se presentan en la Tabla 5.1. Para realizar las simulaciones se dividió la muestra de bioresiduo en dos fracciones, de modo que los diámetros medios fueran representativos. Los sólidos retenidos en las mallas 18 y 20 fueron tratados en conjunto (denominados: Biomasa1820), y por otro lado se agruparon los retenidos en las mallas 25 y 30 (denominados: Biomasa 2530).

Tanto para la arena como las partículas de vidrio, por tratarse de sólidos no porosos, los valores de densidad aparente y absoluta son equivalentes (Capítulo 3, subsección 3.4.1.2). Sin embargo, los bioresiduos son sólidos porosos, por lo que se determinó su densidad absoluta utilizando un porosímetro de helio y la densidad aparente mediante un picnómetro de mercurio. Sumado a ello, y con base en la norma API RP 56 (Capítulo 3, sub-sección 3.4.1.4) se analizó la esfericidad de las partículas. 
Tabla 5.1 - Propiedades de los sólidos.

\begin{tabular}{|l|c|c|c|c|c|}
\hline \multicolumn{1}{|c|}{ Material } & $\begin{array}{c}\text { Diámetro } \\
{[\mathrm{mm}]}\end{array}$ & $\begin{array}{c}\text { Densidad } \\
\text { aparente } \\
{[\mathrm{kg} / \mathrm{m} 3]}\end{array}$ & $\begin{array}{c}\text { Densidad } \\
\text { absoluta } \\
{[\mathrm{kg} / \mathrm{m} 3]}\end{array}$ & Esfericidad & $\begin{array}{c}\text { Clasificación } \\
\text { de Geldart }\end{array}$ \\
\hline Arena & 0,513 & 2650 & 2650 & 0,8 & $\mathrm{~B}$ \\
\hline Aserrín & 0,7 & 402 & 1406 & 0,66 & $\mathrm{~B}$ \\
\hline Vidrio & 0,275 & 2484 & 2484 & 0,9 & $\mathrm{~B}$ \\
\hline Biomasa 1820 & 1,008 & 1200 & 1460 & 0,52 & $\mathrm{~B}$ \\
\hline Biomasa 2530 & 0,718 & 1200 & 1460 & 0,52 & $\mathrm{~B}$ \\
\hline
\end{tabular}

\subsection{2 - Análisis de bioresiduos: poder calorífico superior (PCS) e inferior (PCI),} contenido de lignina, celulosa y hemicelulosa

El proximal (humedad, cenizas y material volátil) se llevó a cabo según normas ASTM (ASTM E872 - 82, 1998; ASTM D1102-84, 2001) y el análisis elemental se realizó con un analizador elemental (AuroEA3000) siguiendo las especificaciones descriptas por Fernandez y colab. (2019).

El PCS se midió experimentalmente utilizando una bomba calorimétrica automatizada (IKA C5000) según el procedimiento descripto en la norma ASTM D240. El valor PCI se determinó en base al PCS y el contenido correspondiente de agua (wt.\%) considerando el contenido de hidrógeno elemental, de acuerdo a lo recomendado por Soria y colab. (2019).

El contenido de lignina (LIG), celulosa (CEL) y hemicelulosa (HCE) para ambos bioresiduos se determinó según normas ASTM (ASTM D1106-56; ASTM D1103-60)

Las Tablas 5.2.a y 5.2.b resumen los resultados de los análisis antes mencionados. Los contenidos de agua resultantes del análisis proximal muestran valores inferiores al $10 \%$ para ambas muestras. El contenido de cenizas puede ser un aspecto problemático en el uso energético de biomasa lignocelulósica. En este caso, tanto el aserrín como el bagazo de manzana presentaron un contenido de cenizas muy pequeño, lo que afecta positivamente su HHV (Channiwala y Parikh, 2002). Los elevados contenidos de materia volátil hacen que ambos bioresiduos sean apropiados para procesos de degradación térmica (Demirbas, 2004). En este contexto, la gasificación se presenta como una alternativa factible para la valorización del aserrín y del bagazo de manzana estudiados. 
Tabla 5.2.a - Composición y valores de poder calorífico superior e inferior del aserrín.

\begin{tabular}{|c|c|c|c|c|c|c|c|}
\hline \multicolumn{5}{|c|}{ Análisis elemental (wt.\%, b.s.) } & \multicolumn{3}{|c|}{ Análisis proximal (wt.\%, b.s.) } \\
\hline $\mathrm{C}$ & $\mathrm{H}$ & 0 & $\mathrm{~N}$ & S & $\begin{array}{c}\text { Materia } \\
\text { volátil }\end{array}$ & C fijo & Ceniza \\
\hline 50,93 & 6,03 & 42,36 & 0,11 & 0,05 & 82,4 & 17,03 & 0,53 \\
\hline \multicolumn{3}{|c|}{ Análisis bioquímico (wt.\%, b.s.) } & \multirow{2}{*}{\multicolumn{3}{|c|}{ Contenido de agua (wt.\%) }} & \multicolumn{2}{|c|}{ Poder calorífico [MJ/kg] } \\
\hline CEL & HCE & LIG & & & & PCI & PCS \\
\hline 42,96 & 19,99 & 26,8 & & 6,22 & & 18,45 & 20,04 \\
\hline
\end{tabular}

Tabla 5.2.b - Composición y valores de poder calorífico superior e inferior del bagazo.

\begin{tabular}{|c|c|c|c|c|c|c|c|}
\hline \multicolumn{5}{|c|}{ Análisis elemental (wt.\%, b.s.) } & \multicolumn{3}{|c|}{ Análisis proximal (wt.\%, b.s.) } \\
\hline $\mathrm{C}$ & $\mathrm{H}$ & 0 & $\mathrm{~N}$ & $\mathrm{~S}$ & $\begin{array}{c}\text { Materia } \\
\text { volátil }\end{array}$ & C fijo & Ceniza \\
\hline 43,59 & 5,69 & 42,11 & 4,71 & 3,89 & 84,1 & 7,97 & 1,55 \\
\hline \multicolumn{3}{|c|}{ Análisis bioquímico (wt.\%, b.s.) } & \multirow{2}{*}{\multicolumn{3}{|c|}{ Contenido de agua (wt.\%) }} & \multicolumn{2}{|c|}{ Poder calorífico $[\mathrm{M}] / \mathrm{kg}$} \\
\hline CEL & HCE & LIG & & & & $\mathrm{PCI}$ & PCS \\
\hline 10,3 & 10,6 & 18,1 & & 4,34 & & 16,35 & 17,61 \\
\hline
\end{tabular}

\subsection{3 - Procedimiento Experimental}

Se trabajó con un lecho construido en acrílico de geometría cilíndrica, que fue descripto en la sección 3.4.2 del Capítulo 3 (ver Figura 3.7).

En la primera etapa del trabajo, se estudió el SISTEMA 1. Se fluidizó la arena (estudiada en el Capítulo 3), luego el aserrín y finalmente distintas mezclas binarias de ambos sólidos. En una segunda etapa, se llevó a cabo el análisis experimental de los sólidos puros y las distintas mezclas binarias correspondientes al SISTEMA 2.

Las determinaciones experimentales se realizaron a presión y temperatura ambiente ( $1 \mathrm{~atm}$ y $20^{\circ} \mathrm{C}$ ). Se partió de una altura de lecho en reposo de $150 \mathrm{~mm}$ para el SISTEMA 1 y de $120 \mathrm{~mm}$ para el SISTEMA 2, en base a la masa disponible de muestra. Se registró tanto la curva de fluidización como la de desfluidización y todas las experiencias se realizaron por triplicado. En todos los casos, antes de comenzar las mediciones, se mezclaron los sólidos.

Durante las experiencias, la válvula de control de caudal se abrió o cerró en forma gradual y lenta según correspondiera a ensayos de fluidización o desfluidización, respectivamente. Una vez estabilizado el caudal de aire, se registró el mismo y el valor correspondiente de pérdida de carga $(\Delta P)$ a través del lecho (sección 3.6, Capítulo 3). 
La velocidad $U_{m f}$ se evaluó gráficamente a partir de la intersección de las líneas de ajuste de $\Delta \mathrm{P}$ en función de la velocidad superficial del gas $(U)$ de ambas regiones, lecho en reposo y lecho fluidizado, utilizando los valores obtenidos en la desfluidización, conforme al procedimiento secuencial establecido en la norma ASTM D7743-12 y coincidentemente con lo recomendado por Yates (1983), Kunii y Levenspiel (2013) y Felizardo y Freire (2018).

Para cada sistema se realizaron cinco experiencias de fluidización, correspondientes a los sólidos puros (inertes y biomasa) y tres sistemas binarios, cuyas composiciones volumétricas y en peso se detallan en las Tablas 5.3.a y 5.3.b. Las composiciones volumétricas de las distintas mezclas fueron calculadas respecto de las alturas de lecho en reposo correspondientes.

Tabla 5.3 a - Composición de las mezclas aserrín-arena (SISTEMA 1).

*Arena40, Arena30 y Arena15 son mezclas que contienen 40\%, 30\% y 15\% de arena v/v respectivamente.

\begin{tabular}{|c|c|c|c|c|c|}
\hline & $\begin{array}{c}\text { Arena } \\
(100 \% \\
\text { arena })\end{array}$ & Arena40* & Arena30* & Arena15* & $\begin{array}{c}\text { Aserrín } \\
(100 \% \\
\text { aserrín })\end{array}$ \\
\hline Masa de arena [g] & 1757,44 & 965,13 & 770,70 & 324,99 & 0,00 \\
\hline Masa de aserrín [g] & 0,00 & 116,25 & 122,56 & 131,65 & 179,41 \\
\hline Masa total $[\mathrm{g}]$ & 1757,44 & 1081,38 & 893,26 & 456,64 & 179,41 \\
\hline $\mathrm{R}_{\mathrm{w}}(\%)=\mathrm{W}_{\text {arena }} / \mathrm{W}_{\text {total }}$ & 100 & 89 & 86 & 71 & 0 \\
\hline
\end{tabular}

Tabla 5.3 b - Composición de las mezclas bagazo-esferas de vidrio (SISTEMA 2).

${ }^{* *}$ Esferas-vidrio50, Esferas-vidrio30 y Esferas-vidrio10 son mezclas que contienen 50\%, 30\% y $10 \%$ de esferas de vidrio $\mathrm{v} / \mathrm{v}$ respectivamente.

\begin{tabular}{|c|c|c|c|c|c|}
\hline & $\begin{array}{c}\text { Esferas- } \\
\text { vidrio } \\
(100 \% \\
\text { vidrio })\end{array}$ & $\begin{array}{c}\text { Esferas- } \\
\text { vidrio50** }\end{array}$ & $\begin{array}{c}\text { Esferas- } \\
\text { vidrio30** }\end{array}$ & $\begin{array}{c}\text { Esferas- } \\
\text { vidrio10** }\end{array}$ & $\begin{array}{c}\text { Bagazo } \\
(100 \% \\
\text { bagazo })\end{array}$ \\
\hline $\begin{array}{c}\text { Masa de esferas de vidrio } \\
{[\mathrm{g}]}\end{array}$ & 1619,13 & 774,35 & 457,59 & 159,94 & 0,00 \\
\hline Masa de bagazo [g] & 0,00 & 446,19 & 517,31 & 622,12 & 642,5 \\
\hline Masa total [g] & 1619,13 & 1220,54 & 974,9 & 782,06 & 642,5 \\
\hline $\mathrm{R}_{\mathrm{w}}(\%)=\mathrm{W}_{\text {vidrio }} / \mathrm{W}_{\text {total }}$ & 100 & 63 & 47 & 20 & 0 \\
\hline
\end{tabular}

\section{3 - MODELADO POR CFD}

Para llevar a cabo las simulaciones se utilizó el software de fluidodinámica computacional ANSYS-Fluent 18.1, aplicando la metodología descripta en la sección 3.5 y 
el Anexo 3.II del Capítulo 3 de la presente tesis. Los esquemas de simulación pueden construirse en base a geometrías bidimensionales o tridimensionales. Taghipour y colab. (2005) llevaron a cabo el estudio experimental y mediante simulaciones 2D de un lecho bidimensional cargado con esferas de vidrio de diámetro $250-300 \mu \mathrm{m}$. Los autores informaron que los resultados obtenidos mediante CFD para predicciones de pérdida de carga y del mezclado de sólidos que permitiera una buena calidad de fluidización, mostraron un muy buen ajuste respecto de los resultados obtenidos experimentalmente. Sumado a ello, la diferencia en el costo computacional respecto de simulaciones 3D fue considerable. Xie y colab. (2008) reportaron, para el régimen de burbujeo, buena concordancia entre los resultados obtenidos mediante simulaciones 2D y 3D en las que se determinó la expansión, fracción de gas y velocidades de gas y sólido, tanto para un lecho cilíndrico como para uno rectangular. Estos resultados indican que la aproximación 2D puede ser aplicada de modo satisfactorio para simular el comportamiento de un lecho fluidizado burbujeante, con costo computacional moderado, cuando se desea analizar pérdida de carga y expansión de lecho. Sin embargo, las simulaciones 3D resultan esenciales cuando se intenta estudiar el comportamiento de la fase burbuja o procesos de segregación en lechos fluidizados aplicando CFD (Acosta-Iborra y colab., 2011; Sobrino y colab., 2015). En consecuencia, se adoptó una geometría bidimensional para desarrollar las simulaciones.

La simulación del régimen de lecho fijo (hasta el estado de fluidización incipiente) se llevó a cabo en régimen estacionario, aplicando el modelo del medio poroso (PMM), mientras que para simular el régimen específico de lecho fluidizado se trabajó en régimen transitorio, aplicando el modelo multifásico Euleriano-Euleriano (Capítulo 3, sección 3.5). Las condiciones de borde utilizadas fueron: Velocity Inlet en la base del lecho (se especificó la velocidad superficial de entrada del gas); Pressure Outlet en el tope (se definió la presión atmosférica como valor de la presión de salida); Wall (se estableció la condición de no-deslizamiento sobre las fronteras que representan las paredes del lecho).

Con respecto a los modelos de arrastre gas-sólido, Askaripour y Dehkordi (2015) analizaron el desempeño de los modelos de Gidaspow, Syamlal-O’Brien, Hill-Koch-Ladd y Wen-Yu, entre otros. Para simular el lecho fluidizado burbujeante adoptaron el modelo de dos fluidos (TFM) estándar combinado con la teoría cinética de flujo granular (KTGF). Reportaron un buen ajuste entre los datos experimentales y los resultados de las 
simulaciones, cuando se estudió la expansión del lecho, fracción volumétrica de gas y velocidad promediada en el tiempo para un amplio rango de valores de diámetro de partícula, alturas iniciales de lecho y velocidades de fluidización. Los autores informaron que, en la predicción de expansión del lecho para partículas pequeñas, los modelos de arrastre de Gidaspow y Wen-Yu arrojaron buenos resultados, mientras que para partículas medianas los cuatro modelos analizados generan buenos resultados. Respecto a la expansión para partículas grandes a bajas velocidades de fluidización, los modelos de Gidaspow, Wen-Yu y Hill-Koch-Ladd proporcionan buenas predicciones, mientras que, para partículas grandes con alturas iniciales de lecho grandes, los autores reportaron que únicamente el modelo de Syamlal-O’Brien conduce a resultados aceptables. Finalmente, los autores concluyeron que la mejor predicción de la fracción volumétrica de gas se obtiene con los modelos de Gidaspow y Wen-Yu.

Otros autores también reportaron buena concordancia entre resultados experimentales y simulaciones en estudios del comportamiento de lechos fluidizados burbujeantes mediante CFD, principalmente para partículas Geldart B (Busciglio y colab. 2009; Acosta-Iborra y colab. 2011; Sobrino y colab. 2015; García-Gutiérrez y colab. 2017). Recientemente Venier y colab. (2020) estudiaron la fluidización de diferentes sólidos Geldart A, B y D, incluyendo distintos modelos de arrastre. En particular, los autores reportaron una muy buena concordancia entre simulaciones llevadas a cabo mediante los programas de CFD ANSYS-Fluent y OpenFoam para partículas Geldart B y el modelo de arrastre de Gidaspow.

Owoyemi y colab. (2007) compararon tres ecuaciones de arrastre (Gidaspow y colab., 1985; Bell, 2000 y Syamlal, 1987). Realizaron cuatro simulaciones: tres de ellas incluyendo las ecuaciones previamente mencionadas para el modelo de arrastre sólidosólido y una cuarta considerando no-interacción entre los sólidos presentes (no se consideró ninguna fuerza de arrastre). En los primeros tres casos se obtuvieron resultados similares en términos de la distribución de partículas jetsam (de mayor tamaño o peso) en el lecho, con mezclado casi perfecto y buen ajuste con datos experimentales. Respecto del cuarto caso (sin interacción), los autores reportaron una sobreestimación de la movilidad de las partículas jetsam, resultando en la segregación de esta fase hacia el fondo del lecho, resultado opuesto a los valores experimentales. 
Con respecto a la interacción sólido-sólido, Tagliaferri y colab. (2013) estudiaron un sistema fluidizado constituido por una mezcla binaria arena-perlas de vidrio, considerando que la fuerza de interacción entre partículas tiene únicamente una contribución del tipo fuerza de arrastre que es proporcional a la velocidad de deslizamiento entre las fases sólidas. Los autores expresaron ese término mediante la ecuación de Syamlal (1987), obteniendo resultados que permitieron reproducir satisfactoriamente el comportamiento experimental.

Teniendo en cuenta las descripciones mencionadas previamente, las simulaciones llevadas a cabo en este trabajo están basadas en el modelo de arrastre de Gidaspow para la interacción gas-sólido y la ecuación simétrica de Syamlal (Syamlal, 1987) para las interacciones sólido-sólido, en los análisis del presente capítulo.

Se trabajó con una malla estructurada de 19250 celdas para el SISTEMA 1 y de 10800 para el SISTEMA 2, que fueron validadas para asegurar que representaran adecuadamente los modelos físicos sin incrementar innecesariamente el tiempo de cómputo (ver Anexo 5.I). En el SISTEMA 1 se definieron 2 sólidos en las simulaciones, por lo que las mismas estuvieron compuestas por 3 fases: gas, arena y aserrín. Para el SISTEMA 2, dado que el bagazo de manzana se dividió en dos fracciones (debido al amplio rango en los diámetros de la muestra), las simulaciones constaron de 4 fases: gas, esferas de vidrio, biomasa1820 y biomasa2530. Todas las simulaciones se realizaron durante 12 segundos. Al analizar los resultados, los datos de los primeros 3 segundos fueron descartados con el fin de evitar los efectos iniciales siguiendo la recomendación de Asegehegn y colab. (2011).

En la Tabla 5.4 se presentan los datos introducidos en el software para llevar a cabo las simulaciones y los principales modelos aplicados. 
Tabla 5.4 - Principales parámetros y propiedades utilizados en las simulaciones del presente capítulo.

\begin{tabular}{|c|c|c|}
\hline Descripción & SISTEMA 1 & SISTEMA 2 \\
\hline$\alpha_{\text {s inerte }}$ & 0,53 & 0,58 \\
\hline$\alpha_{s \text { biomasa }}$ & 0,28 & 0,49 \\
\hline$\rho_{g}\left[\mathrm{~kg} / \mathrm{m}^{3}\right]$ & 1,225 & 1,225 \\
\hline$\mu_{g}[\mathrm{~Pa} \cdot \mathrm{s}]$ & $1,789.10^{-5}$ & $1,789.10^{-5}$ \\
\hline$\rho_{\text {s inerte }}\left[\mathrm{kg} / \mathrm{m}^{3}\right]$ & 2650 & 2484 \\
\hline$\rho_{\text {s biomasa }}\left[\mathrm{kg} / \mathrm{m}^{3}\right]$ & 402 & 1200 \\
\hline$d_{\text {p inerte }}[\mathrm{mm}]$ & 0,513 & 0,275 \\
\hline$d_{p \text { biomasa }}[\mathrm{mm}]$ & 0,7 & 1,008 y 0,718 \\
\hline$H_{o}[\mathrm{~m}]$ & 0,15 & 0,12 \\
\hline Viscosidad granular $\left(\mu_{s, \text { kin }}-\mu_{s, c o l}\right)$ & GD & GD \\
\hline Temperatura granular & Algebraic & Algebraic \\
\hline Presión de sólidos $\left(\nabla P_{s}\right)$ & LUN & LUN \\
\hline Distribución radial & OGA & OGA \\
\hline Límite de empaquetamiento $\left(\alpha_{s, \text { max }}\right)$ & 0,63 & 0,63 \\
\hline Coeficiente de restitución $\left(e_{S S}\right)$ & 0,9 & 0,9 \\
\hline Paso de tiempo $[\mathrm{s}]$ & $0,001 \mathrm{~s}$ & $0,001 \mathrm{~s}$ \\
\hline Máx. iteraciones/Paso de tiempo & 40 & 40 \\
\hline Criterio de convergencia & 0,001 & 0,001 \\
\hline
\end{tabular}

Referencias: GD: Gidaspow y colab. (1992), LUN: Lun y colab. (1984), OGA: Ogawa y colab. (1980)

\section{4 - RESULTADOS Y DISCUSIÓN}

En esta sección se presentan, para los dos casos estudiados (sistemas aserrínarena y esferas de vidrio- bagazo), los resultados obtenidos y su discusión.

\subsection{1 - SISTEMA 1 (aserrín-arena)}

\subsubsection{1 - Lecho de partículas de arena}

En la Figura 5.1 se muestran los valores de pérdida de carga $(\Delta P)$ a través del lecho en función de la velocidad $U$, obtenidos experimentalmente y mediante CFD. Se observa que $\Delta P$ aumenta linealmente con el incremento de velocidad $U$ durante la etapa de lecho fijo. Posteriores incrementos de la velocidad $U$, llevan a un punto donde $\Delta P$ se mantiene prácticamente constante, situación que coincide con el movimiento de las partículas en el lecho (incremento de movimientos rotacionales y breves traslaciones), dando lugar al régimen fluidizado. 
Durante la experiencia, la velocidad del aire se incrementó hasta 0,56 m/s, valor en la cual se detectó la ocurrencia del fenómeno de elutriación (arrastre de finos). En este punto se inició la disminución gradual de la velocidad $U$, hasta retornar al estado de lecho fijo. Las curvas de fluidización y desfluidización obtenidas fueron coincidentes, sin presencia de la histéresis típica de estos sistemas (Zhang y colab., 2011). Este comportamiento se atribuye a que la fluidización previa de las partículas, antes de comenzar las experiencias, disminuyó la compactación del lecho.

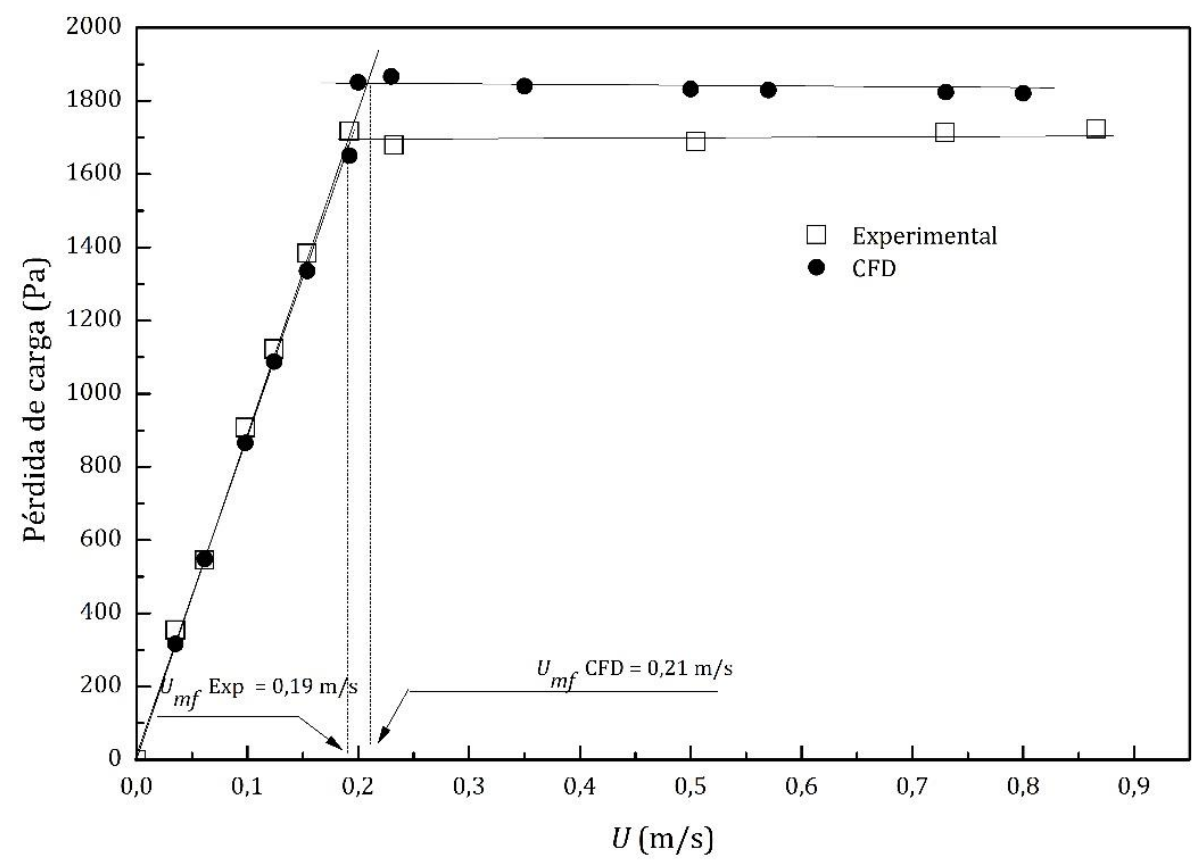

Figura 5.1 - Curva de fluidización: $\Delta P$ vs. $U$ para el lecho de arena fluidizada por aire.

En la región de la curva donde el régimen imperante es el de lecho fluidizado, se observa que los valores de $\Delta P$ obtenidos por CFD son superiores a los experimentales. Sin embargo, el valor teórico, correspondiente a la relación entre el peso del lecho y el área transversal del recipiente (W/A) es de $1837,5 \mathrm{~Pa}$, por lo que el error obtenido mediante CFD respecto del valor teórico es muy bajo (0,5\%). En la Tabla 5.5 se presentan los valores de $U_{m f}$ y $\Delta P$. La diferencia entre los valores teórico y experimental de $\Delta P$ puede explicarse por la influencia de las paredes del tubo que, en lechos con $\mathrm{D}<150 \mathrm{~mm}$, provoca una disminución de $\Delta P$ (Yang, 2003; Dhodapkar y colab., 2012). Puede observarse que los errores relativos para $\Delta P$ y $U_{m f}$ son de $11,1 \%$ y $8,4 \%$ respectivamente. 
Tabla 5.5 - Fluidización de arena/aire. Comparación CFD con valores experimentales.

\begin{tabular}{|l|c|c|c|}
\hline & CFD & Experimental & Error \% \\
\hline$U_{m f}[\mathrm{~m} / \mathrm{s}]$ & 0,206 & 0,190 & 8,4 \\
\hline$\Delta P$ promedio $[\mathrm{Pa}]$ & 1827,6 & 1645,3 & 11,1 \\
\hline
\end{tabular}

El estudio cualitativo de la formación de burbujas en función de $U$, es la fase final del análisis realizado. En el caso de las simulaciones CFD, dicho estudio fue llevado a cabo mediante los diagramas de contorno de fracción volumétrica de sólido. En las imágenes de la Figura 5.2 se visualiza la expansión del lecho, el aumento del tamaño de las burbujas y de la agitación al incrementar la velocidad del gas, corresponden coincidencia con las observaciones realizadas durante los ensayos experimentales.
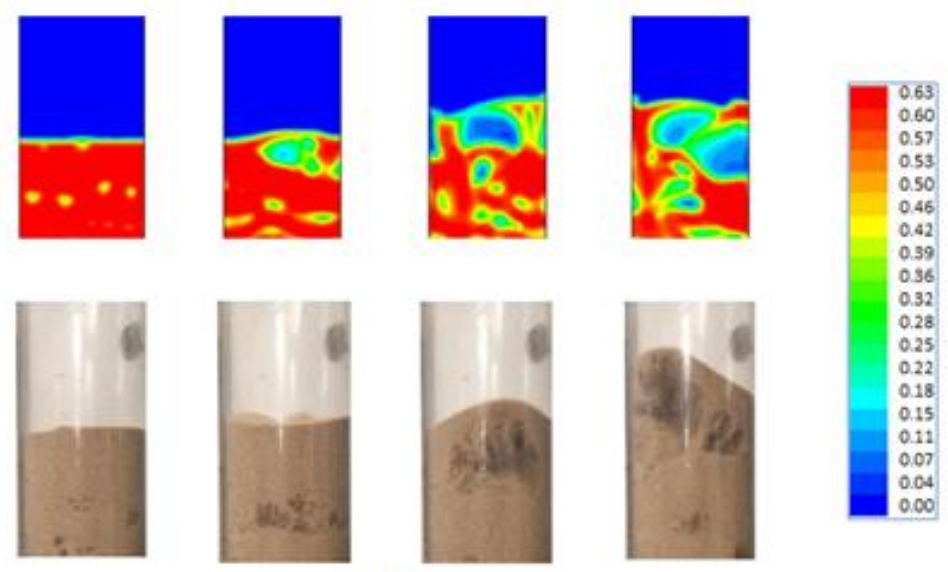

Figura 5.2 - Diagramas de contorno del lecho de arena obtenidas por CFD (arriba) y fotografías de la condición experimental (abajo), para valores de $U: 0,27 \mathrm{~m} / \mathrm{s}, 0,36 \mathrm{~m} / \mathrm{s}, 0,39 \mathrm{~m} / \mathrm{s}$ y 0,45 $\mathrm{m} / \mathrm{s}$. La escala de colores indica la fracción de sólidos.

\subsubsection{2 - Lecho de partículas de aserrín}

En la Figura 5.3 se muestran los resultados de $\Delta P$ en función de $U$ para la fluidización del aserrín. Su comportamiento difiere del observado en la fluidización de arena. A velocidades bajas, el lecho se mantiene en reposo y $\Delta P$ aumenta linealmente con $U$, pero, a partir del valor $U=0,12 \mathrm{~m} / \mathrm{s}$, comienzan a producirse pequeñas canalizaciones tanto en el centro del lecho como sobre las paredes del tubo. Al continuar aumentando $U$, las canalizaciones se incrementan en número y magnitud. Para el valor $U=0,174 \mathrm{~m} / \mathrm{s}$ se observa el máximo $\Delta P$ y un aumento posterior de $U$ produce un reacomodamiento de las partículas, que va acompañado por una ligera disminución en $\Delta P$. Las partículas en la zona 
superior del lecho alcanzan a fluidizar, mientras que las que se encuentran en la zona inferior se mantienen estáticas. Las diferencias de tamaño y/o densidad en las partículas pueden producir efectos de segregación. En este caso, si bien la densidad de las partículas de aserrín tiene un único valor, la distribución de tamaños provoca que las partículas de mayor tamaño (correspondientes a los sólidos retenidos en la malla 30) tiendan a permanecer en el fondo del lecho (Chiba y colab., 1979; Di Maio y colab., 2012). Al continuar aumentando $U$, la cantidad de partículas en movimiento dentro del lecho será cada vez mayor $\mathrm{y}$, para el valor $U=0,314 \mathrm{~m} / \mathrm{s}$, la totalidad de las partículas estarán fluidizadas.

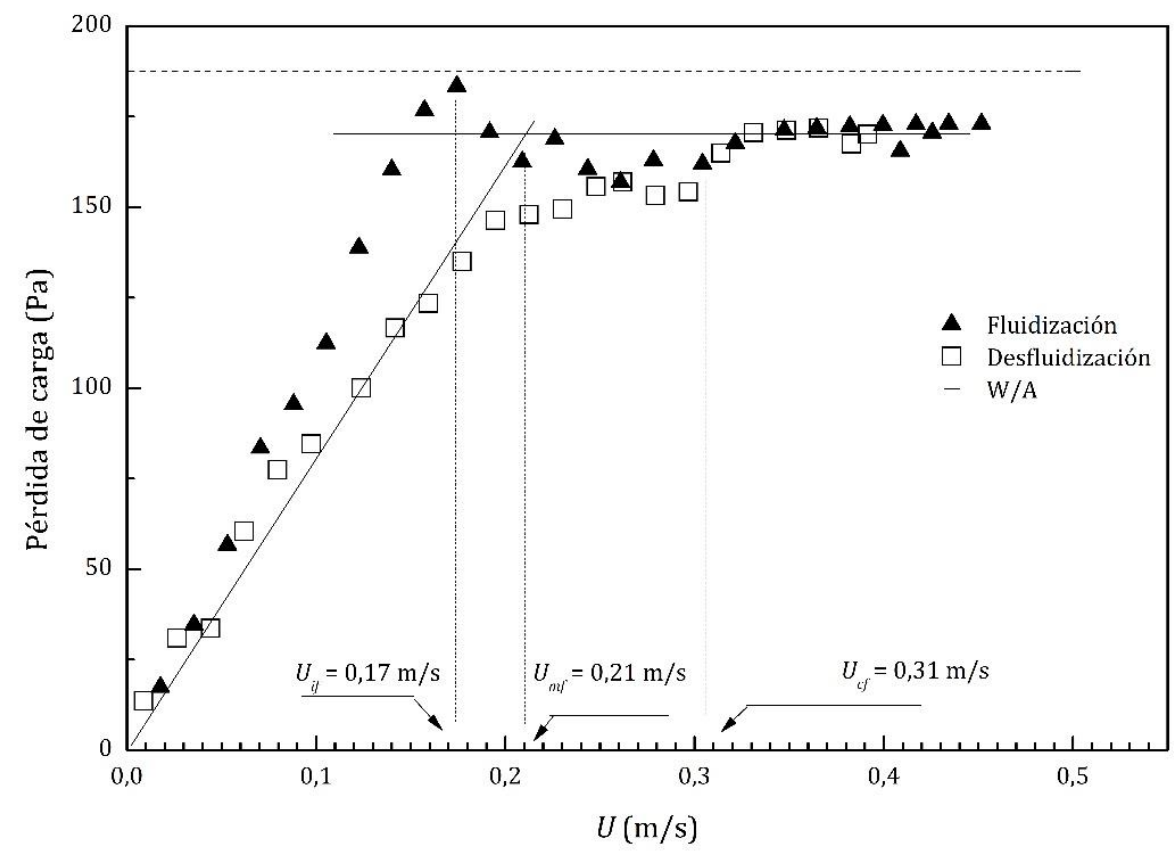

Figura 5.3 - Curva de fluidización: $\Delta P$ vs. $U$ para el lecho de aserrín fluidizado por aire.

Puede observarse que el lecho pasa por dos regímenes de fluidización diferentes, similares a los observados por Zhang y colab. (2011). El primero de ellos está comprendido entre la velocidad de fluidización incipiente $\left(U_{i f}\right)$ y la velocidad de fluidización completa $\left(U_{c f}\right)$. A partir de la velocidad $U_{i f}$, la fluidización ocurre en el tope del lecho, abarcando una capa cada vez mayor al aumentar U. Durante este intervalo, la pérdida de carga es irregular, oscilando entre 170 y $146 \mathrm{~Pa}$. Al alcanzarse la velocidad $U_{c f}$, comienza el segundo régimen de fluidización, en el que se fluidiza completamente el lecho y la pérdida de carga se mantiene prácticamente constante al aumentar $U$. 
Al desfluidizar el lecho, disminuyendo gradualmente la velocidad de aire, se presenta el fenómeno de histéresis, como se puede apreciar en la Figura 5.4. El valor de $0,21 \mathrm{~m} / \mathrm{s}$ para la velocidad $U_{m f}$ obtenida experimentalmente se encuentra comprendido entre los valores de $U_{\text {if }}$ y $U_{c f}(0,174$ y $0,314 \mathrm{~m} / \mathrm{s}$, respectivamente).

Por otro lado, se realizaron las simulaciones mediante CFD de modo de obtener la curva de fluidización y poder compararla con la experimental. En la Figura 5.4 se muestran los resultados obtenidos experimentalmente y simulaciones CFD.

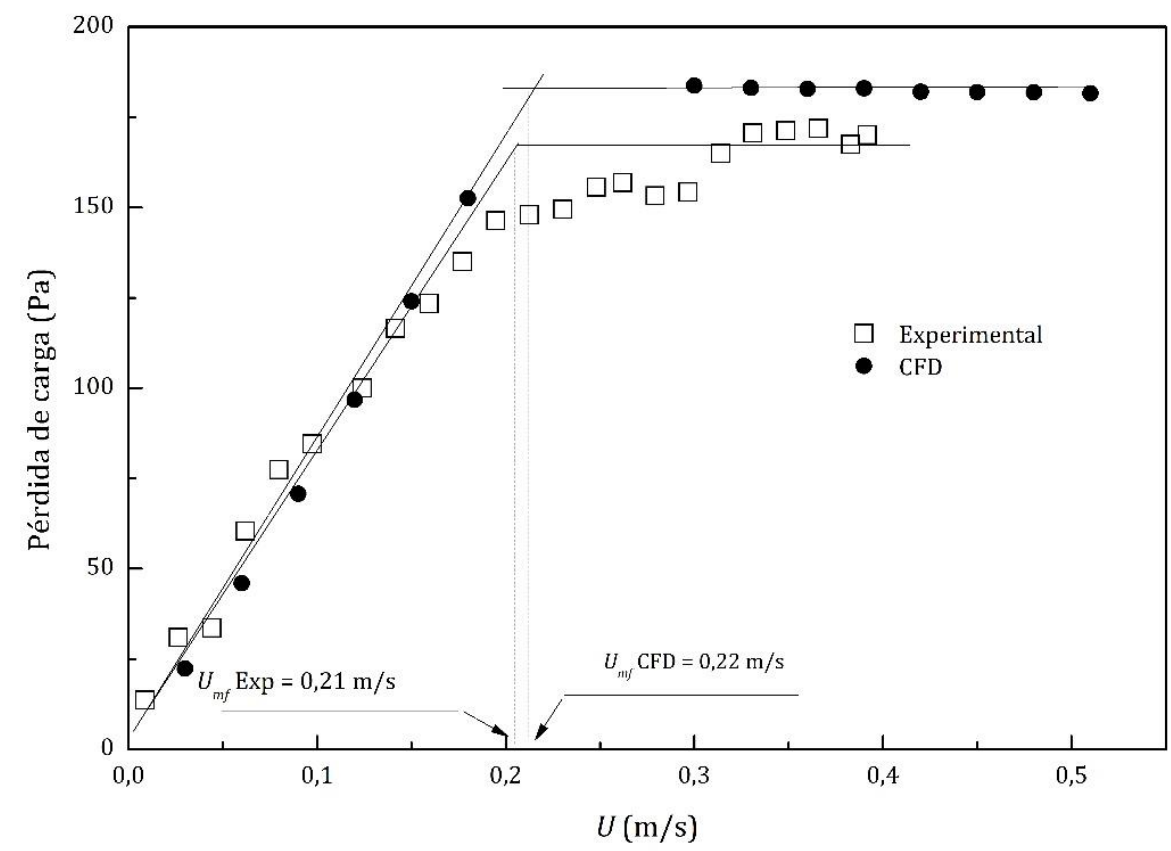

Figura 5.4 - Resultados experimentales y modelado por CFD para el lecho de aserrín fluidizado por aire.

Se puede observar que con el modelado CFD no es posible representar la región comprendida entre $U_{i f}$ y $U_{c f}$. Los valores de $U_{m f}$ obtenidos experimentalmente y a partir de las simulaciones se resumen en la Tabla 5.6.

Tabla 5.6 - Lecho aserrín/aire. Comparación CFD con valores experimentales.

\begin{tabular}{|l|c|c|c|}
\hline & CFD & Experimental & Error \% \\
\hline$U_{m f}[\mathrm{~m} / \mathrm{s}]$ & 0,221 & 0,210 & 5,2 \\
\hline$\Delta \mathrm{P}$ promedio $[\mathrm{Pa}]$ & 182,36 & 170,52 & 6,9 \\
\hline
\end{tabular}


La Figura 5.5 muestra los diagramas de contorno de fracción volumétrica de sólido obtenidos por CFD, junto con las fotografías de la condición experimental, que permiten analizar cualitativamente la formación y crecimiento de las burbujas con el aumento de $U$.
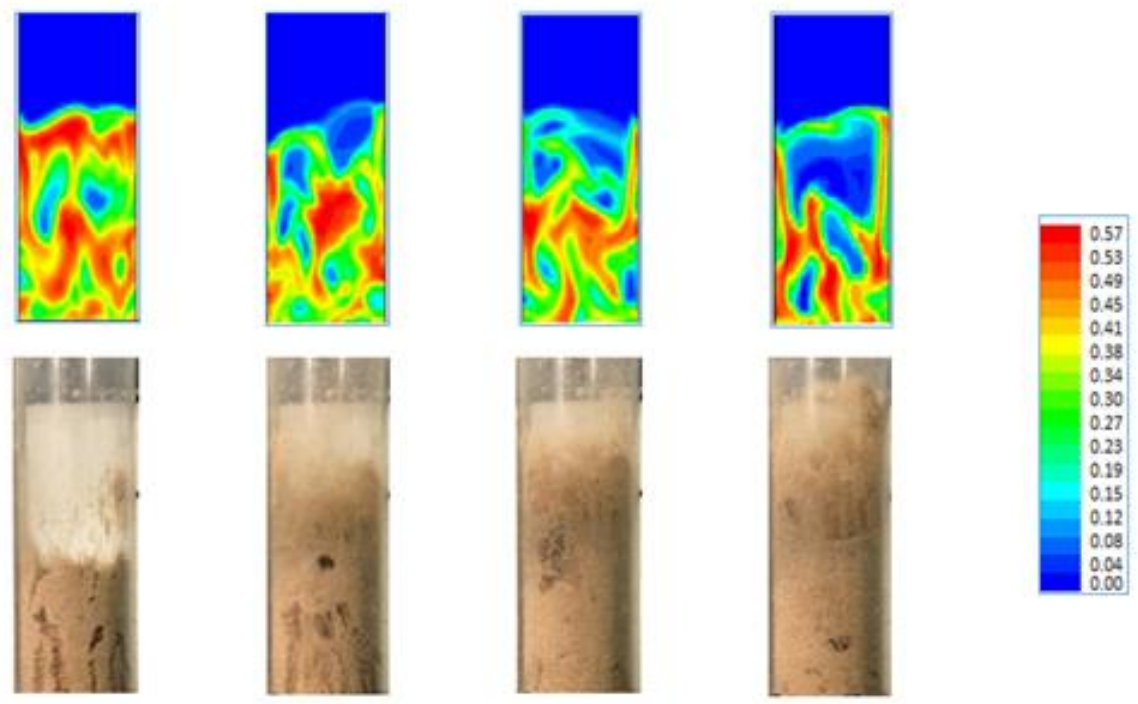

Figura 5.5 - Diagramas de contorno del lecho de aserrín obtenidas por CFD (arriba) y fotografías de la condición experimental (abajo), a las velocidades U: 0,36 m/s, 0,39 m/s, 0,42 m/s y 0,45 $\mathrm{m} / \mathrm{s}$. La escala de colores indica la fracción de sólido.

\subsubsection{3 - Mezclas binarias aserrín-arena}

Las curvas de fluidización (F) y desfluidización (DF) obtenidas para los 3 sistemas binarios aserrín-arena estudiados, junto con los resultados correspondientes a los sólidos puros se muestran en la Figura 5.6.

En el caso de las mezclas binarias, puede observarse que, al aumentar la fracción volumétrica de arena, aumenta la pendiente de la línea de tendencia $\Delta P$ vs. $U$ correspondiente a la zona en régimen de lecho fijo; disminuye levemente la velocidad mínima de fluidización y se incrementa el valor de $\Delta P$ promedio de la región de lecho fluidizado.

En los tres casos de mezclas analizados, al aumentar la velocidad $U$ es posible observar la fluidización parcial y luego completa del lecho y distinguir las velocidades características, $U_{i f}, U_{m f}$ y $U_{c f}$. Para velocidades superiores a ésta última, se observa al lecho completamente fluidizado y la pérdida de carga se mantiene constante ante 
posteriores incrementos de $U$. El valor de $U_{m f}$ obtenido gráficamente, siempre se encuentra comprendido entre las velocidades $U_{i f}$ y $U_{c f}$ correspondientes.

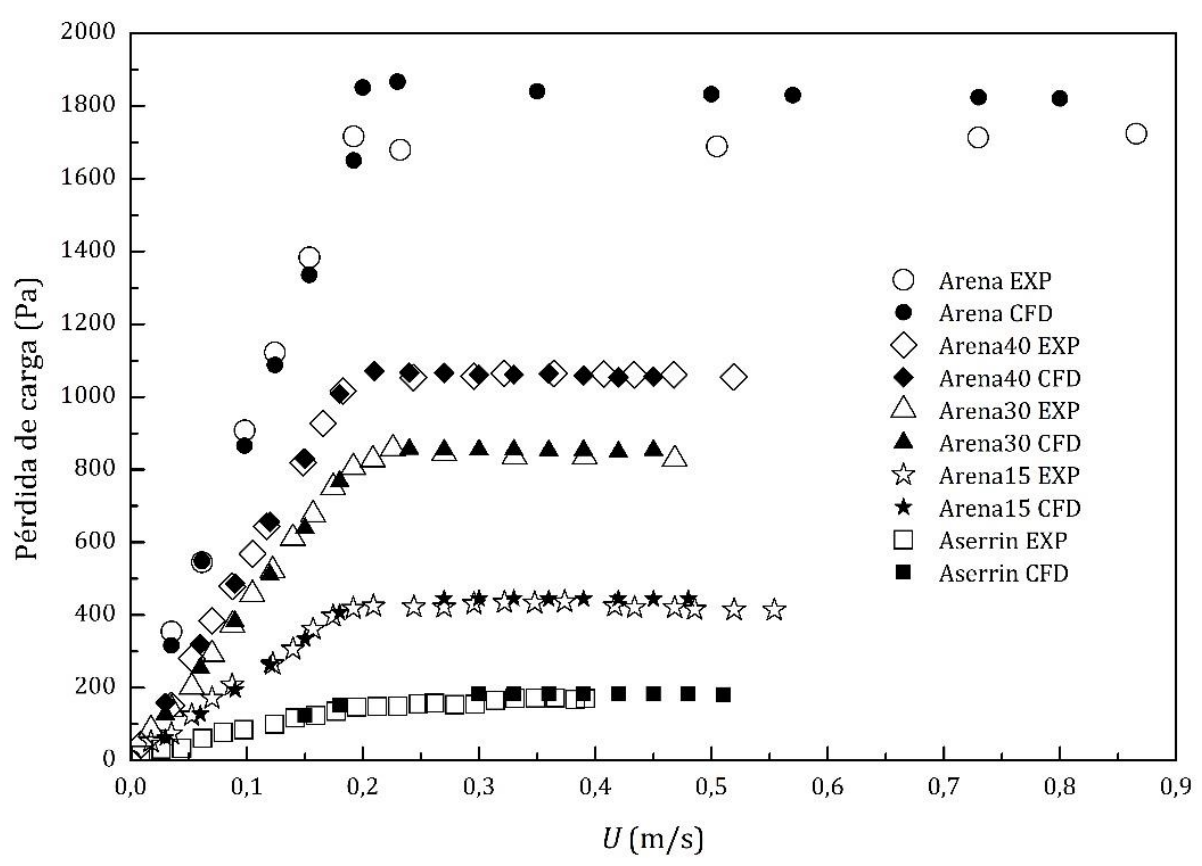

Figura 5.6 - Resumen de resultados de $\Delta P$ en función de $U$ para las mezclas aserrín-arena estudiadas (expresadas en $\mathrm{V} / \mathrm{V} \%$ ).

En la Tabla 5.7 se comparan los valores de $U_{m f}$ obtenidos mediante CFD con los resultados experimentales, observándose una muy buena concordancia. Estos resultados permiten afirmar que la metodología de simulación propuesta es adecuada para predecir la velocidad $U_{m f}$ de mezclas aserrín-arena.

Tabla 5.7 - Mezclas aserrín-arena. Comparación de los resultados obtenidos por CFD con valores experimentales.

\begin{tabular}{|l|l|c|c|c|}
\hline \multicolumn{2}{|c|}{} & CFD & Experimental & Error \% \\
\hline Arena15 & $U_{m f}[\mathrm{~m} / \mathrm{s}]$ & 0,200 & 0,192 & 4,17 \\
\cline { 2 - 5 } & $\Delta \mathrm{P}$ promedio $[\mathrm{Pa}]$ & 444,78 & 430,11 & 3,41 \\
\hline Arena30 & $U_{m f}[\mathrm{~m} / \mathrm{s}]$ & 0,200 & 0,196 & 2,04 \\
\cline { 2 - 5 } & $\Delta \mathrm{P}$ promedio $[\mathrm{Pa}]$ & 853,15 & 835,86 & 2,07 \\
\hline Arena40 & $U_{m f}[\mathrm{~m} / \mathrm{s}]$ & 0,192 & 0,193 & 0,52 \\
\cline { 2 - 5 } & $\Delta \mathrm{P}$ promedio $[\mathrm{Pa}]$ & 1060,9 & 162,4 & 0,14 \\
\hline
\end{tabular}


El cambio observado en le velocidad $U_{m f}$ de las mezclas, con respecto al aserrín, no es muy significativo debido a que la $U_{m f}$ de ambos sólidos puros es muy cercana. Sin embargo, es importante destacar la mejora observada en la calidad de la fluidización del aserrín, aun incorporando una pequeña proporción de arena. El agregado de arena permite reducir las fuerzas de cohesión y enlace presentes entre las partículas de aserrín, disminuyendo la segregación y formación de canales preferenciales y, por lo tanto, favoreciendo la fluidización.

En la Tabla 5.8 se resumen los resultados experimentales de los cinco ensayos realizados. Para las mezclas se observa que, al aumentar el porcentaje volumétrico de arena, disminuye la diferencia $U_{c f}-U_{i f}$, tendiendo paulatinamente al comportamiento del lecho de arena pura fluidizada.

Tabla 5.8 - Velocidades características de las mezclas y materiales puros fluidizados.

\begin{tabular}{|l|c|c|c|c|c|}
\hline & Arena & Arena40 & Arena30 & Arena15 & Aserrín \\
\hline$U_{i f}[\mathrm{~m} / \mathrm{s}]$ & 0,19 & 0,192 & 0,195 & 0,191 & 0,174 \\
\hline$U_{m f}[\mathrm{~m} / \mathrm{s}]$ & 0,19 & 0,193 & 0,196 & 0,192 & 0,21 \\
\hline$U_{c f}[\mathrm{~m} / \mathrm{s}]$ & 0,19 & 0,227 & 0,235 & 0,2686 & 0,314 \\
\hline$\left(U_{c f} U_{i f}\right)[\mathrm{m} / \mathrm{s}]$ & 0,00 & 0,035 & 0,040 & 0,078 & 0,140 \\
\hline
\end{tabular}

En la literatura se han reportado diferentes correlaciones para predecir la velocidad de mínima fluidización de mezclas biomasa-inerte en lechos fluidizados burbujeantes (Clarke y colab., 2005, Proenza Perez y colab., 2017). En la Tabla 5.9 se presenta un conjunto representativo de correlaciones para predecir $U_{m f}$. Las funciones matemáticas que definen estas correlaciones están basadas en las características físicas de los sólidos involucrados y sus concentraciones relativas.

La Figura 5.7.a muestra los resultados de $U_{m f}$ obtenidos en este trabajo, tanto experimentales como mediante CFD, para las tres mezclas estudiadas y los compuestos puros, así como también los valores predichos por las correlaciones presentadas en la Tabla 5.9. Dicha figura revela que los valores de $U_{m f}$ obtenidos mediante las correlaciones presentan mayor dispersión que aquéllos obtenidos mediante CFD. Ello puede explicarse por el tipo de funciones y elementos que incluyen las diferentes correlaciones seleccionadas. Además, se puede apreciar que los resultados obtenidos mediante CFD son 
consistentes con los resultados experimentales para las tres mezclas estudiadas. Con respecto a las correlaciones, las propuestas por Chiba y colab. (1979) y por Rowe y Nienow (1975), ambas basadas en las velocidades $U_{m f}$ de los compuestos puros, muestran el mejor ajuste respecto de los resultados experimentales.

La Figura 5.7.b presenta los valores experimentales y predichos mediante CFD de la velocidad $U_{m f}$ en función de la composición de la mezcla $(\% v / v$ de aserrín en cada mezcla estudiada). Puede observarse que pequeños agregados de inerte son suficientes para reducir los valores de velocidad $U_{m f}$ de la mezcla y acercarlos a aquél correspondiente a la arena pura. Como se ha explicado precedentemente, este efecto puede ser atribuido a la reducción en las fuerzas de cohesión entre partículas de aserrín con el agregado de arena. Al aumentar el porcentaje de arena adicionado, se observó una disminución en la segregación, así como también la disminución de la canalización, mejorando por consiguiente la fluidización. 
Tabla 5.9 - : Correlaciones para predecir la velocidad $U_{m f}$ de mezclas binarias.

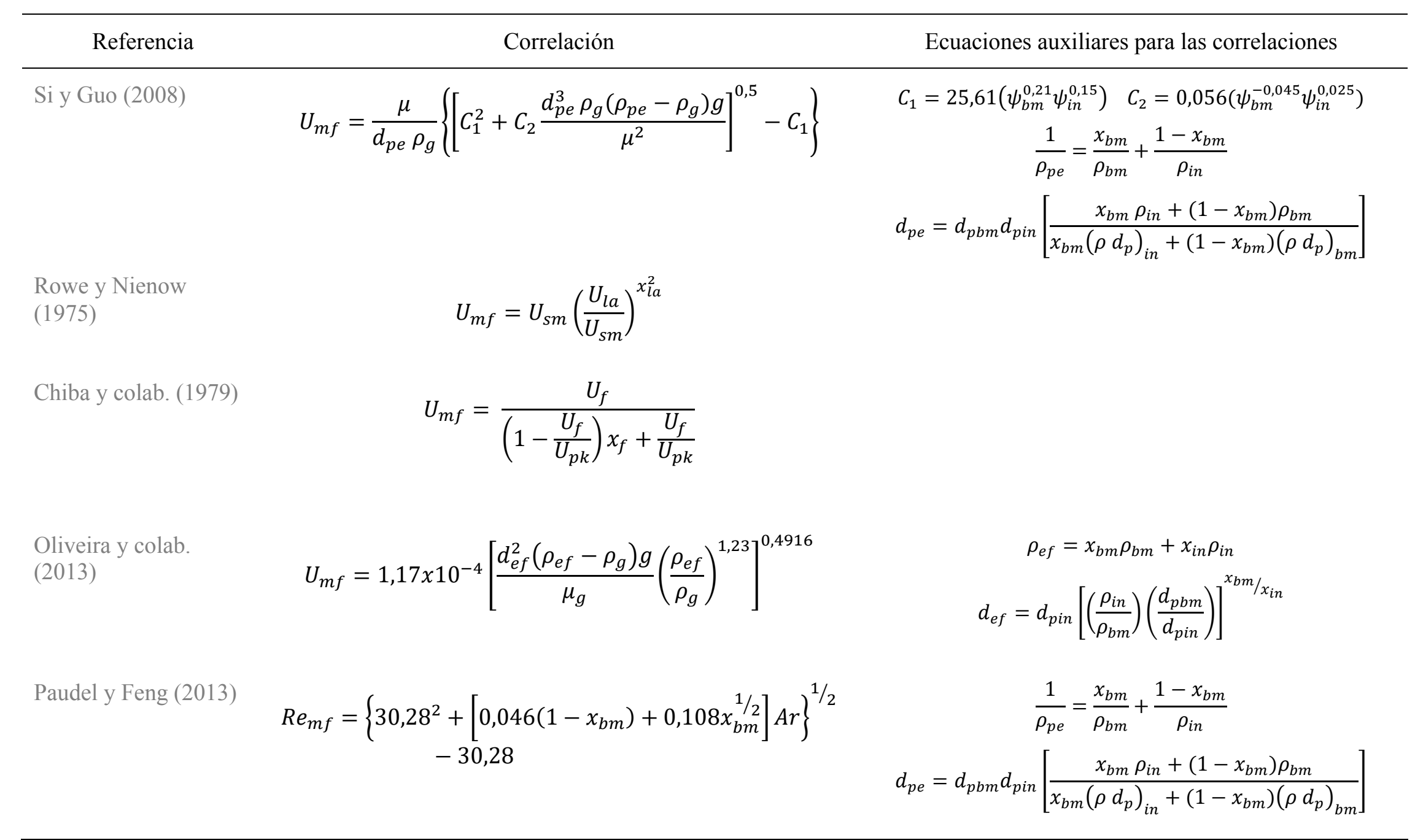




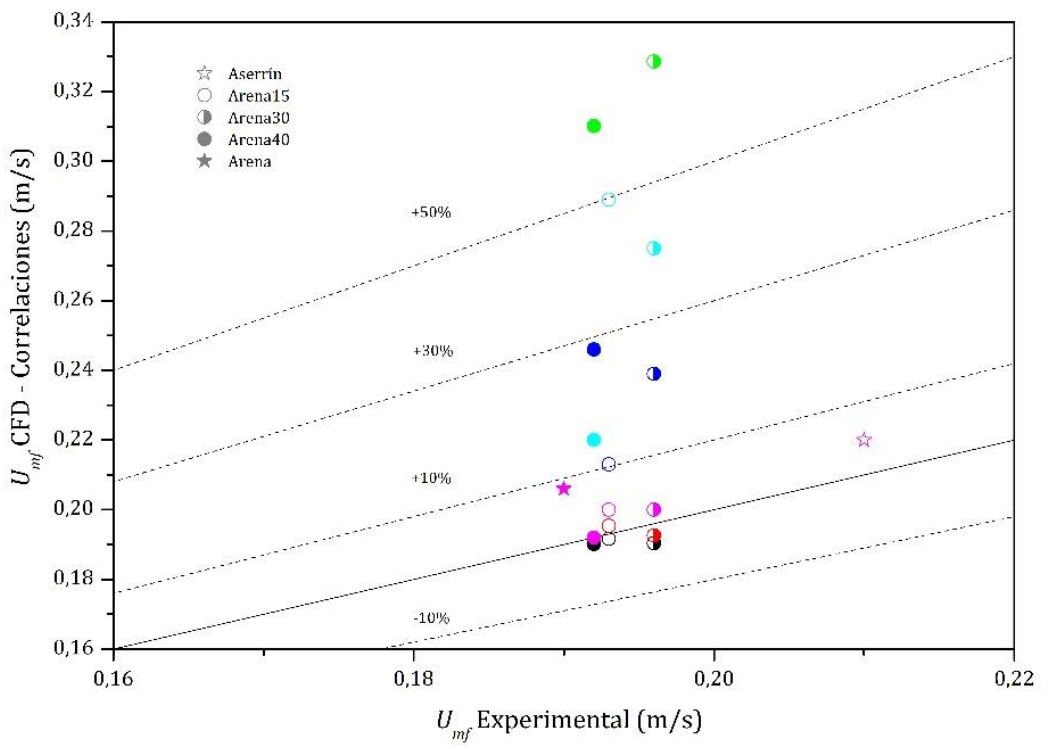

$\mathbf{a}^{\mathrm{a}}$

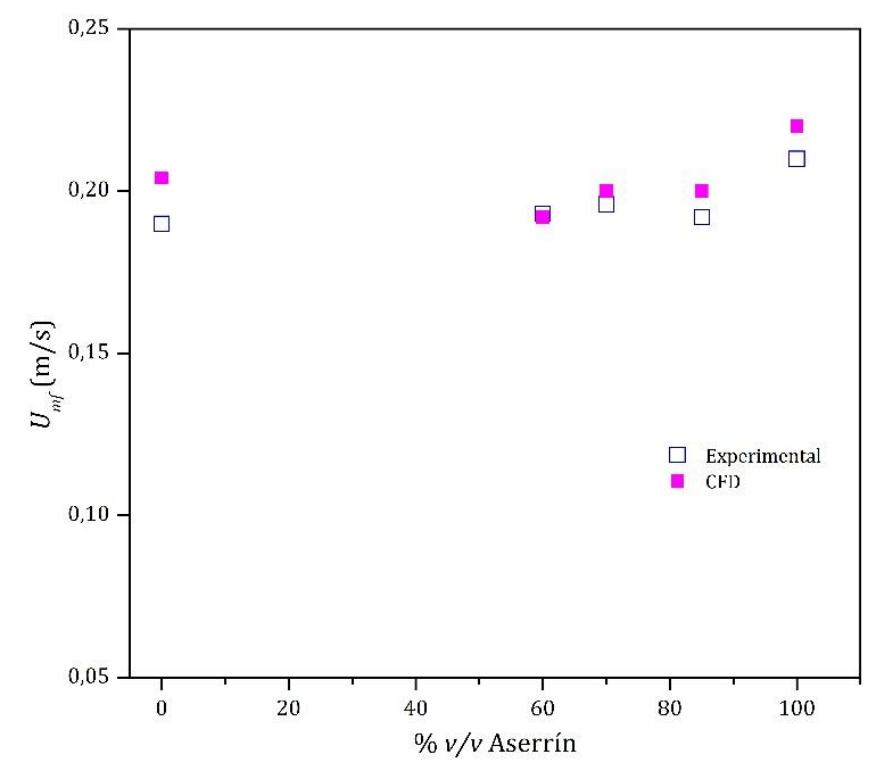

b

al tipo de símbolo detallado en la leyenda interna de la Figura 5.7a indica las tres mezclas estudiadas y los compuestos puros. Los símbolos deben combinarse con la siguiente referencia de colores para identificar las correlaciones de la Tabla 5.9 y las predicciones mediante CFD (este trabajo).
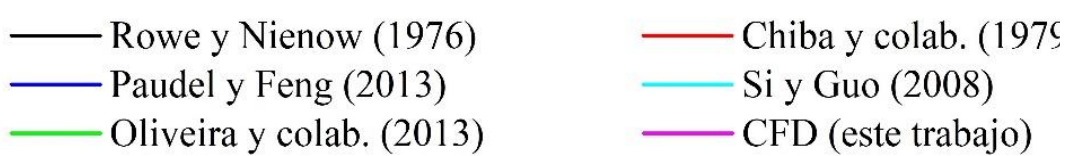

Figura 5.7 - Velocidad de mínima fluidización, experimental (este trabajo), predicciones mediante CFD (este trabajo) y predicciones según las correlaciones de la Tabla 5.9, para el SISTEMA 1. 


\subsection{2 - SISTEMA 2 (bagazo de manzana - esferas de vidrio)}

\subsubsection{1 - Lecho de esferas de vidrio}

Como puede observarse en la Figura 5.8, al igual que en el caso del lecho de arena, la pérdida de carga aumenta linealmente con el incremento de velocidad $U$ durante el régimen de lecho fijo. Una vez que las partículas incrementan su movilidad desde el estado de reposo, dando lugar al régimen fluidizado, se observa que el valor de $\Delta P$ se mantiene prácticamente constante. La velocidad $U$ se varió entre $0,01 \mathrm{~m} / \mathrm{s}$ y $0,6 \mathrm{~m} / \mathrm{s}$, asegurando el régimen completamente fluidizado. Luego se disminuyó lentamente el caudal de aire hasta el cierre total de la válvula.

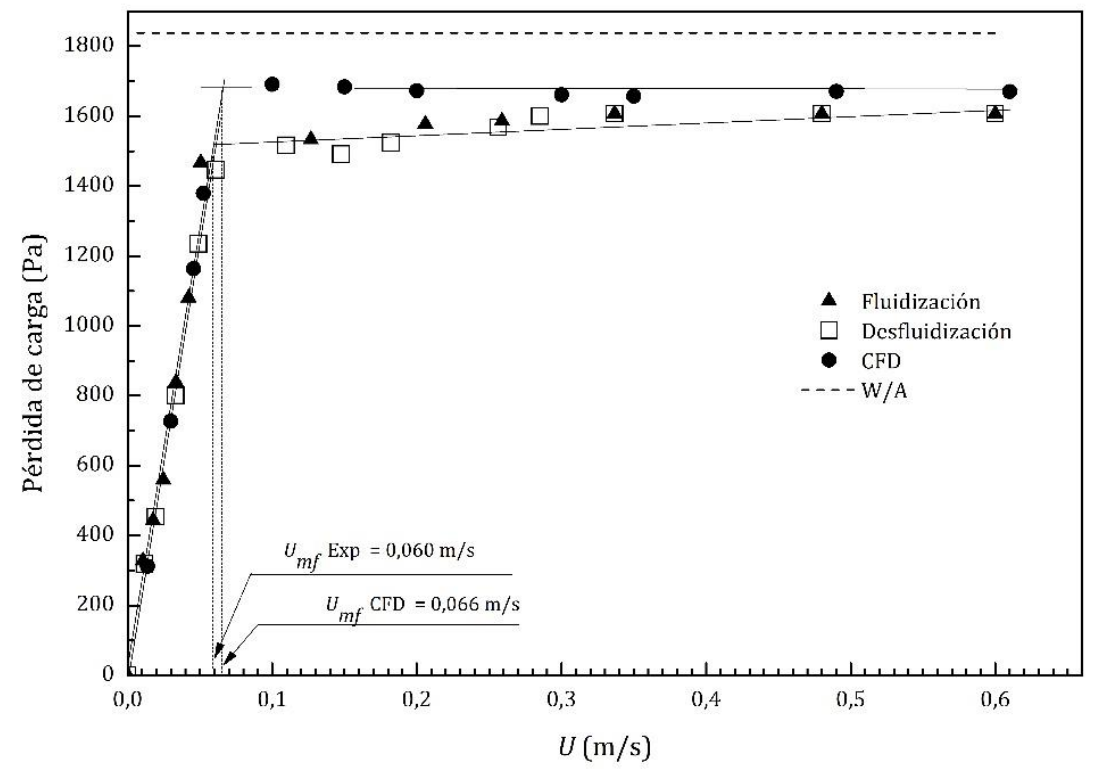

Figura 5.8 - Curva de fluidización: $\Delta P$ vs. $U$ para el lecho de esferas de vidrio fluidizadas por aire.

De igual modo que en el caso de la arena, las curvas de fluidización y desfluidización fueron coincidentes, debido a la disminución de la compactación del lecho por el mezclado previo de las partículas, pero los valores de pérdida de carga experimentales en la zona de lecho fluidizado son inferiores al valor teórico. Sin embargo, los valores obtenidos mediante CFD evidencian un muy buen ajuste respecto del valor teórico. En la Tabla 5.10 se presentan los valores de velocidad $U_{m f}$ y $\Delta P$, donde se observa que el error relativo entre datos experimentales y CFD es de 9,3\% y 7,9\%, respectivamente. 
Tabla 5.10 - Fluidización de esferas de vidrio/aire. Comparación CFD con valores experimentales.

\begin{tabular}{|l|c|c|c|}
\hline & CFD & Experimental & Error \% \\
\hline$U_{m f}[\mathrm{~m} / \mathrm{s}]$ & 0,066 & 0,060 & 9,3 \\
\hline$\Delta P$ promedio $[\mathrm{Pa}]$ & 1673,13 & 1549,85 & 7,9 \\
\hline
\end{tabular}

En este caso también se realizó, al igual que con la arena, el estudio cualitativo de la formación de burbujas. En la Figura 5.9 se observa la expansión del lecho, aumento del tamaño de burbujas y agitación al incrementar la velocidad del gas.
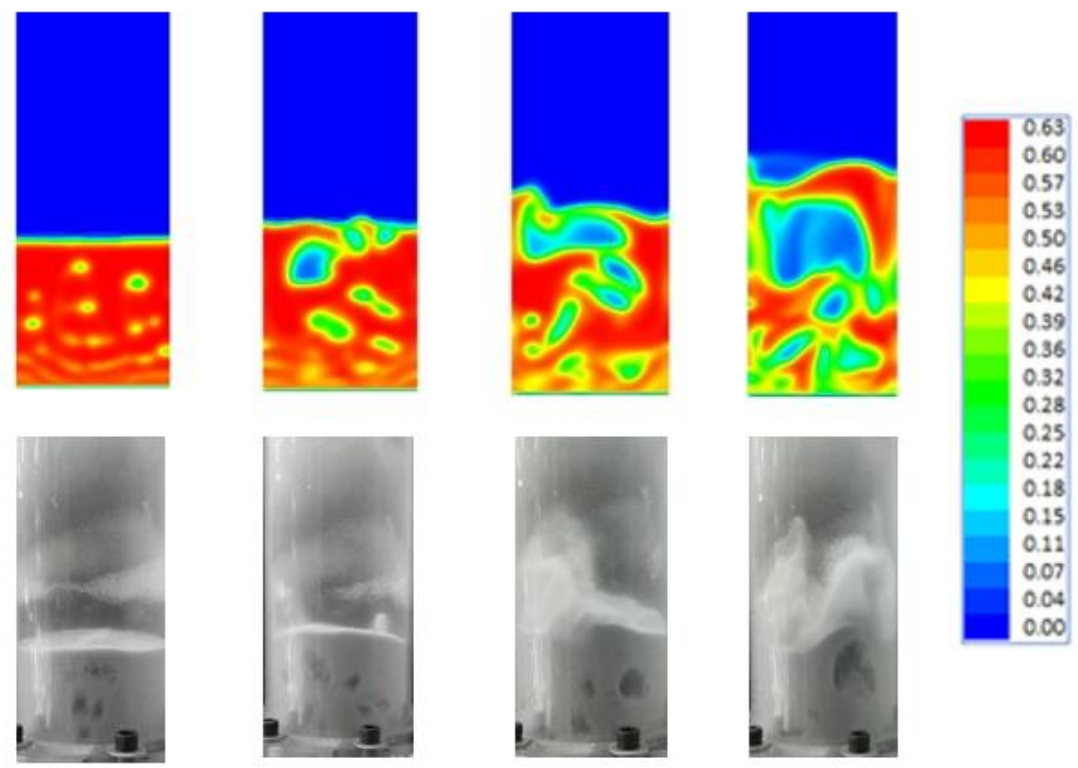

$U$

Figura 5.9 - Diagramas de contorno del lecho de esferas de vidrio obtenidas por CFD (arriba) y fotografías de la condición experimental (abajo), para valores de $U: 0,11 \mathrm{~m} / \mathrm{s}, 0,17 \mathrm{~m} / \mathrm{s}, 0,30 \mathrm{~m} / \mathrm{s}$ y $0,46 \mathrm{~m} / \mathrm{s}$. La escala de colores indica la fracción de sólidos.

\subsubsection{2 - Lecho de bagazo de manzana}

Durante la fluidización del bagazo de manzana se observaron zonas de canalizaciones. Se observa también en este caso la ausencia del fenómeno de histéresis entre las curvas de fluidización y desfluidización del bioresiduo (Figura 5.10), debido, en principio, al mezclado previo realizado.

A diferencia del caso de fluidización de aserrín, al fluidizar el bagazo de manzana se observa una única velocidad característica, $U_{m f}$ (Figura 5.10). Este comportamiento 
puede deberse a que el bagazo presenta menores fuerzas cohesivas que el aserrín. En la Tabla 5.11 se observa que el error relativo entre los valores experimentales y obtenidos mediante CFD es del 3,7\% para $U_{m f}$ y del $4,5 \%$ para $\Delta P$

Tabla 5.11 - Fluidización de bagazo de manzana/aire. Comparación CFD con valores experimentales.

\begin{tabular}{|l|c|c|c|}
\hline & CFD & Experimental & Error \% \\
\hline$U_{m f}[\mathrm{~m} / \mathrm{s}]$ & 0,340 & 0,353 & 3,7 \\
\hline$\Delta \mathrm{P}$ promedio $[\mathrm{Pa}]$ & 650,12 & 621,88 & 4,5 \\
\hline
\end{tabular}

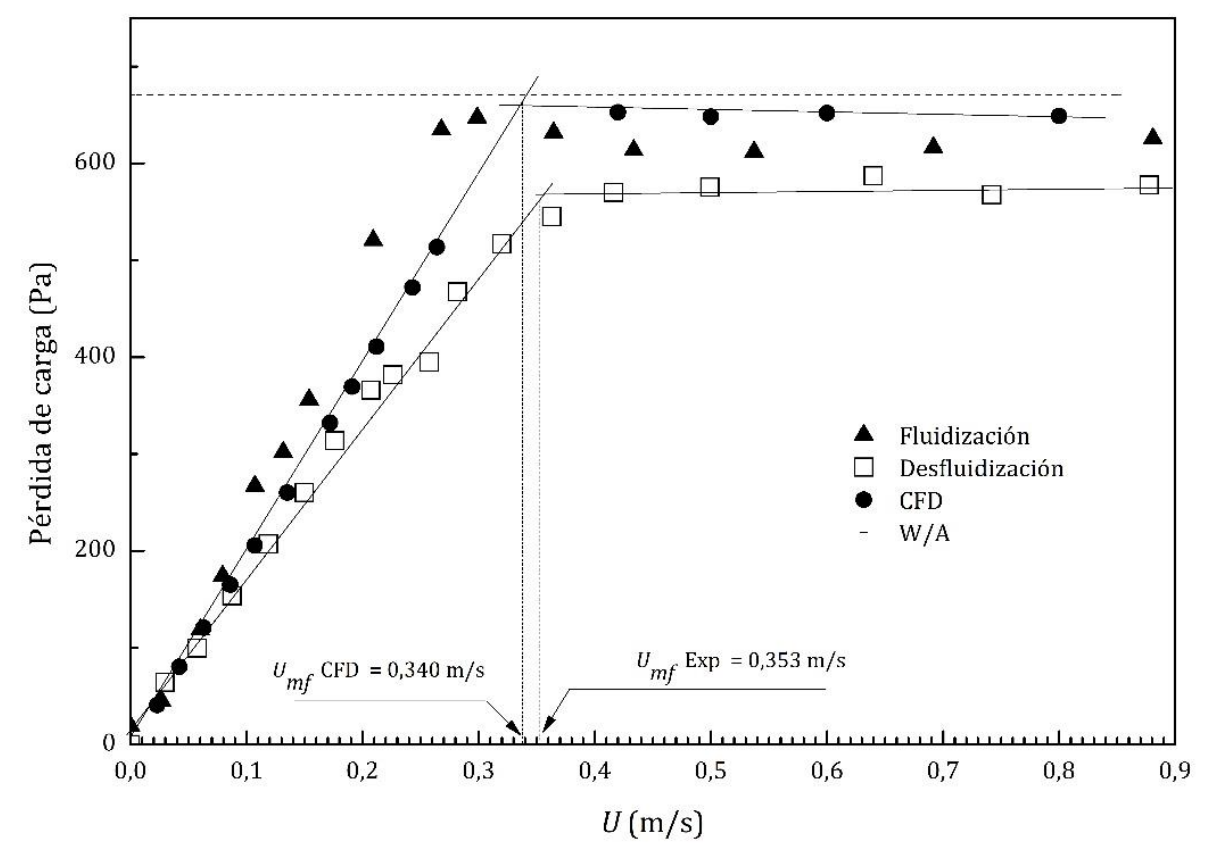

Figura 5.10 - Curvas de fluidización experimental y por CFD para el lecho de bagazo fluidizado por aire.

La Figura 5.11 permite visualizar el estudio cualitativo de las imágenes obtenidas. Si bien en las fotografías experimentales no logran observarse las burbujas debido al color de las partículas, se observa la expansión del lecho y el aumento de la agitación al incrementar la velocidad del gas, tanto para las fotografías experimentales como para los diagramas de contorno. 

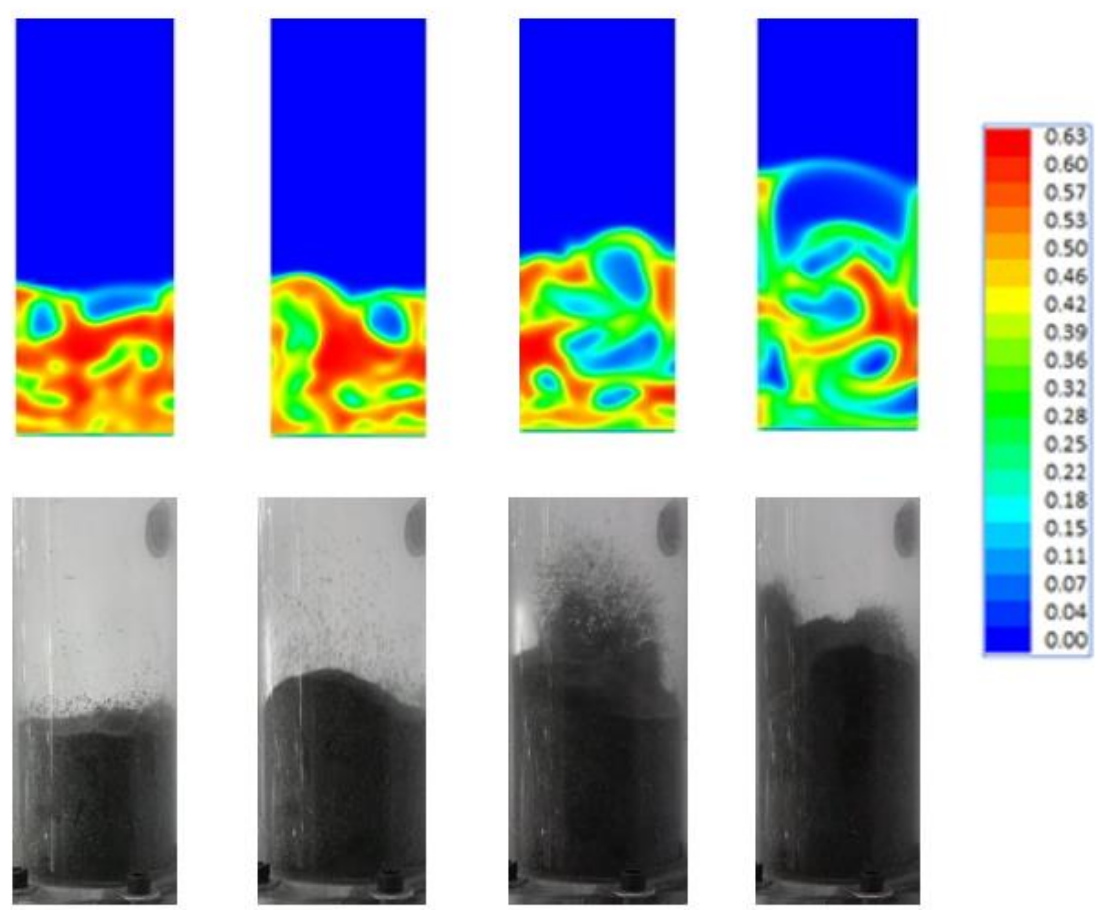

$U$

Figura 5.11 - Diagramas de contorno del lecho de bagazo de manzana obtenidas por CFD (arriba) y fotografías de la condición experimental (abajo), para valores de $U: 0,42 \mathrm{~m} / \mathrm{s}, 0,5 \mathrm{~m} / \mathrm{s}$, $0,8 \mathrm{~m} / \mathrm{s}$ y $1,0 \mathrm{~m} / \mathrm{s}$. La escala de colores indica la fracción de sólidos.

\subsubsection{3 - Mezclas binarias bagazo-esferas de vidrio}

En la Figura 5.12 se representan las curvas experimentales de desfluidización y aquéllas obtenidas mediante CDF tanto para los sólidos puros (esferas de vidrio y bagazo) como para las mezclas. En el caso de las mezclas binarias, se observa que, al aumentar la fracción volumétrica de las esferas de vidrio, aumenta la pendiente de la línea de tendencia de pérdida de carga en función de $U$, en la zona correspondiente a lecho fijo; mientras que el valor de la pérdida de carga promedio de la zona de lecho fluidizado aumenta. Esto conduce a una disminución considerable de la velocidad de mínima fluidización, obtenida como la intersección entre las curvas, tal como se explicó en la sección 5.2.3 de este Capítulo.

Es importante destacar la ausencia de zonas de fluidización parcial, que eran esperables para una mezcla de sólidos de distinto diámetro. Esto también se debe a mezclado de los sólidos previo a cada experiencia. 


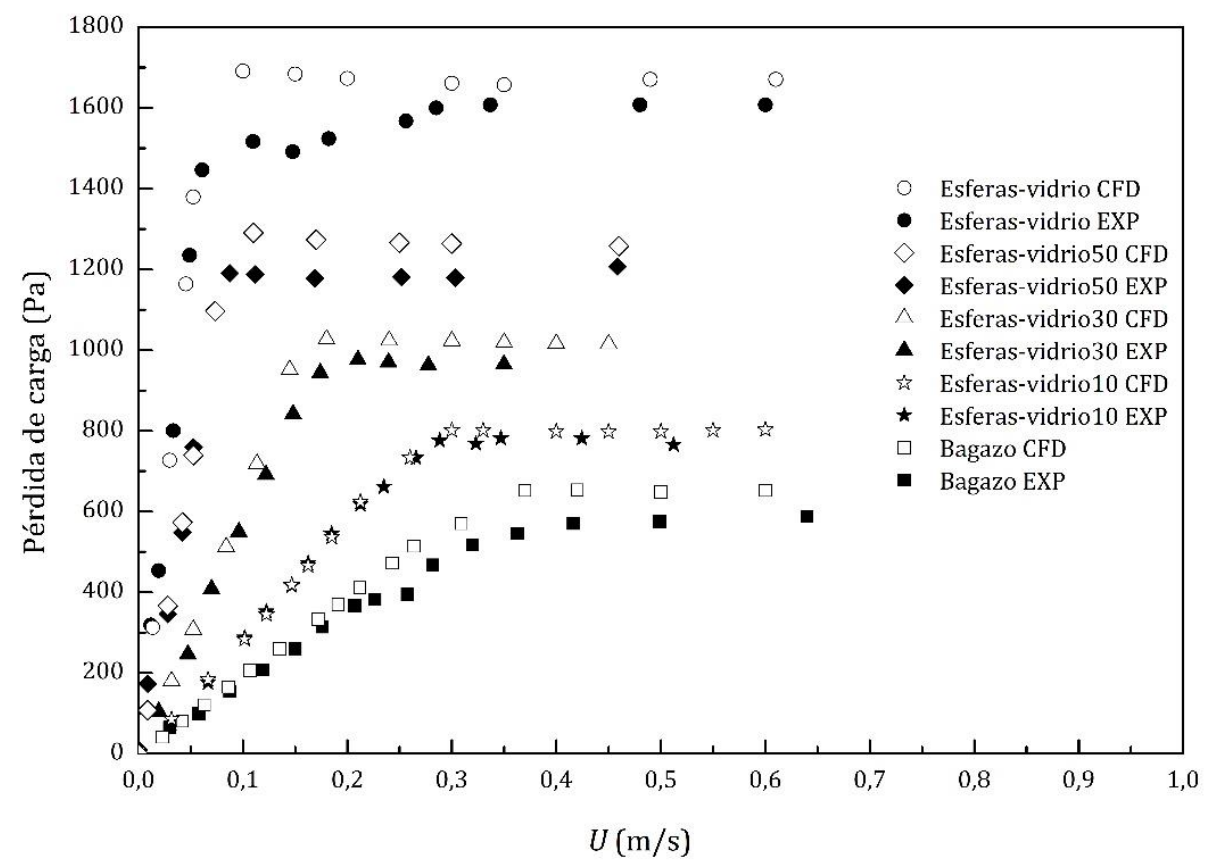

Figura 5.12 - Resumen de resultados de $\Delta P$ en función de $U$ para las mezclas bagazo de manzana - esferas de vidrio estudiadas (expresadas en $\mathrm{V} / \mathrm{V} \%$ ).

En la Tabla 5.12 se presenta una síntesis de los valores calculados de velocidades $U_{m f}$ y los errores relativos respecto del valor experimental. En la Figura 5.12 puede apreciarse que la velocidad de mínima fluidización disminuye al incrementarse la proporción de material inerte, lo que implica un menor requerimiento del agente fluidizante. En las mezclas con $50 \%$ en volumen de inerte, la velocidad $U_{m f}$ alcanza un valor similar al del vidrio puro. Además, durante las experiencias, se verificó que el agregado de las partículas de vidrio al bagazo mejora notablemente la calidad de fluidización.

Tabla 5.12 - Velocidades de mínima fluidización y errores relativos.

\begin{tabular}{|l|c|c|c|}
\hline & Experimental [m/s] & CFD [m/s] & Error \% \\
\hline Biomasa & 0,353 & 0,340 & 3,7 \\
\hline Esferas-vidrio10 & 0,274 & 0,28 & 1,31 \\
\hline Esferas-vidrio30 & 0,169 & 0,16 & 4,62 \\
\hline Esferas-vidrio50 & 0,097 & 0,09 & 7,33 \\
\hline Esferas-vidrio & 0,060 & 0,066 & 9,27 \\
\hline
\end{tabular}




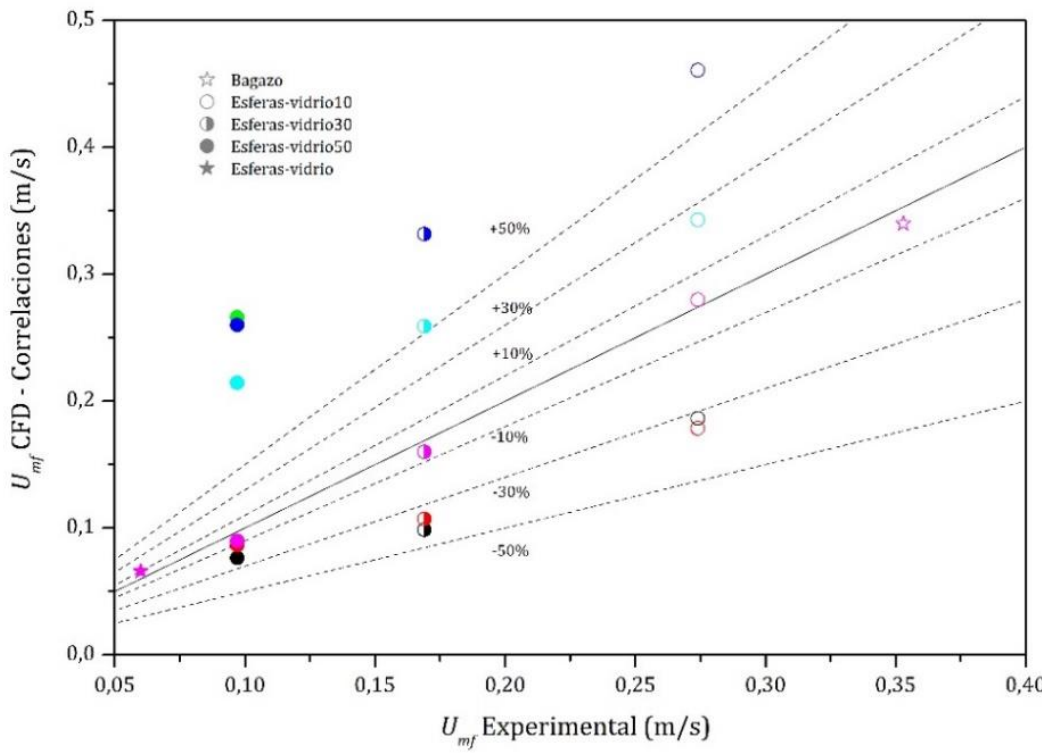

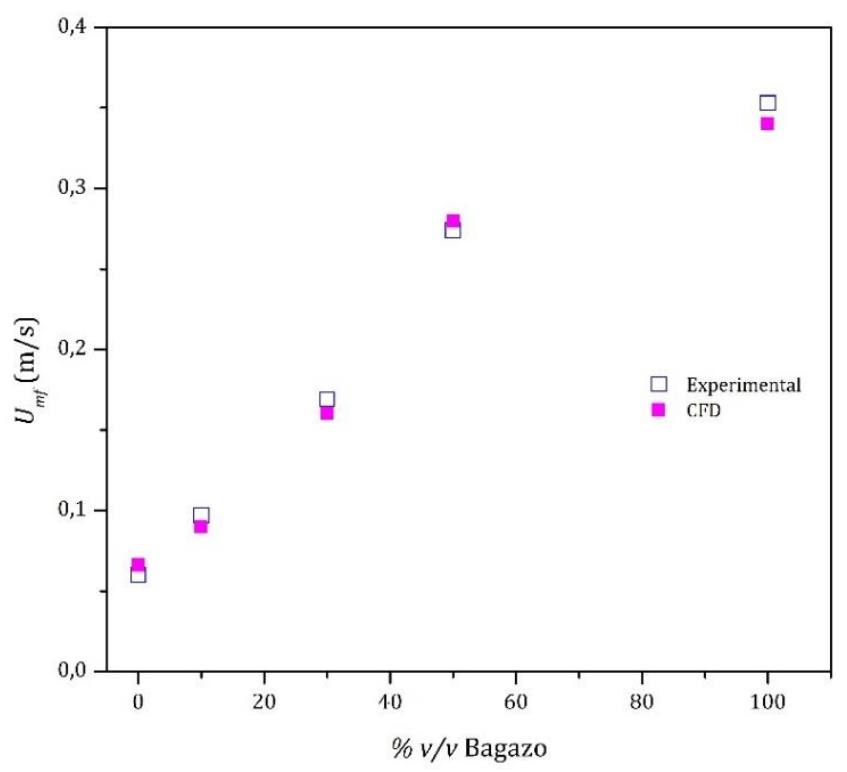

b

a El tipo de símbolo detallado en la leyenda interna de la Figura 5.12a indica las tres mezclas estudiadas y los compuestos puros. Los símbolos deben combinarse con la siguiente referencia de colores para identificar las correlaciones de la Tabla 5.9 y las predicciones mediante CFD (este trabajo)

\section{- Rowe y Nienow (1976) \\ Paudel y Feng (2013) \\ Oliveira y colab. (2013)}

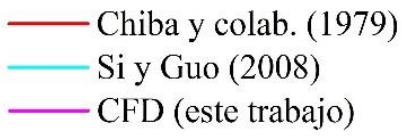

Figura 5.13 - Velocidad de mínima fluidización, experimental (este trabajo), predicciones mediante CFD (este trabajo) y predicciones según las correlaciones de la Tabla 5.9 para el SISTEMA 2. 
La Figura 5.13a muestra los resultados de $U_{m f}$ obtenidos, tanto experimentales como mediante CFD, para las tres mezclas de esferas de vidrio-bagazo estudiadas y los compuestos puros, así como también los valores predichos por las correlaciones presentadas en la Tabla 5.9. Al igual que en el sistema aserrín-arena, los valores de $U_{m f}$ obtenidos mediante las correlaciones presentan una dispersión mayor que los que fueron obtenidos mediante CFD. Los resultados obtenidos mediante CFD se encuentran dentro del corredor de $\pm 10 \%$ tanto para los compuestos puros como para las mezclas analizadas. Al igual que en el caso anterior, las correlaciones propuestas Chiba y colab. (1979) y por Rowe y Nienow (1975), muestran el mejor ajuste respecto de los resultados experimentales.

La Figura 5.13b permite la visualización de los valores de velocidad $U_{m f}$ experimentales y obtenidos mediante CFD según la composición de la mezcla $(\% \mathrm{v} / \mathrm{v}$ de bagazo de manzana). Se observa que con el agregado de inerte disminuye el valor de $U_{m f}$ en forma ostensible.

\section{5 - CONCLUSIONES DEL CAPÍTULO 5}

Para ambos sistemas se pudo observar una mejora en la calidad de fluidización mediante el agregado de inerte, aun en bajas proporciones. Este último logra disminuir las fuerzas de cohesión entre las partículas de biomasa, disminuyendo la segregación y atenuando la formación de canales preferenciales. Se alcanzaron resultados cualitativamente satisfactorios en relación con el estado de agitación, expansión y formación de burbujas de los distintos sistemas, reflejados tanto en los diagramas de contorno de las fracciones de sólido generados como en el resultado de las simulaciones. Estas imágenes concuerdan con las observaciones experimentales. Finalmente se obtuvo una menor velocidad de mínima fluidización en comparación con la de la biomasa pura, como era esperable a partir de las consideraciones teóricas pertinentes.

En el caso del SISTEMA 1, se confirmó la existencia de dos regímenes de fluidización diferentes tanto en el aserrín como en las mezclas aserrín-arena, que da origen a la definición de dos velocidades de fluidización adicionales: $U_{i f}$ y $U_{c f}$. Por el contrario, en el SISTEMA 2 no se observaron regímenes intermedios de fluidización ni 
para el bagazo de manzana ni para las mezclas estudiadas, por lo que las únicas velocidades características en este caso fueron las $U_{m f}$.

Se verificó el potencial de la CFD como herramienta de trabajo para el estudio del comportamiento fluidodinámico de los lechos fluidizados de mezclas binarias bioresiduoinerte. Para la totalidad de las mezclas estudiadas, los valores de velocidad $U_{m f}$ obtenidos mediante simulaciones CFD arrojaron un error relativo, respecto de los valores experimentales, inferior al 5\%. Teniendo en cuenta las correlaciones analizadas para el cálculo de la velocidad $U_{m f}$, aquéllas propuestas por Chiba y colab. (1979) y por Rowe y Nienow (1975), que tienen en cuentas las velocidades $U_{m f}$ de los compuestos puros, mostraron los mejores ajustes respecto de los resultados experimentales para ambos sistemas. 


\section{ANEXO 5.I \\ VALIDACIÓN DE LAS MALLAS DE LAS MEZCLAS BINARIAS}

\section{GENERACIÓN DEL DOMINIO, MALLADO Y VALIDACIÓN}

Mediante el programa ANSYS-Design Modeler se dibujó el lecho a estudiar, creando así el dominio 2D para la resolución numérica. Para discretizar el dominio se utilizó una malla de tipo estructurada con elementos cuadriláteros, como puede observarse en la Figura A5.I.1. Se evaluaron tres tamaños de elementos diferentes, adoptando la pérdida de carga a través del lecho como parámetro de referencia en la validación.

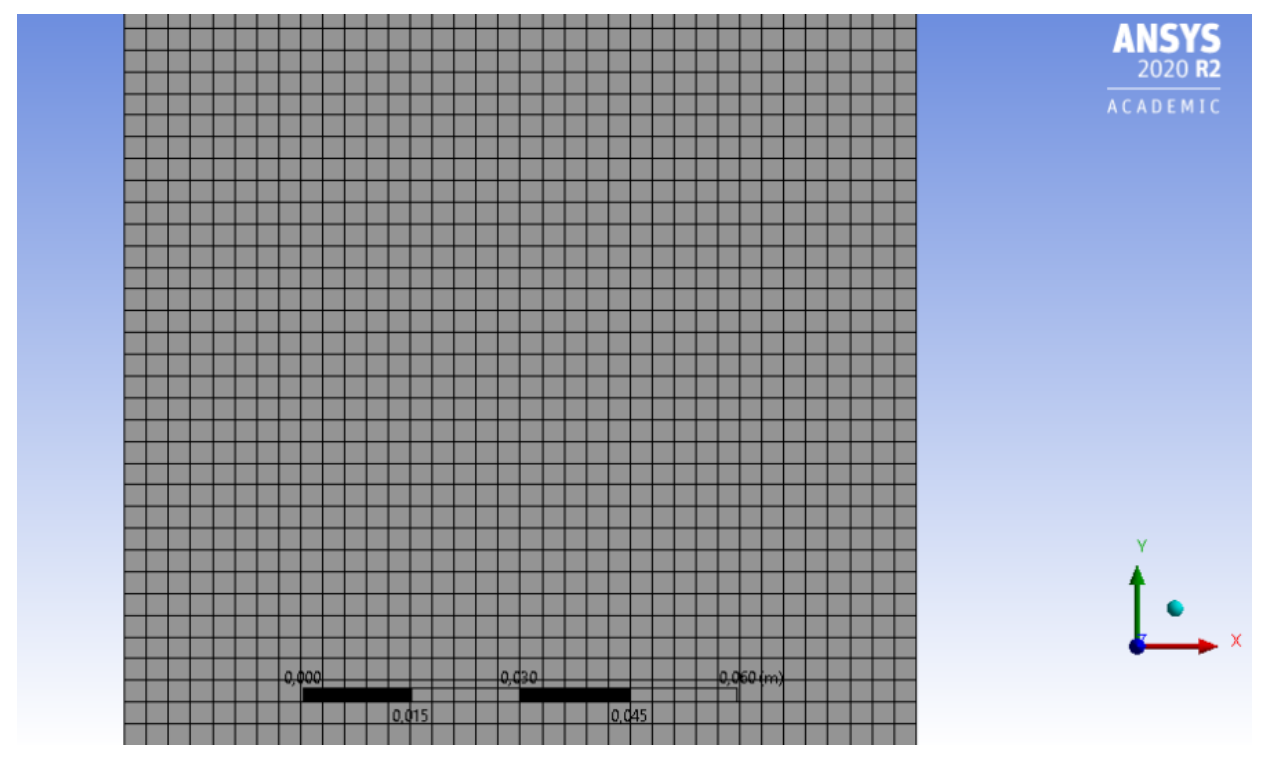

Figura A5.I.1 - Esquema de las mallas con elementos cuadriláteros.

Las verificaciones se realizaron para la arena (SISTEMA 1) y para las esferas de vidrio (SISTEMA 2). Las velocidades $U$ seleccionadas en cada caso fueron de 0,35 m/s para la arena y de $0,27 \mathrm{~m} / \mathrm{s}$ para las esferas de vidrio, ambas comprendidas entre la velocidad $U_{m f}$ obtenida experimentalmente, y la velocidad $U$ a la cual se comenzó a observar elutriación. Se registró la pérdida de carga durante un intervalo de 12 segundos y se obtuvo un valor promedio para cada malla. El error relativo fue calculado respecto de la Malla 1, debido a que es la que cuenta con mayor densidad de elementos. 
El análisis se realizó simulando el lecho en régimen fluidizado, aplicando un modelado de estado transitorio. En la Tabla A5.I.1 se muestran los resultados de la validación.

\section{Tabla A5.I.1}

a - Validación de malla para el desarrollo de experiencias en CFD 2D con arena.

\begin{tabular}{|l|c|c|c|c|c|}
\cline { 2 - 6 } \multicolumn{1}{c|}{} & $\begin{array}{c}\text { Tamaño } \\
\text { celda [m] }\end{array}$ & $\Delta \mathrm{P}[\mathrm{Pa}]$ & $\begin{array}{c}\text { Cantidad } \\
\text { de } \\
\text { elementos }\end{array}$ & $\begin{array}{c}\text { Error } \\
\text { relativo }\end{array}$ & $\begin{array}{c}\text { Tiempo de } \\
\text { cómputo [horas] }\end{array}$ \\
\hline Malla 1 & 0,001 & 1804,30 & 76300 & --- & 24 \\
\hline Malla 2 & 0,002 & 1806,63 & 19250 & $0,13 \%$ & 15 \\
\hline Malla 3 & 0,003 & 1798,70 & 8388 & $0,31 \%$ & 12 \\
\hline
\end{tabular}

b - Validación de malla para el desarrollo de experiencias en CFD 2D con esferas de vidrio.

\begin{tabular}{|l|c|c|c|c|c|}
\cline { 2 - 6 } \multicolumn{1}{c|}{} & $\begin{array}{c}\text { Tamaño } \\
\text { celda }[\mathrm{m}]\end{array}$ & $\Delta \mathrm{P}[\mathrm{Pa}]$ & $\begin{array}{c}\text { Cantidad } \\
\text { de } \\
\text { elementos }\end{array}$ & $\begin{array}{c}\text { Error } \\
\text { relativo }\end{array}$ & $\begin{array}{c}\text { Tiempo de } \\
\text { cómputo [horas] }\end{array}$ \\
\hline Malla 1 & 0,001 & 1650,23 & 98100 & --- & 36 \\
\hline Malla 2 & 0,002 & 1662,32 & 24750 & $0,73 \%$ & 18 \\
\hline Malla 3 & 0,003 & 1666,40 & 10800 & $0,98 \%$ & 8 \\
\hline Malla 4 & 0,004 & 1659,93 & 6075 & $0,59 \%$ & 6 \\
\hline
\end{tabular}

Para la arena, se optó por utilizar la Malla 2, que reproduce el $\Delta P$ con un error del $0,13 \%$ respecto a la Malla 1 y en un tiempo de computo $37 \%$ menor. Para las esferas de vidrio, se decidió trabajar con la Malla 3, ya que reproduce el $\Delta P$ con un error del 0,98\% respecto de la Malla 1 y el tiempo de cómputo es un 77\% inferior. La Malla 4 se descartó debido a que la diferencia de tiempo de cómputo respecto a la Malla 3 no es significativa y, si bien el error relativo en la presión disminuye, también disminuye significativamente la calidad de las superficies de contorno utilizadas para analizar de modo cualitativo el mezclado de sólidos. 


\section{CONCLUSIONES GENERALES}

En este trabajo se llevó a cabo el estudio y caracterización del comportamiento de lechos fluidizados, mediante modelado y simulación en la plataforma de CFD ANSYSFluent. Los sistemas fueron validados con determinaciones experimentales específicas en laboratorio y/o escala piloto, a fin de detectar aspectos críticos desde el punto de vista fluidodinámico, que condicionaran y/o limitaran la performance del equipo bajo diferentes regímenes de operación y sólidos fluidizados.

A tal fin se realizó un estudio preliminar de la teoría de fluidización y los distintos parámetros fundamentales que rigen el estado fluidizado. Luego se estudiaron de manera exhaustiva los regímenes de burbujeo para partículas Geldart B y D y de slug para partículas Geldart A. Finalmente se estudió la fluidización de mezclas binarias, enfocadas en la mejora de la calidad de fluidización de dos tipos distintos de partículas de biomasa mediante la adición de material inerte. En todos los casos, se evaluó la capacidad de software de CFD ANSYS-Fluent para llevar a cabo la simulación de los sistemas mencionados.

Se realizó el estudio de un lecho de partículas Geldart B (arena) fluidizadas por aire, centrando el análisis en el estudio detallado de la fase burbuja. Se analizaron los parámetros pérdida de carga y velocidad de mínima fluidización, experimentalmente y mediante simulaciones desarrolladas por CFD. Se observó una muy buena concordancia entre ambas metodologías.

Se estudió la influencia de los parámetros y modelos definidos en las simulaciones (modelo de arrastre, viscosidad friccional y coeficiente de especularidad $\varphi$ ), sobre los resultados obtenidos para partículas Geldart B. Este estudio puso de manifiesto que los modelos utilizados tienen mayor influencia en el análisis de la fase burbuja que en el cálculo de la pérdida de carga, aun sin ser ésta despreciable. En base al análisis realizado, se seleccionaron los parámetros óptimos para las simulaciones. 
Una vez efectuadas las simulaciones, se llevó a cabo la caracterización de la fase burbuja evaluando diámetro, velocidad y frecuencia de burbuja en función de la altura del lecho, en un equipo con geometría pseudo-2D y para distintas velocidades superficiales de gas $U$. Los resultados evidenciaron una buena concordancia entre los valores experimentales y los calculados por CFD. Los estudios de diámetro y velocidad de ascenso de burbujas obtenidos experimentalmente y mediante CFD fueron comparados con los valores calculados a partir de diferentes correlaciones. Se verificó el fenómeno de coalescencia de las burbujas mediante los resultados de frecuencia de burbuja en función de la altura del lecho.

Los parámetros seleccionados para las simulaciones se utilizaron para realizar la simulación en un lecho cargado con las mismas partículas, pero con geometría cilíndrica. En este caso, se desarrolló una metodología para el análisis tridimensional de las burbujas presentes en un lecho cilíndrico, utilizando el software AutoDesk 3DSMax, que permitió el tratamiento aislado de cada burbuja obteniéndose datos de centro de masa, volumen y área de burbuja, que permitieron el cálculo de su diámetro y velocidad de ascenso. En la geometría cilíndrica, si bien los resultados obtenidos siguen las mismas tendencias que el lecho pseudo-2D, se observaron ciertas discrepancias debidas al cambio de geometría, ya que las burbujas tienen mayor sección disponible para poder crecer.

Se realizó también el estudio de un lecho fluidizado de geometría cónica cargado con partículas Geldart D (Anexo 3.I). Se aplicaron dos métodos alternativos para la evaluación del diámetro de burbujas y se concluyó que con ambas metodologías se puede evaluar el diámetro de las burbujas en función de la altura del lecho y la velocidad de ascenso de las mismas, sin embargo, el método A (equivalente al utilizado para las partículas Geldart B) resultó más apropiado para el sistema estudiado.

Se concluyó que modelado CFD constituye una poderosa herramienta para el análisis y estudio minucioso de lechos burbujeantes de los pares arena-aire y urea-aire.

Se llevó a cabo el modelado mediante CFD de un lecho fluidizado denso de partículas de SiC (Geldart A) fluidizadas con aire, con y sin transferencia de calor a 
través de su pared. Las condiciones empleadas en las simulaciones fueron idénticas a las utilizadas en un prototipo experimental colector solar perteneciente al laboratorio PROMES-CNRS, Francia. El modelo CFD reprodujo de manera adecuada la porosidad del sistema experimental. También, a partir de los resultados obtenidos para la temperatura de las partículas en el ingreso a la zona de intercambio, se concluyó que el modelo reproduce la recirculación de las partículas de SiC entre la zona de intercambio y la zona baja del lecho antes mencionado.

Un aspecto relevante de los resultados obtenidos fue que el modelo pone en evidencia la formación de slugs de pared en los casos con y sin transferencia de calor. Se presentaron perfiles axiales de diferentes variables para conocer el comportamiento del sistema en diversas condiciones operativas. La presencia de la pared caliente ocasiona el aumento del espesor de los slugs y también promueve la ocupación de gran parte de la superficie interna de intercambio del tubo.

Luego, se realizó el modelado mediante CFD de un lecho operando en régimen slug y se estudiaron sus características fluidodinámicas. Si bien el modelado CFD logró reproducir la tendencia de los datos de frecuencia slugs, fracción de sólidos y fracción de burbujas en el lecho, los resultados de longitud y velocidad de ascenso presentaron aun diferencias considerables. Se observó que las simulaciones arrojan valores inferiores de expansión del lecho, lo que podría influir en las diferencias observadas en todos los resultados.

Tanto para la longitud de slug como para su velocidad de ascenso $\left(u_{s}\right)$, los valores obtenidos mediante CFD presentaron valores cercanos a la correlación para slug axial, mientras que los datos experimentales tienden a la correlación de slugs de pared. Para el caso de la velocidad $u_{s}$, la discrepancia en los resultados está relacionada a la frecuencia de slug obtenida por CFD, que, si bien respeta la tendencia de los valores experimentales, prácticamente los duplica, implicando una cantidad superior de burbujas para un mismo caudal volumétrico de gas y reduciendo directamente las velocidades $u_{s}$ resultantes. Sumado a ello, las diferencias observadas entre los resultados experimentales y los obtenidos por CFD puede deberse a que el modelo 
friccional utilizado en las simulaciones tenga una fuerte influencia sobre el modelado del movimiento de las partículas.

Por último, en el Capítulo 5 se estudiaron dos sistemas binarios inerte biomasa. Para ambos sistemas se pudo observar una mejora en la calidad de fluidización mediante el agregado de inerte, aun en bajas proporciones. Este último logra disminuir las fuerzas de cohesión entre las partículas de biomasa, disminuyendo la segregación y atenuando la formación de canales preferenciales. Se alcanzaron resultados cualitativamente satisfactorios en relación con el estado de agitación, expansión y formación de burbujas de los distintos sistemas, reflejados tanto en los diagramas de contorno de las fracciones de sólido generados como en el resultado de las simulaciones. Estas imágenes concuerdan con las observaciones experimentales. Para ambos sistemas pudo observare que la incorporación de un material inerte disminuye el valor de la velocidad de mínima fluidización en comparación con la de la biomasa pura, como era esperable a partir de las consideraciones teóricas pertinentes.

En el caso del SISTEMA 1, se confirmó la existencia de dos regímenes de fluidización diferentes, tanto en el aserrín como en las mezclas aserrín-arena, que da origen a la definición de dos velocidades de fluidización adicionales: $U_{i f}$ y $U_{c f}$. Por el contrario, en el SISTEMA 2 no se observaron regímenes intermedios de fluidización ni para el bagazo de manzana ni para las mezclas estudiadas, por lo que la única velocidad características en este caso fue la $U_{m f}$.

$\mathrm{Al}$ igual que en los casos anteriores, se verificó el potencial de la CFD como herramienta de trabajo para el estudio del comportamiento fluidodinámico de los lechos fluidizados de mezclas binarias bioresiduo-inerte. Para la totalidad de las mezclas estudiadas, los valores de velocidad $U_{m f}$ obtenidos mediante simulaciones CFD arrojaron un error relativo, respecto de los valores experimentales, inferior al 5\%. Los resultados obtenidos para la velocidad $U_{m f}$ fueron contrastados con diferentes correlaciones. Las propuestas por Chiba y colab. (1979) y por Rowe y Nienow (1975), que tienen en cuentas las velocidades $U_{m f}$ de los compuestos puros, mostraron los mejores ajustes respecto de los resultados experimentales para ambos sistemas. 
Es importante mencionar que se desarrollaron programas para el análisis de resultados, en los entornos MATLAB y Autodesk 3DSMax, que permitieron analizar un gran volumen de datos en tiempos muy inferiores a los necesarios cuando el análisis se lleva a cabo de forma manual.

En base al análisis y conclusiones presentadas, pueden señalarse algunos aspectos que podrían estudiarse en futuras actividades:

$\checkmark$ Desarrollo o modificación de un modelo para la viscosidad friccional entre partículas, cuya influencia sobre el movimiento total de las mismas sea inferior a la del modelo de Schaeffer (1987) aplicado en el análisis preliminar de partículas Geldart B.

$\checkmark$ Llevar a cabo un estudio más exhaustivo de alternativas de modelo de arrastre, que permitan una mejor evaluación del tamaño y velocidad de burbujas, y permitiendo la extrapolación del ajuste a distintas velocidades superficiales de gas.

$\checkmark$ Desarrollo o modificación de modelos de arrastre que permitan obtener mejores resultados para longitud y velocidad de slug con partículas Geldart A.

$\checkmark$ Desarrollo de programas en entorno MATLAB o afín que permitan el tratamiento de grandes cantidades de datos, para poder estudiar de forma experimental el régimen burbujeante mediante monitores de fracción de sólidos de partículas Geldart D realizando un mapeo del lecho.

$\checkmark$ Evaluación de un software que permita evaluar de forma integral las propiedades de burbujas en un lecho cilíndrico (de modo similar al llevado a cabo en la geometría pseudo-2D), ya que la mayor desventaja en este estudio estuvo centrada en los tiempos requeridos para el análisis inicial de datos (hallar valores de centro de masa, área superficial y volumen de cada burbuja en particular). 


\title{
NOMENCLATURA
}

\author{
A Área transversal del lecho [m] \\ $A_{b} \quad$ Área plana de una burbuja $\left[\mathrm{cm}^{2}\right]$ \\ $A_{\text {pix }}, A_{\text {real }} \quad$ Área de un píxel y área de la referencia en sistema métrico \\ $\left[\mathrm{cm}^{2}\right]$ \\ Ar $\quad=d_{p}^{3} \rho_{g}\left(\rho_{s}-\rho_{g}\right) g / \mu^{2}$ Número de Arquímedes \\ $C_{D} \quad$ Coeficiente de arrastre \\ $C_{p, s} \quad$ Capacidad calorífica del sólido $[\mathrm{J} / \mathrm{kgK}]$ \\ $C_{2} \quad$ Factor de resistencia inercial en PMM $[1 / \mathrm{m}]$ \\ D Diámetro interno del lecho [m] (salvo especificación contraria) \\ $d_{b} \quad$ Diámetro de burbuja [cm] \\ $d_{f}, d_{v l} \quad$ Diámetro frontal y vertical de burbuja [cm] \\ $d_{0} \quad$ Tamaño inicial de burbuja [cm] \\ $d_{p}, \overline{d_{p}} \quad$ Diámetro y diámetro medio de partícula [mm] \\ $d_{s v} \quad$ Diámetro de Sauter $[\mathrm{cm}]$ \\ $d_{v} \quad$ Diámetro de una burbuja de volumen equivalente [cm] \\ $e_{\text {lecho }} \quad$ Espesor de lecho $[\mathrm{cm}]$ \\ $e_{s s} \quad$ Coeficiente de restitución \\ $f_{b}, \overline{f_{b}} \quad$ Fracción volumétrica y fracción volumétrica promedio de burbujas \\ $f_{\text {nube }} \quad$ Relación del volumen de nube a burbuja \\ $\mathrm{F}_{\mathrm{S}} \quad$ Frecuencia de slugs $[1 / \mathrm{s}]$ \\ $g \quad$ Aceleración de la gravedad $\left[\mathrm{cm} / \mathrm{s}^{2}\right]$ \\ $H \quad$ Altura del lecho [m] \\ $h \quad$ Altura de burbuja desde el distribuidor [cm] \\ $\mathrm{H}_{\mathrm{L}} \quad$ Altura mínima para espaciado estable entre slugs
}


$H_{o}, H_{m f}, H_{\max }$ Altura inicial, en mínima fluidización y máxima, respectivamente, alcanzadas por el lecho. [m]

$k_{p, o} \quad$ Conductividad térmica del sólido $[\mathrm{W} / \mathrm{mK}]$

$L_{p i x, X}, L_{p i x, Y}, \quad$ Dimensiones lineales de un píxel y dimensiones de referencia $L_{\text {real }} \quad$ en sistema métrico $[\mathrm{cm}]$

$\mathrm{L}_{\mathrm{S}} \quad$ Longitud de slugs $[\mathrm{cm}]$

m Masa de sólidos [kg]

$\dot{m} \quad$ Caudal másico $[\mathrm{kg} / \mathrm{h}]$

$n_{p i x} \quad$ Cantidad de píxeles

$N_{T} \quad$ Cantidad de diámetros de lecho entre la parte inferior de un slug y la punta del slug siguiente

$P_{b} \quad$ Perímetro de la burbuja plana [cm]

$Q, Q_{s} \quad$ Flujo volumétrico de gas y sólido respectivament $\left[\mathrm{m}^{3} / \mathrm{s}\right]$

$q \quad$ Flujo volumétrico de gas que atraviesa una burbuja $\left[\mathrm{m}^{3} / \mathrm{s}\right]$

$Q_{m f} \quad$ Flujo volumétrico para mínima fluidización $\left[\mathrm{m}^{3} / \mathrm{s}\right]$

$Q_{b} \quad$ Flujo volumétrico de burbujas $\left[\mathrm{m}^{3} / \mathrm{s}\right]$

$\dot{Q} \quad$ Energía intercambiada entre fases $\left[\mathrm{W} / \mathrm{m}^{2}\right]$

$R_{c}, R_{b} \quad$ Radio de nube y burbuja respectivamente

$\operatorname{Re} \quad=d_{p} U \rho_{g} / \mu$ Número de Reynolds

$S_{b} \quad$ Área superficial de una burbuja $\left[\mathrm{cm}^{2}\right]$

$S_{b h} \quad$ Superficie de burbuja proyectada sobre un plano horizontal

$T_{p, i}, T_{p, o} \quad$ Temperatura de ingreso y salida de la zona de transferencia de calor $[\mathrm{K}]$

$T_{p, \text { cold }} \quad$ Temperatura de las partículas cuando ingresan al lecho[K]

$T_{w, i}^{e x t}, T_{w, o}^{e x t} \quad$ Temperatura en la cara externa del tubo en ingreso y salida de la zona de transferencia de calor [K]

$T_{w, z}^{i n t} \quad$ Función de temperatura interna en la pared del tubo [K] 


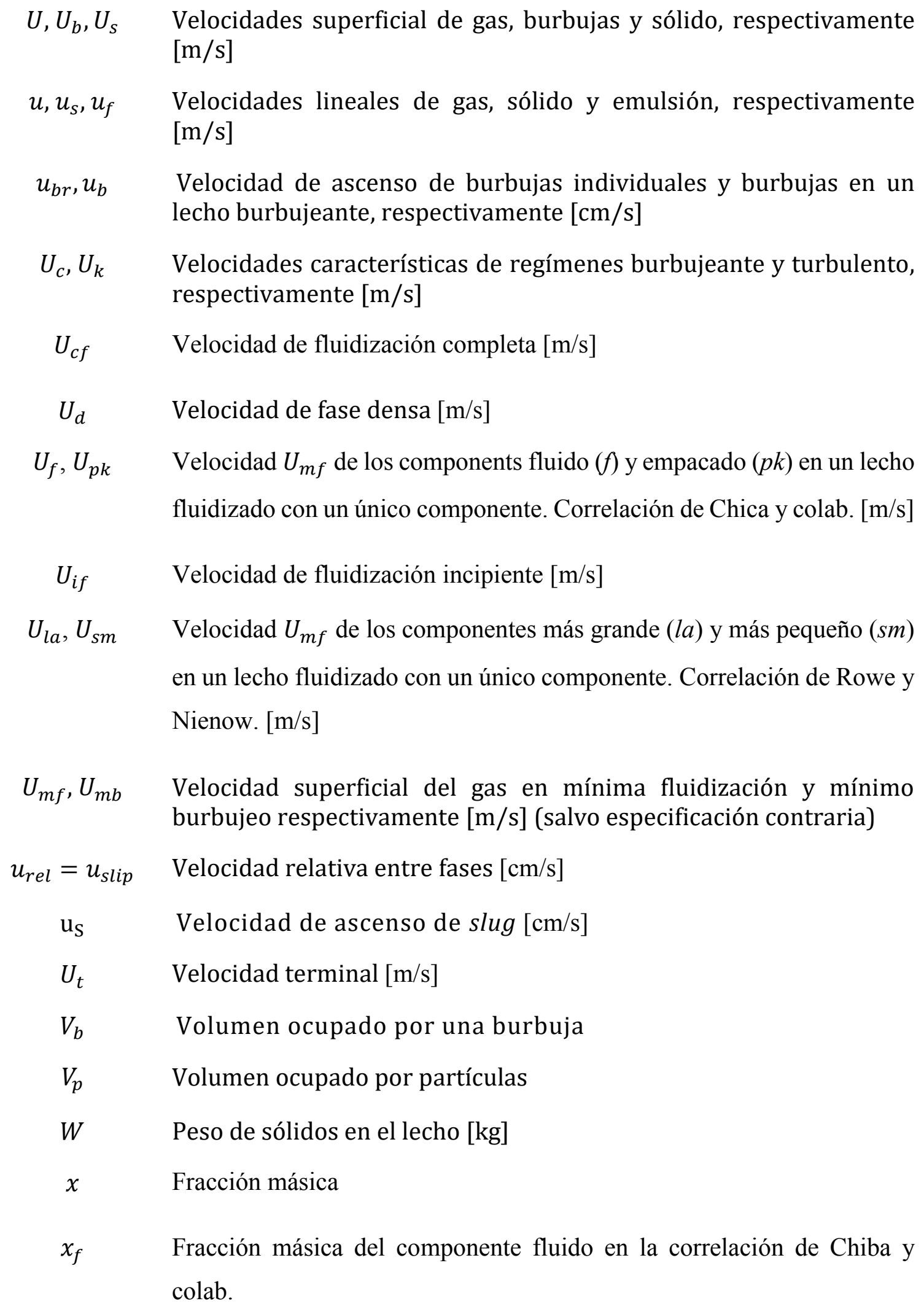


$x_{l a} \quad$ Fracción másica del componente de mayor tamaño en la correlación de Rowe y Nienow.

$y \quad$ Pierced length de burbuja [cm]

\section{LETRAS GRIEGAS}

\begin{tabular}{|c|c|}
\hline$\alpha_{g}, \alpha_{s}$ & Fracción volumétrica de gas y sólido respectivamente \\
\hline$\varphi$ & Coeficiente de especularidad \\
\hline$\mu_{s, k i n}$ & Viscosidad cinética de sólidos \\
\hline$\mu_{s, \mathrm{col}}$ & Viscosidad por colisiones de sólidos \\
\hline$\mu_{s, f r}$ & Viscosidad friccional de sólidos \\
\hline$\lambda_{s}$ & Viscosidad granular \\
\hline$\Delta t$ & Paso de tiempo [s] \\
\hline$\nabla P_{S}$ & Presión de sólidos \\
\hline$\rho_{g}, \rho_{s}$ & Densidad de gas y sólido respectivamente \\
\hline$\mu$ & Viscosidad del gas [Pa s] \\
\hline$\varepsilon$ & Porosidad del lecho \\
\hline$\varepsilon_{m f}, \varepsilon_{m b}$ & $\begin{array}{l}\text { Porosidad del lecho en mínima fluidización y mínimo } \\
\text { burbujeo respectivamente }\end{array}$ \\
\hline$\varepsilon_{e}$ & Porosidad de emulsión o fase densa \\
\hline$\psi$ & Esfericidad de los sólidos \\
\hline$\alpha$ & Permeabilidad del medio poroso en PMM $\left[\mathrm{m}^{2}\right]$ \\
\hline$\Delta P$ & Pérdida de carga \\
\hline$\omega$ & Factor de forma de burbujas \\
\hline$v_{b}$ & Frecuencia de pulsación de las burbujas \\
\hline
\end{tabular}




\section{ACRÓNIMOS}

$\begin{array}{cl}\text { CFD } & \text { Fluididinámica computacional } \\ \text { TDF } & \text { Teoría de las dos fases } \\ \text { TFM } & \text { Modelos de dos flujos } \\ \text { PMM } & \text { Modelo del medio poroso }\end{array}$

\section{SUBÍNDICES}

$\begin{array}{ll}b m & \text { Biomasa } \\ g & \text { Gas } \\ \text { in } & \text { Material inerte } \\ & \\ s & \text { Sólido }\end{array}$




\section{REFERENCIAS BIBLIOGRÁFICAS}

Acosta-Iborra, A., Sobrino, C., Hernández-Jiménez, F., \& de Vega, M. (2011). Experimental and computational study on the bubble behavior in a 3-D fluidized bed. Chemical Engineering Science, 66(15), 3499-3512. https://doi.org/10.1016/j.ces.2011.04.009

Agarwal, P.K. (1985). Bubble characteristics in gas fluidized beds. Chemical Engineering Research and Design, 63, 323-337.

Alagha, M. S., \& Szentannai, P. (2020). Analytical review of fluid-dynamic and thermal modeling aspects of fluidized beds for energy conversion devices. International Journal of Heat and Mass Transfer, 147, 118907. https://doi.org/10.1016/j.ijheatmasstransfer.2019.118907

Altantzis, C., Bates, R. B., \& Ghoniem, A. F. (2015). 3D Eulerian modeling of thin rectangular gas-solid fluidized beds: Estimation of the specularity coefficient and its effects on bubbling dynamics and circulation times. Powder Technology, 270(Part A), 256-270. https://doi.org/10.1016/j.powtec.2014.10.029

ANSYS, Inc. (2020). ANSYS Fluent User's Guide 18.2. United States of America.

API RP 56 (1995). Recommended practices for Testing Sand Used in Hydraulic Fracturing Operation.

Armstrong L. M., Gu, S. \& Luo, K. H. (2010). Study of wall-to-bed heat transfer in a bubbling fluidised bed using the kinetic theory of granular flow. International Journal of Heat and Mass Transfer 53, 4949-4959.

Asegehegn T. W., Schreiber M. \& Krautz H. J. (2012). Influence of two- and three- dimensional simulations on bubble behavior in gas-solid fluidized beds with and without immersed horizontal tubes. Powder Technology, 219, 9-19. 
Asegehegn, T. W., Schreiber, M., \& Krautz, H. J. (2011). Numerical Study of Bubbling Gas-Solid Fluidized Beds Hydrodynamics : Influence of Immersed Horizontal Tubes and Data Analysis. International Journal of Chemical Reactor Engineering, 9.

Askaripour, H., \& Molaei Dehkordi, A. (2015). Simulation of 3D freely bubbling gas-solid fluidized beds using various drag models: TFM approach. Chemical Engineering Research and Design, 100, 377-390. https://doi.org/10.1016/j.cherd.2015.05.041

ASTM, A. S. for T. and M. (1998). E872 - 82 . Standard Test Method for Volatile Matter in the Analysis of Particulate Wood Fuels. https://doi.org/10.1520/E087282R06.2

ASTM, A. S. for T. and M. (2001). D1102-84. Standard Test Method for Ash in Wood. https://doi.org/10.1520/D1894-14.2.

ASTM, A. S. for T. and M. (1979). D1103-60. Standard test method for $\alpha$ cellulose in wood.

ASTM, A. S. for T. and M. (1983). D 1106-56. Standard test method for lignin in wood.

ASTM, A. S. for T. and M. (2012). D7743-12. Standard Test Method for Measuring the Minimum Fluidization Velocity of Free Flow Powders. DOI: 10.1520/D7743.

ASTM, A. S. for T. and M. (2013). D7743 - 12 Standard Test Method for Measuring the Minimum Fluidization Velocities of Free flowing powders. 1-8. https://doi.org/10.1520/D7743-12.2

Baeyens, J. \& Geldart, D. (1980). Modelling approach to the effect of equipment scale on fluidised bed heat transfer data. Journal of Powder \& Bulk Solids Technology $4(1)$.

Baeyens, J., \& Geldart, D. (1974). An investigation into slugging fluidized beds. Chemical Engineering Science, 29(1), 255-265. https://doi.org/10.1016/00092509(74)85051-7 
Baeyens, J., \& Wu, S. Y. (1992). Bed expansion and the visible bubble flow rate in gas fluidized beds. Advanced Powder Technology, 3(3), 163-189. https://doi.org/10.1016/S0921-8831(08)60668-8

Bakshi, A., Altantzis, C., \& Ghoniem, A. F. (2014). Towards accurate threedimensional simulation of dense multi-phase flows using cylindrical coordinates. Powder Technology, 264, 242-255. https://doi.org/10.1016/j.powtec.2014.04.052

Bakshi, A., Altantzis, C., Bates, R. B., \& Ghoniem, A. F. (2015). Eulerian-Eulerian simulation of dense solid-gas cylindrical fluidized beds: Impact of wall boundary condition and drag model on fluidization. Powder Technology, 277, 47-62.

Barreto, G., Yates, J.G. \& Rowe, P.N. (1984). The effect of pressure on the flow of gas in fluidized beds of fine particles. Chemical Enginnering Science, 1935-1945.

Barreto, G.F. (1984). Behavior of beds of fine powders fluidized by gases at pressures of up to 20 bar. Ph. D. Thesis, University College, Londres, Inglaterra.

Basu, P. (2010). Biomass Gasification and Pyrolisis, Practical Design and Theory. 1st ed. United States of America, Academic Press.

Beetstra, R., van der Hoef, M. A., \& Kuipers, J. A. M. (2006). A lattice-Boltzmann simulation study of the drag coefficient of clusters of spheres. Computers and Fluids, 35(8-9), 966-970. https://doi.org/10.1016/j.compfluid.2005.03.009

Bell, R.A. (2000). Numerical Modelling of Multi-Particle Flows in Bubbling GasSolid Fluidized Beds. Licentiate Thesis, Melbourne: Swinburne University of Technology.

Bi, H. T. (2007). A critical review of the complex pressure fluctuation phenomenon in gas-solids fluidized beds. Chemical Engineering Science, 62(13), 34733493. https://doi.org/10.1016/j.ces.2006.12.092

Bi, H.T., Grace, J.R. \& Zhu, J.X. (1995). Regime transitions affecting gas-solids suspensions and fluidized beds. Chemical Engineering Research and Design, 73, 154161. 
Birkhoff, G. \& Carter, D. (1957). Rising plane bubbles. Journal of Mathematics and Mechanics 6, 769-779.

Busciglio, A, Vella, G., Micale, G., \& Rizzuti, L. (2008). Cfd Prediction of Bubbles Behaviour in 2- Dimensional Gas - Solid Fluidized Beds. 11th Int. Conf. on Multiphase Flow in Industrial Plants, Palermo, Italy, (c), 259-266.

Busciglio, A., Vella, G., Micale, G., \& Rizzuti, L. (2010). Experimental analysis of bubble size distributions in 2D gas fluidized beds. Chemical Engineering Science, 65(16), 4782-4791. https://doi.org/10.1016/j.ces.2010.05.016

Busciglio, Antonio, Vella, G., Micale, G., \& Rizzuti, L. (2008). Analysis of the bubbling behaviour of 2D gas solid fluidized beds. Part I. Digital image analysis technique. Chemical Engineering Journal, 140(1-3), 398-413. https://doi.org/10.1016/j.cej.2007.11.015

Busciglio, Antonio, Vella, G., Micale, G., \& Rizzuti, L. (2009). Analysis of the bubbling behaviour of 2D gas solid fluidized beds. Part II. Comparison between experiments and numerical simulations via Digital Image Analysis Technique. Chemical Engineering Journal, 148(1), 145-163. https://doi.org/10.1016/j.cej.2008.11.010

Cai, P., Chen, S.P., Jin, Y., Yu, Z.Q. \& Wang, Z.W. (1989). Effect of operating temperature and pressure on the transition from bubbling to turbulent fluidization. AIChE Symposium Series, 85(270), 37-43.

Cai, P., Schiavetti, M., Michele, G.D. \& Grazzini, G.C. (1994). Quantitative estimation of bubble size in PFBC. Powder Technology, 80, 99-109.

Cammarata, L., Lettieri, P., Micale, G. D. M., \& Colman, D. (2003). 2D and 3D CFD Simulations of Bubbling Fluidized Beds Using Eulerian-Eulerian Models. International Journal of Chemical Reactor Engineering, 1.

Canada, G.S., McLaughlin, M.H. \& Staub, F.W. (1978). Flow regimes and void fraction distribution in gas fluidization of large particles in beds without tube banks. AIChE Symposium Series, 74, 14-26. 
Cano-Pleite, E., Hernández-Jiménez, F., de Vega, M., \& Acosta-Iborra, A. (2014). Experimental study on the motion of isolated bubbles in a vertically vibrated fluidized $\begin{array}{llll}\text { bed. } \quad \text { Chemical Journal, 255, 114-125. } & \text { Engineering }\end{array}$ https://doi.org/10.1016/j.cej.2014.06.016

Chandran R. \& Chen, J. C. (1985). A Heat Transfer Model for Tubes Immersed in Gas Fluidized Beds. AlChE Journal, 31(2), 244-252.

Channiwala, S.A. \& Parikh, P. P. (2002). Unified correlation for estimating HHV of solid, liquid and gaseous fuels. Fuel 81 (8), 1051-1063.

Chiba, S., Chiba, T., Nienow, A. W. \& Kobayashi, H. (1979). The minimum fluidization velocity, bed expansion and pressure-drop profile of binary particle mixtures. Powder Technology 22, 255-269.

Clarke, K., Pugsley, T. \& Hill, G. (2005). Fluidization of moist sawdust in binary particle systems in a gas-solid fluidized bed. Chemical Engineering Science 60, 69096918.

Cornelissen, J.T., Taghipour, F., Escudié, R., Ellis, N. \& Grace, J.R. (2007). CFD modeling of a liquid-solid fluidized bed. Chemical Engineering Science, 62, 6334-6348.

Cossu, R., Liu, J., Pivato, A., \& Ragazzi, M. (2020). Biomass to biofuels: Challenges $\begin{array}{lllll}\text { and } & \text { opportunities. } & \text { Renewable }\end{array}$ https://doi.org/10.1016/j.renene.2020.04.114

Couderc, J. (1985). Incipient Fluidization and Particulate Systems. En: Fluidization, Davidson, J.F., Clift, R. \& Harrison, D. Eds., Cap. 1, 1-46.

Dai, J., Saayman, J., Grace, J. R. \& Ellis, N. (2015). Gasification of Woody Biomass. Annual Review of Chemical and Biomolecular Engineering 6, 77-99.

Darton, R.C., La Naueza, R.D., Davidson, J.F. \& Harrison, D. (1977). Bubble grouth due to coalescence in fluidized beds. Transactions of the Institution of Chemical Engineers, 55, 274-280.

Davidson, J. F. \& Harrison, D. (1963). Fluidised particles. Cambridge University Press. 
Davidson, J. F. \& Harrison, D. (1966). The behaviour of a continuously bubbling fluidised bed. Chemical Engineering Science, 21, 731-738.

Davidson, J. F., Clift, R. D. \& Harrison, D. (1963). Fluidization. Academic Press, Orlando, Florida.

Demirbas, A. (2004). Effects of temperature and particle size on bio-charyield from pyrolysis of agricultural residues. Journal of Analytical and Applied Pyrolysis 72, 243-248.

Dhodapkar, S.V., Zaltash, A. \& Klinzing, G. (2012). A primer on gas-solids fluidization. Chemical Engineering, 119, 38-47.

Di Maio, F., Di Renzo, A. \& Vivacqua, V. (2012). A particle segregation model for gas-fluidization of binary mixtures. Powder Technology 226, 180-188.

Ding, J., \& Gidaspow, D. (1990). A bubbling fluidization model using kinetic theory of granular flow. AIChE Journal, 36(4), 523-538. https://doi.org/10.1002/aic.690360404

Encinar, J. M., González, J. F., Rodríguez, J. J. \& Ramiro, M. J. (2001). Catalysed and uncatalysed steam gasification of eucalyptus char: influence of variables and kinetic study. Fuel 80(14), 2025-2036.

Ergun, S. (1952). Fluid flow through packed columns. Chemical Engineering Progress, 48(2), 89-94.

Fabich, H. T., Sederman, A. J., \& Holland, D. J. (2017). Study of bubble dynamics in gas-solid fluidized beds using ultrashort echo time (UTE) magnetic resonance imaging (MRI). Chemical Engineering Science, 172, 476-486. https://doi.org/10.1016/j.ces.2017.07.003

Felizardo, M.P. \& Freire, J. T. (2018). Characterization of barley grains in different levels of pearling process. Journal of Food Engineering 232, 29-35.

Fernandez, A., Mazza, G. \& Rodriguez, R. (2018). Thermal decomposition under oxidative atmosphere of lignocellulosic wastes: Different kinetic methods application. Journal of Environmental Chemical Engineering 6,404-415. 
Fernandez, A., Soria, J., Rodriguez, R., Baeyens, J. \& Mazza, G. D. (2019). MacroTGA steam-assisted gasification of lignocellulosic wastes. Journal of Environmental Management 233, 626-635.

Flamant, G., Gauthier, D., Benoit, H., Sans, J. L., Garcia, R., Boissière, B., Hemati, M. (2013). Dense suspension of solid particles as a new heat transfer fluid for concentrated solar thermal plants: On-sun proof of concept. Chemical Engineering Science, 102, 567-576. https://doi.org/10.1016/j.ces.2013.08.051

García-Gutierrez, L.M., Hernández-Jiménez, F., Cano-Pleite, E. \& Soria-Verdugo, A. (2017). Improvement of the simulation of fuel particles motion in a fluidized bed by considering wall friction. Chemical Engineering Journal 321, 175-183.

Geldart, D. (1973). Types of gas fluidization. Powder Technology, 7, 285-292

Geldart, D., \& Baeyens, J. (1985). The design of distributors for gas-fluidized beds. Powder Technology, 42(1), 67-78. https://doi.org/10.1016/0032$5910(85) 80039-5$

Gibilaro, L. G., Di Felice, R. \& Waldram, S. P. (1985). Generalized friction factor and drag coefficient correlations for fluid-particle interactions. Chemical Engineering Science, 40(10), 1817-1823.

Gidaspow, D., Bezburuah, R. \& Ding, J. (1992). Hydrodynamics of circulating fluidized beds, Kinetic Theory approach. In Fluidization VII, Proceedings of the 7th Engineering Foundation Conference on Fluidization, 75-82.

Gidaspow, D., Syamlal, M. \& Seo, Y. (1985). Hydrodynamics of fluidization of single and binary size particles: supercomputer modelling. In: Proceedings of the Fifth Engineering Foundation Conference on Fluidization 5, 1-8.

Girimonte, R., Formisani, B. \& Vivacqua, B. (2019). Application of the theory of binary fluidization to solids of irregular shape: Choosing the granulometry of sand in processes for energy production from wastes of the olive oil industry. Powder Technology 345, 563-570. 
Goldsmith, J. A. \& Rowe, P. N. (1974). The shape of the bubbles in a twodimensional gas fluidized bed. Chemical Engineering Science, 30(Shorter Communications), 439-440.

Goossens, W.R.A. (1998). Classification of fluidized particles by Archimedes number. Powder Technology, 98, 48-53.

Grace, J. R. \& Clift, R. (1974). On the two-phase theory of fluidization. Chemical Engineering Science, 29, 327-334.

Grace, J.R. (1986). Contacting modes and behavior classification of gas-solid and other two-phase suspension. Canadian Journal of Chemical Engineering, 64, 35336.

Gunn, D. J. (1978). Transfer of heat and mass to particles in fixed and fluidized beds. International Journal of Heat and Mass Transfer, 21, 467-476.

Gunn, D. J. (1978). Transfer of Heat or Mass to Particles in Fixed and Fluidized Beds. International Journal of Heat Mass Transfer, 21, 467-476.

Haider, A. \& Levenspiel, O. (1989). Drag coefficient and terminal velocity of spherical and nonspherical particles. Powder Technology, 58, 63-70.

Harrison, D., Davidson, J.F. \& de Kock, J.W. (1961). On the nature of aggregative and particulate fluidization. Transactions of the Institution of Chemical Engineers, 39, 202-211.

Herzog, N., Schreiber, M., Egbers, C., \& Krautz, H. J. (2012). A comparative study of different CFD-codes for numerical simulation of gas-solid fluidized bed hydrodynamics. Computers and Chemical Engineering, 39, 41-46. https://doi.org/10.1016/j.compchemeng.2011.12.002

Hilligardt, K. \& Werther, J. (1986). Local bubble gas hold-up and expansion of gas/solid fluidized beds. German Chemical Engineering, 9, 215-221.

Horio, M. (1990). Hydrodynamics of circulating fluidization - Present status and research needs. En: Circulating Fluidized Bed Technology III, Basu, P., Horio M, \& Hasatani, M. Eds., Pergamon Press, Oxford, 3-14. 
Hosseini, S. H., Ahmadi, G., Rahimi, R., Zivdar, M., \& Esfahany, M. N. (2010). CFD studies of solids hold-up distribution and circulation patterns in gas-solid fluidized beds. Powder Technology, 200(3), 202-215. https://doi.org/10.1016/j.powtec.2010.02.024

Hulme, I., \& Kantzas, A. (2004). Determination of bubble diameter and axial velocity for a polyethylene fluidized bed using X-ray fluoroscopy. Powder Technology, 147(1-3), 20-33. https://doi.org/10.1016/j.powtec.2004.08.008

Hulme, I., \& Kantzas, A. (2004). Determination of bubble diameter and axial velocity for a polyethylene fluidized bed using X-ray fluoroscopy. Powder Technology, 147(1-3), 20-33. https://doi.org/10.1016/j.powtec.2004.08.008

Hulme, I., Clavelle, E., van der Lee, L., \& Kantzas, A. (2005). CFD Modeling and Validation of Bubble Properties for a Bubbling Fluidized Bed. Industrial \& Engineering Chemistry Research, 44(12), 4254-4266. https://doi.org/10.1021/ie049837j

Johnson, P. C. \& Jackson, R. (1987). Frictional-collisional constitutive relations for granular materials, with application to plane shearing. Journal of Fluid Mechanics, 176, 67-93.

Karimipour, S., \& Pugsley, T. (2011). A critical evaluation of literature correlations for predicting bubble size and velocity in gas-solid fluidized beds. Powder Technology, 205(1-3), 1-14. https://doi.org/10.1016/j.powtec.2010.09.016

Kong, W., Li, S., Ke, H., Zhang, H., \& Baeyens, J. (2019). The use of ultrasound probes to monitor multi-phase behavior in opaque systems. Particuology, 45, 91-97. https://doi.org/10.1016/j.partic.2018.05.009

Kong, W., Tan, T., Baeyens, J., Flamant, G., \& Zhang, H. (2017). Bubbling and Slugging of Geldart Group A Powders in Small Diameter Columns. Industrial and Engineering Chemistry Research, 56(14), 4136-4144. https://doi.org/10.1021/acs.iecr.6b04798 
Kuipers J. A. M., Prins W. \& Van Swaaij W. P. M. (1992). Numerical calculation of wall-to-bed heat transfer coefficients in gas-fluidized beds. AIChE Journal, 38, 10791091.

Kunii, D. \& Levenspiel, O. (2013). Fluidization Engineering. 2nd edition, Ed. Butterworth-Heinemann.

Levenspiel, O. (1998). Flow in Fluidized Beds. En: Engineering Flow and Heat Exchange. The Plenum Chemical Engineering Series. Springer, Boston, MA. https://doi.org/10.1007/978-1-4899-0104-0_7

Li, J., \& Kwauk, M. (2001). Multiscale nature of complex fluid-particle systems. Industrial and Engineering Chemistry Research, 40(20), 4227-4237. https://doi.org/10.1021/ie0011021

Li, J., \& Kwauk, M. (2003). Exploring complex systems in chemical engineering - The multi-scale methodology. Chemical Engineering Science, 58(3-6), 521-535. https://doi.org/10.1016/S0009-2509(02)00577-8

Li, X., Jaworski, A. J., \& Mao, X. (2018). Bubble size and bubble rise velocity estimation by means of electrical capacitance tomography within gas-solids fluidized beds. Measurement: Journal of the International Measurement Confederation, 117(September 2017), 226-240. https://doi.org/10.1016/j.measurement.2017.12.017

Li, Y., Rong, J., Zhang, K., \& Fan, X. (2018). Impact of solid and gas flow patterns on solid mixing in bubbling fluidized beds. Chemical Engineering Research and Design, 132, 1037-1053. https://doi.org/10.1016/j.cherd.2017.12.014

Lockett, M. J., Davidson, J. F. \& Harrison, D. (1967). On the two phase theory of fluidisation. Chemical Engineering Science, 22, 1059-1066.

Loha, C., Chattopadhyay, H., \& Chatterjee, P. K. (2013). Euler-Euler CFD modeling of fluidized bed: Influence of specularity coefficient on hydrodynamic behavior. Particuology, 11(6), 673-680. https://doi.org/10.1016/j.partic.2012.08.007 
Lu Y., Huang J. \& Zheng, P. (2015). A CFD-DEM study of bubble dynamics in fluidized bed using flood fill method. Chemical Engineering Journal 274,123-131.

Lu, Y., Huang, J., \& Zheng, P. (2015). A CFD-DEM study of bubble dynamics in fluidized bed using flood fill method. Chemical Engineering Journal, 274, 123-131. https://doi.org/10.1016/j.cej.2015.03.117

Lun, C.K.K, Savage, S.B, Jeffrey, D.J \& Chepurniy, N (1984). Kinetic theories for granular flow: ineslastic particles in Couette flow and slightly inlestaic particles in a general flow field. Journal of Fluid Mechanics, 140, 223-256.

Ma, H. \& Zhao, Y. (2018). CFD-DEM investigation of the fluidization of binary mixtures containing rod-like particles and spherical particles in a fluidized bed. Powder Technology 336, 533-545.

Ma, J., Ge, W., Wang, X., Wang, J., \& Li, J. (2006). High-resolution simulation of gas-solid suspension using macro-scale particle methods. Chemical Engineering Science, 61(21), 7096-7106. https://doi.org/10.1016/j.ces.2006.07.042

Matsen, J. M., Hovmand, S. \& Davidson, J. F. (1969). Expansion of fluidized beds in slug flow. Chemical Engineering Science, 24, 1743-1754.

Maurer, S., Gschwend, D., Wagner, E. C., Schildhauer, T. J., Ruud van Ommen, J., Biollaz, S. M. A., \& Mudde, R. F. (2016). Correlating bubble size and velocity distribution in bubbling fluidized bed based on X-ray tomography. Chemical Engineering Journal, 298, 17-25. https://doi.org/10.1016/j.cej.2016.02.012

Maurer, S., Gschwend, D., Wagner, E. C., Schildhauer, T. J., Ruud van Ommen, J., Biollaz, S. M. A., \& Mudde, R. F. (2016). Correlating bubble size and velocity distribution in bubbling fluidized bed based on X-ray tomography. Chemical Engineering Journal, 298, 17-25. https://doi.org/10.1016/j.cej.2016.02.012

Mazza, G.D. (1993). Análisis de la transferencia de calor entre un lecho fluidizado y superficies sumergidas. Tesis Doctoral, Departamento de Ingeniería Química, Universidad Nacional de La Plata, Argentina. 
McKeen, T., \& Pugsley, T. (2003). Simulation and experimental validation of a freely bubbling bed of FCC catalyst. Powder Technology, 129(1-3), 139-152. https://doi.org/10.1016/S0032-5910(02)00294-2

Miwa, K., Mori, S., Kato, T. \& Muchi, I. (1972). Behaviour of bubbles in gaseous fluidized bed. International Chemical Engineering, 12, 187-194.

Molerus, O. (1982). Interpretation of Geldart's Type A, B, C and D powders by taking into account interparticle cohesion forces. Powder Technology, 33, 81-87.

Müller, C. R., Davidson, J. F., Dennis, J. S., Fennell, P. S., Gladden, L. F., Hayhurst, A. N., ... Sederman, A. J. (2007). Rise velocities of bubbles and slugs in gas-fluidised beds: Ultra-fast magnetic resonance imaging. Chemical Engineering Science, 62(1-2), 82-93. https://doi.org/10.1016/j.ces.2006.08.019

Nagel, B., Dellweg, H. \& Gierasch, L. M. (1992). Glossary for chemists of terms used in biotechnology (IUPAC Recommendations 1992). Pure Applied Chemistry 64 (1), 143 - 168. https://doi.org/10.1351/pac199264010143.

Ogawa, S., Umemura, A. \& Oshima, N. (1980). On the equation of fully fluidized granular materials. Journal of Applied Mathematics and Physics, 31, 483.

Oliveira P., Cardoso, T. \& Ataíde, C. (2013). Bubbling fluidization of biomass and sand binary mixtures: Minimum fluidization velocity and particle segregation. Chemical Engineering and Processing: Process Intensification 72, 113-121.

Owoyemi, O., Mazzei, L. \& Lettieri, P. (2007). CFD modeling of binary-fluidized suspensions and investigation of role of particle-particle drag on mixing and segregation. AIChE Journal 53 (8), 1924-1940.

Pain, C.C., Mansoorzadeh, S., de Oliviera, C.R.E. (2001), A study of bubbling and slugging fluidized beds using the two-fluid granulat temperatura model. International Journal of Multiphase Flow, 27, 527-551.

Patil D. J., van Sint Annaland M. \& Kuipers J. A. M. (2005). Critical comparison of hydrodynamica models for gas-solid fluidized beds - Part II: freely bubbling gas-solid fluidized beds. Chemical Engineering Science, 60, 73-84. 
Paudel, B. \& Feng, Z. (2013). Prediction of minimum fluidization velocity for binary mixtures of biomass and inert particles. Powder Technology 237, 134-140.

Perales, J.F., Coll, T., Llop, M.F., Puigjaner, L., Arnaldos, J. \& Cassal, J. (1990). On the transition from bubbling to fast fluidization regimes. En: Circulating Fluidized Bed Technology III, Basu, P, Horio, M. \& Hasatani, M., Eds., Pergamon Press, Oxford, 73-78.

Proenza Pérez, N., Travieso, D., Blanco, E., Santana, J., Verdú, R. \& Silveira, J. (2017). Fluid Dynamic study of mixtures of sugarcane bagasse and sand particles: Minimun fluidization velocity. Biomass and Bioenergy 107, 135-149.

Ramirez, E., Finney, C. E. A., Pannala, S., Daw, C. S., Halow, J., \& Xiong, Q. (2017). Computational study of the bubbling-to-slugging transition in a laboratory-scale fluidized bed. Chemical Engineering Journal, 308, 544-556. https://doi.org/10.1016/j.cej.2016.08.113

Reuge, N., Cadoret, L., Coufort-Saudejaud, C., Pannala, S., Syamlal, M., \& Caussat, B. (2008). Multifluid Eulerian modeling of dense gas-solids fluidized bed hydrodynamics: Influence of the dissipation parameters. Chemical Engineering Science, 63(22), 5540-5551. https://doi.org/10.1016/j.ces.2008.07.028

Reyes Urrutia, A., Benoit, H., Zambon, M., Gauthier, D., Flamant, G., \& Mazza, G. (2016). Simulation of the behavior of a dense SiC particle suspension as an energy transporting vector using computational fluid dynamics (CFD). Chemical Engineering Research and Design, 106, 141-154. https://doi.org/10.1016/j.cherd.2015.12.008

Rhodes, M. J. (1998). Introduction to particles technology, 1st edition. Ed. Wiley.

Rowe, P. N. \& Matsuno, R. (1971). Single gas bubbles injected into a gas fluidized bed and observed by X-ray. Chemical Engineering Science, 26, 923-925.

Rowe, P. N. \& Nienow, A. W. (1975). Minimum Fluidization Velocity of MultiComponent Particle Mixtures. Chemical Engineering Science 30 (11), 1365-1369.

Rowe, P. N. \& Partridge, B. A. (1965). An X-Ray study of bubbles in fluidised beds. Transactions of the Institution of Chemical Engineers, 43, S116-S134. 
Rüdisüli, M., Schildhauer, T. J., Biollaz, S. M. A., \& Ruud van Ommen, J. (2012). Bubble characterization in a fluidized bed by means of optical probes. International $\begin{array}{llll}\text { Journal of } & \text { Multiphase }\end{array}$ https://doi.org/10.1016/j.ijmultiphaseflow.2012.01.001

Rudolph, V. \& Judd, M. R. (1985). Circulation and slugging in a fluid bed gasifier fitted with a draft tube. In: Basu, P. (Ed.), Circulating Fluidized Bed TechnologyProceedings of the First International Conference on Circulating Fluidized Beds. Pergamon Press, New York, 437-442.

Ruiz, J. A., Juárez, M. C., Morales, M. P., Muñoz, P. \& Mendívil, M. A. (2013). Biomass gasification for electricity generation: Review of current technology barriers. Renewable and Sustainable Energy Reviews 18, 174-183.

Sabatier, F., Ansart, R., Zhang, H., Baeyens, J., \& Simonin, O. (2020). Experiments support simulations by the NEPTUNE_CFD code in an Upflow Bubbling Fluidized Bed $\begin{array}{lllll}\text { reactor. Chemical } & \text { Engineering Journal, 385, } & 123568 .\end{array}$ https://doi.org/10.1016/j.cej.2019.123568

Schaeffer, D.G (1987). Instability in the evolution equations describing incompressible granular flow. Journal of Differential Equations, 66, 19-50.

Secretaría de energía Argentina (2008). Energías Renovables - Energía Biomasa. Coordinación de Energías Renovables, Dirección Nacional de Promoción, Subsecretaría de Energía Eléctrica.

Sette, P., Fernandez, A., Soria, J., Rodriguez, R., Salvatori, D. \& Mazza, G. (2020). Integral valorization of fruit waste from wine and cider industries. Journal of Cleaner Production 242,118486.

Sette, P., Fernandez, A., Soria, J., Rodriguez, R., Salvatori, D. \& Mazza, G. D. (2020). Integral Valorization of Fruit Waste from Wine and Cider Industries. Journal of Cleaner Production, 242, article number 118486

Seville, J.P.K., Tüzün, U. \& Clift, R. (1997). Processing of particulate solids. Kluwer, Amsterdam. 
Shabanian, J., \& Chaouki, J. (2017). Effects of temperature, pressure, and interparticle forces on the hydrodynamics of a gas-solid fluidized bed. Chemical Engineering Journal, 313, 580-590. https://doi.org/10.1016/j.cej.2016.12.061

Si, C. \& Guo, Q. (2008). Fluidization Characteristics of Binary Mixtures of Biomass and Quartz Sand in an Acoustic Fluidized Bed. Industrial and Engineering Chemistry Research 47 (23), 9773-9782.

Singh, B. K., Roy, S., \& Buwa, V. V. (2020). Bubbling/slugging flow behavior in a cylindrical fluidized bed: ECT measurements and two-fluid simulations. Chemical $\begin{array}{lll}\text { Engineering Journal, } & \text { 383(January), }\end{array}$ https://doi.org/10.1016/j.cej.2019.123120

Sobrino, C., Acosta-Iborra, A., Izquierdo-Barrientos, M. A., \& de Vega, M. (2015). Three-dimensional two-fluid modeling of a cylindrical fluidized bed and validation of the Maximum Entropy method to determine bubble properties. Chemical Engineering Journal, 262, 628-639. https://doi.org/10.1016/j.cej.2014.10.014

Sobrino, C., Acosta-Iborra, A., Santana, D., \& de Vega, M. (2009). Bubble characteristics in a bubbling fluidized bed with a rotating distributor. International Journal of Multiphase Flow, 35(10), 970-976. https://doi.org/10.1016/j.ijmultiphaseflow.2009.04.005

Sobrino, C., Almendros-Ibáñez, J. A., Santana, D., Vázquez, C., \& de Vega, M. (2009). Maximum entropy estimation of the bubble size distribution in fluidized beds. Chemical Engineering Science, 64(10), 2307-2319. https://doi.org/10.1016/j.ces.2009.01.046

Soria, J. M., Li, R., Flamant, G. \& Mazza, G. D. (2019). Influence of pellet size on product yields and syngas composition during solar-driven high temperature fast pyrolysis of biomass. Journal of Analytical and Applied Pyrolysis 140, 299-311.

Sousa Sant'Anna, M. C., dos Santos Cruz, W. R., da Silva, G. F. , de Andrade Medronho, R. \& Lucena, S. (2017). Analyzing the fluidization of a gas-sand-biomass mixture using CFD techniques. Powder Technology 316, 367-372. 
Stewart, P. S. B. \& Davidson, J. F. (1967). Slug flow in fluidised beds. Powder Technology 1, 61-80.

Syamlal, M. \& O'Brien, T. J. (1987). Derivation of a Drag Coefficient from Velocity-Voidage Correlation. U.S. Department of Energy, Office of Fossil Energy, National Energy Technology Laboratory, Morgantown, WV.

Syamlal, M. \& O'Brien, T. J. (1989). Computer simulation of bubbles in a fluidized bed. AIChE Symposium Series, 85, 22-31.

Syamlal, M. (1987). The Particle-Particle Drag Term in a Multiparticle Model of Fludization, Topical Report. Springfield: National Technical Information Service.

Syamlal, M., Rogers, W. \& O'Brien, T. J. (1993). MFIX documentation: Volume 1, Theory Guide. National Technical Information Service, Springfield, VA.

Taghipour, F., Ellis, N., \& Wong, C. (2005). Experimental and computational study of gas-solid fluidized bed hydrodynamics. Chemical Engineering Science, 60(24), 6857-6867. https://doi.org/10.1016/j.ces.2005.05.044

Tagliaferri, C., Mazzei, L., Lettieri, P., Marzocchella, A., Olivieri, G. \& Salatino, P. (2013). CFD simulation of bubbling fluidized bidisperse mixtures: Effect of integration methods and restitution coefficient. Chemical Engineering Science 102, 324-334.

Thapa, R. K. \& Halvorsen, B. M. (2013). Study of Flow Behavior in Bubbling Fluidized Bed Biomass Gasification Reactor Using CFD Simulation. In: The 14th International Conference on Fluidization-From Fundamentals to Products, J.A.M. Kuipers, R.F. Mudde, J.R. van Ommen \& N.G. Deen (Eds), ECI Symposium Series. http://dc.engconfintl.org/fluidization_xiv/69.

Thapa, R. K., \& Halvorsen, B. M. (2013). Study of flow behavior in bubbling fluidized bed biomass gasification reactor using CFD simulation. International Conference on Fluidization.

Toomey, R. \& Johnstone, H. F. (1952). Gas fluidization of solid particles. Chemical Engineering Progress, 48, 220-226. 
Van de Velden, M., Baeyens, J. \& Boukis, I. (2008). Modeling CFB biomass pyrolysis reactors. Biomass Bioenergy 32, 128-139.

Van der Drift, A., Van Doorn, J. \& Vermeulen, J. (2001). Ten residual biomass fuels for circulating fluidized-bed gasification. Biomass and Bioenergy 20(1), 45-56.

Van Wachem, B. G. M., Schouten, J. C., Krishna, R., \& Van Den Bleek, C. M. (1998). Eulerian simulations of bubbling behaviour in gas-solid fluidised beds. Computers and Chemical Engineering, 22(SUPPL.1). https://doi.org/10.1016/s0098-1354(98)000684

Vashisth, S., Ahmadi Motlagh, A. H., Tebianian, S., Salcudean, M., \& Grace, J. R. (2015). Comparison of numerical approaches to model FCC particles in gas-solid bubbling fluidized bed. Chemical Engineering Science, 134, 269-286. https://doi.org/10.1016/j.ces.2015.05.001

Venier, C.M., Reyes Urrutia, A., Capossio, J. P., Baeyens, J. \& Mazza, G. D. (2020). Comparing ANSYS Fluent ${ }^{\circledR}$ and OpenFOAM ${ }^{\circledR}$ simulations of Geldart A, B and D bubbling fluidized bed hydrodynamics. International Journal of Numerical Methods for Heat and Fluid Flow 30 (1), 3-118.

Wang, H. \& Zhong, Z. (2019). A Mixing Behavior Study of Biomass Particles and Sands in Fluidized Bed Based on CFD-DEM Simulation. Energies 12, 1-17.

Weimer, A. W. \& Quarderer, G. J. (1985). On dense phase voidage and bubble size in high pressure fluidized beds of fine powders. AIChE Journal, 31, 1019-1028.

Wen, C.Y. \& Yu Y. H. (1966). A generalized method for predicting the minimum fluidization velocity. AIChE Journal, 12, 610-612.

Wen, C.Y. \& Yu, Y. H. (1966). Mechanics of fluidization. Chemical Engineering Progress Symposium Series, 62, 100-111.

Werther, J. (1978). Effect of gas distributor on the hydrodynamics of gas fluidized beds. German Chemical Engineering, 1, 166-174. 
Wu, C., Cheng, Y., Ding, Y., Wei, F., \& Jin, Y. (2007). A novel X-ray computed tomography method for fast measurement of multiphase flow. Chemical Engineering Science, 62(16), 4325-4335. https://doi.org/10.1016/j.ces.2007.04.026

Xie, N., Battaglia, F. \& Pannala, S. (2008). Effects of using two- versus threedimensional computational modeling of fluidized beds: Part I, hydrodynamics. Powder Technology 182, 1-13.

Yamazaki, R., Nakajima, M., Ueda, N. \& Jimbo, G. (1985). Fluidization'85 Science and Technology. Science Press, Beijing.

Yang, W. C. (2003). Handbook of Fluidization and Fluid-particle Systems. 1st ed. New York: Marcel Dekker.

Yates, J.G. (1983). Fundamentals of fluidized-bed chemical processes. Butterworths Monographs in Chemical Engineering, Ed. Butterworths.

Ye, M., Wang, J., Van der Hoef, M. A. \& Kuipers, J. A. M. (2008). Two fluid modeling of Geldart A particles in gas-fluidized beds. Particuology, 6, 540-548.

Yerushalmi, H. \& Cankurt, N.T. (1979). Further studies of the regimes of fluidization. Powder Technology, 24, 187-205.

Yerushalmi, H., Cankurt, N.T., Geldart, D. \& Liss, B. (1978). Flow regimes in vertical gas-solid contact systems. AIChE Symposium Series 176, 74, 1-13.

Zambon, M., Mora Basaure, C., Veliz, S., Bucalá, V. \& Mazza, G. (2011). Experimental and CFD study of the hidrodynamics of air-urea bubbling fluidized beds. Récents Progrès en Génie des Procédés, 101, A328-1-A328-6.

Zehner P. \& Schlunder, E. U. (1970). Thermal conductivity of granular materials at moderate temperatures (in German). Chemie Ingenieur Technik, 42, 933941.

Zhang, Y., Wenqi, Z. \& Jin, B. (2011). Experimental and theoretical study on fluidization of stalk shaped biomass particle in a fluidized bed. International Journal of Chemical Reactor Engineering 9, A54. 